MAPPING THE UNMEASURABLE?

SPATIAL ANALYSIS OF VULNERABILITY TO CLIMATE CHANGE AND CLIMATE VARIABILITY 
Examining committee:
Prof.dr.ing A. Fekete
University of Cologne
Prof.dr. P. Hooimeijer
University of Utrecht
Prof.dr. V.G. Jetten
University of Twente
Prof.dr. P.Y. Georgiadou
University of Twente
Dr. D. Reckien
University of Twente

ITC dissertation number 263

ITC, P.O. Box 217, 7500 AA Enschede, The Netherlands

ISBN 978-90-365-3809-1

DOI $10.3990 / 1.9789036538091$

Cover designed by Job Duim

Printed by ITC Printing Department

Copyright $@ 2014$ by de Sherbinin, Alexander M.

\section{UNIVERSITY OF TWENTE.}

-1 C Faculty of geO-INFORMATION SCIENCE AND EARTH OBSERVATION 


\title{
MAPPING THE UNMEASURABLE?
}

\section{SPATIAL ANALYSIS OF VULNERABILITY TO CLIMATE CHANGE AND CLIMATE VARIABILITY}

\author{
DISSERTATION
}

to obtain

the degree of doctor at the University of Twente, on the authority of the rector magnificus, prof.dr. H. Brinksma, on account of the decision of the graduation committee, to be publicly defended

on Wednesday 3 December 2014 at 14.45 hrs

by

Alexander Michael de Sherbinin

born on 29 August 1962

in Massachusetts, United States of America 
This thesis is approved by

Prof.dr.ir, M.F.A.M. van Maarseveen, promoter

Dr. R.V. Sliuzas, co-promoter 


\section{Foreword}

In October 2011 I contacted Dr. Sliuzas at ITC about the possibility of engaging in a fast-track PhD program through ITC, building on a number of ISI listed publications on the broad topic of spatial approaches to climate vulnerability assessment. By January 2012, I was enrolled in the Population, Land and Urban Systems program and beginning work on the PhD.

My interest in this subject was conceived because of my role as deputy manager of a NASA data center (the NASA Socioeconomic Data and Applications Center (SEDAC)) that produces socioeconomic data to complement NASA's earth satellite remote sensing data sets. SEDAC data have been widely used in journal articles and reports focusing on climate change impacts, vulnerability and adaptation (IVA). I began by including examples of SEDAC data usage in lectures on climate change IVA, and also started to do my own analyses (see Chapter 4 ) and maps depicting potential climate impacts (see Figure 3.1 in Chapter 3).

In 2009 CIESIN, the center at The Earth Institute of Columbia University where I work, was contacted by Koko Warner of the United Nations University Institute for Environment and Human Security (UNU-EHS) and Charles Ehrhardt of CARE to develop maps for a report entitled In Search of Shelter. I had the privilege of leading the team of GIS specialists and designers who produced the maps in this report. The report resulted in substantial media attention in part because of the maps CIESIN produced, which complemented field research from the Environmental Change and Forced Migration project (EACH-FOR) (see Chapter 5). This successful collaboration resulted in two more reports that included maps produced under my direction, Where the Rainfalls: Climate Change, Food and Livelihood Security, and Migration (2012) and Evidence from the Frontlines of Climate Change: Loss and Damage to Communities Despite Coping and Adaptation (2012).

Since 2012 I have been involved with work under the USAID-funded African and Latin American Resilience to Climate Change (ARCC) project. Under ARCC I was able to lead vulnerability mapping projects for Mali and Coastal West Africa, to assist in the development of a spatial vulnerability assessment training program, and to develop a technical report entitled Spatial Climate Change Vulnerability Assessments: A Review of Data, Methods and Issues (2014). Through these projects I gained considerable first-hand experience in vulnerability mapping using the spatial index approach, and was able to review the growing literature in this field. 
As I write this forward, I am returning from a workshop entitled INQUIMUS: Spatial Indicators and Assessment of Vulnerability and Resilience (Salzburg, Austria, 15-17 September 2014), for which I served as a co-organizer, along with colleagues at University of Salzburg's Z_GIS, the European Academy (EURAC), and University of Cologne. It was invigorating being amongst fellow scholars wrestling with the challenges of vulnerability mapping and spatial index creation. I owe a debt of gratitude to many of the participants for their critical perspectives on the vulnerability mapping enterprise, especially those whose work I cite in this thesis (i.e., David Abson, Alexander Fekete, and Stefan Kienberger). My sense is that this field is, for better or worse, a "growth industry" that will continue to require scientific contributions in order to guide adaptation decision-making.

I dedicate this thesis to my mother, Dr. Polly Robinson de Sherbinin, who demonstrated to me that it is possible to pursue one's dreams later in life. She acquired her doctorate in Education from the University of Massachusetts at Amherst in 1983 at the age of 60 and went on to practice marriage and family counseling until her death in 1997, touching many lives in the process. As a Christian, I wish to give thanks to my Lord and Savior Jesus Christ for helping me to fulfill this dream. 


\section{Acknowledgements}

I would like to express my gratitude to Prof. Dr. van Maarseveen and Dr. Sliuzas for comments and suggestions on various manuscripts, and for support throughout the process. I would like to acknowledge my co-authors on two of the chapters in this publication, Andrew Schiller and Alex Pulsipher on Chapter 3, and Koko Warner and Charles Erhart on Chapter 5. I appreciate the comments of numerous anonymous reviewers of the journal articles contained in this thesis, who helped sharpen the arguments of each chapter. Acknowledgements for additional contributions to specific chapters are included in the footnotes on the title page of each chapter.

Finally, I would like to acknowledge the support of my bosses, Robert Chen and Marc Levy, who encouraged me to publish, and staff members of the science and geospatial divisions of CIESIN (especially Susana Adamo, Tricia Chai-Onn, Malanding Jaiteh, Vali Mara, Linda Pistolesi, and Sylwia Trzaska) for engaging in a true "co-production of knowledge" over the past few years. I gained tremendously from the insights and support of these colleagues in the past few years. 


\section{Table of Contents}

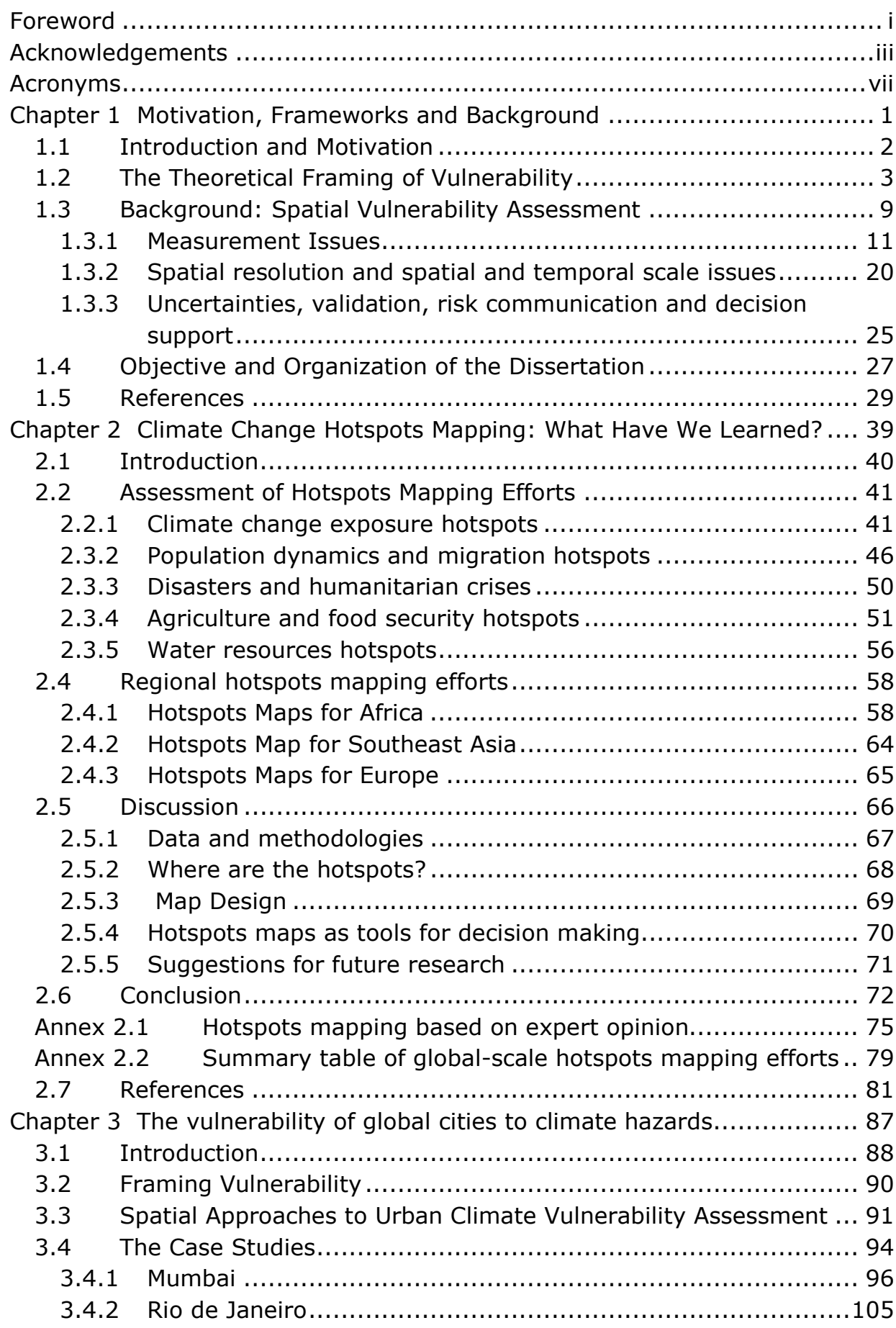




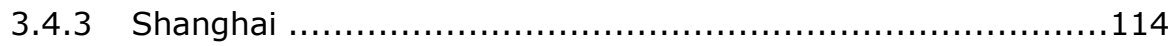

3.5 Discussion and Conclusions........................................... 119

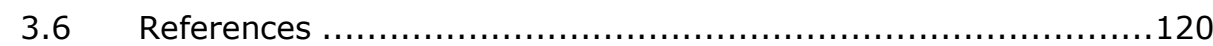

Chapter 4 Climatic, Biophysical, and Socioeconomic Factors Affecting

Malnutrition in Sub-Saharan Africa ...................................... 131

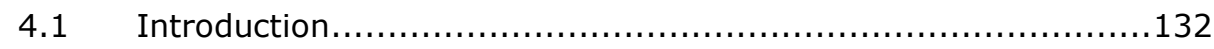

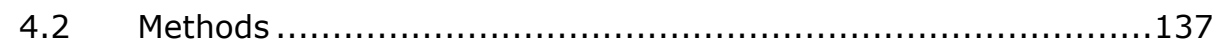

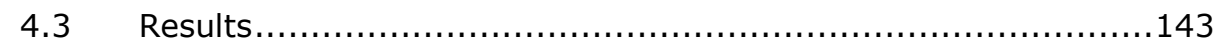

4.5 Recommendations for Development Policy and Climate

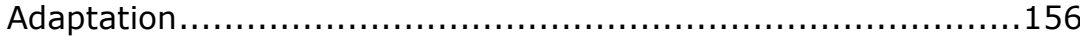

4.6 Assessment of strengths and weaknesses........................ 158

4.7 References ................................................... 159

Chapter 5 Climate Change: Three Hotspots of Human Mobility..............165

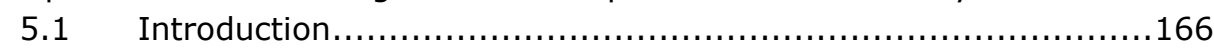

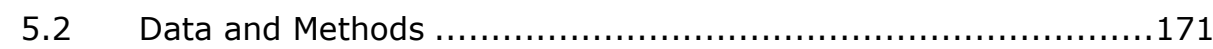

5.3 The Case Studies............................................... 175

5.3.1 Mexico and Central America ....................................... 175

5.3.2 Mozambique: The Double Blow of Flooding and Drought ........178

5.3.3 The Mekong: Flooding and the Threat of Sea Level Rise.........184

5.4 Policy considerations: How best to safeguard those displaced? ...187

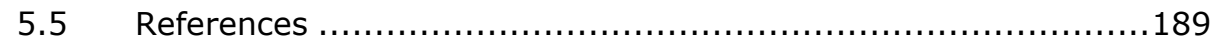

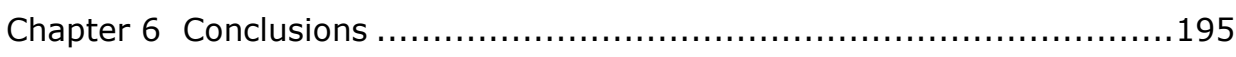

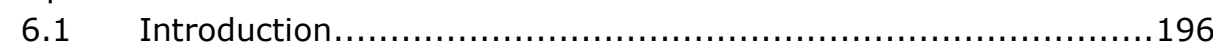

6.2 Assessment of Spatial VA Approaches .............................196

6.2.1 Chapter 2: Climate change hotspots mapping .....................196

6.2.2 Chapter 3: The vulnerability of global cities to climate hazards .................................................... 199

6.2.3 Chapter 4: Climatic, biophysical and socioeconomic factors affecting malnutrition ........................................201

6.2.4 Chapter 5: Climate change - three hotspots of human

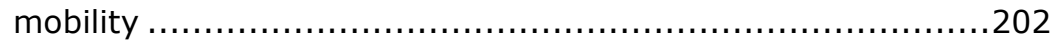

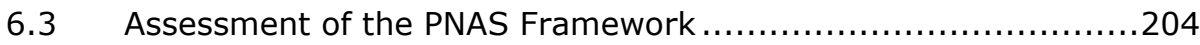

6.3.1 General assessment ........................................ 205

6.3.2 Utility of the PNAS Framework in the Context of this

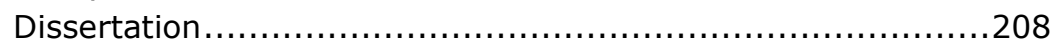

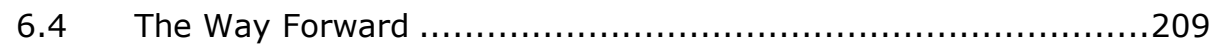

6.4.1 Trends in Vulnerability Assessment and Spatial Approaches....211

6.4.2 Stakeholder Engagement ...................................... 212

6.4 .3 Spatial Data Needs........................................... 213

6.4.4 Conveying Uncertainty to Policy Audiences .......................218

6.4.5 Recommendations for Spatial VA Planning .......................221

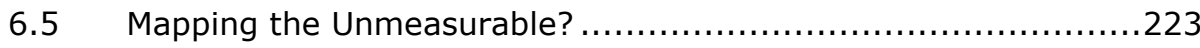

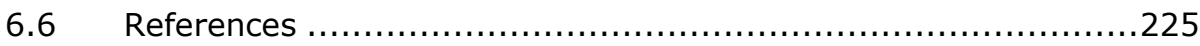

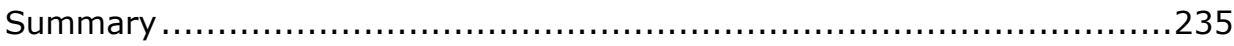




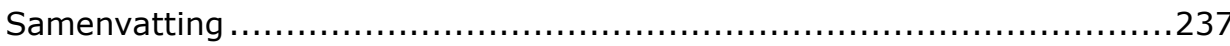

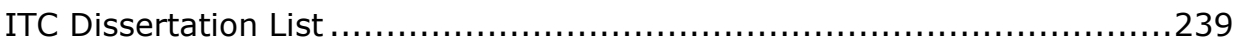




\section{Acronyms}

\begin{tabular}{|c|c|}
\hline ACCRN & Asia Climate Change Research Network \\
\hline AfSIS & Africa Soil Information System \\
\hline ANDI & Africa Nutrition Database Initiative \\
\hline AR4 & IPCC Fourth Assessment Report \\
\hline $\begin{array}{l}\text { ARCC } \\
\text { project }\end{array}$ & African and Latin American Resilience to Climate Change \\
\hline BLUE & Best Linear Unbiased Estimator \\
\hline CARE & Cooperative for American Relief Everywhere \\
\hline CCAFS & $\begin{array}{l}\text { CGIAR Climate Change, Agriculture and Food Security } \\
\text { program }\end{array}$ \\
\hline CCI & Climate Change Index \\
\hline CCLM & COSMO Model in Climate Mode \\
\hline CDVI & Climate-Demography Vulnerability Index \\
\hline CGIAR & Consultative Group for International Agricultural Research \\
\hline CHES & Coupled Human-Environment System \\
\hline CHRR & Center for Hazards and Risk Research, Columbia University \\
\hline CIESIN & $\begin{array}{l}\text { Center for International Earth Science Information Network, } \\
\text { Columbia University }\end{array}$ \\
\hline CMIP & Coupled Model Intercomparison Project \\
\hline COSMO & Consortium for Small-scale Modeling \\
\hline CPC & Climate Prediction Center \\
\hline CRED & Centre for Research on the Epidemiology of Disasters \\
\hline CVI & Climate Vulnerability Index \\
\hline DCW & Digital Chart of the World \\
\hline DEM & Digital Elevation Model \\
\hline DHS & Demographic and Health Survey \\
\hline DMSP-OLS & $\begin{array}{l}\text { Defense Meteorological Satellite Program's Optical Line } \\
\text { Scanner }\end{array}$ \\
\hline $\mathrm{EACH}-\mathrm{FOR}$ & Environmental Change and Forced Migration Scenarios \\
\hline ECMWF & European Centre for Medium-Range Weather Model \\
\hline EMO & Chinese Emergency Management Office \\
\hline ENSO & El-Niño/Southern Oscillation \\
\hline ESPON & $\begin{array}{l}\text { Climate Change and Territorial Effects on Regions and Loca } \\
\text { Economies in Europe }\end{array}$ \\
\hline $\mathrm{FAO}$ & Food and Agriculture Organization of the United Nations \\
\hline FEEMA & Brazilian State Environmental Engineering Foundation \\
\hline FIVIMS & $\begin{array}{l}\text { Food Insecurity and Vulnerability Information and Mapping } \\
\text { System }\end{array}$ \\
\hline GCM & General Circulation Model (or Global Climate Model) \\
\hline GDP & Gross Domestic Product \\
\hline GEO & Group on Earth Observations \\
\hline GEOSS & Group on Earth Observations System of Systems \\
\hline
\end{tabular}




\begin{tabular}{|c|c|}
\hline GIM & Global Impact Model \\
\hline GIS & Geographic Information System \\
\hline GMT & Global Mean Temperature \\
\hline GPS & Global Positioning System \\
\hline GRUMP & Global Rural-Urban Mapping Project \\
\hline IBGE & Brazilian Institute for Geography and Statistics \\
\hline IIASA & International Institute for Applied Systems Analysis \\
\hline INMET & Brazilian National Institute for Meteorology \\
\hline IPCC & Intergovernmental Panel on Climate Change \\
\hline ITC & Faculty of Geo-Information Science and Earth Observation \\
\hline ITOS & $\begin{array}{l}\text { Information Technology Outreach Services of the University } \\
\text { of Georgia }\end{array}$ \\
\hline IVA & impacts, vulnerability and adaptation \\
\hline LECZ & Low Elevation Coastal Zone \\
\hline MAUP & modifiable area unit problem \\
\hline MICS & Multiple Indicator Cluster Survey \\
\hline MODIS & Moderate Resolution Imaging Spectroradiometer \\
\hline NASA & US National Aeronautics and Space Administration \\
\hline NCAR & US National Center for Atmospheric Research \\
\hline NCEP & US National Center for Environmental Prediction \\
\hline NDVI & Normalized Difference Vegetation Index \\
\hline NGO & non-governmental organization \\
\hline NOAA & US National Oceanographic and Atmospheric Administration \\
\hline NSDF & Indian National Slum Dwellers Federation \\
\hline NUTS & Nomenclature of Territorial Units for Statistics \\
\hline OLS & Ordinary Least Squares regression \\
\hline PAR & Pressure-and-Release model \\
\hline PNAS & Proceedings of the National Academy of Sciences \\
\hline PROVIA & $\begin{array}{l}\text { UNEP Programme on Research on Climate Change } \\
\text { Vulnerability, Impacts and Adaptation }\end{array}$ \\
\hline RCCI & Regional Climate Change Index \\
\hline $\mathrm{RCP}$ & Representative Concentration Pathway \\
\hline $\mathrm{RH}$ & Risk-Hazards model \\
\hline SA & spatial autocorrelation \\
\hline SEDAC & NASA Socioeconomic Data and Applications Center \\
\hline SLR & Sea level rise \\
\hline SOPAC & Pacific Islands Applied Geosciences Commission \\
\hline SNU & sub-national unit \\
\hline SRES & IPCC Special Report on Emissions Scenarios \\
\hline SREX & IPCC Special Report on Climate Extremes \\
\hline SRTM & NASA Shuttle Radar Topography Mission \\
\hline SSP & Shared Socioeconomic Pathway \\
\hline TERI & Tata Energy Research Institute \\
\hline UNDP & United Nations Development Programme \\
\hline
\end{tabular}




$\begin{array}{ll}\text { UNEP } & \text { United Nations Environment Programme } \\ \text { UNFCCC } & \text { United Nations Framework Convention on Climate Change } \\ \text { UNFPA } & \text { United Nations Population Fund } \\ \text { UNHABITAT } & \text { United Nations Human Settlements Programme } \\ \text { UNICEF } & \text { United Nations Children's Fund } \\ \text { UNISDR } & \text { United Nations International Strategy for Disaster Reduction } \\ \text { UNU } & \text { United Nations University } \\ \text { UNU-EHS } & \text { UNU Institute for Environment and Human Security } \\ \text { USAID } & \text { US Agency for International Development } \\ \text { UT } & \text { University of Twente } \\ \text { VA } & \text { Vulnerability Assessment } \\ \text { WBGU } & \text { German Advisory Council on Global Change } \\ \text { WHO } & \text { World Health Organization } \\ \text { YCELP } & \text { Yale Center for Environmental Law and Policy } \\ \text { Z_GIS } & \text { Center for Geoinformation Sciences, University of Salzburg }\end{array}$


Chapter 1

Motivation, Frameworks and Background 


\subsection{Introduction and Motivation}

Climate change, climate variability, and climate extremes will have far reaching implications for societies in the $21^{\text {st }}$ century (IPCC 2012, McElroy and Baker 2012, Parry et al. 2007). There is considerable policy interest in (1) identifying the specific vulnerabilities of populations that will be exposed to climate change impacts; (2) understanding how various climate impacts (e.g. secular declines in precipitation, extreme events, and heat stress) will impact urban and regional systems; and (3) how, in turn, populations will respond through in situ adaptation or migration (e.g., Warner et al. 2009, UNDP 2008, WBGU 2007). Because vulnerability is place-based (Cutter et al. 2003, Turner et al. 2003a), spatial analyses based on combinations of climate data, spatial representations of current climate hazards, spatial representations of population distribution, and spatial representations of factors that influence vulnerability (e.g., poverty maps) can greatly assist in developing this understanding and in helping to target interventions. Indeed, spatial analysis and spatial data integration have become standard tools in the toolkit of climate change vulnerability assessments (e.g., de Sherbinin 2014, de Sherbinin 2013, PROVIA 2013a, Martine and Schensul 2013, Fekete 2012, Preston et al. 2011, UNDP 2010). Yet there remains considerable methodological diversity and there is little consensus in the research community on the best ways to measure and map vulnerability (Preston et al. 2011). There are even those who argue that for most purposes vulnerability as a concept cannot be adequately quantified (Hinkel 2011) and hence is "unmeasurable" (Birkman and Wisner 2006) - a topic we return to in Section 6.5 of Chapter $6{ }^{1}$

In this thesis we provide examples of spatial analyses - including quantitative and qualitative analyses and map representations - that contribute to understanding patterns of vulnerability to climate change. Specifically, we explore this methodological diversity and discuss the relative merits of different approaches to understanding spatial patterns of vulnerability with a particular emphasis on the utility of vulnerability maps for policy making. We also examine the utility of an extended vulnerability framework developed by a team of researchers at Harvard and Clark Universities for guiding research and illuminating vulnerabilities of coupled human-environment systems (Turner et al. 2003a).

In this introductory chapter, we discuss the concept of vulnerability, introduce the framework, and provide some background on spatial vulnerability assessment (VA).

\footnotetext{
${ }^{1}$ For this chapter, "we" refers to A. de Sherbinin, M. van Maarseveen, and R. Sliuzas.
} 


\subsection{The Theoretical Framing of Vulnerability}

Definitions of vulnerability have proliferated in the past two decades (Birkmann 2006, Adger 2006, Schiller et al. 2001). In a broad sense, vulnerability can be defined as the degree to which a system or unit is likely to experience harm due to exposure to perturbations or stress (Turner et al. 2003a). The concept of vulnerability originated in research communities examining risks and hazards, climate adaptation, and resilience. The vulnerability concept emerged out of the recognition by these research communities that a focus on stressors alone (e.g., floods or earthquakes) was insufficient for understanding responses of, and impacts on, systems exposed to such stressors. With the concept of vulnerability, it became clear that the ability of a system-whether an economy, an economic sector, a population group, or an ecosystem-to attenuate stresses or cope with consequences constitutes a key determinant of impacts on that system and system response.

In the last decade, the terminology of vulnerability has been refined as researchers and policy makers have focused increasingly on vulnerability to climate change impacts. There are essentially two major conceptualizations of vulnerability (O'Brien et al. 2007, Füssel 2009). The first is contextual vulnerability, which focuses on factors that determine a system's ability to withstand and recover from shocks. This approach comes out of political economy, and focuses on the intrinsic characteristics of a population (e.g., age, sex, socioeconomic status, ethnicity, livelihood strategies, etc.) and other factors (e.g., institutions, entitlements, historical inequalities, market forces) that may influence a population's (or system's) ability to withstand stressors. There is often a strong emphasis on differential vulnerabilities across social strata, and a concern for poor or marginal groups.

The second conceptualization is outcome vulnerability (Füssel 2009: 5), which "represents an integrated vulnerability concept that combines information on potential climate impacts and on the socio-economic capacity to cope and adapt." A framework developed by the Intergovernmental Panel on Climate Change (IPCC) Working Group 2 builds on this, conceptualizing vulnerability as a function of exposure to climate impacts, including variability and extremes, and the sensitivity and adaptive capacity of the system being exposed (Parry et al. 2007). The three components can be expanded as follows:

$\mathrm{E}=$ exposure - size of the area and/or system, sector or group affected (i.e., does the event occur there or might it occur there under climate change?), and the magnitude of the event/hazard. 
$\mathrm{S}=$ sensitivity - as in contextual vulnerability (above), the intrinsic characteristics of a population and governance/market structures that may influence abilities to withstand stressors; in modeling approaches, on the other hand, sensitivity can represent the dose-response function (e.g., the impact on crop yields or water stress of an $X^{\circ}$ rise in temperature or $Y \%$ change in precipitation).

$A=$ adaptive capacity - capacities of the system, sector or group to resist impacts, cope with losses, and/or regain functions. ${ }^{2}$

The IPCC definition suggests that the most vulnerable individuals, groups, classes, and regions or places are those that (1) experience the most exposure to perturbations or stresses, (2) are the most sensitive to perturbations or stresses (i.e., most likely to suffer from exposure), and (3) have the weakest capacity to respond and ability to recover (Schiller et al. 2001).

The social sciences apply to vulnerability various frameworks and causal structures, each of which generates different research questions and methodologies (Birkmann 2006). Extending the vulnerability concept to ecological systems serves to amplify this variation. At least two primary framing designs for vulnerability are common in the human sciences: riskhazards (RH) (Burton et al. 1978) and pressure-and-release (PAR) (Blaikie et al. 1994) (Figures 1.1 and 1.2). The frameworks are conceptual or reduced form "models" that attempt to both identify and connect the basic elements involved in producing vulnerability. Those concerned with behavioral or decision-making resources and opportunities that can be utilized in response to stresses or perturbations most often use the RH model. The focus is on reducing exposure and the sensitivity of the exposed system. It starts with the event (e.g., natural hazard) and works its way through to the impacts, but with little consideration of the differential vulnerabilities of social groups within society and the role of social structures and institutions in shaping consequences. Partly in response to these deficiencies, Blaikie et al. developed the PAR model, which directs attention to the causes of unsafe conditions. Emerging from political economic theory, it focuses on the political or economic structures that constrain behaviors and restrict opportunities for response to stresses or perturbations (Turner et al. 2003a).

\footnotetext{
2 Adaptive capacity includes but is not limited to "coping capacity", which is seen as a shorter term ability to cope with stressors.
} 


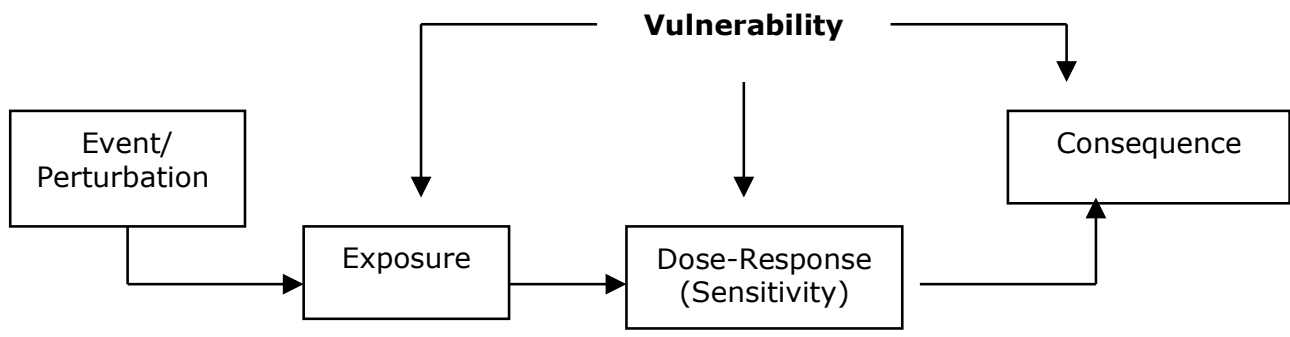

Source: Turner et al. 2003, after Burton et al. 1978.

Figure 1.1: Risk-Hazards Framework

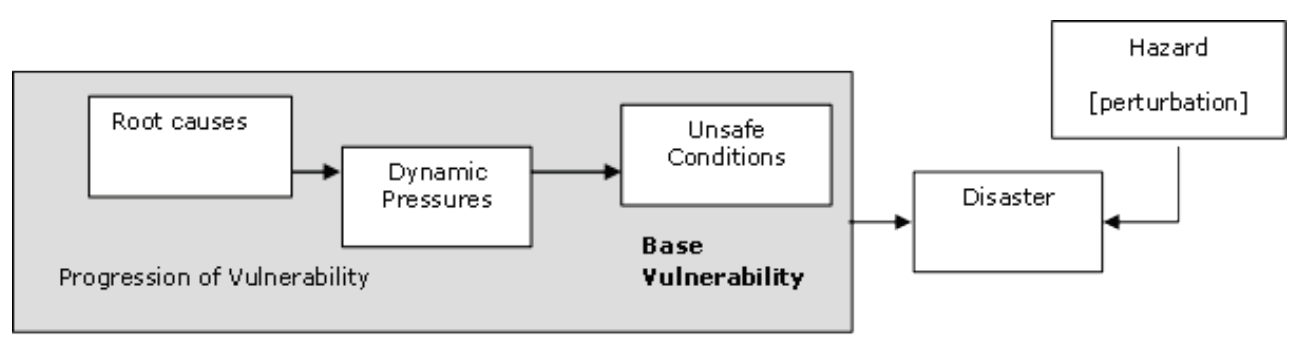

Source: Turner et al. 2003, after Blaikie et al. 1994.

Figure 1.2: Pressure-and-Release Model

These frameworks are useful in characterizing human vulnerability, but they mask the complexity of the components, states, and interactions that enter into a more robust construction of vulnerability, and thus they frequently provide simplistic indices and measures that may be misleading or even incorrect. According to Turner et al. (2003a), key conceptual issues that are masked or missing from the RH and PAR models include entitlements (legal and customary rights to exercise command over food and other resources), coping capacities (defense mechanisms against hazards such as diversification), and resilience (system ability to bounce back to a reference state after a disturbance and the capacity of a system to maintain certain structures and functions despite disturbance).

In the past decade, expanded vulnerability frameworks have been developed with more inclusive dimensions of vulnerability, including how it emerges and ways to reduce it (Soares et al. 2012, Birkmann 2006). They have emerged from different research communities - e.g., those focused on disaster risk reduction, political economy, sustainable development, and global environmental change - and address different questions. A complete review of the frameworks is beyond the scope of this chapter, but here we choose to focus on a recent example by Turner et al. (2003a), which emerged from the global environmental change and sustainability science research 
communities. This so-called "PNAS framework" ${ }^{3}$ (Figure 1.3) takes into account multiple/sequential stressors that relate synergistically, interacting human-environment systems, and dynamically changing coping strategies and mechanisms. In this framework, vulnerability is identified in terms of three elements that are broadly analogous to the IPCC tripartite definition: system exposure to crises, stresses and shocks (i.e., exposure); inadequate system capacity to cope (i.e., sensitivity); and consequences and attendant risks of slow (or poor) system recovery (i.e., adaptive capacity and resilience). This conceptualization also recognizes that as the system changes, it in turn may have impacts on the stressors (the so-called coupled socio-ecological system (Holling 2001)).

Primary attributes of this framework, as outlined by Turner et al. (2003a), include:

- Multiple interacting perturbations and stressors/stresses and the sequencing of them;

- Exposure beyond the presence of a perturbation and stressor/stress, including the manner in which the coupled system experiences hazards;

- Sensitivity of the coupled system to the exposure;

- The system's capacities to cope or respond (resilience), including the consequences and attendant risks of slow (or poor) recovery;

- The system's restructuring after the responses taken (i.e., adjustments or adaptations); and

- Nested scales and scalar dynamics of hazards, coupled systems, and their responses.

The figure is organized such that drivers- whether climatological, environmental or human system changes - are found on the left-hand side. The changes may be slow onset, such as secular changes in temperature or gradual increases in interconnectedness through economic globalization, or fast onset, such as climate extremes (flood and drought) or social upheavals (collapse of financial markets or conflict events). Consequences of change are arrayed on the right hand side, and include impacts (economic losses, deaths, or morbidity) and adaptation responses. The framework is nested at different scales, from global (colored teal), to regional (yellow), to local/place (gray). The variability and change in human conditions (top left) and environmental conditions (bottom left) coincide to produce stressors and perturbations to the local system. These are first filtered (blue lines indicating place-based processes) through the characteristics and components of the exposure unit (be it an ecosystem, a livelihood system, an economic sector, or something else), and the consequences are then determined in large part

\footnotetext{
${ }^{3}$ Named after the journal in which it was first published, the Proceedings of the National Academy of Sciences. The framework has also been widely referred to as the "Turner et al. framework."
} 
by the magnitude of the stressor and the sensitivity and resilience of the coupled socio-ecological system.

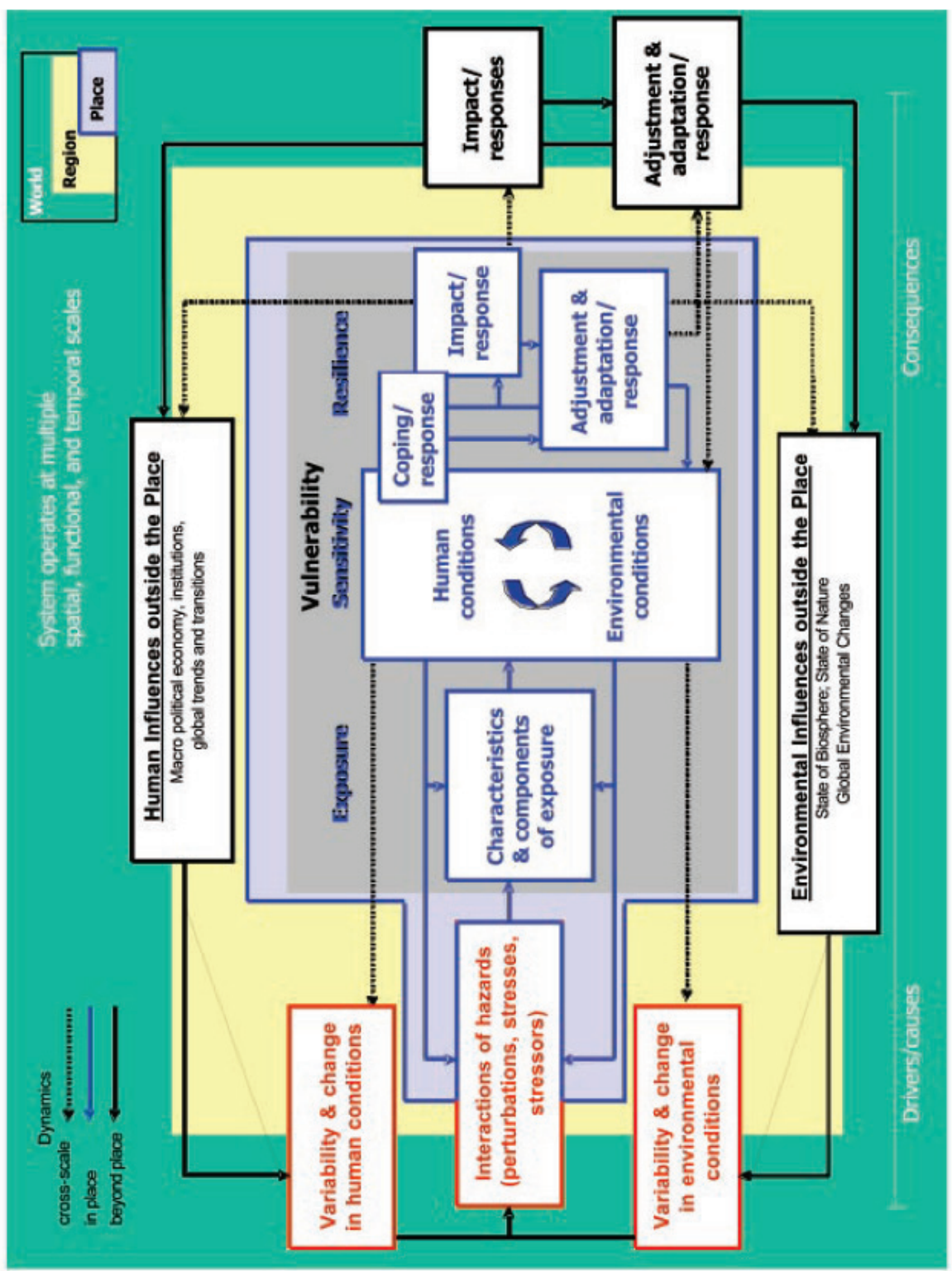

Source: Turner et al. 2003a.

Figure 1.3: The PNAS Extended Vulnerability Framework

Environmental and human conditions do not change in isolation from one another, but rather impact each other based on particular place-based 
constellations of environmental factors, social vulnerability and resilience. To quote Turner et al. (2003a: 8077):

[T] he social and biophysical responses or coping mechanisms influence and feed back to affect each other, so that a response in the human subsystem could make the biophysical subsystem more or less able to cope, and vice versa. In some cases, coping mechanisms per se give way to adaptation, significant system-wide changes in the humanenvironment conditions. The responses, whether autonomous action or planned, public or private, individual or institutional, tactical or strategic, short- or long-term, anticipatory or reactive in kind, and their outcomes collectively determine the resilience of the coupled system and may transcend the system or location of analysis, affecting other scalar dimensions of the problem with potential feedback of the coupled system in question.

In the short term the system deploys coping capacities in the immediate aftermath of a shock or perturbation (e.g., emergency response infrastructure), and in the event of prolonged exposure, in the medium to long term the system adjusts and adapts to changed circumstances. Local responses may influence (dashed lines from gray to yellow boxes) the political economy and institutions (top box) and environmental conditions (bottom box) at broader spatial scales. Local responses may also influence global responses (far right).

Versions of this framework have been applied to the study of agricultural systems in the tropical southern Yucata'n and the arid Yaqui Valley of northwest Mexico (Turner et al. 2003b), the coupled human environment system in the Arctic (Turner et al. 2003b), megacity vulnerability to climate hazards (de Sherbinin et al. 2007), urban heat island impacts on health (Wilhelmi et al. 2012, Wilhelmi and Hayden 2010), and a quantitative assessment of vulnerability to global environmental change (Kok et al. 2010). Although ideally all vulnerability assessments would investigate all aspects of the system, Turner et al. (2003a: 8076) recognize that this framework is difficult to completely operationalize:

Comprehensive vulnerability analysis ideally considers the totality of the system. This ideal, however, is unrealistic. Real world data and other constraints invariably necessitate a "reduced" vulnerability assessment.

Similarly, Levy (2012) argues that there are significant tradeoffs between the relevance (or generalizability) of findings and the richness in terms of variables and considerations of interactions in time and space. 
In the remaining chapters we utilize the PNAS framework as a broad analytical framework for understanding the factors that contribute to vulnerability to climate change, climate variability, and climate extremes. Although the PNAS framework incorporates a broad range of factors influencing vulnerability, as discussed above (and we will see in the following chapters) it remains a challenge to implement frameworks characterized by complex spatio-temporal dimensions and scales both because of data limitations and the inability to model all of the interactions in a satisfactory manner. Thus, while the framework has conceptual uses in terms of identifying the full suite of issues that are relevant to consider in vulnerability assessment (and spatial VA) - a point the authors emphasize - the research community's ability to implement it remains limited. In Preston et al.'s (2011) review of 45 vulnerability mapping studies, only $9 \%$ of the studies employed expanded frameworks. These limitations notwithstanding, we chose the PNAS framework because it is widely cited in the literature on vulnerability assessment and because it is comprehensive and integrative, thus providing an adequate framework for a thesis largely focused on the issues surrounding data integration. So while it and other expanded vulnerability frameworks have limitations, there is perhaps no ideal framework for spatial vulnerability assessment. Even the far simpler IPCC definition can run into significant data and methodological limitations when it comes to quantitative measurement (Hinkel 2011), a subject we return to in Section 1.3.1.

\subsection{Background: Spatial Vulnerability Assessment4}

Spatial data integration and spatial analysis have become standard tools in the toolkit of climate change vulnerability assessments (BMZ 2014, UNDP 2010). The PROVIA Research Priorities on Vulnerability, Impacts and Adaptation (PROVIA 2013a) highlights "measuring and mapping vulnerability" as a first priority for supporting adaptation decision-making. In many cases "vulnerability assessment" is synonymous with spatial VA, owing in part to an understanding that vulnerability and its constituent components exhibit high degrees of spatial and temporal heterogeneity (Preston et al. 2011). The purposes vary according to the specific study, but spatial VAs are generally intended to identify areas at potentially high risk of climate impacts-so called climate change "hotspots" —and to better understand the determinants of vulnerability in order to identify planning and capacity building needs, or to better target funding and adaptation programs. There is as yet no consensus

\footnotetext{
4 The material in this section has been adapted from de Sherbinin, A. 2014. Spatial Climate Change Vulnerability Assessments: A Review of Data, Methods, and Issues. Technical publication for the USAID Africa Resilience to Climate Change (ARCC) project. Washington, DC: USAID.
} 
on what constitutes "best practice" in spatial VA, but there are a number of common approaches. we group these into four broad categories:

1. Spatial vulnerability indices: In this approach, components of vulnerability are normalized as indicators and aggregated to create a spatial index. Typically the architecture is guided by a vulnerability framework such as the IPCC vulnerability framework, with indicators grouped according to the components of exposure, sensitivity and adaptive capacity (e.g., Preston et al. 2007, Midgley et al. 2011, de Sherbinin et al. 2014, BMZ 2014). Other data reduction methods are also common, such as principal components analysis (e.g., Cutter et al. 2003, Abson et al. 2012).

2. Community-based and stakeholder-driven vulnerability mapping: This typically takes place in local jurisdictions over fairly small areas. Community-based mapping is in the tradition of participatory rural appraisal (PRA) and its variants (e.g., Kienberger 2012), while the stakeholder-driven VA generally engages local authorities though it may include community members (e.g., UNHABITAT 2013).

3. Map illustrations: In this approach, developers use maps or spatial data overlays to illustrate climate change impacts or to "tell a story." This is less formalized, and can represent everything from qualitative hotspots maps (Chapter 2) to map illustrations in a journal article or report (Chapter 5) (e.g., Warner et al. 2012a and 2012b). Often, spatial data layers are used to simply visualize the spatial extent of various stressors and target systems, sectors or groups (e.g., UNEP 2011).

4. Impact assessment and mapping: While technically distinct from vulnerability assessment, impact assessment is commonly used for mapping climate risks (e.g., Preston et al. 2007, UNHABITAT 2013). Because it is part of the broader toolkit for assessing climate impacts spatially we include it for completeness. The approach involves either the direct use of scenarios describing climate extremes (e.g., flood or storm hazards), or the integration of climate scenario data into process-based crop or hydrological models (e.g. Ericksen et al. 2011), to generate maps of likely areas of high climate impacts. In some cases a simple overlay of areas at risk to various climate stressors is used to identify the systems that may be affected (Chapter 5). Results of impact assessment could feed into a broader VA. ${ }^{5}$

\footnotetext{
5 Preston et al. (2007) suggest that VA describes how a system behaves in response to stressors, whereas impact assessment describes how a system responds to climate variability and change. Kok et al. (2010:15) write that "In a vulnerability analysis one might, for example, identify specific dryland areas in which smallholders are more
} 
None of the methods are necessarily superior to the others, nor are they mutually exclusive (e.g., one could have a participatory approach involving vulnerability indices or impact assessment), but the choice of method will depend on objectives, data availability, funding, and the time frame for the assessment.

In this section we address a number of common issues with spatial VA, starting with measurement issues, then moving on to issues related to spatial and temporal scale, uncertainty, validation, and decision making.

\subsubsection{Measurement Issues}

\section{Conceptual issues}

The topic of data and indicators, or "measurement" more broadly, is fundamental to the process of developing spatial indices of vulnerability. As Abson et al. (2012:516) state, indices have the advantage of reducing "the amount and complexity of the information that must be communicated while simultaneously providing an indication of the interaction of multiple, spatially homogenous indicators through a single aggregated vulnerability 'score'." There is an inherent trade off, however, between, on the one hand, the richness of information and the complexity of real world, and on the other, the communicability and utility of that information for policymaking (Abson et al. 2012). Furthermore, because vulnerability cannot be measured directly, ${ }^{6}$ it involves a process of identifying "indicating variables", which point to the construct of vulnerability, and aggregating them (Hinkel 2011). Thus for the sensitivity part of the IPCC framework it is common to use indicating variables such as poverty levels and infant mortality rates; and for factors such as coping or adaptive capacity, measures might include education, institutional capacity, funding levels for disaster risk reduction, or insurance coverage. Even where adequate data are available, these are often less-thanadequate proxies for intrinsic vulnerability. As Kasperson et al. (2005: 149) write, "political and social marginalization, gendered relationships, and

prone to droughts, not only because of climatic conditions but also because of characteristics of the people living there as well as other conditions like distance to markets, soil quality and the like. An impact analysis will forecast the number of people that may be affected by things such as hunger, death and migration, if drought conditions in these drylands were to change."

${ }^{6}$ Vulnerability has been termed an "emergent phenomena", in that it emerges from the stresses on the system, and therefore cannot easily be measured directly. Generally, a stressor, such as a major storm or flood, is said to reveal the underlying vulnerabilities of the coupled human-environment system. Two recent examples include the earthquake that struck Haiti in January 2010 and the one that struck Chile in February 2010 which was 500 times stronger (though at some distance from populated areas). The Haiti earthquake was far more devastating, and revealed underlying fragility in buildings and infrastructure, endemic poverty, and failures of governance that contributed to far higher casualties. 
physiological differences are commonly identified variables influencing vulnerability, but incorporating this conceptual understanding in global mapping remains a challenge."

Differentiating between indicators that measure sensitivity (or susceptibility) versus adaptive capacity may be challenging (Fekete 2012). For example, illiteracy or low education levels could be measures indicating high sensitivity and low adaptive capacity. According to Lucas and Hilderink (2004), determinants of coping/adaptive capacity are awareness, ability, and action. The ability to cope in the face of a climate stressor, or to take action with regard to restoring and rebuilding, are heavily influenced by insurance markets, emergency services and broader institutions and governance structures that can be difficult to measure (Chen et al., 2011). As an example, an assessment of climate vulnerability in southern Africa by Midgley et al. (2011) provides a comprehensive list of indicators by IPCC category, including 16 exposure indicators, 23 sensitivity indicators, and 12 adaptive capacity indicators. Yet the rationale for including a given indicator in the sensitivity or adaptive capacity categories can seem somewhat arbitrary (e.g., percent land under irrigation is a sensitivity indicator but could arguably be seen as an adaptive mechanism for rainfall deficits). This could be seen as an argument in favor of collapsing sensitivity and adaptive capacity into an overall "social vulnerability" term similar to the SREX framework (IPCC 2012), were it not for the fact that addressing them in policy contexts may imply a different set of interventions.

Adger and Vincent (2005) and Preston et al. (2011) argue that indicators should only be selected on the basis of theoretical linkages, and with some understanding of the relative contributions of exposure versus sensitivity and adaptive capacity to overall vulnerability. The reality is, however, that the precise contributions are difficult to quantify. Uncertainties in underlying data layers and insufficient understanding regarding the relative importance of the different components and the functional form of relationships among them makes spatial VA challenging, especially when covering larger regions at coarser spatial scales, an issue we take up again below. While recognizing the many conceptual ambiguities in adequately capturing vulnerability in quantitative metrics, spatial VA is still the only approach available for providing some degree of spatial precision in targeting interventions and identifying the spatial dynamics of vulnerability. Most of its shortcomings are inherent in any effort to model a complex world.

While there is no one correct way to characterize vulnerability, there are certainly wrong ways to do so. Füssel (2007) argues that quantitative vulnerability assessment requires definition of the system of analysis (what is vulnerable?), the valued attributes of concern (why is it important?), the 
external hazard (to what is the system vulnerable?), and a temporal reference (when?). We take this up as an organizing principle for the table describing hotspots mapping efforts in Chapter 2.

\section{Measuring the exposed elements}

In this section we address the majority of spatial VA approaches that rely on available data, rather than participatory mapping approaches that generate their own data. Measurement of the exposed elements entails cataloging of available data, and evaluating them in terms of their conceptual proximity to the component being measured, their spatial resolution, how up-to-date they are, and their reliability and validity. It may be possible to set up a scoring system across these axes in order to communicate the confidence that the developers have in each data set underlying the assessment (e.g., see Appendix A, Table A.6, of YCELP et al., 2005). At a minimum, it is recommended for developers of spatial VAs to provide ample metadata on each data layer, including an assessment of data limitations.

We addressed some of the issues surrounding the conceptual proximity of indicators to the component being measured above. Two measures may purport to address the same thing, but one may be conceptually and methodologically closer than the other. For example, an ideal sensitivity measure might be household wealth as measured by material assets through a Demographic and Health Survey (DHS), or small area estimates of poverty on a census tract basis. These may be available for a national assessment, if the statistical infrastructure is fairly robust, but they are less likely to be available for an international assessment. So measures have been developed such as "infrastructure poverty" (Midgley et al. 2011, Abson et al. 2012), which measures the population count relative to satellite observed night-time lights, and identifies areas that are poor on the basis of lower brightness per population in a given area. This, however, relies on certain assumptions concerning the luminosity of an area and the degree to which a population is under-served by electricity, and also is subject to compounding uncertainties such as the spatial location of populations (census units are often too coarse) or the effects of dense vegetation on luminosity in relatively affluent areas. Thus, this is a proxy measure of less validity than direct measurements of poverty or affluence. In other words, the direct measures of household wealth or poverty are closer in proximity to the sensitivity category than the infrastructure poverty measure, even if the latter may be resolved at a higher spatial resolution.

Consideration of the spatial resolution of input variables is important for any vulnerability assessment. The next section will address the spatial resolution of climate indicators, which in the absence of downscaling can be quite coarse (grid cells on the order of $50 \mathrm{~s}$ to $100 \mathrm{~s}$ of $\mathrm{km}$ on a side). Here we focus 
on variables representing social vulnerability or other systems of interest. Figure 1.4 shows the relative input unit size for a variety of measures in a spatial VA for Mali. At left are depicted the communes nested in cercles (equivalent to provinces), and at right the DHS cluster centroids, which represent the approximate locations of surveys responses from 10 households. Data at the commune level would generally be considered adequate, but data at the cercle level would be too coarse to adequately identify spatial patterns at the subnational level. The DHS centroids tend to be denser in more populated areas, and hence spatial interpolations between the cluster points are more robust in those areas and less robust in the sparsely populated north of the country. ${ }^{7}$ Note that the data reporting units will have an impact on statistical properties, since the more populated the unit the more averaging that occurs. Indicator values in units with smaller populations will typically exhibit greater variance than in larger units (see below on the modifiable areal unit problem).

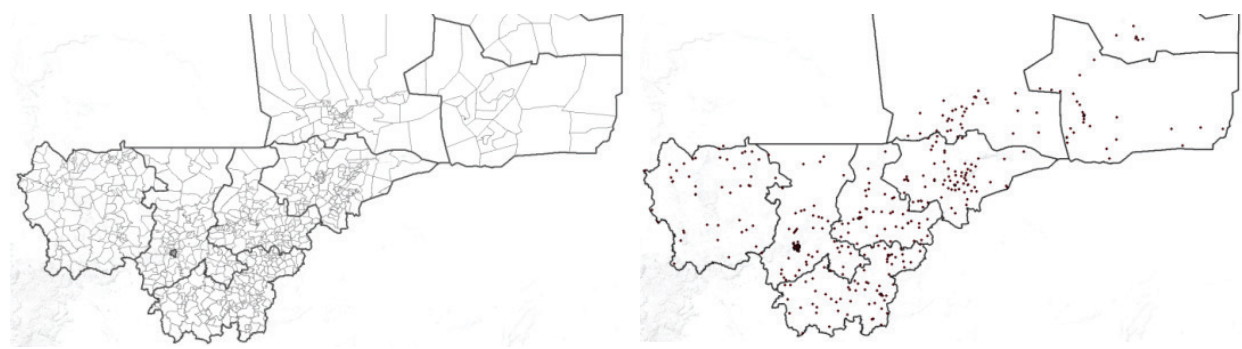

Source: de Sherbinin et al. 2014.

Figure 1.4. Input Units for Mali Spatial VA: Communes and Cercles (left) and DHS clusters (right)

Spatial layers representing cropping systems, land cover types (e.g., forests, biomes), water resources, fisheries, or other exposed elements tend to vary in spatial resolution depending on the data collection mechanism. Global land cover maps vary in resolution from $300 \mathrm{~m}$ to $1 \mathrm{~km}$, based on the resolution of the satellite sensors utilized. ${ }^{8}$ Cropping system maps tend to be coarser in resolution, at closer to 5 arc-minutes (20km) (e.g., Ramankutty et al. 2010). Livelihood systems can be even coarser, encompassing broad areas with common livelihood strategies.

\footnotetext{
7 Bayesian spatial interpolation between cluster points is recommended because it provides a spatial error map along with the interpolated surface.

${ }^{8}$ New Landsat resolution $(30 \mathrm{~m})$ land cover products will soon be available as well.
} 
Regarding the "recency" of data, up-to-date data can be difficult to obtain in many regions, and it is not uncommon to find vulnerability maps with input layers that are more than 10 years old. If the situation on the ground has changed dramatically owing to an ensuing event (e.g., conflict, economic downturn, or a major disaster) or rapid processes such as urbanization, then the indicators may no longer be valid. There may be little that can be done regarding the recency of data other than to clearly document the reference date of all the data layers in the metadata, and to highlight major uncertainties owing to out-of-date data in the document that accompanies the maps.

The last two evaluation criteria are reliability and validity. From a statistical standpoint, reliability is the degree to which an instrument or assessment tool produces stable and consistent results, and validity refers to how well an instrument measures what it is purported to measure. Thus, a survey of poverty may be said to be reliable to the degree that it captures certain metrics consistently over time and space, and it is valid insofar as it accurately captures parameters relevant to poverty (e.g., it captures income to within a few cents per day or malnutrition with a modest standard error). For productive systems, some land cover types are easier to map than others, and most global land cover maps are derived from semi-automated techniques (i.e., decision-tree algorithms) that require relatively little visual interpretation, meaning that the approach is likely to be more accurate to some regions than others. ${ }^{9}$ While land cover may be measured with fairly high degrees of confidence (and quantifiable uncertainty), other parameters may require accurate in situ data from agricultural censuses or river gauges that may be difficult to obtain or contain important gaps. These data collection systems are notoriously sparse in the most climate-sensitive regions such as Africa.

Typically it is very difficult to obtain information on the reliability and validity of many data layers, and even when they are available, time constraints and the multi-disciplinary nature of spatial VAs may make it difficult in practice to fully document and assess uncertainties in the underlying data. This is certainly best practice and should be encouraged, and indeed all composite vulnerability maps should ideally include an accompanying uncertainty map. Process-based impact model outputs typically either provide multiple

\footnotetext{
9 For example, global land and forest cover maps have difficulty accurately capturing woody vegetation cover in the Sahel, which is sparsely vegetated. Much has been made of the regreening in this region, yet owing to the coarseness of their resolution and the algorithms used, greenness maps based on the normalized difference vegetation index (NDVI) are almost entirely reflecting the presence of herbaceous vegetation (Tappan, personal communication).
} 
scenarios or an accompanying uncertainty map. But even where information on the standard errors for data layers are absent, judgment calls need to be made concerning data sources, and developers of spatial VAs would do well to read through data documentation and to assess the data visually (in map form) and statistically to better understand spatial patterns and basic descriptive statistics such as mean, median, standard deviations, skewness, and outliers. For example, if administrative units with extremely high values are surrounded by units with very low values for the same parameter, this may point to data quality issues unless there is an explanation for the anomaly. Running spatial statistical tests in Geoda or other spatial statistics packages (Moran's I or mapping of residuals for OLS regressions; see Chapter 4) can help to identify patterns in the data that may be difficult to pick up visually.

Whereas many Spatial VAs do include future climate scenarios, they generally do not include projected changes in the spatial distribution of populations or other exposed elements (Preston 2012), which themselves have considerable uncertainties, nor do they generally factor in likely adaptation responses, which may be hard to predict. Work by Giannini et al. (2011) and Preston (2013) represent exceptions to this general rule, in that they do include population and economic projections. Efforts are now underway to develop spatially explicit population scenarios for the shared socioeconomic pathways (SSPs) (Jones 2013), but the task of anticipating likely future population distributions can be rendered difficult by unanticipated economic or conflict events that can alter migration patterns. Because of the difficulty of projecting the exposed elements, most spatial VAs extrapolate from current vulnerability to climate variability and extremes to identify how climate change may alter the climate component, leaving aside changes in the populations or sectors/systems that will be impacted. Yet, Preston (2013) notes that natural disaster losses have increased significantly in the United States owing more to growth in socioeconomic exposure than to changes in the frequency or intensity of extreme events, so ignoring future changes in the spatial distribution and "density" of exposed systems is likely to yield suboptimal results in a risk assessment framework.

\section{Measuring the climate stressors}

Turning to climate data, or the "exposure" aspect of vulnerability assessments, it should be stated up front that all vulnerability assessmentsspatial or not-encounter issues with the use of climate data. The intent here is not to develop a comprehensive list of issues, which can be found elsewhere (e.g., PROVIA 2013b), but rather to focus on the issues most commonly encountered in spatial VAs. 
Given difficulties in using climate scenario data from general circulation models (GCMs), many spatial VAs use past climate variability or recent histories of extreme events (e.g., flood or drought occurrence or economic losses associated with them) as proxies for future changes. The underlying assumption is that those regions that are most exposed today will likely have similar or greater levels of exposure in the future. Frequently used data collections that assess the frequency of extremes include the World Bank Hazard Hotspots collection (Dilley et al. 2005, CHRR et al. 2005) and the United Nations Environment Programme (UNEP) Global Assessment Reports (UNISDR 2009). Both efforts faced significant methodological challenges to map the frequency of extremes, since flooding is generally a local phenomenon that is difficult to characterize globally (the UNEP report developed higher resolution data using hydro models and remote sensing), and drought metrics are heavily dependent on regional definitions of rainy seasons and long term historical averages of rainfall that are difficult to capture in global maps (Lyon, personal communication). Furthermore, data sparseness and gaps can plague efforts to map historical climate extremes. Local-level fine scale analyses, ${ }^{10}$ particularly in developing countries, may run into problems with obtaining adequate meteorological station data to adequately represent local climatology.

Broad scale efforts, from regional to global, generally have to rely on longterm historical climate data sets, all of which rely to some extent on meteorological station data networks and satellite data. This may be less problematic for temperature data, for which interpolation techniques are reasonably robust, but for precipitation these data sets may run into issues with the spatial coverage of the underlying gauge-based data. This affects drought mapping and a range of other applications. In an eight-country study of climate variability, livelihoods and migration (Warner et al. 2012a), assessment of climate reanalysis data for given localities compared to local rain gauge data often produced different conclusions with regards to variability, drought or even trends over recent decades. Common historical data sets range in scale from 0.5 degrees to 2.5 degrees, or grid cells of 55 to $275 \mathrm{~km}$ on a side at the equator (e.g., CPC Merged Analysis of Precipitation, NCEP/NCAR Reanalysis, and ECMWF Reanalysis). In data-poor developing regions, characterizing past climate accurately can be difficult owing to gaps in monitoring networks, temporal gaps in measurement at

\footnotetext{
10 Note: Cartographers and geographers use the term "small scale" to refer to maps that cover large areas (regional to global) and "large scale" for maps that cover small areas (provinces/states down to localities). These scales refer to the number of map units to real world units, so a small scale map with a scale of $1: 1,000,000$ is a map in which $1 \mathrm{~cm}$ on the map represents $10 \mathrm{~km}$ on the Earth's surface. However, non specialists tend to use these terms with the exact opposite meanings. To avoid confusion I use the terms "broad scale" for maps that cover large areas and "fine scale" for maps that cover small areas.
} 
given stations, and discrepancies between satellite measurement and gauges (Dinku et al. 2011).

Those that do use climate model outputs run into a number of issues that are common to any assessment that seeks to incorporate information about likely future climate. A fundamental challenge for vulnerability mapping that relies on accurate prediction of extremes, such as that for disaster response or humanitarian needs, is the limited ability of GCMs to capture historical variance or future extremes (IPCC 2012, Brown and Wilby 2012). For example, Brown and Wilby found, in a comparison of observed and GCMbased downscaled annual streamflow estimates for the northeastern United States, that "downscaled GCMs underestimate both the standard deviation and [temporal] autocorrelation when compared with observations" (2012: 401). The use of multi-model ensembles only tends to further reduce variance, since they average multiple model runs together, resulting in a dampening of the extremes.

Coarseness of the model outputs-ranging in resolution from 1 to 2 degree grid cells (110-220 km on a side at the equator)-is also a concern, and in some cases the outputs need to be resampled from a rectangular grid in order to be used in GIS packages that require grids with equal latitude and longitude increments. While climate model downscaling may be an option for well-resourced VAs, most do not have the resources to do so. ${ }^{11}$ Fortunately, a new generation of higher resolution GCMs with outputs in the range of 20 $\mathrm{km}^{2}$ is being produced for the IPCC Fifth Assessment report (e.g., Kitoh 2012). An issue with these models, however, is the sheer volume of data that is generated, considering that GCM time steps are generally every 30 minutes. Given the volumes of data, users will need to rely on pre-calculated parameters of variability, since desktop computers are unlikely to be able to handle the processing. The complexity of formats and outputs can also overwhelm the non-climate scientists who often conduct spatial VAs.

Given the coarseness of GCM outputs and their inability to accurately represent some local scale climate phenomena (e.g., orographic precipitation), downscaled climate information is increasingly being used for climate vulnerability assessments. For those studies that do use regional models, a significant issue is variability across model runs. For example, Oettli et al. (2011:1) find, in a study of regional models as inputs to crop modeling in Africa, that "the performances of regional models in reproducing the most crucial variables for crop production are extremely variable." The result is that there is a large dispersion in crop yield prediction owing to the

11 de Sherbinin (2014) found only a handful of spatial VAs use downscaling; it is more common for impact assessments to downscale the climate data. 
different physics in each regional model and also the choice of parameterizations. Oettli et al. note that two configurations of the same regional model are sometimes more distinct than those of different regional models.

Another common issue is that the broad changes in temperature and precipitation are used as proxies for climate variables that are most relevant for the system under consideration. For agricultural systems, water management, or natural hazard prediction, the most important variables would be anticipated change in rainy season onset, gaps in rainfall during growing seasons, changes in drought periodicity, or changes in rainfall duration and intensity. Many of these changes are already occurring (IPCC 2012; Warner et al. 2012a, Warner et al. 2012b). Yet these parameters require significant additional processing to extract from either historical climate data or climate model outputs. Finally, most climate models do not take into account the possibility for abrupt change or tipping points in the climate system (e.g., Duarte et al. 2012). The primary way to address this in spatial VA is to develop scenarios of future extreme events, or a "stress test" approach (Storch et al. 2011, Brown and Wilby 2012).

It is worth noting that even something as "simple" as mapping vulnerability to sea level rise (SLR) can hold uncertainties. SLR impacts in theory are easy to model, since the impacts are restricted to low elevation coastal zones and can be approximated with a digital elevation model (DEM), and exposure is simple to assess: you are either in or outside the area at risk. Several reports and articles have assessed global SLR impacts on coastal populations and assets (e.g., de Sherbinin et al. 2012, McGranahan et al. 2007, Dasgupta et al. 2007, Nicholls et al. 1999), and Klein (2012) found 13 articles covering the Nile Delta alone. Yet, here again, there are significant uncertainties. Most mapping efforts rely on maps of current mean sea level and elevation as defined by the Shuttle Radar Topography Mission (SRTM), one of two highresolution globally available DEMs, which has a vertical accuracy in low slope areas of only +/- 4-5 m (Gorokhovich and Voustianiouk 2006). This means that areas that are mapped at $0 \mathrm{~m}$, or current sea level, could in fact be $-5 \mathrm{~m}$ (submerged) or $+5 \mathrm{~m}$ (well out of harm's way for years to come). Furthermore, the time by which a given sea level will be attained is not known with great certainty (Rahmstorf 2012), SLR will vary regionally, and SLR will be complicated by tides and storm surge in certain locations (Strauss et al. 2012, Tebaldi et al. 2012). The best approach for local assessment is to rely on lidar, GPS, or high resolution stereoscopic imagery for elevation data, and to develop local models for storm surge.

Taken together, the data challenges translate into higher levels of uncertainty. While the list of data problems may seem like an insurmountable 
challenge to spatial VAs, it should be underscored that any effort to characterize an uncertain future will face challenges, yet for decision making related to climate adaptation the only real option apart from major investments in new data development is to work with best available data. A key issue is uncertainty and risk communication, which is addressed below. Here it is worth noting that the power of maps to summarize information is partially offset by their ability to hide uncertainties, and that developers of climate vulnerability or hotspot maps need to think about how to communicate those uncertainties and increase the level of transparency regarding likely sources of error both in the reports that accompany the maps, and to the extent possible in the maps themselves.

\subsubsection{Spatial resolution and spatial and temporal scale issues}

There are a number of choices in any vulnerability assessment that relate to spatial scale. One is the choice of spatial units of analysis and another is the geographic extent (bounding box) of the system under consideration. Both are affected by the resolution of the available data. A good overview on scale issues in global change research can be found in Gibson et al. (2000), and discussions of issues of spatial and temporal scale/resolution in vulnerability assessments are found in Kienberger et al. (2013) and Soares et al. (2012).

\section{Spatial resolution and temporal scale}

Preston et al. (2011) describe the common resolutions of data sets used in vulnerability mapping (Figure 1.5). On the one end are biophysical data, often derived from remote sensing, that are at high spatial resolutions. On the other end are climate data, which are generally coarse. Sandwiched between are the socio-economic data from censuses and surveys. This is a generalized view, as there are obvious exceptions, such as remote sensing derived vegetation data that are only available at $1 \mathrm{~km}$ pixel sizes, or climate data from individual meteorological stations that represent highly localized areas. Yet it is a useful representation since it highlights the fact that spatial VAs need to draw on data at different spatial scales, and hence the choice of output resolution in spatial VA needs to be considered carefully. Often this is determined by the highest resolution data sets available, but it is important to remember that even if coarser data are resampled at a high resolution, their nominal resolution is much lower. For local VAs, a resolution of $1 \mathrm{~km}$ is probably too coarse for available data, nor would it adequately resolve local features, so a higher resolution of 30-250m may be desirable. Developers of spatial VAs should seek to map at a resolution appropriate for the end users (decision-makers), and should avoid using coarse resolution data when higher resolution alternatives are available. 
Integrating data at different spatial scales can result in artifacts in the maps that unintentionally draw attention to differences between areas that are not necessarily present on the ground. For example, abrupt discontinuities across borders may be an artifact of using national level adaptive capacity indicators, or it may reflect actual changes owing to different governance regimes. Apart from rigorous ground-level data collection it would be difficult to determine if these discontinuities actually reflect "real" changes in on-theground vulnerability. Maps that include continuous variables derived, for example, from remote sensing data (e.g., forest or crop land cover) may result in maps with pixelated results that may appear noisy; in these cases the use of a low-pass filter may help to reduce the noise and increase the communication value.

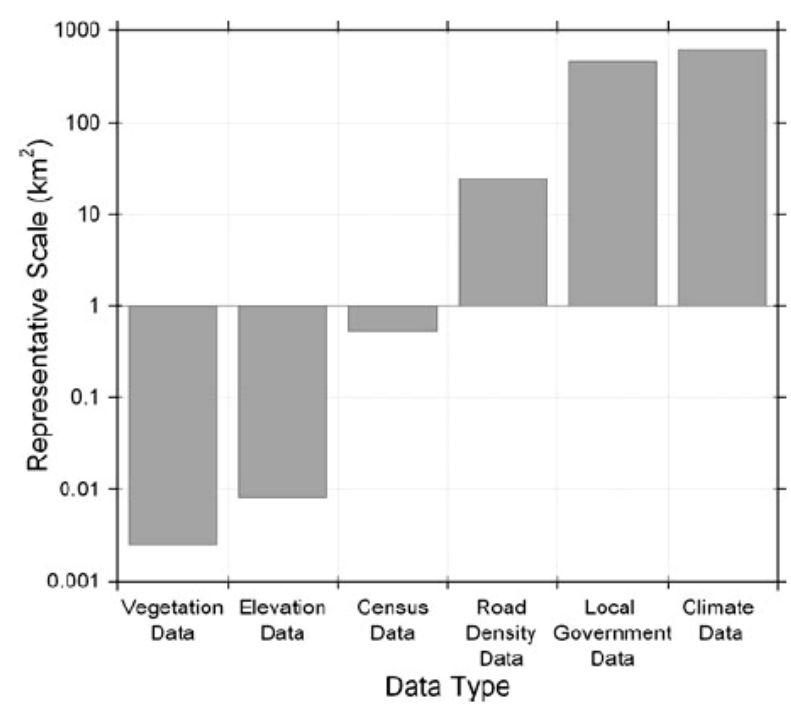

Source: Preston et al., 2011, p. 189.

Figure 1.5 Spatial scale differences among different data sources

Temporal scale relates to the time frame of the assessment (the "when?" identified by Füssel (2007)) as well as the temporal frequency of the phenomena of interest, which is the generally the climate stressor to which the system is exposed (Kienberger et al. 2013). It can also refer to the frequency of measurement, e.g., from hourly (for climate data) to weekly (for higher resolution remote sensing data) to decadal (for census data). Generally speaking, spatial VAs integrate data representing multiple time periods. Climate analyses may require historical data for $50-100$ year periods in order to adequately capture trends or the frequency of extreme events. Socioeconomic data may be limited to the dates of the most recent census or 
survey, and land cover data may be available for several points in time. For local assessments, quite recent data may be collected by community members themselves (UNHABITAT 2013, Kienberger 2012) or provided by local agencies (Preston et al, 2007). It is a good practice to clearly communicate the approximate time frame that the assessment represents, and to advise users of the incorporation of older data owing to data limitations.

\section{Scale and spatial level}

The spatial level of analysis relates to the bounding box of the spatial VA. Measures of relative vulnerability will necessarily depend on the bounding box one uses to delimit one's study. For example, in an assessment of vulnerability in southern Africa, Abson et al. (2012) created vulnerability indices for all countries in the Southern African Development Cooperation (SADC) zone and the same set of indices for one ecosystem, drylands, within the SADC. They found that "the spatial extent over which the analysis is undertaken is likely to have a considerable influence on the resulting indices" (Abson et al. 2012:20), such that for the larger region vulnerability differences between ecoregions were found to be high, but within ecoregions vulnerability differences were generally lower. For a spatial VA conducted for Mali (de Sherbinin et al. 2014), all data layers were obtained for the whole country. However, in the normalization process all areas north of $17.2^{\circ} \mathrm{N}$ latitude were excluded from consideration on two grounds. Firstly, because vulnerability results are less meaningful for a region that is so thinly populated and where climate variability and change may have less of an impact owing to already harsh conditions, and secondly, because inclusion of indicator data values for this region might skew results for the remainder of Mali (owing to extreme values for many indicators in this region), which is the primary region of interest.

Choice of bounding box can be straightforward, for example, for countrybased assessments where the unit of analysis is everything within the country's borders. Yet, as Preston et al. (2011) suggest, choice of geographic bounds are often determined by the availability of relevant data or stakeholder needs, rather than by the dynamics of the system under investigation. It is important to have a clear rationale for choosing the extent of the study area (e.g., a watershed or an administrative area), and if the study is longitudinal, to be sure to retain the same extent over time.

Interactions across scales, teleconnections (e.g., trade networks) and nonclimatic shocks are often overlooked in spatial VAs. For example, demand for a cash crop such as coffee could be affected by economic downturn in Europe or North America or competition from growers in other countries, and this could be a greater determinant of local vulnerability than short-term climate 
fluctuations (Eakin et al, 2006). Some have suggested a "hot systems" approach as an alternative to hotspots mapping, which would consider perturbations to socio-economic and ecological systems in disparate geographic locations (Shen et al., 2010). An example of an approach that looks at teleconnections and systems is the syndromes approach developed by researchers at the Potsdam Institute for Climate Impact Research (Lüdeke et al. 2004).

Fekete et al. (2010) recognize that each scale of analysis has benefits and drawbacks and that these should be examined and documented within each study. They argue "that a more transparent and thorough understanding of which vulnerability phenomena can be detected at which spatial level and scale might help enormously in the aggregation and combination of single aspects" (Fekete et al., 2010:744). By developing sound theoretical frameworks and achieving better understandings of scale implications, investigators are better able to determine how studies focused on single levels can benefit from each other and how best to approach multi-scale or cross-scale vulnerability assessments. Scalar dynamics are illustrated in two chapters. The megacity climate hazard vulnerability assessment (Chapter 3 ) identifies cross-scale vulnerabilities, such as local level flood and landslide risk and broader scale drought risks that could affect water supplies. In Chapter 4, the framework presented for the drivers of child malnutrition (Figure 4.1) depicts drivers from national to household level, suggesting distinct policy levers for addressing this important issue.

\section{Units of analysis}

A choice needs to be made regarding the units of analysis. For example, Abson et al. (2012) and de Sherbinin (2014) used grid cells as the units of analysis, gridding all socio-economic variables and re-sampling grids at various spatial resolutions to common 10 arc-minute and 30 arc-second grids, respectively. The grid cells then became the units of analysis. On the other hand, Antwi-Agyei et al. (2012) aggregated all data to sub-regional units within Ghana, and the approach described in Chapter 4 analyzes the correlates of malnutrition in Africa using 367 subnational units. This implies some sort of spatial averaging (zonal statistics) of the biophysical data so that they conform to administrative units. The geon approach (Lang et al. 2008, Kienberger et al. 2009) permits developers to create units independent of administrative boundaries based on underlying similarities in their vulnerability "profiles" (across indicators) and spatial contiguity. ${ }^{12}$

\footnotetext{
12 The geon approach takes information on the statistical properties but also the location of units/cells in constructing geons (or objects). Thus, building out from a core grouping, the object-based approach will preferentially assign neighboring cells to that geon if their statistical and spatial properties are broadly similar, thus avoiding the
} 
There is no one "right" answer for the choice of units, and often these are driven by the needs of stakeholders or the goals of the assessment. But it is important to recognize that the choice of units will affect results owing to the modifiable area unit problem (MAUP) (Openshaw 1983). MAUP refers to the fact that the results of a statistical analysis can be substantially altered by the choice of areal units that are chosen as the unit of analysis-e.g., enumeration areas or post codes or higher levels of aggregation such as counties. Values for almost all parameters-e.g., population count or density or population characteristics-will depend in part on the choice of unit, with larger units tending to average out extremes in the data. Interpolation of data, area averaging and aggregation can all introduce errors and spatial biases in statistical relations owing to the MAUP.

Decisions on appropriate units of analysis and how to aggregate are generally driven by theory and data availability. Some choose census units since those are the native units of the social vulnerability factors. In some cases, administrative units may vary greatly in spatial extent; for example, units in sparsely populated areas tend to be much larger than those in urban areas. Hence, the standard deviation around the averages of biophysical features in rural areas (e.g., rainfall levels or soil quality) is likely to be much higher than those in urban areas. Furthermore, if the purpose of an assessment is to understand how a biophysical factor such as rainfall amount or variability affects the population within a large unit, as in Chapter 4, it is probably best to remove from one's zonal average those areas that are not densely populated through the use of spatial masking.

This ties in with risk communication as well, as described below. For example, a district level map of vulnerability simply will not permit an identification of risks associated with particular households or allow decision makers to target resources with adequate precision (Fekete 2012).

\section{Ecological Fallacy}

If one is not careful in one's understanding of scalar dynamics, it is possible to commit what is termed an "ecological fallacy." A textbook definition of ecological fallacy is "the danger of making an analysis at one level apply at other levels, for example, of inferring individual characteristics from group characteristics" (Mayhew 1997). Wood and Skole (1998:87) extend this definition to the spatial realm, writing that "the ecological fallacy can be thought of as a special case of spuriousness in which the relationships found in... regression analyses are due to a shared spatial location, rather than a causal connection." Clearly one cannot infer that a given household is vulnerable based on spatial location alone, even if it is located in a highly

"speckling" effect common in many cell-based image processing and statistical approaches. 
vulnerable grid cell or unit and has characteristics associated with high exposure and sensitivity. Much comes down to local context. For example, elderly residents living alone will be differently vulnerable to floods or heat waves than elderly residents living in assisted living facilities. Thus, a poor elderly resident living alone would need a different intervention strategy than an affluent elderly resident of a retirement community or an assisted living facility.

\subsubsection{Uncertainties, validation, risk communication and decision support}

A number of issues related to uncertainty in data commonly used in spatial VAs were discussed above. As Fekete (2012:1175) points out, "uncertainties in primary data are inherited by secondary data sets," and these uncertainties may be made obvious when units have missing values, made opaque when averages are used, or hidden altogether when numbers are based on assumptions, miscalculations or errors. According to Preston et al. (2011:191), the failure on the part of spatial VAs to address uncertainty "often results in questions regarding the validity, accuracy and precision of vulnerability maps, or, in other words, whether maps themselves represent sufficiently robust visions of vulnerability to guide stakeholders regarding the potential for harm."

Researchers coming from the climate and integrated assessment communities tend to produce map arrays depicting multiple scenarios (e.g., Parish et al. 2012). One strength of process-based modeling is the ability to run multiple scenarios reflecting uncertainties in likely futures, which gives decision makers a better sense of the spread in relative risk. However, this often reduces legibility (since map arrays often present many maps of the same area at very low resolution) and can lead to confusion in the reader's mind since there is seldom any guidance on how to interpret the range of scenarios, or whether under certain assumptions one outcome is more likely than another. This can result in information overload. As Patt and Dessai (2005:427) point out, users have varying abilities to understand probabilistic information, and "people will either choose to ignore information that is too complicated for them, or will respond in ways that disproportionately makes use of some types of information over others."

Partly to compensate, spatial VA results are often couched in highly tentative terms. Representative quotes from recent global scale reports (Box 1.1) illustrate how results are often presented as preliminary, suggesting that the authors recognize that the results cannot be viewed as definitive but rather as part of an ongoing process of knowledge generation. The primary means of moving beyond highly tentative conclusions would be through rigorous 
validation. Preston et al. (2009: 270) caution that because "vulnerability assessments specifically attempt to build understanding about future states where uncertainty regarding drivers and outcomes is high (or simply unknown), means validation of vulnerability assessments is inherently challenging", but they argue that it is clearly preferable to at least partially validate a VA against an independent set of metrics or criteria. Although validation is still relatively rare in spatial VA (though more widely employed in impact assessment), Preston et al. (2009) and Fekete (2009) are examples where validation was employed using an independent set of metrics.

\section{Box 1.1 Representative quotes highlighting the contingent nature of spatial vulnerability assessment}

"Given the extreme complexity of climate change and human vulnerability, this study should be considered as indicative only. We have taken a pragmatic approach in order to produce useful results and analysis within the scope and resources of this project." (Thow and de Blois, 2008:6)

"Local vulnerability analyses are often case studies that address the usually complex context-specific situations that shape specific vulnerabilities. Out of necessity, global vulnerability assessments are based on aggregated data and rather crude assumptions about the underlying mechanisms being assessed. The gap between both is a major challenge for integrated assessments of vulnerability." (Kok et al., 2010:13)

In terms of risk communication, Dransch et al. (2010) discuss the usefulness of maps for improving risk perception by improving awareness and understanding of risk among key target groups and the public. They develop a frame to guide map-based risk communication efforts. This frame helps the designer to systematically formulate the risk communication objectives, tasks, and suitable visualization methods and assists the designer in identifying important challenges and constraints. They point out that map designs should aim to meet the needs of differentiated target groups, i.e., primary audiences, which may be those most affected by a hazard, those least informed about a hazard and its consequences, and those most involved in the risk management decision-making process. In some cases, the target audience may be the general public. Key considerations in map design include how to increase attractiveness and how to reduce the complexity of the information presented.

Finally, there are broader questions regarding the use of information in policy contexts that are not unique to spatial $V A$, but which may be particularly germane in these contexts (Hinkel 2011, de Sherbinin et al. 2013). A 
fundamental question is whether the maps are fulfilling their purported intent, which is to guide policy and management decisions. Preliminary evidence suggests that spatial index approaches can be useful to policy audiences (Midgley personal communication, Preston et al. 2009, de Sherbinin et al. 2014), but as mentioned above, special care needs to be given to the communication of uncertainties to end users. Preston et al. (2011) describe vulnerability mapping projects in two Australian contexts in which the direct link between the map and decision making was difficult to trace. Recognizing the fact that policy makers may act (or fail to act) regardless of available information, they suggest that such maps probably best serve as boundary objects, linking "communities together as they allow different groups to collaborate on a common task" (Wenger 1998). This suggests that maps can facilitate debate and deliberation, but are at best one input into broader decision-making processes that are inherently political (de Sherbinin et al. 2013).

\subsection{Objective and Organization of the Dissertation}

To reiterate, in this thesis we provide examples of spatial analyses including quantitative and qualitative analyses and map representations that contribute to understanding patterns of vulnerability to climate change. Specifically, we explore this methodological diversity and discuss the relative merits of different approaches to understanding spatial patterns of vulnerability with a particular emphasis on the utility of vulnerability maps for policy making. We also examine the utility of an extended vulnerability framework developed by a team of researchers at Harvard and Clark Universities for guiding research and illuminating vulnerabilities of coupled human-environment systems (Turner et al. 2003a).

To accomplish this, we examine different case studies representing different approaches to vulnerability mapping in the chapters of this thesis. We seek to answer a set of questions pertaining to each approach, as shown in Table 1.1. The table also shows which aspects of the PNAS framework and issues related to spatial vulnerability assessment are addressed in each of the chapters. 
Table 1.1: Overview of Chapters in this Thesis

\begin{tabular}{|c|c|c|c|}
\hline Chapter Title & Key Questions & PNAS Framework & Issues Addressed \\
\hline $\begin{array}{l}\text { 2. Climate Change } \\
\text { Hotspots Mapping: } \\
\text { What Have We } \\
\text { Learned? }\end{array}$ & $\begin{array}{l}\text { - Which regions are } \\
\text { most affected by } \\
\text { climate change past } \\
\text { and future? } \\
\text { - What } \\
\text { improvements can } \\
\text { be made to the } \\
\text { practice of hotspots } \\
\text { mapping? }\end{array}$ & $\begin{array}{l}\text { A number of global } \\
\text { mapping efforts touch on } \\
\text { elements of the PNAS } \\
\text { Framework, but only one } \\
\text { explicitly utilizes it. }\end{array}$ & $\begin{array}{l}\text { This chapter reviews a } \\
\text { range of methods for } \\
\text { mapping vulnerable } \\
\text { regions through the } \\
\text { lens of global } \\
\text { assessments. }\end{array}$ \\
\hline $\begin{array}{l}\text { 3. The vulnerability of } \\
\text { global cities to climate } \\
\text { hazards }\end{array}$ & $\begin{array}{l}\text { - What is the } \\
\text { interplay } \\
\text { biophysical of and } \\
\text { human factors } \\
\text { influencing the } \\
\text { vulnerability of } \\
\text { coastal megacities } \\
\text { to climate hazards? }\end{array}$ & $\begin{array}{l}\text { The PNAS Framework } \\
\text { was explicitly used to } \\
\text { frame the research, and } \\
\text { all aspects of the } \\
\text { framework were } \\
\text { explored in a qualitative } \\
\text { assessment. }\end{array}$ & $\begin{array}{l}\text { This chapter primarily } \\
\text { focuses on qualitative } \\
\text { aspects of vulnerability } \\
\text { mapping, including } \\
\text { spatial, historical and } \\
\text { governance aspects. }\end{array}$ \\
\hline $\begin{array}{l}4 . \quad \text { Climatic, } \\
\text { Biophysical, and } \\
\text { Socioeconomic Factors } \\
\text { Affecting Malnutrition } \\
\text { in Sub-Saharan Africa }\end{array}$ & $\begin{array}{l}\text { - Which biophysical } \\
\text { and socioeconomic } \\
\text { variables best } \\
\text { explain the spatial } \\
\text { variation in } \\
\text { vulnerability, as } \\
\text { measured by child } \\
\text { malnutrition rates? } \\
\text { - How does spatial } \\
\text { autocorrelation } \\
\text { affect results and } \\
\text { how do results of a } \\
\text { spatial error model } \\
\text { compare to } \\
\text { standard oLS } \\
\text { regression? }\end{array}$ & $\begin{array}{lr}\text { Consistent with the } \\
\text { PNAS framework, the } \\
\text { analysis explicitly adopts } \\
\text { a coupled r human- } \\
\text { environment } & \text { system } \\
\text { approach r by } \\
\text { incorporating a } & \text { series of } \\
\text { biophysical r } & \text { and } \\
\text { socioeconomic indicators } \\
\text { into a spatial } & \text { regression } \\
\text { analysis }\end{array}$ & $\begin{array}{l}\text { This chapter focuses on } \\
\text { an inductive approach } \\
\text { to vulnerability } \\
\text { mapping, but looking } \\
\text { at one outcome } \\
\text { measure } \\
\text { malnutrition) (child } \\
\text { seeking the best } \\
\text { predictors of that } \\
\text { outcome. The chapter } \\
\text { also addresses issues } \\
\text { of } \\
\text { autocorrelation. }\end{array}$ \\
\hline $\begin{array}{l}\text { 5. Climate Change: } \\
\text { Three "Hot Spots" of } \\
\text { Human Mobility }\end{array}$ & $\begin{array}{l}\text { - How can maps be } \\
\text { used to illustrate } \\
\text { the climate and } \\
\text { other factors that } \\
\text { influence human } \\
\text { mobility? }\end{array}$ & $\begin{array}{l}\text { The PNAS extended } \\
\text { vulnerability framework } \\
\text { was influential in the } \\
\text { development map } \\
\text { illustrations insofar as } \\
\text { they focus on multiple } \\
\text { interacting perturbations } \\
\text { and stressors/stresses; } \\
\text { coupled socio-ecological } \\
\text { systems, with particular } \\
\text { reference to rainfed } \\
\text { subsistence agriculture; } \\
\text { and the sensitivity of } \\
\text { different systems to } \\
\text { stressors. }\end{array}$ & $\begin{array}{l}\text { This chapter addresses } \\
\text { the use of maps as } \\
\text { illustrations for case } \\
\text { studies, providing } \\
\text { context for the } \\
\text { migration patterns } \\
\text { being experienced in } \\
\text { each region. }\end{array}$ \\
\hline
\end{tabular}

To summarize the chapter contents, Chapter 2 presents a meta-analysis of global climate vulnerability "hotspots" mapping efforts covering a range of issue areas including population vulnerability and migration, disasters and humanitarian crises, and agriculture and food security. The chapter assesses 
the state of the art in hotspots mapping and identifies strengths and weaknesses in the different approaches, identifying what contributions the PNAS framework has made and could make to this important research area. Chapter 3 applies a traditional "top-down" approach to vulnerability assessment - using climate scenarios to assess likely climate impacts coupled with more recent advances in vulnerability mapping through "bottom-up" assessments to assess the vulnerability of three mega-cities to climate hazards. The result is something of a hybrid, which, guided by the PNAS framework, facilitates an understanding of likely future climate impacts while assessing the resilience of the current socio-ecological system in the face of bundles of stresses that are partly related to climate impacts and partly related to fragilities in the system itself.

While Chapter 3 is qualitative, Chapter 4 introduces a quantitative approach to identifying the biophysical and geographical correlates of child malnutrition in Africa. In this chapter, vulnerable regions are identified a priori on the basis of child malnutrition levels, and the focus is instead on identifying the correlates of malnutrition that can help to elucidate underlying causal mechanisms, including climate variables. This is an inductive approach to identifying indicating variables of vulnerability through their statistical explanatory power (Hinkel 2011). Chapter 5 is policy focused, weaving together the results of field work from the Environmental Change and Forced Migration Scenarios (EACH-FOR) project with vulnerability mapping in order to educate the public and policy makers about the need to anticipate and to plan for migration as well as to protect migrant's rights. A concluding chapter, Chapter 6, assesses the strengths and weaknesses of the different approaches and the utility of the PNAS framework, and points to ways forward in spatial vulnerability assessment.

\subsection{References}

Abson, D.J., A.J. Dougill, and L.C. Stringer. 2012. Using Principal Component Analysis for information-rich socio-ecological vulnerability mapping in Southern Africa. Applied Geography, 35:515-524.

Adger, N. 2006. Vulnerability. Global Environmental Change, 16:268-281.

Adger, W.N., and K. Vincent. 2005. Uncertainty in adaptive capacity. Comptes Rendus Geoscience, 337: 339-410.

Antwi-Agyei, P., E. D. G. Fraser, A. J. Dougill, L. C. Stringer, and E. Simelton. 2012. Mapping the vulnerability of crop production to drought in Ghana using rainfall, yield and socioeconomic data. Applied Geography, 32:324-334.

Birkmann, J. 2006. "Measuring vulnerability to promote disaster-resilient societies: Conceptual frameworks and definitions." In: J. Birkmann 
(ed.), Measuring vulnerability to natural hazards: Towards disaster resilient societies. Tokyo: United Nations University Press.

Birkmann, J., and B. Wisner. 2006. Measuring the Un-Measurable: The Challenge of Vulnerability. UNU-EHS SOURCE, No. 5. Bonn: United Nations University-Environment and Human Security.

Blaikie, P., T. Cannon, I. Davis, and B. Wisner. 1994. At risk: natural hazards, people's vulnerability and disasters. London: Routledge.

BMZ (German Federal Ministry for Economic Cooperation and Development). (2014). The Vulnerability Sourcebook: Concept and guidelines for standardised vulnerability assessments. Berlin, Germany: GIZ (Deutsche Gesellschaft fur Internationale Zusammenarbeit).

Brown, C., and R. L. Wilby. 2012. An alternate approach to assessing climate risks. Eos, Transactions American Geophysical Union, 92, 401-412.

Burton, I., R.W. Kates, and G.F. White. 1978. The Environment as Hazard. Oxford: Oxford Univ. Press.

Chambers, R. 1994. Participatory Rural Appraisal (PRA): analysis of experience. World Development, 22:1253-1268.

Chen, R.S., A. de Sherbinin, T.W. Miner, and M. Levy. 2011. "A Conceptual Framework for A Global Resilience Index." Unpublished paper for the World Bank's Global Facility for Disaster Risk Reduction. Palisades, NY: CIESIN, Columbia University.

CHRR (Center for Hazards and Risk Research), CIESIN (Center for International Earth Science Information Network), and World Bank. 2005. Natural Disaster Hotspots Data Collection. Palisades, NY: NASA Socioeconomic Data and Applications Center. http://sedac.ciesin.columbia.edu/data/collection/ndh

Cutter, S.L., B.J. Boruff, and W.L. Shirley. 2003. Social Vulnerability to Environmental Hazards. Social Science Quarterly, 84(2), 242-261. doi: 10.1111/1540-6237.8402002

Dasgupta, S., B. Laplante, C. M. Meisner, D. Wheeler, and D. Jainping Yan. 2007. The impact of sea level rise on developing countries: a comparative analysis. In World Bank Policy Research Working Paper No. 4136. Washington DC: The World Bank.

de Sherbinin, A. 2014. Spatial Climate Change Vulnerability Assessments: A Review of Data, Methods and Issues. Technical Paper for the USAID African and Latin American Resilience to Climate Change (ARCC) project. Washington, DC: USAID.

de Sherbinin, A., T. Chai-On, A. Giannini, M. Jaiteh, M. Levy, V. Mara, and L. Pistolesi. 2014. Mali Climate Vulnerability Mapping. Technical Paper for the USAID African and Latin American Resilience to Climate Change (ARCC) project. Washington, DC: USAID.

de Sherbinin, A. 2013. Climate Change Hotspots Mapping: What Have We Learned? Climatic Change, 123(1): 23-37. 
de Sherbinin, A., A. Reuben, M. Levy, and L. Johnson. 2013. Indicators in Practice: How Environmental Indicators are Being Used in Policy and Management Contexts. New Haven and New York: Yale and Columbia Universities. http://ciesin.columbia.edu/binaries/web/global/news/ 2013/indicatorsinpractice.pdf.

de Sherbinin, A., A. Lacko, and M. Jaiteh. 2012. Evaluating the risk to Ramsar Sites from climate change induced sea level rise. Ramsar Convention on Wetlands of international Importance Scientific and Technical Review Panel (STRP) Briefing Note No. 5. Gland, Switzerland: Ramsar Secretariat. Available at http://www.ramsar.org/bn/bn5.pdf.

de Sherbinin, A., A. Schiller, and A. Pulsipher. 2007. The Vulnerability of Global Cities to Climate Hazards. Environment \& Urbanization, 19(1): 39-64.

Dilley, M., R. Chen, U. Deichmann, A. Lerner-Lam, and M. Arnold. 2005. Natural Disaster Hotspots. Washington, DC: World Bank.

Dinku, T., S. Connor, and P. Ceccato. 2011. Evaluation of Satellite Rainfall Estimates and Gridded Gauge Products over the Upper Blue Nile Region. In Nile River Basin, ed. A. Melesse, 109-127. Springer Netherlands.

Dransch, D., H. Rotzoll, and K. Poser. 2010. The contribution of maps to the challenges of risk communication to the public. International Journal of Digital Earth, 3: 292-311.

Duarte, C. M., T. M. Lenton, P. Wadhams, and P. Wassmann. 2012. Abrupt climate change in the Arctic. Nature Climate Change, 2:60-62.

Eakin, H., C. Tucker, and E. Castellanos. 2006. Responding to the coffee crisis: a pilot study of farmers' adaptations in Mexico, Guatemala and Honduras The Geographical Journal, 172:156-171.

Ericksen, P., P. Thornton, A. Notenbaert, L. Cramer, P. Jones \& M. Herrero. 2011. Mapping hotspots of climate change and food insecurity in the global tropics. In CCAFS Report no. 5. Copenhagen, Denmark: CGIAR Research Program on Climate Change, Agriculture and Food Security (CCAFS).

Fekete, A., M. Damm, and J. Birkmann. 2010. Scales as a challenge for vulnerability assessment. Natural Hazards, 55: 729-747. doi:/10.1007/s11069-009-9445-5

Füssel, H.-M. 2009. "Review and quantitative analysis of indices of climate change exposure, adaptive capacity, sensitivity, and impacts." Background note to the World Development Report 2010. Washington, DC: World Bank. Accessed at http://wdronline.worldbank.org/ worldbank/a/nonwdrdetail/145 on 10 February 2013.

Füssel, H.-M. 2007. Vulnerability: a generally applicable conceptual framework for climate change research. Global Environmental Change, 17:155-167. 
Giannini, V., L. Ceccato, C. Hutton, A. A. Allan, S. Kienberger, W. A. Flügel, and C. Giupponi. 2011. Development of responses based on IPCC and "what-if?" IWRM scenarios. Advances in Science and Research, 7: 7181.

Gibson, C.C., E. Ostrom, and T.K. Ahn. 2000. The concept of scale and the human dimensions of global change: a survey, Ecological Economics, 32:217-239.

Gorokhovich, Y., and A. Voustianiouk. 2006. Accuracy assessment of the processed SRTM-based elevation data by CGIAR using field data from USA and Thailand and its relation to the terrain characteristics. Remote Sensing of Environment, 104:409-415.

Hinkel, J. 2011. "Indicators of vulnerability and adaptive capacity": Towards a clarification of the science-policy interface. Global Environmental Change, 21:198-208.

Holling, C. 2001. Understanding the complexity of economic, ecological, and social systems. Ecosystems, 4(5):390-405.

IPCC (Intergovernmental Panel on Climate Change). 2012. Managing the risks of extreme events and disasters to advance climate change adaptation. In A Special Report of Working Groups I and II, C.B. Field (ed.). Cambridge: Intergovernmental Panel on Climate Change.

Jones, B. 2013. "Improving research across scales: the shared socioeconomic pathways." Panel contribution to the Population-Environment Research Network Cyberseminar, "IPCC's New Scenario Process: Shared Socioeconomic Pathways", October 2013.

Kasperson, R. E., K. Dow, E. R. M. Archer, D. Cáceres, T. E. Downing, T. Elmqvist, S. Eriksen, C. Folke, G. Han, K. Iyengar, C. Vogel, K. A. Wilson, and G. Ziervogel. 2005. Chapter 6: Vulnerable people and places. In Millennium Ecosystem Assessment, R. Norgaard, and D. Rapport (eds.), 143-164. Washington, D.C.: Island Press.

Kienberger, S., T. Blaschke, and R. Z. Zaidi. 2013. A framework for spatiotemporal scales and concepts from different disciplines: the 'vulnerability cube'. Natural Hazards, 68, 1343-1369.

Kienberger, S. 2012. Spatial modelling of social and economic vulnerability to floods at the district level in Búzi, Mozambique. Natural Hazards, 64:2001-2019.

Kienberger, S., S. Lang, and P. Zeil. 2009. Spatial vulnerability units expert-based spatial modelling of socio-economic vulnerability in the Salzach catchment, Austria. Natural Hazards Earth System Science, 9:767-778.

Kitoh, A. 2012. High-resolution climate modeling for projecting hydrometeorological extremes in the future. Meteorological Research Institute, Japan Meteorological Agency.

Klein, R J.T. 2012. "Enhancing the rigour of climate change vulnerability, impact and adaptation research." Paper presented at the Climate 
Adaptation Futures: Second International Climate Change Adaptation Conference, 30 May 2012, Tuscon, Arizona.

Kok, M.T.J., M.K.B. Lüdeke, T. Sterzel, P.L. Lucas, C. Walter, P. Janssen and I. de Soysa. 2010. Quantitative analysis of patterns of vulnerability to global environmental change. Den Haag/Bilthoven, Netherlands: Netherlands Environmental Assessment Agency (PBL).

Lang, S., P. Zeil, S. Kienberger, and D. Tiede. 2008. Geons - policy-relevant geo-objects for monitoring high-level indicators. In Geospatial Crossroads@ @I_Forum. Proceedings of the Second Geoinformatics Forum, eds. G. Griesebner \& J. Strobl, 180-185. Salzburg, Germany: Heidelberg: Wichmannn.

Levy, M. 2012. "Data Implications of Priority Research Needs." Paper presented at the Climate Adaptation Futures: Second International Climate Change Adaptation Conference, Tucson, Arizona, 30 May 2012.

Lucas, P. L. and H. Hilderink. 2004. Vulnerability Concept and its Application to Food Security. RIVM report 550015004. The Netherlands: RIVM.

Lüdeke, M. K. B., G. Petschel-Held, and H. J. Schellnhuber. 2004. Syndromes of Global Change. GAIA - Ecological Perspectives for Science and Society, 13, 42-49.

Lyon, B. International Research Institute for Climate and Society. personal communication, September 2011.

Martine, G. and D. Schensul (eds.). 2013. The Demography of Adaptation to Climate Change. New York, London and Mexico City: UNFPA, IIED, and El Colegio de México.

Mayhew, S. 1997. A Dictionary of Geography. New York: Oxford University Press.

McElroy, M., and J. Baker. 2012. Climate Extremes: Recent Trends with Implications for National Security. Cambridge, Mass.: Harvard University.

McGranahan, G., D. Balk \& B. Anderson. 2007. The rising tide: assessing the risks of climate change and human settlements in low elevation coastal zones. Environment and Urbanization, 19:17-37.

Midgley, S. J. E. 2013. OneWorld Group. personal communication, 5 May 2013.

Midgley, S. J. E., R. A. G. Davies, and S. Chesterman. 2011. Climate risk and vulnerability mapping in southern Africa: status quo (2008) and future (2050). Report produced for the Regional Climate Change Programme for Southern Africa (RCCP), UK Department for International Development (DFID). Cape Town, South Africa: OneWorld Sustainable Investments.

Moser, S. and J. Ekstrom. 2011. Taking ownership of climate change: participatory adaptation planning in two local case studies from California. Journal of Environmental Studies and Sciences, 1, 63-74. doi:/10.1007/s13412-011-0012-5 
Nicholls, R. J., F. M. J. Hoozemans, and M. Marchand. 1999. Increasing flood risk and wetland losses due to global sea-level rise: regional and global analyses. Global Environmental Change, 9, Supplement 1, S69-S87.

O'Brien, K.L., S. Eriksen, L. Nygaard, and A. Schjolden. 2007. Why different interpretations of vulnerability matter in climate change discourses. Climate Policy, 7: 73-88.

O'Brien, K.L., and R.M. Leichenko. 2000. Double exposure: assessing the impacts of climate change within the context of economic globalization. Global Environmental Change. 10:221-232

Oettli, P., B. Sultan, C. Baron \& M. Vrac (2011) Are regional climate models relevant for crop yield prediction in West Africa? Environmental Research Letters, 6, 014008.

Openshaw, S. 1983. The Modifiable Areal Unit Problem. Norwich UK: Geo Books.

Parish, E.S., E. Kodra, K. Steinhauser, and A.R. Ganguly. 2012. Estimating future global per capita water availability based on changes in climate and population. Computers \& Geosciences, 42: 79-86.

Parry, M.L., O.F. Canziani, J.P. Palutikof, et al. 2007. Technical Summary. Climate Change 2007: Impacts, Adaptation and Vulnerability. Contribution of Working Group II to the Fourth Assessment Report of the Intergovernmental Panel on Climate Change. M.L. Parry, O.F. Canziani, J.P. Palutikof, P.J. van der Linden and C.E. Hanson (Eds.). Cambridge, UK: Cambridge University Press, pp. 23-78.

Patt, A., and S. Dessai. 2005. Communicating uncertainty: lessons learned and suggestions for climate change assessment. Current Reviews Geoscience, 337:425-441.

Preston, B. L. 2013. Local path dependence of U.S. socioeconomic exposure to climate extremes and the vulnerability commitment. Global Environmental Change, 23, 719-732.

Preston, B. 2012. Vulnerability mapping for climate change: a critical look at a common practice. Paper presented at Climate Adaptation Futures, 31 May 2012, Tucson, AZ.

Preston, B., E. Yuen, and R. Westaway. 2011. Putting vulnerability to climate change on the map: a review of approaches, benefits, and risks. Sustainability Science, 6, 177-202. http://dx.doi.org/10.1007/s11625011-0129-1

Preston, B., C. Brooke, T. Measham, T. Smith and R. Gorddard. 2009. Igniting change in local government: lessons learned from a bushfire vulnerability assessment. Mitigation and Adaptation Strategies for Global Change, 14, 251-283. doi:/10.1007/s11027-008-9163-4

Preston, B. L., D. Abbs, B. Beveridge, C. Brooke, R. Goddard, G. Hunt, M. Justus, P. Kinrade, I. Macadam, T. G. Measham, K. McInnes, C. Morrison, J. O'Grady, T. F. Smith \& G. Withycombe. 2007. Spatial Approaches for Assessing Vulnerability and Consequences in Climate 
Change Assessments In Proceedings of MODSIM 2007: International Congress on Modelling and Simulation. Christchurch, NZ: Modelling and Simulation Society of Australia and New Zealand.

PROVIA (Programme on Vulnerability, Impacts and Adaptation). 2013a. Research Priorities on Vulnerability, Impacts and Adaptation: Responding to the Climate Change Challenge. Nairobi, Kenya: United Nations Environment Programme (UNEP).

PROVIA (Programme on Vulnerability, Impacts and Adaptation). 2013b. PROVIA Guidance on Assessing Vulnerability, Impacts and Adaptation to Climate Change. Nairobi, Kenya: United Nations Environment Programme (UNEP).

Rahmstorf, S. 2012. Modeling sea level rise. Nature, 3:4.

Ramankutty, N., A. T. Evan, C. Monfreda \& J. A. Foley. 2010. Global Agricultural Lands: Croplands, 2000. Palisades, NY: NASA Socioeconomic Data and Applications Center (SEDAC). http://sedac. ciesin.columbia.edu/data/set/aglands-croplands-2000

Schiller, A., A. de Sherbinin, W. Hsieh \& A. Pulsipher. 2001. "The vulnerability of global cities to climate hazards." Paper presented at the 2001 Open Meeting of the Human Dimensions of Global Environmental Change Research Community. Rio de Janeiro, Brazil.

Shen, X., T. E. Downing \& M. Hamza. 2010. Tipping Points in Humanitarian Crisis: From Hot Spots to Hot Systems. Studies of the University: Research, Counsel, Education (SOURCE) Publication Series of UNUEHS.

Soares, M.B., A.S. Gagnon, and R.M. Doherty. 2012. Conceptual elements of climate change vulnerability assessments: a review. International Journal of Climate Change Strategies and Management, 4(1):6-35.

Storch, H., N. Downes, and H. Rujner. 2011. A scenario-based approach to assessing the exposure and flood risk of Ho Chi Minh City's urban development strategy in times of climate change. In EnviroInfo 2011: Innovations in Sharing - Environmental Observations and Information, eds. W. Pillmann, S. Schade \& P. Smits. Shaker Verlag, Ispra.

Strauss, B. H., R. Ziemlinski, J. L. Weiss \& J. T. Overpeck. 2012. Tidally adjusted estimates of topographic vulnerability to sea level rise and flooding for the contiguous United States. Environmental Research Letters, 7, 014033.

Tappan, G. US Geological Survey, EROS Data Center. Personal communication, 18 August 2013.

Tebaldi, C., B. H. Strauss \& C. E. Zervas. 2012. Modelling sea level rise impacts on storm surges along US coasts. Environmental Research Letters, 7, 014032.

Thow, A. \& M. de Blois. 2008. Climate change and human vulnerability: mapping emerging trends and risk hotspots for humanitarian actors. In Discussion Paper. Bath, UK: Maplecroft. 
Turner, B. L., R. E. Kasperson, P. A. Matson, J. J. McCarthy, R. W. Corell, L. Christensen, N. Eckley, J. X. Kasperson, A. Luers, M. L. Martello, C. Polsky, A. Pulsipher, and A. Schiller. 2003a. A framework for vulnerability analysis in sustainability science. Proceedings of the National Academy of Sciences, 100:8074-8079.

Turner, B.L., P.A. Matson, J.J. McCarthy, R.W. Corell, L. Christensen, N. Eckley, G.K. Hovelsrud-Broda, J.X. Kasperson, R.E. Kasperson, A. Luers, M.L. Martello, S. Mathiesen, R. Naylor, C. Polsky, A. Pulsipher, A. Schiller, H. Selin, and N. Tyler. 2003b. Illustrating the coupled human-environment system for vulnerability analysis: Three case studies. Proceedings of the National Academy of Sciences. 100(14):8080-8085.

UNDP (United Nations Development Program). 2010. Mapping climate change vulnerability and impact scenarios: A guidebook for sub-national planners. New York: UNDP.

UNDP (United Nations Development Program). 2008. Human Development Report 2007/8: Fighting Climate Change in a Divided World. New York: Oxford University Press.

UNEP (United Nations Environment Program). 2011. Climate Change, Migration and Conflict in the Sahel. Geneva: UNEP.

UNHABITAT. 2013. Flood Risk Assessment, Strategies and Actions for Improving Flood Risk Management in Kampala. Nairobi, Kenya: UNHABITAT.

UNISDR (United Nations International Strategy for Disaster Reduction). 2009. Global Assessment Report on Disaster Risk Reduction. Geneva: United Nations.

Warner, K., T. Afifi, K. Henry, T. Rawe, C. Smith, and A. de Sherbinin. 2012a. Where the Rain Falls: Climate Change, Food and Livelihood Security, and Migration. Bonn, Germany: United Nations University and CARE. http://wheretherainfalls.org/.

Warner, K., K. van der Geest, S. Kreft, S. Huq, S. Harmeling, K. Koesters, and A. de Sherbinin. 2012b. Evidence from the Frontlines of Climate Change: Loss and Damage to Communities Despite Coping and Adaptation. Bonn, Germany: United Nations University.

Warner, K., C. Erhart, A. de Sherbinin, S.B. Adamo, T.Chai-Onn. 2009. In search of Shelter: Mapping the effects of climate change on human migration and displacement. Bonn, Germany: United Nations University, CARE, and CIESIN-Columbia University.

WBGU (German Advisory Council on Global Change). 2007. Climate Change as Security Risk. Berlin: WBGU.

Wenger, E. 1998. Communities of Practice: Learning, Meaning, and Identity. Cambridge: Cambridge University Press. ISBN 978-0-521-66363-2. 
Wilhelmi, O., A. de Sherbinin, and M.H. Hayden. 2012. "Exposure to Heat Stress in Urban Environments" In: Crews, K., and B. King (eds.), Ecologies and Politics of Health. Oxon, UK: Routledge.

Wilhelmi, O.V., and M.H. Hayden. 2010. Connecting people and place: a new framework for reducing urban vulnerability to extreme heat. Environmental Research Letters, 5 014021. doi:/10.1088/17489326/5/1/014021.

Wood, C., and D. Skole. 1998. Linking satellite, census, and survey data to study deforestation in the Brazilian Amazon. In People and Pixels: Linking Remote Sensing and Social Science, eds. D. Liverman, E. Moran, R. Rindfuss \& P. Stern. Washington, D.C.: National Academy Press.

YCELP (Yale Center for Environmental Law and Policy), CIESIN (Center for International Earth Science Information Network), WEF (World Economic Forum), and JRC (Joint Research Centre). 2005. 2005 Environmental Sustainability Index. Palisades, NY: NASA Socioeconomic Data and Applications Center (SEDAC). http://sedac.ciesin.columbia.edu/data/set/esi-environmentalsustainability-index-2005 


\section{Chapter 2}

\section{Climate Change Hotspots Mapping: What Have We Learned? ${ }^{13}$}

\footnotetext{
13 This chapter was originally published as de Sherbinin, A. 2013. Climate Change Hotspots Mapping: What Have We Learned? Climatic Change, 123(1): 23-37. http://dx.doi.org/10.1007/s10584-013-0900-7 (reprinted with permission from Springer Science + Business Media). It has been revised and updated for this thesis.
} 


\subsection{Introduction}

Maps depicting climate change "hotspots" have been issued with increasing regularity in recent years by researchers, advocacy groups, and NGOs. By identifying likely climate change impacts and conveying them in a map format with strong visual elements, hotspots maps can help to communicate issues in a manner that may be easier to interpret than text. Hotspots maps are developed with a number of goals in mind. Academic researchers are generally seeking to vet data and methodologies, applied researchers may be interested in guiding institutional strategies, and NGOs are often communicating climate impacts. In addition, building on early roots in biodiversity hotspots mapping (Myers 1990) where hotspots were developed to target conservation efforts, hotspots maps are often explicitly developed to help aid organizations in priority setting and strategic planning with regards to climate adaptation projects (Kok et al. 2011, Midgley et al. 2011, Yusuf and Francisco 2009). At a time of increasing pressure on donors and development organizations to show that scarce public resources are being used in a responsible manner, spatial indicators and hotspots maps hold the promise of transparent, "scientific", and defensible priority setting (Barnett et al. 2008). Although hotspots mapping holds great promise for informing policy, there are a number of risks as well, which are reviewed in the discussion section. This chapter offers a timely assessment of the strengths and weaknesses of current hotspots mapping approaches with the goal of improving future efforts. It also highlights regions that are anticipated, based on combinations of high exposure, high sensitivity and low adaptive capacity, to suffer significant impacts from climate change.

This review focuses on global and regional data-driven GIS or modeling approaches to hotspots identification. Unlike national index approaches to hotspots mapping, these efforts capture subnational variation in vulnerability by combining spatial data layers, generally by converting each layer to a unitless scale and aggregating the layers to reveal vulnerability levels. In this approach, hotspots emerge from the spatial analysis, being revealed through the integration of spatial layers. In Annex 2.1, I also review several expertbased hotspots mapping efforts.

I exclude from this review hotspots mapping efforts that use countries as the units of analysis, since these are essentially repackaging of country level indicators (e.g., Birkmann et al. 2011, Wheeler 2011, DARA 2010, Yohe et al. 2006), with all the limitations inherent in those approaches (Barnett et al. 2008). I also limit this review to mapping efforts whose primary goal is explicitly to identify hotspots or geographic areas where impacts will be greatest (even if not labeled per se as hotspots), rather than maps describing impacts that are incidental to a publication or report. 
Papers meeting these criteria were identified through Google Scholar searches on "climate change hotspots" and "hot spots", announcements, and bibliographies of other spatial vulnerability assessment reviews. These are reviewed in Section 2.2, which focuses on global mapping efforts, and Section 2.3, which focuses on regional mapping efforts. Issues common to the mapping efforts are addressed in Section 2.4, and Section 2.5 provides some concluding thoughts, including a discussion of how the mapping efforts relate to the PNAS vulnerability framework. Annex 2.1 provides a brief review of qualitative expert-based hotspots mapping efforts. Common conceptual, measurement and methodological issues that are germane to hotspots mapping efforts are addressed in Section 1.3 of Chapter 1.

\subsection{Assessment of Hotspots Mapping Efforts}

In this section I review a range of hotspots mapping efforts covering broad vulnerability themes, assessing methods, strengths and weaknesses, and commonly identified regions. Hotspots mapping efforts can be divided into three broad categories: those based solely on climate parameters, those that portray patterns of societal vulnerability to climate change impacts, and those that seek to portray impacts on particular systems, such as agriculture or water. This provides an organizing framework for the sub-sections which follow. Table 2.1 provides a summary list of the studies and, to the extent provided in the reports, identifies important components of quantitative vulnerability assessment per Füssel (2007) (c.f. Section 1.3.1). For the global mapping efforts only, Table 2.2 in Annex 2.2 summarizes the study's primary focus, audience, geographic scope, framework, methods, regions identified as most at risk from climate impacts, and funding sources.

\subsubsection{Climate change exposure hotspots}

There is a subset of hotspots mapping efforts that focus only on projected changes in temperature and selected precipitation parameters, that is, the "exposure" part of the IPCC formulation. Giorgi's (2006) Regional Climate Change Index (RCCI) was the first to depict climate hotspots based solely on climate model outputs. The RCCI measures changes by 2080-99 against a baseline of 1960-79 in regional mean precipitation, mean surface air temperature, and in the interannual variability in precipitation and temperature. Giorgi uses a multi-model ensemble across a range of IPCC scenarios (A1B, B1, and A2) to define changes. The RCCI is a comparative index designed to identify the regions that will see the greatest relative changes in these variables, which are identified as hotspots. Note that a small RCCI value does not imply a small absolute change, but only a small climate response compared to other regions. The RCCI is calculated for 26 land regions (not on a pixel basis) from a set of climate change projections by 20 global climate models for the A1B, A2 and B1 IPCC emission scenarios. 
Table 2.1: Hotspots mapping efforts reviewed for this chapter

Key: system of analysis (what is vulnerable?), the valued attributes of concern (why is it important?), the external hazard (to what is the system vulnerable?), and a temporal reference (when?).

\begin{tabular}{|c|c|c|c|c|}
\hline Reference & System & Valued Attribute & $\begin{array}{l}\text { External } \\
\text { Hazard }\end{array}$ & $\begin{array}{l}\text { Temporal } \\
\text { Reference }\end{array}$ \\
\hline \multicolumn{5}{|c|}{ Global Hotspots Mapping Efforts (data driven - Section 2.3) } \\
\hline Giorgi (2006) & \begin{tabular}{|l|l|}
.. & \\
\end{tabular} & $\begin{array}{l}\text { Implicit: Climate } \\
\text { stability }\end{array}$ & Climate variability & $\begin{array}{l}2080-2099 \\
\text { against a } \\
\text { baseline of } \\
1960-79\end{array}$ \\
\hline $\begin{array}{l}\text { Baettig et al. } \\
(2007)\end{array}$ &.$\cdot$ & $\begin{array}{l}\text { No chg in probability } \\
\text { distrib. of extremes }\end{array}$ & $\begin{array}{l}\text { Increased } \\
\text { probability of } \\
\text { hot/wet/dry years }\end{array}$ & $\begin{array}{l}2071-2100 \\
\text { against a } \\
\text { baseline of } \\
1961-90\end{array}$ \\
\hline $\begin{array}{l}\text { UK Met Office } \\
(2009)\end{array}$ & Multiple & Multiple & $\begin{array}{l}\text { Temperature } \\
\text { change }\end{array}$ & $\begin{array}{l}\text { When global } \\
\text { temp increases } \\
\text { by } 4^{\circ} \mathrm{C}\end{array}$ \\
\hline $\begin{array}{l}\text { Piontek et al. } \\
(2013)\end{array}$ & $\begin{array}{l}\text { River flow, crop } \\
\text { yields, } \\
\text { ecosystems, } \\
\text { malaria }\end{array}$ & $\begin{array}{l}\text { Stability in systems } \\
\text { vital to livelihoods }\end{array}$ & $\begin{array}{l}\text { Temperature } \\
\text { change }\end{array}$ & $\begin{array}{l}\text { Based on timing } \\
\text { of "crossing } \\
\text { temp." }\end{array}$ \\
\hline $\begin{array}{l}\text { Samson et al. } \\
(2011)\end{array}$ & \begin{tabular}{l|} 
Human \\
population \\
distribution
\end{tabular} & $\begin{array}{l}\text { Implicit: Climate } \\
\text { stability }\end{array}$ & $\begin{array}{l}\text { Reductions in pop. } \\
\text { carrying capacity }\end{array}$ & 2050 \\
\hline $\begin{array}{l}\text { McGranahan et al. } \\
(2007)\end{array}$ & $\begin{array}{l}\text { Coastal } \\
\text { populations and } \\
\text { lands }\end{array}$ & $\begin{array}{l}\text { Human populations } \\
\text { and land }\end{array}$ & Sea level rise & $\begin{array}{l}\text { When sea levels } \\
\text { rise by } 8-10 \mathrm{~m}\end{array}$ \\
\hline $\begin{array}{l}\text { CARE/Maplecroft } \\
\text { and Thow \& de } \\
\text { Blois (2008) }\end{array}$ & \begin{tabular}{l|} 
Human \\
populations
\end{tabular} & Human security & Climate hazards & $\begin{array}{l}1980-2000 \\
\text { hazards, } 2071- \\
2100 \text { for GCMs }\end{array}$ \\
\hline $\begin{array}{l}\text { Erickson et al. } \\
(2011)\end{array}$ & Agriculture & $\begin{array}{l}\text { Ag. productivity and } \\
\text { food security }\end{array}$ & $\begin{array}{l}\text { Changes in } \\
\text { temperature and } \\
\text { rainfall }\end{array}$ & 2050 \\
\hline Fraser et al. (2012) & $\begin{array}{l}\text { Soil moisture } \\
\text { and agriculture }\end{array}$ & $\begin{array}{l}\text { Agricultural } \\
\text { productivity }\end{array}$ & $\begin{array}{l}\text { Reduced } \\
\text { precipitation and } \\
\text { soil moisture }\end{array}$ & $\begin{array}{l}2045-2060 \\
\left(" 2050 s^{\prime \prime}\right), \\
2075-2090 \\
\left(" 2080 s^{\prime \prime}\right)\end{array}$ \\
\hline Kok et al. (2011) & $\begin{array}{l}\text { Rural } \\
\text { livelihoods }\end{array}$ & $\begin{array}{l}\text { Ag. productivity and } \\
\text { food security }\end{array}$ & $\begin{array}{l}\text { Global } \\
\text { environmental } \\
\text { change }\end{array}$ & Recent past \\
\hline Parish et al. (2012) & Water & $\begin{array}{l}\text { Water availability p.c. } \\
\text { above a threshold }\end{array}$ & $\begin{array}{l}\text { Climate change } \\
\text { and population } \\
\text { growth }\end{array}$ & 2100 \\
\hline Döll (2009) & Ground water & $\begin{array}{l}\text { Ground water } \\
\text { recharge/availability }\end{array}$ & $\begin{array}{l}\text { Climate change } \\
\text { and population } \\
\text { growth }\end{array}$ & $\begin{array}{l}2041-70 \\
\left(" 2050 s^{\prime \prime}\right)\end{array}$ \\
\hline $\begin{array}{l}\text { De Stefano et al. } \\
(2009)\end{array}$ & River Basin & $\begin{array}{l}\text { Resilience to } \\
\text { precipitation variability }\end{array}$ & $\begin{array}{l}\text { Precipitation } \\
\text { variability }\end{array}$ & 2030 and 2050 \\
\hline \multicolumn{5}{|c|}{ Regional Hotpots Mapping Efforts (data driven - Section 2.4) } \\
\hline $\begin{array}{l}\text { Busby et al. (2011) } \\
\text { (Africa) }\end{array}$ & \begin{tabular}{|l|} 
Human \\
populations and \\
governance \\
sys.
\end{tabular} & $\begin{array}{l}\text { Political stability and } \\
\text { human security }\end{array}$ & $\begin{array}{l}\text { A range of climate } \\
\text { stressors }\end{array}$ & $\begin{array}{l}\text { Past climate } \\
\text { variability }\end{array}$ \\
\hline $\begin{array}{l}\text { Midgley et al. } \\
\text { (2011) (Southern } \\
\text { Africa) }\end{array}$ & $\begin{array}{l}\text { Agriculture and } \\
\text { human health }\end{array}$ & Mostly food security & $\begin{array}{l}\text { Precip and temp } \\
\text { change (average } \\
\text { and maximum) }\end{array}$ & 2050 \\
\hline $\begin{array}{l}\text { Abson et al. (2012) } \\
\text { (Southern Africa) }\end{array}$ & $\begin{array}{l}\text { Socio-ecolog- } \\
\text { ical systems }\end{array}$ & .. & $\begin{array}{l}\text { Aridity and rainfall } \\
\text { variability }\end{array}$ & .. \\
\hline $\begin{array}{l}\text { Liu et al. (2008) } \\
\text { (Africa) }\end{array}$ & Agriculture & Food security & $\begin{array}{l}\text { Impact ratios of } \\
\text { climate change } \& \\
\text { CO2 fertilization }\end{array}$ & $2030 s$ \\
\hline
\end{tabular}


Table 2.1 (continued)

\begin{tabular}{|c|c|c|c|c|}
\hline Reference & System & $\begin{array}{l}\text { Valued } \\
\text { Attribute }\end{array}$ & $\begin{array}{l}\text { External } \\
\text { Hazard }\end{array}$ & $\begin{array}{l}\text { Temporal } \\
\text { Reference }\end{array}$ \\
\hline $\begin{array}{l}\text { Thornton et al. } \\
\text { (2008) } \\
\text { (Africa) }\end{array}$ & Agriculture & Food Security & $\begin{array}{l}\text { CC impacts on } \\
\text { crop and livestock } \\
\text { productivity }\end{array}$ & 2050 \\
\hline $\begin{array}{l}\text { Yusuf and } \\
\text { Francisco (2009) } \\
\text { (S.E. Asia) }\end{array}$ &.. &.. & Climate hazards & $\begin{array}{l}\text { Past climate } \\
\text { variability }\end{array}$ \\
\hline $\begin{array}{l}\text { ESPON Climate } \\
\text { (2011) (Europe) }\end{array}$ & Multiple & Multiple & $\begin{array}{l}\text { Extreme events } \\
\text { and } \Delta \text { in average } \\
\text { conditions }\end{array}$ & $2071-2100$ \\
\hline $\begin{array}{l}\text { Schroter et al. } \\
\text { (2005) (Europe) }\end{array}$ & Ecosystems & $\begin{array}{l}\text { Ecosystem } \\
\text { services }\end{array}$ & $\begin{array}{l}\Delta \mathrm{s} \text { in } \mathrm{CO}_{2} \\
\text { concentra-tions, } \\
\text { temp., and precip. }\end{array}$ & 2080 \\
\hline \multicolumn{5}{|c|}{ Global Hotspots Mapping Efforts (expert judgment - Annex 2.1) } \\
\hline $\begin{array}{l}\text { Warner et al. } \\
(2009 / 2012)\end{array}$ & Livelihoods & $\begin{array}{l}\text { Food security and } \\
\text { in situ adaptation }\end{array}$ & $\begin{array}{l}\text { An array of climate } \\
\text { impacts/rainfall } \\
\text { variab. }\end{array}$ & .. \\
\hline $\begin{array}{l}\text { Schubert et al. } \\
(2007)\end{array}$ & $\begin{array}{l}\text { Political } \\
\text { systems }\end{array}$ & $\begin{array}{l}\text { Security and } \\
\text { stability }\end{array}$ & $\begin{array}{l}\text { Broad array of } \\
\text { climate impacts }\end{array}$ &.. \\
\hline $\begin{array}{l}\text { Scheffran and } \\
\text { Battaglini (2011) }\end{array}$ & $\begin{array}{l}\text { Political } \\
\text { systems }\end{array}$ & $\begin{array}{l}\text { Security and } \\
\text { stability }\end{array}$ & $\begin{array}{l}\text { Broad array of } \\
\text { climate impacts }\end{array}$ & .. \\
\hline
\end{tabular}

".."= not specified

The "hottest" hotspots are those in northern latitudes, which are predicted to experience the greatest temperature changes (Figure 2.1). The two most prominent hotspots are the Mediterranean, which will see declines in mean precipitation, and North Eastern Europe, which will see increases in winter precipitation and a strong regional warming relative to the global mean. Central America is the main tropical hotspot, which is predicted to see a decrease in precipitation and an increase in precipitation variability, followed by southern Africa. The global RCCI is limited by the representation of the hotspots (broad regions) and the fact that change measurements are bidirectional, and thus a strong increase in precipitation, which could be viewed as positive for some regions, is seen as equally problematic as a strong decrease in precipitation. On its own, the index says very little about vulnerability per se, but it has been applied together with socioeconomic indicators to identify socio-climatic hotspots in Brazil (Torres et al. 2012), and a similar approach was used to map hotspots in the U.S. (Diffenbaugh et al. 2006). 
RCCl, 20 Models, Three Scenarios (A1B, A2, B1)

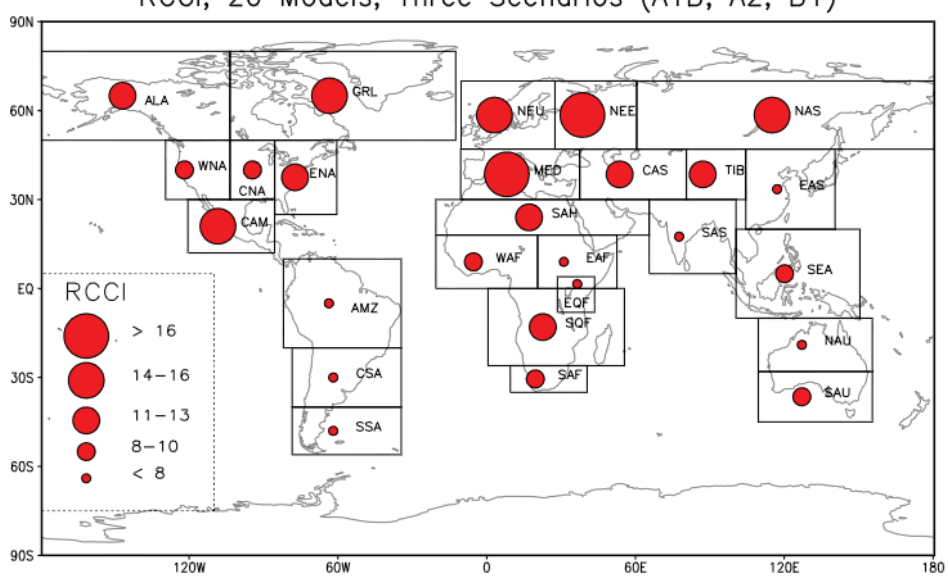

Source: Giorgi 2006, p. L08707.

Figure 2.1: Regional Climate Change Index

Baettig et al. (2007) introduced a Climate Change Index (CCI) which seeks to measure the strength of future climate change relative to today's natural variability. The index tracks increases in the probabilities of such events relative to a 1 in 20 year return cycle for the same events under current climatology. It is calculated based on GCMs running SRES A2 and B2 scenarios, with indicators such as additional hottest years, additional driest years, and additional extremely warm/wet/dry seasons (winter and summer months). According to the CCI, the largest changes in frequency will occur in the tropics and high latitudes. The CCI has the advantage that results are presented on a pixel basis, and they are also summarized by country for the benefit of policy audiences, and the scores are also relatively easy to interpret. The CCI depicts similar hotspots to the RCCI, except for northern southern Africa and the Amazon, which are found to have much greater exposure to climate risks when compared to the present (Figure 2.2). 


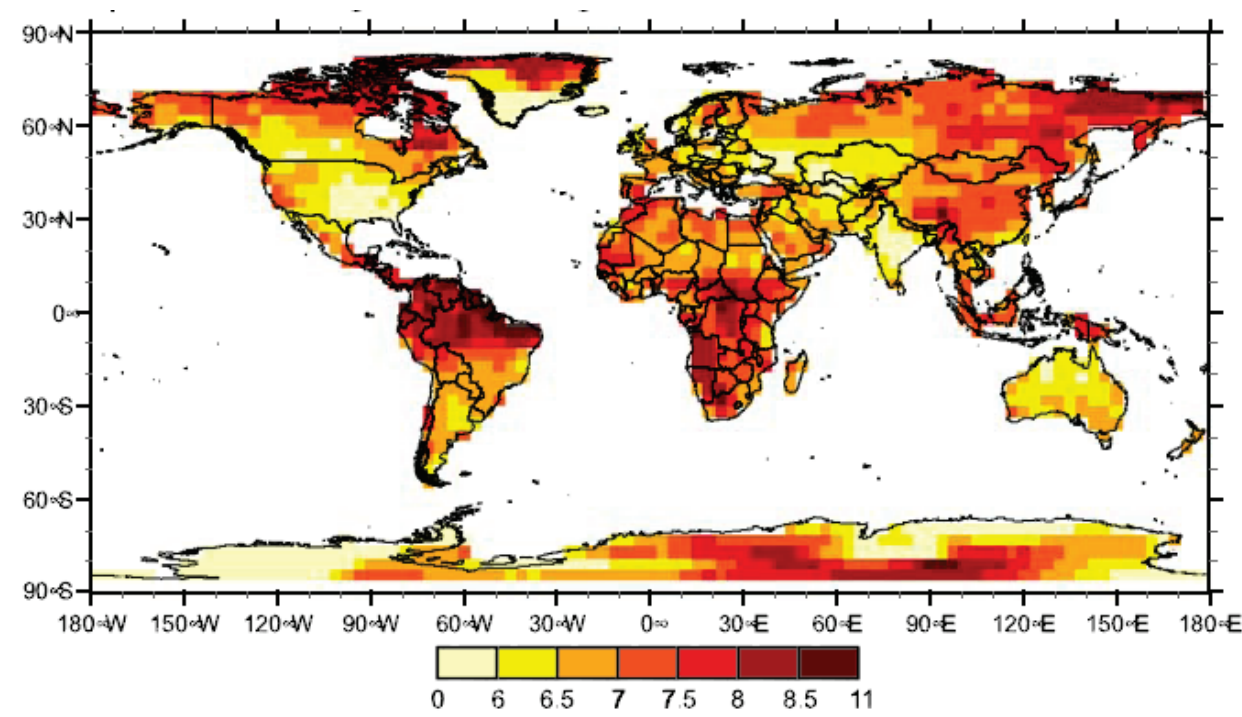

Source: Baettig 2007, p. L01705

Figure 2.2: Climate Change Index (CCI)

The RCCI and CCI contribute to the literature by describing changes to climate parameters that could serve as inputs to broader vulnerability assessments. However, despite claims to the contrary, both are clearly for academic audiences. By contrast, the UK Met Office has produced a map depicting the regional temperature changes associated with a $4^{\circ} \mathrm{C}$ rise in global mean temperature (Figure 2.3). The map, produced in poster and online interactive forms, is intended for policy audiences, utilizing circles of various colors to highlight likely impacts. Areas with the greatest temperature changes include the Arctic and high northern latitudes, the western US, the Amazon, West Africa, southern Africa, and Central Asia. 


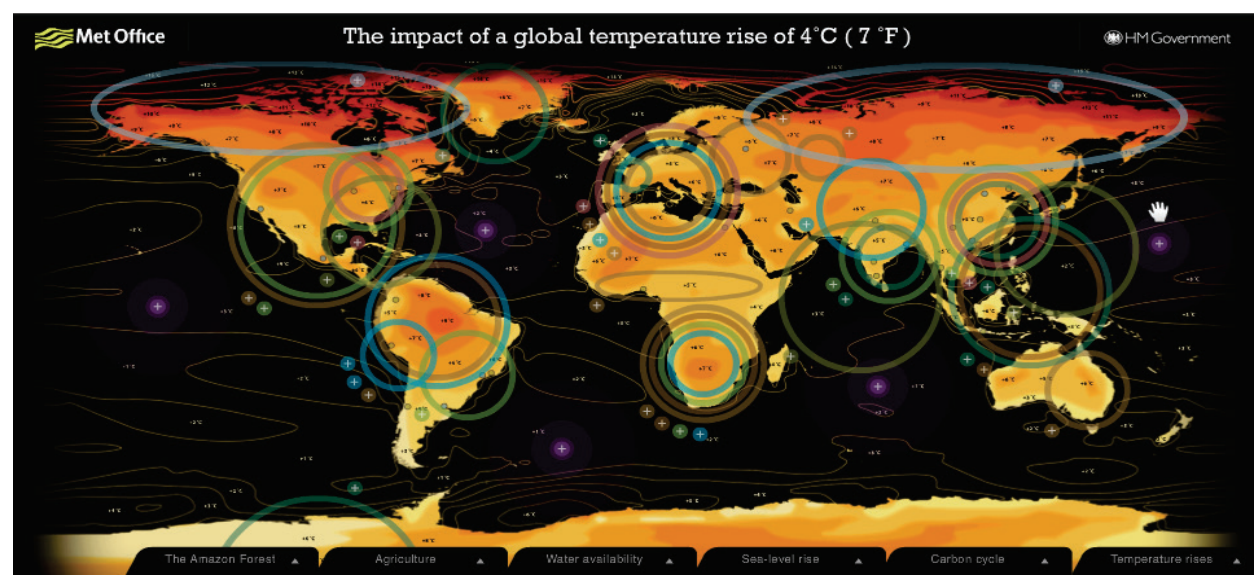

Source: UK Met Office, http://www.metoffice.gov.uk/climatechange/guide/impacts/high-end/map

Figure 2.3: The impact of a global temperature rise of $4^{\circ} \mathrm{C}$

A hybrid approach, based on climate parameters but tied to thresholds in four important sectors (water, agriculture, ecosystems and health), was recently developed by Piontek et al. (2013). The authors use the outputs of three GCMs simulating the highest representative concentration pathway (RCP8.5) to feed multiple Global Impact Models (GIMs), and then identify temperature thresholds in each sector where impacts could be considered to be severe. For example, the thresholds for the water and agriculture sectors are defined as the $10^{\text {th }}$ percentile of the reference period distribution $(1980-2010)$ of river discharge and crop yields, respectively. For each GIM-GCM combination and at each grid cell they define a "crossing temperature" that is the global mean temperature change (GMT $\Delta$ ) at which the sectoral metric crosses the respective impact threshold. Hotspot regions where thresholds are crossed for two or three sectors for a $4.5^{\circ} \mathrm{C}$ GMT $\Delta$ are found in Figure 2.4, with high impacts found in the Amazon, the Andes, southern Mexico and Central America, southern and eastern Europe, the African highlands and parts of West Africa, and the Ganges basin. These results should be seen as conservative, given the stringent criteria for inclusion of severe impacts ( $>50 \%$ of GIM-GCM combinations agreeing) used in the study.

\subsubsection{Population dynamics and migration hotspots}

There has been considerable policy interest in the impact of climate change on population dynamics, and particularly on migration (Black et al. 2011, Adamo and de Sherbinin 2011, de Sherbinin et al. 2011). This has spawned a number of efforts to map hotspots where climate change may affect population dynamics or lead to migration flows. 
Samson et al. (2011) use the relationship between the distribution of human population density and climate as a basis to develop a global index of predicted impacts of climate change on human populations. The authors use an ecological niche model that identifies current population distribution in relationship to climate conditions, and then identifies how climate conditions may change in ways that they no longer support current densities. Their climate vulnerability index (CVI) combines regional climate-density relationships with predicted regional climate change. The climate variables that were found to have the highest predictive power for current population densities, and which were therefore used to determine areas of decline, include $(A)$ annual mean temperature $\left({ }^{\circ} \mathrm{C}\right),(B)$ mean temperature diurnal range $\left({ }^{\circ} \mathrm{C}\right),(\mathrm{C})$ total annual precipitation $(\mathrm{mm})$, and (D) precipitation seasonality (coefficient of variation).

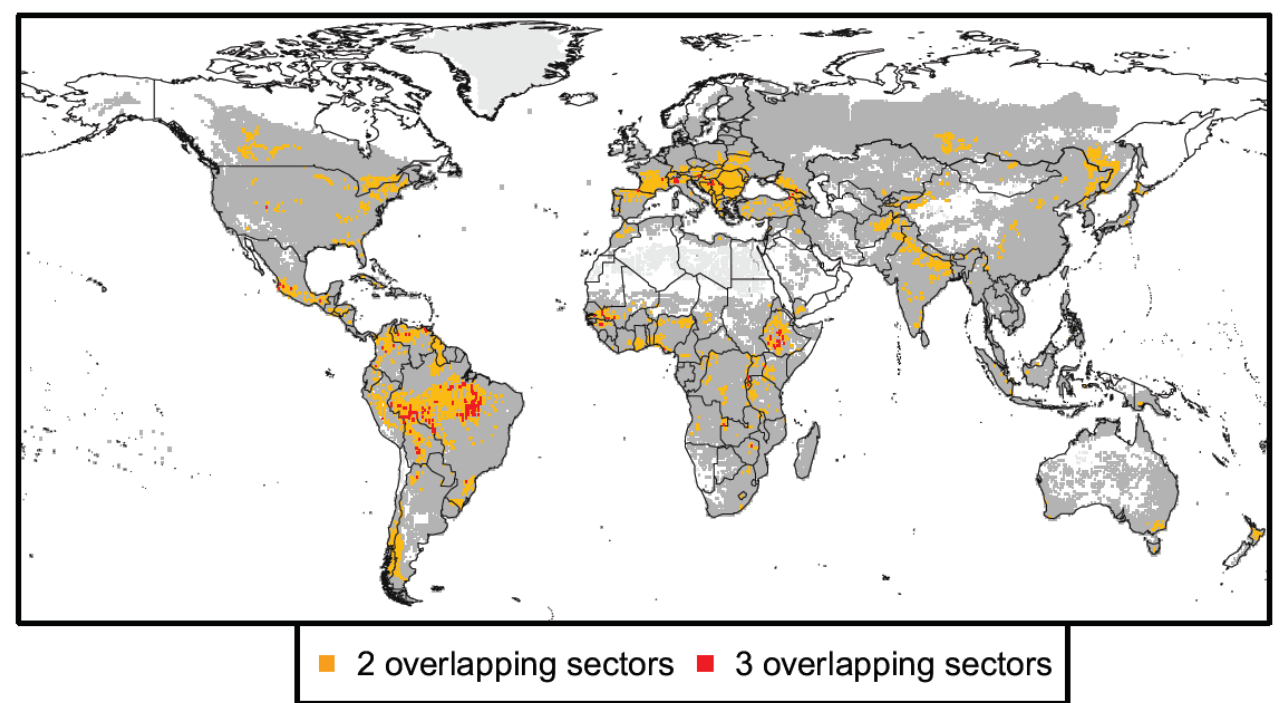

Source: Piontek et al. 2013, Figure 2. Copyright Proceedings of the National Academy of Science.

Figure 2.4: Multisectoral hotspots of impacts for two (orange) and three (red) overlapping sectors

Notes: Multisectoral hotspots of impacts for two (orange) and three (red) overlapping sectors in the strict assessment, with $50 \%$ of GIM-GCM combinations agreeing on the threshold crossing in each sector, for a GMT change of up to $4.5^{\circ} \mathrm{C}$. An overlap of all four sectors does not occur in the strict assessment. Regions in light gray are regions where no multisectoral overlap is possible. The dark gray shows the additional regions affected by multisectoral pressures under the worst-case assessment, where a minimum of $10 \%$ of all sectoral GIM-GCM combinations have to agree on the threshold crossing. 
A second climate-demography vulnerability index (CDVI) adds a third dimension, rapid population growth, to shows areas in which conditions that already support high population densities and where there is rapid population growth will see a decline in climate conditions. The authors ran their model using several climate projections. Figures 2.5 and 2.6 show the resulting maps. For the CVI, hotspots of high vulnerability are found in the Amazon basin, North Africa, Sudan, southern Africa, Central China, Mongolia, and eastern Australia. For the CDVI, the same regions become "hotter", while new areas are added in Central America, the U.S. Southwest, most of Africa, the Arabian Peninsula, Afghanistan, and Indonesia. Many of these are areas where climate change will amplify the conditions currently supporting low population densities, e.g., hot and arid regions that will become drier. Yet the CDVI clearly identifies a number of tropical humid regions (Amazon, Central Africa, and Indonesia) as hotspots as well. One limitation is the treatment of populations as homogenous, and therefore having similar sensitivity and adaptive capacity to climate change impacts.

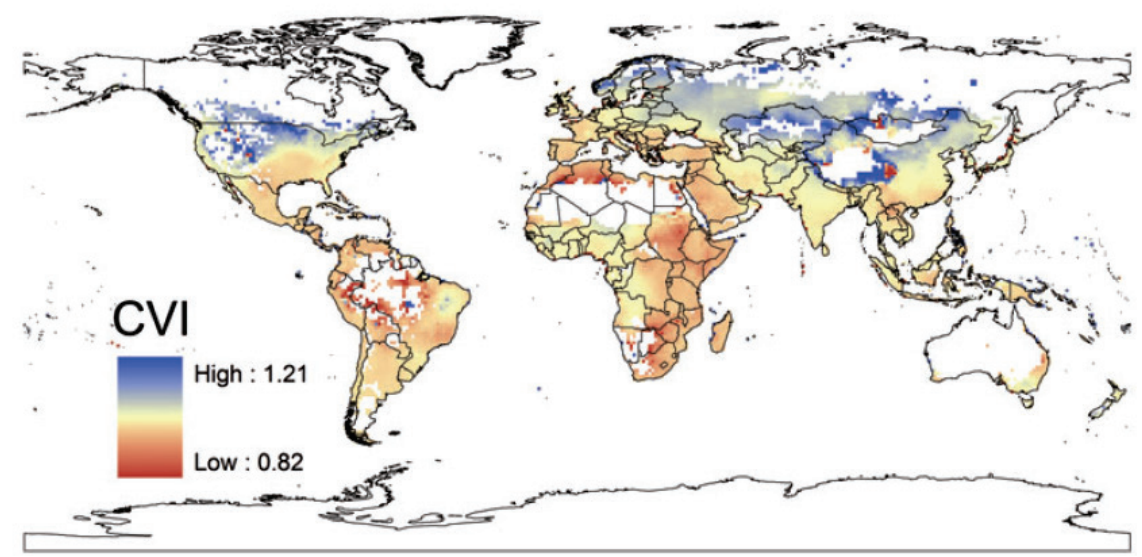

Figure 4 Climate vulnerabilities index (CVI) expressed as climate-consistent annual growth rate $\left(\lambda_{0} ;\right.$ see equation 4$)$ based on current human density-climate relationships (Fig. 3) and a 2050 climate forecast (Fig. S3a). Climate-consistent annual growth rates of less than one, indicated in red, represent negative growth and high vulnerabilities, while changes in annual growth rates of greater than one, indicated in blue, represent positive growth and low vulnerabilities. White regions correspond to human density values of zero in the global gridded population database.

Source: Samson et al. 2011, Figure 4

Figure 2.5: Climate Vulnerability Index (CVI) 


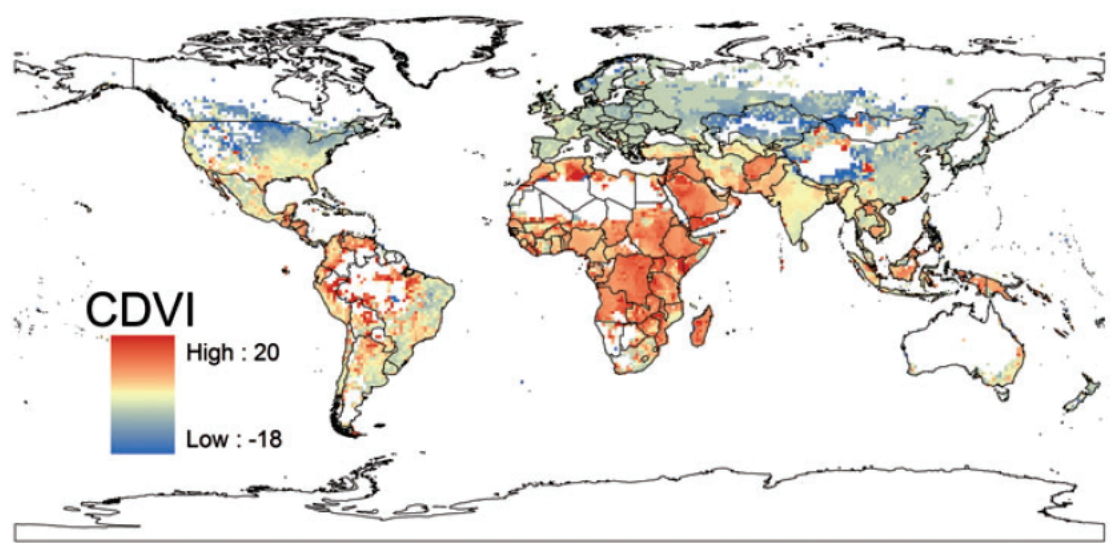

Figure 5 Global climate-demography vulnerability index (CDVI) estimated by subtracting CVI (Fig. 4) from demographic annual growth rates (Fig. S4), expressed as annual growth rates of human population density (see equation 5). Highly negative values, indicated in blue, represent low-vulnerability situations where current demographic growth is much lower than climate-consistent population growth, while highly positive values, indicated in red, represent high-vulnerability situations where current demographic growth vastly exceeds climate-consistent population growth. White regions correspond to human density values of zero in the global gridded population database.

Source: Samson et al. 2011, Figure 5

\section{Figure 2.6: Climate-Demography Vulnerability Index (CDVI)}

A number of efforts have sought to identify hotspots of population vulnerability to sea level rise (SLR). Here I review a representative global assessment by McGranahan et al. (2007a), which utilizes a Low Elevation Coastal Zone (LECZ) mask, representing coastal elevations from $0-10 \mathrm{~m}$, to identify the regions that will be most affected by climate change impacts. Results are provided in spatial and tabular formats, providing estimates of population exposure within the LECZ for urban and rural areas by country (McGranahan et al. 2007b). The method constitutes a simple overlay of the LECZ grid on a year 2000 population grid. The maps identify highly populated areas at high risk of coastal flooding and SLR, especially the Asian "megadeltas" (Figure 2.7). The strength of this effort is that the methodology is simple and easy to understand, and the impacts of SLR are relatively certain, though the timing of specific sea level increments is a matter of some debate, and local impacts are hard to predict with global scale data sets. 


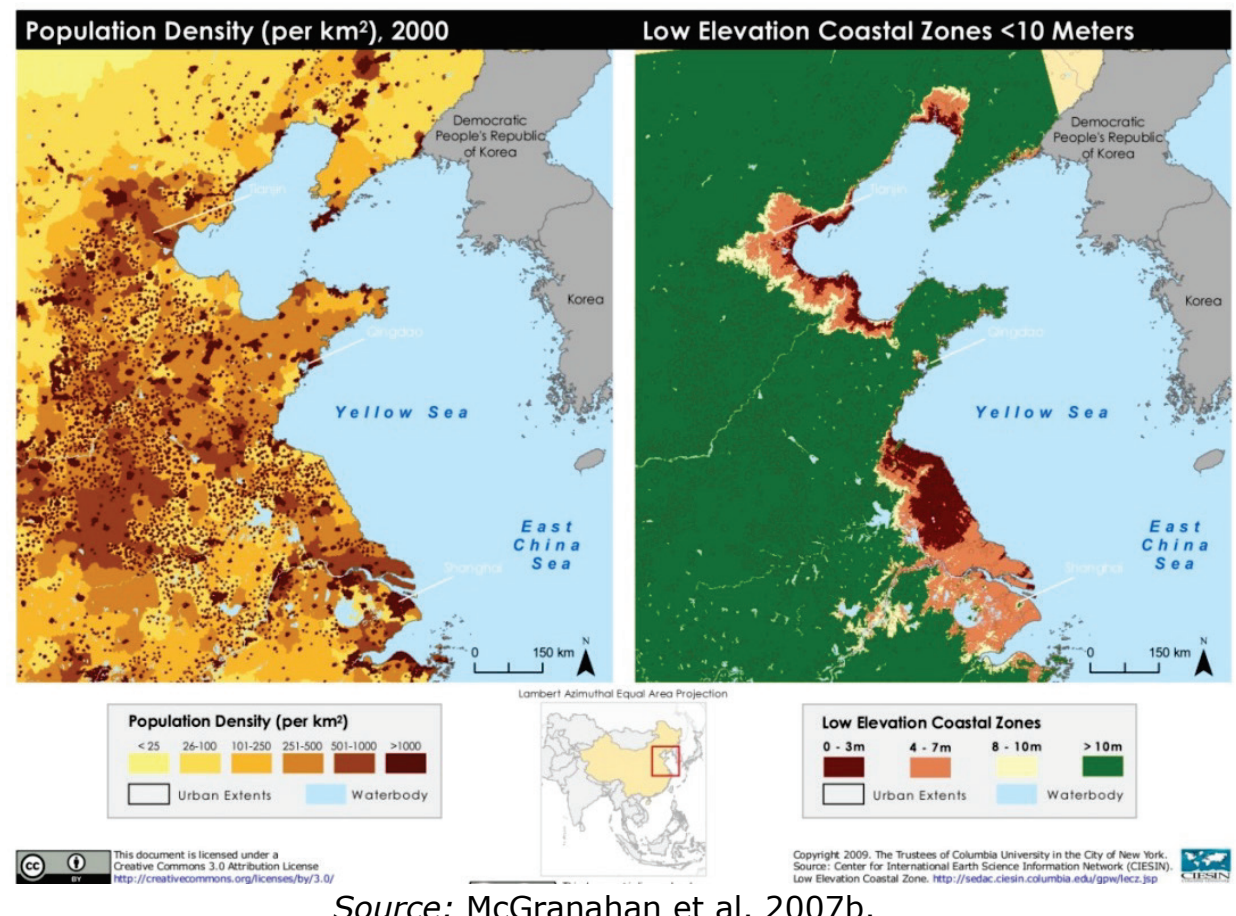

Figure 2.7: Low Elevation Coastal Zone in coastal China

\subsubsection{Disasters and humanitarian crises}

It is widely recognized that the greatest impacts of climate change will not necessarily be the result of secular changes in temperature and precipitation over decades, but rather will be the result of short-term variability and extremes (IPCC 2012). Important mapping efforts have been conducted by the World Bank (Dilley et al. 2005) and UNEP (UNISDR 2009) that assess current exposure to all natural disasters, including climate-related disasters of cyclones, droughts, floods, wildfires and landslides. These are not climate change hotspots per se, since they do not assess future scenarios, but the data layers have been used in a number of climate change hotspots efforts.

One such effort was by CARE and Maplecroft (2008, Thow and de Blois 2008), which sought to identify the most likely humanitarian implications of climate change for the next 20-30 year period. The authors use the World Bank hazard hotspots - floods, cyclones and droughts - to map specific hazards associated with climate change in relation to factors influencing vulnerability. Beyond the climate hazards, two climate projections were used: percentage change in maximum dry periods under scenario A1B and future dynamics of drought risk from 2041-2070. To map sensitivity to climate impacts, the authors combined indicators to create separate indices of 
natural vulnerability (poor natural resource base), human vulnerability, social vulnerability, financial vulnerability, and physical vulnerability (infrastructure). These layers were then combined into an overall human vulnerability index (Figure 2.8). Hotspots include the Andes, the landlocked countries of sub-Saharan Africa as well as southern Mozambique and Namibia, Yemen, Afghanistan and Pakistan, Mongolia, and Myanmar. One weakness is that the authors do not combine the climate risks (past hazards and future scenarios) with the human vulnerability index in such a way as to draw out hotspots at the intersection of climate and societal vulnerability.

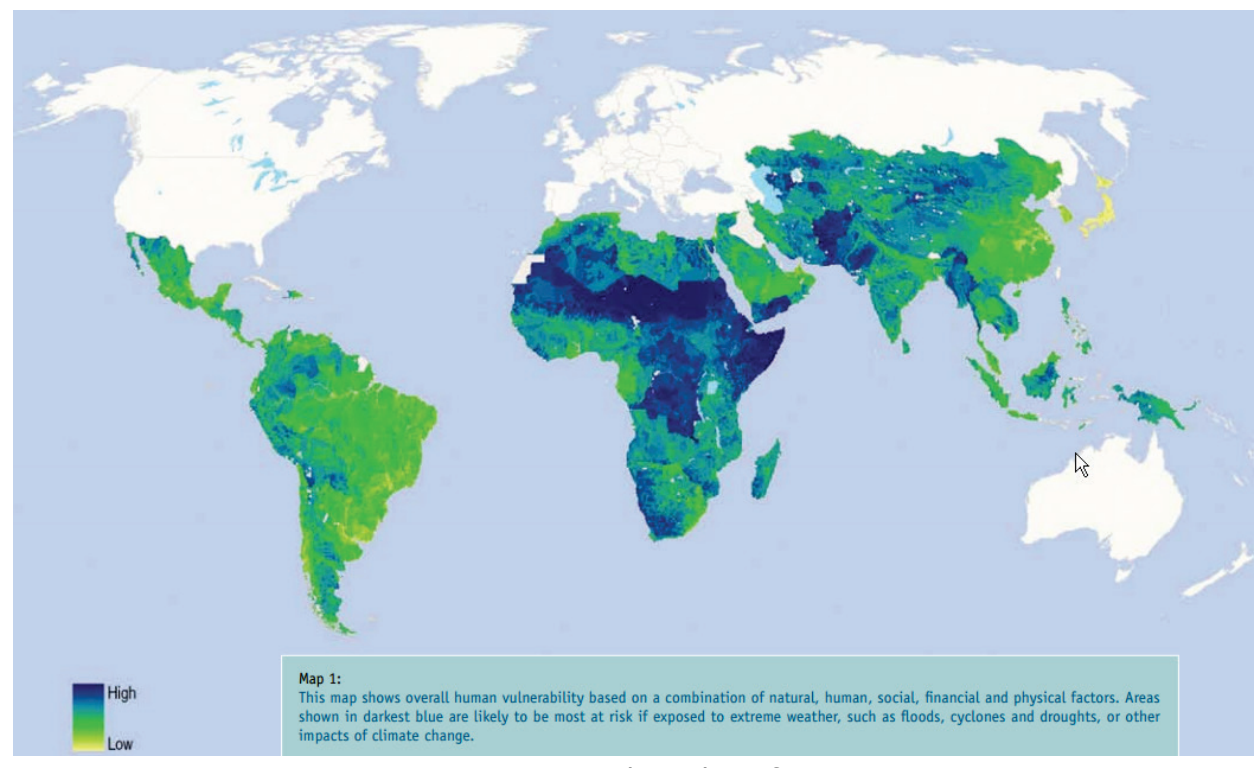

Source: CARE and Maplecroft 2008.

Figure 2.8: Overall Human Vulnerability

\subsubsection{Agriculture and food security hotspots}

There are a number of recent reports looking at climate change and food security hotspots. Under the Climate Change, Agriculture and Food Security (CCAFS) program, Erickson et al. (2011) map hotspots of climate change and food insecurity in the global tropics using a series of spatial indicators for climate change and food security. Indicators for climate change were based on model runs from three models obtained through the Coupled Model Intercomparison Project (CMIP3), and featured factors such as reductions in length of growing season, areas where average annual maximum temperatures will exceed $30^{\circ} \mathrm{C}$ (an important threshold for legumes), and areas where the rainfall coefficient of variation is $>20 \%$. These were tallied into an index identifying the number of climate change thresholds important to agriculture that are likely to be exceeded. Indicators for food security include food availability (current crop yields and a food production index), 
access (GDP per capita, percent population living on less than $\$ 2 /$ day, road density), utilization (stunting prevalence, wasting prevalence, malnourished children per sq. km, population using unimproved water sources), and resource pressure (population growth rate, arable land p.c.).

In a last step, the results are tallied by exposure, sensitivity and coping capacity components into eight vulnerability domains, from high-high-high to low-low-low. Although sophisticated, the resulting array of maps is challenging to interpret without specialized knowledge, and little attempt is made to highlight hotspot scenarios of greater concern or likelihood. Adding to the problems of interpretation, maps represent eight vulnerability dimensions in various shades of yellow, green, blue and red. Focusing on domains with high exposure, high sensitivity, and low coping capacity, which are helpfully mapped in red, hotspots include the forest belt of West Africa, northwestern India and northeastern Pakistan, and in the lower Mekong that are highly affected by changes in growing season length. Areas of Nigeria, the lakes region of Africa, and large swaths of India will be affected by a change in average maximum daily growing season temperatures of $>30^{\circ} \mathrm{C}$ (Figure 2.9). Southern Nigeria and parts of the Gangetic plain will be severely affected by rainy season rainy day decreases of $>-10 \%$. 


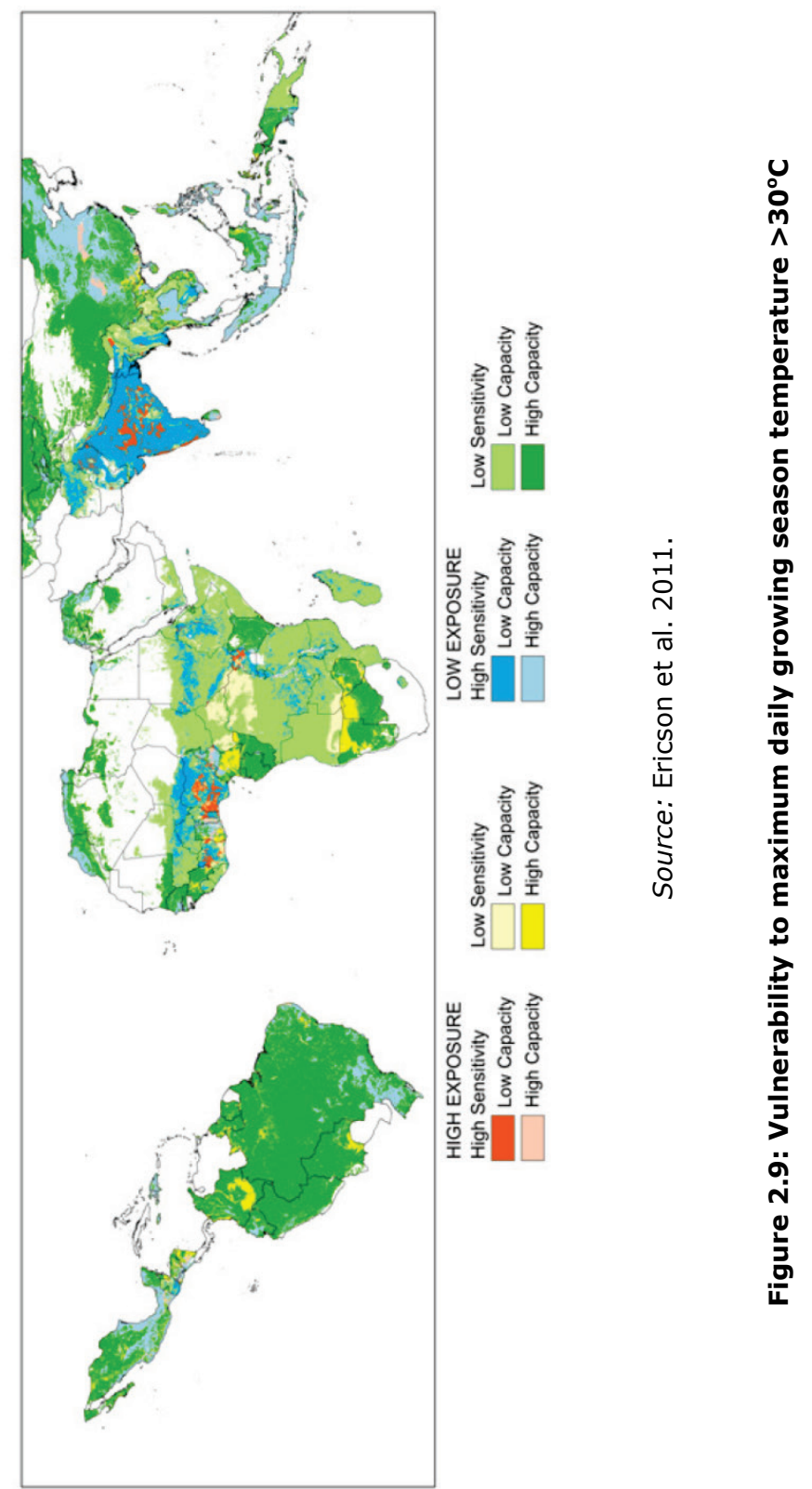

Fraser et al. (2012) map drought vulnerability hotspots with reference to wheat and maize. Unlike the CCAFS maps, which portray seemingly small impacts, by circa 2050 broad swaths of the world are deemed vulnerable to declines of growing season soil moisture availability of greater than $25 \%$, including most of South America, the U.S. mid-West, Southern Africa, the 
Mediterranean Basin, Central Asia, western China, and Australia. When combined with reduced adaptive capacity, there are five wheat and three maize vulnerability hotspots. For wheat, these are the southeastern U.S., southeastern South America, the northeastern Mediterranean, and parts of central Asia, and for maize they are southeastern South America, parts of southern Africa, and the northeastern Mediterranean (Figure 2.10).

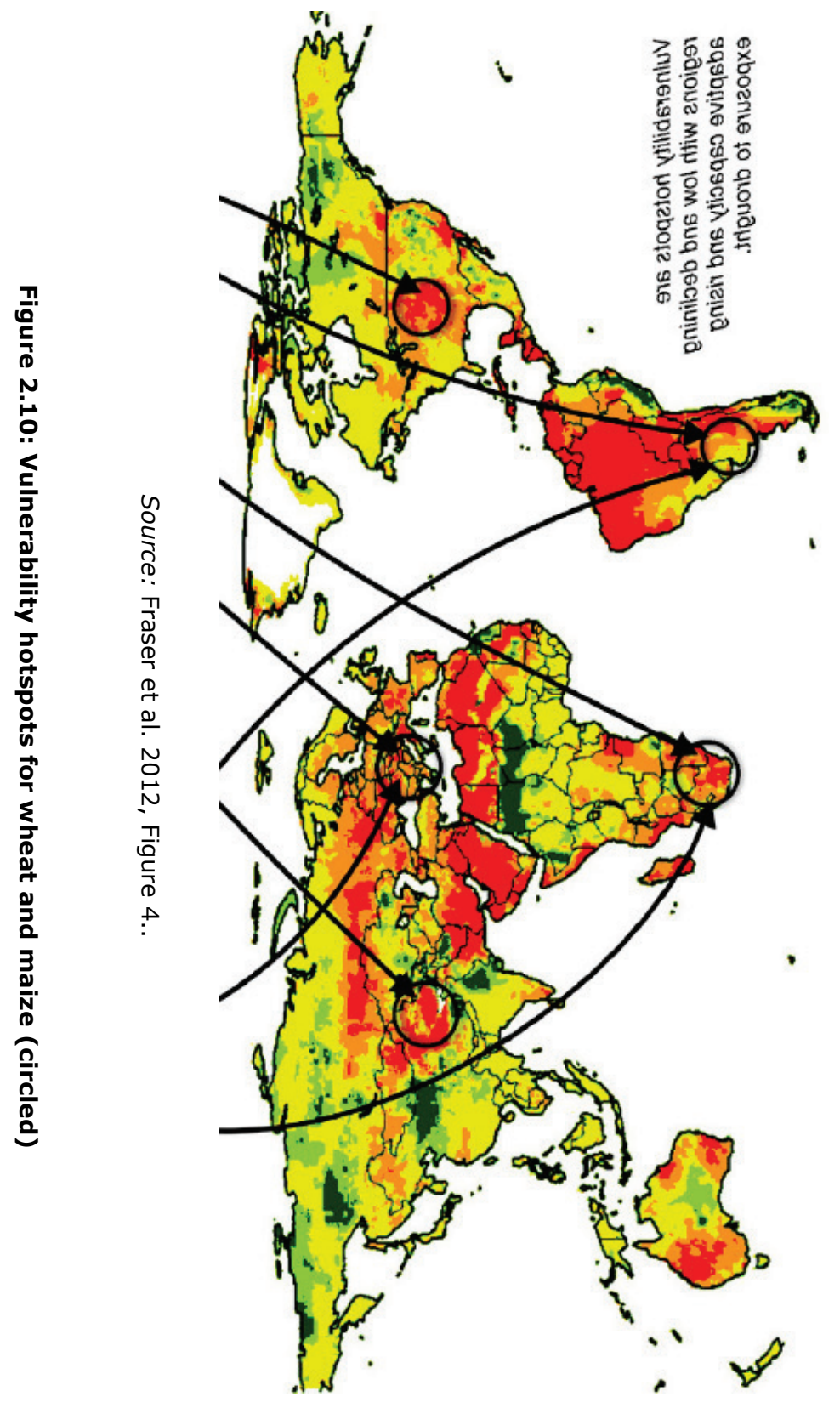


In the only global hotspots mapping effort to explicitly employ the PNAS vulnerability framework, Kok et al. (2010) develop an integrated assessment model to assess livelihood security as a consequence of global change. They define 'archetypical patterns of vulnerability' as specific, representative patterns of the interactions between environmental change and human wellbeing, similar to the "syndrome" approach described below. They used the PNAS framework to determine the questions that need to be answered in analyzing a pattern of vulnerability, tracing specific exposures in similar situations to specific population groups, their sensitivity and possible coping and adaptation mechanisms at various levels of decision making. The questions were (p.17):

1. What are the main exposures, key vulnerable groups and their sensitivities that together define the pattern of vulnerability?

2. What are the basic vulnerability creating mechanisms that constitute this pattern of vulnerability?

3. In what form and where does this pattern manifest itself?

4. How can future changes within the human-environment system affect the human well-being situation for the vulnerable groups?

5. What are the opportunities - individual responses or policy responses to cope with and adapt to future changes?

They identify four major patterns of vulnerability: smallholder farming in dryland areas, overexploitation of natural resources, competition for land for food and biofuels, and rapid urbanization in the coastal fringe (Figure 2.11). 


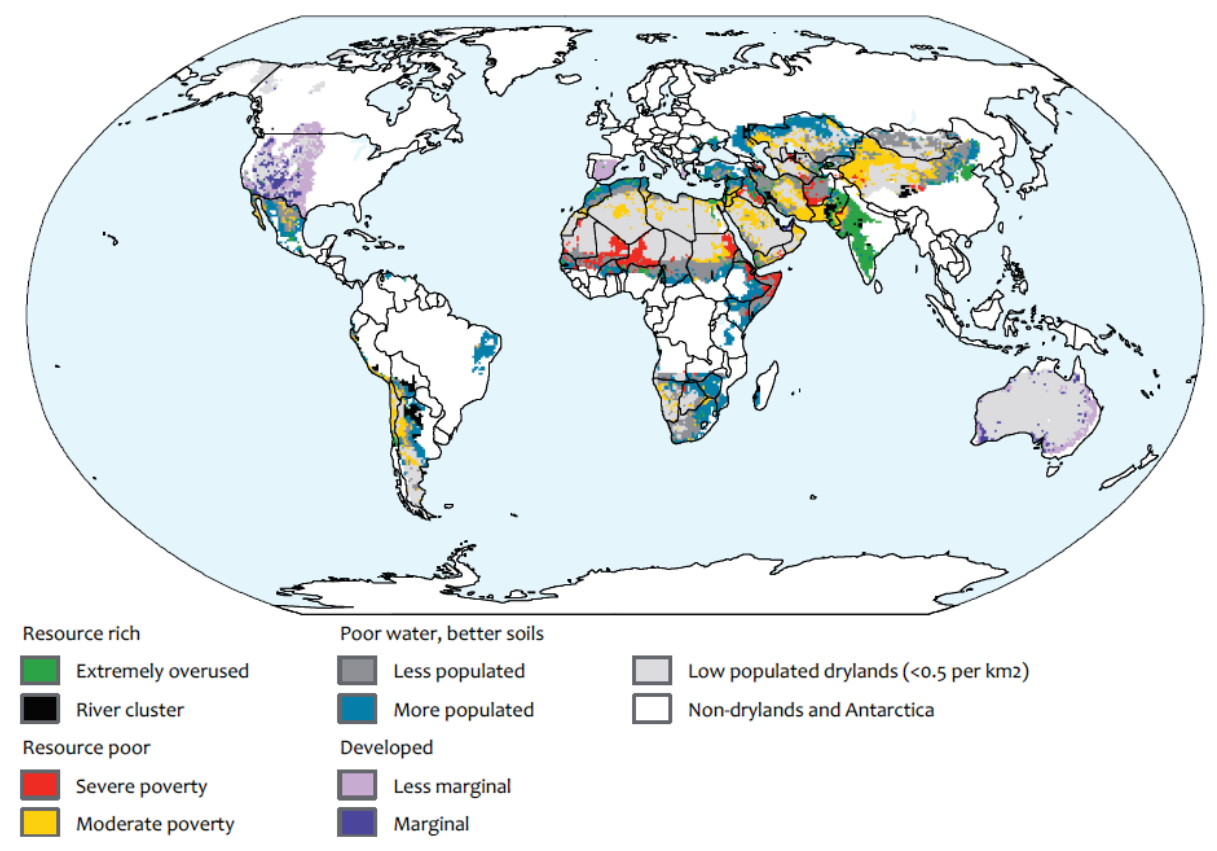

Source: Kok et al. 2010.

Figure 2.11: Geographical distribution of vulnerability profiles

Similar to Erickson, the range of factors considered (resource rich; resource poor; poor water, better soils; developed) makes interpretation difficult, but there are swaths or resource poor areas with severe to moderate poverty that are more vulnerable to global change, including the Sahel, the Horn of Africa, Afghanistan, and small areas of western China. The Andes, southern Maghreb, Arabian peninsula, Iran and Pakistan and the rest of western China are deemed to be resource poor with only moderate poverty.

\subsubsection{Water resources hotspots}

There is a growing effort to map climate and water hotspots. Parish et al. (2012) sought to integrate climate and population data sources to develop first order per capita water availability projections at the global scale. Like many analyses, the authors sought to determine if there may be any new hotspots of water scarcity under a changing climate regime that would require planning and mitigation. Beyond identifying hotspots, the authors were interested in identifying the relative contributions of population and climate change as drivers of water availability. The study used climate projections and multiple SRES scenarios (A1B, B1, A2, and A1F1) as inputs to a hydrological model. To assess population growth, they apply SRES countrylevel population projections to the Landscan population grid, assuming a constant relative distribution of population within countries. The map 
depicting the A1F1 SRES scenario (high emissions) (Figure 2.12, bottom right) depicts quite disparate areas at high risk - ranging from the region surrounding the Great Lakes in the U.S. and Canada, to North Africa, to Iraq and Syria to Southern Russia. Some areas where one might expect increases in stress, e.g., China and India, are actually depicted as showing declining water stress across most scenarios (except in the A2 scenario) owing to projected increases in precipitation. The patterns are not very consistent across SRES scenarios, and there are many isolated "hotspot" pixels, making interpretation difficult.
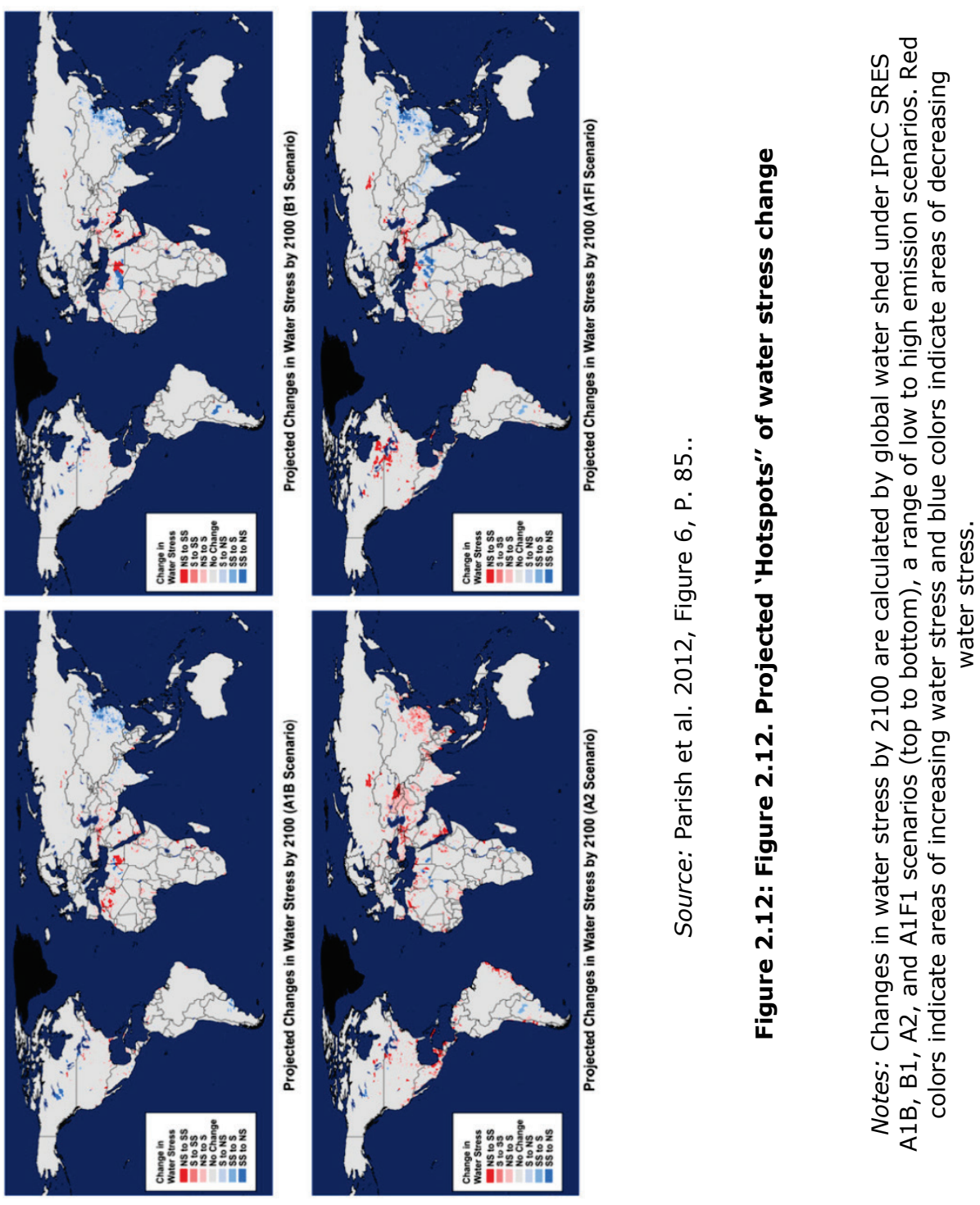
Similar assessments have been conducted by Döll (2009) for climate change and population impacts on groundwater resources, focusing on ground water recharge rates, De Stefano et al. (2010) for international river basins to future climate change-induced water variability, and the World Resource Institute's Aqueduct Water Risk Atlas, which like the UK Met Office's hotspots map, presents future climate impacts on water resources in an attractive online map tool. Döll finds more consistent evidence across the GCMs utilized, with patterns of high vulnerability to decreases in groundwater resource availability in North Africa, Senegal and Mauritania, Namibia and western South Africa, and northeastern Brazil. De Stefano finds high projected water runoff variability by 2030 for the Colorado Basin in the U.S. Southwest, the Parana in South America, basins in West Africa and southern Africa, the Mekong, and southern China.

\subsection{Regional hotspots mapping efforts}

In this section I review a number of regional GIS-based hotspots mapping efforts from Africa, Southeast Asia, and Europe. These cover a range of thematic areas, from agriculture and food security to general vulnerability.

\subsubsection{Hotspots Maps for Africa}

Owing to chronically low levels of development, high levels of food insecurity and natural resource dependence, and high climate variability, many studies find that Africa is likely to be the continent hardest hit by climate change (e.g. Thornton et al. 2008, Yohe et al. 2006). Busby et al. (2011) develop a map of potential climate conflict hotspots based on a geospatial overlay technique that is similar to the humanitarian mapping described above. A composite vulnerability score includes four components: exposure to climate hazards, population density, household and community resilience (health, education, access to health care), and governance and political violence (country level indicators of government responsiveness, effectiveness, polity, and violence against civilians). A useful feature of this report is the focus on specific regions as case examples, where the index is deconstructed (Figure 2.13). Overall, regions that are identified as having the highest vulnerability include much of the Democratic Republic of Congo, Sierra Leone, Somalia, Sudan, Chad and Ethiopia. Portions of Angola, Niger, Cote d'Ivoire, and Central African Republic are also considered vulnerable. Although the maps are attractive, given their histories of conflict there is little surprise that these regions emerge as vulnerable.

Two studies have developed human vulnerability hotspots maps for southern Africa, which is one of the sub-regions of Africa that has been pin-pointed as being particularly vulnerable to climate change (Parry et al. 2007). In the first, Midgley et al. (2011) focus is on agriculture, food security, and human 
health in southern Africa (see also Davies and Midgley 2010). The authors use an index approach with spatial data sets that measure present exposure, future exposure (in 2050), sensitivity and adaptive capacity. Present exposure variables include, inter alia, the rainfall coefficient of variation, risk of cyclones and floods, the standardized precipitation index, fire frequency, and disaster events. Future exposure includes future population density, ensemble GCM outputs for precipitation and temperature change, loss of suitability for crop land, and sea level rise. Sensitivity includes variables such as irrigated land, volume of rainfall per person on agricultural land, crowding on agricultural land, length of growing season, soil degradation, slope, and net primary productivity. Adaptive capacity includes variables such as infrastructure, economic wealth, malnourishment, education, health, malaria, access to improved water, travel time to cities, and night time lights.
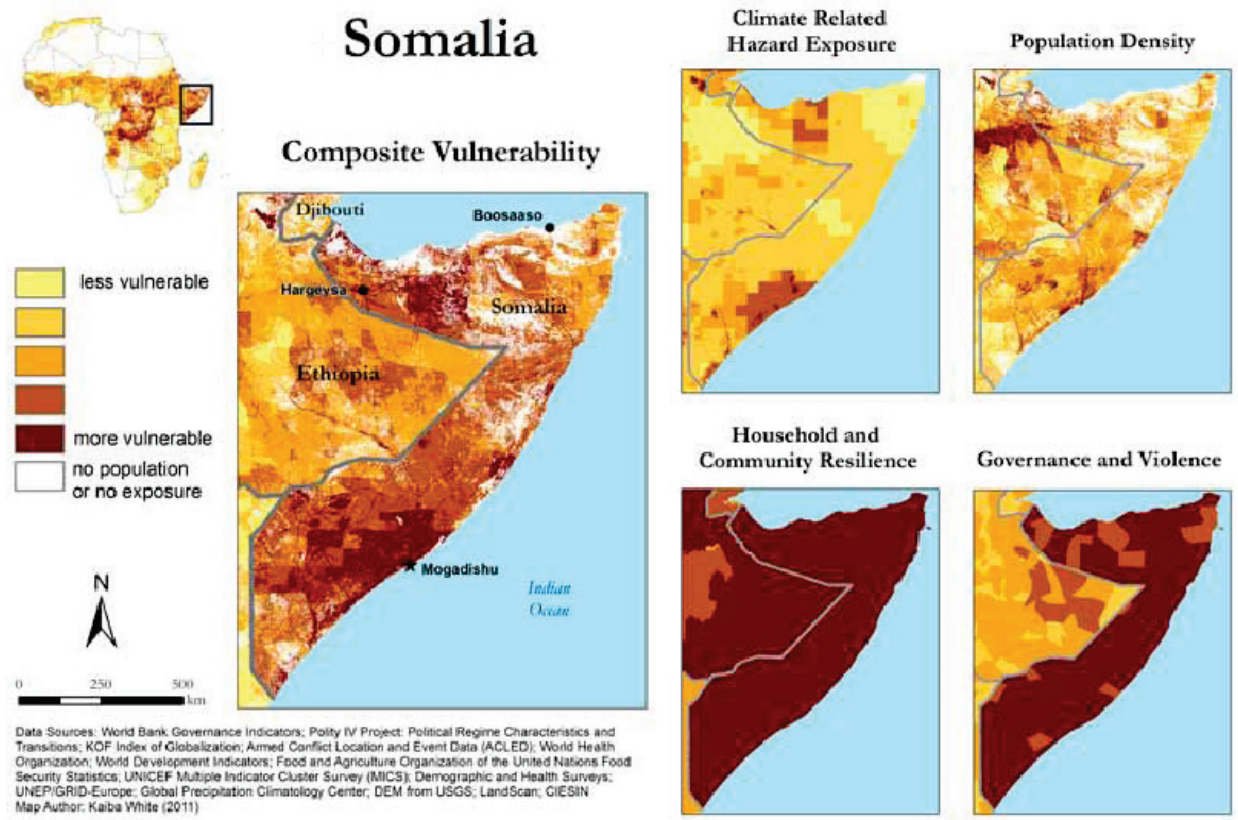

Source: Busby et al. 2011, Figure 2

Figure 2.13: Somalia's Composite Vulnerability Index

All variables were standardized on a $0-1$ scale and then multiplied times a weight ranging from 1 to 3 , and then all variables were added to form a score for each component of vulnerability (Figure 2.14). Most of the adaptive capacity indicators, and those with the greatest weight such as GDP and access to water and sanitation, tend to be reported at national levels, so there are abrupt jumps in values at national borders. Sensitivity tends to be heavily influenced by population density, which is not directly incorporated 
but is implicitly present through measures such as human appropriation of net primary productivity and per capita volume of rainfall.

In the second pilot vulnerability hotspots mapping effort for southern Africa, Abson et al. (2012) created vulnerability maps based on principal components analysis (PCA) and a reduced set of indicators. They argue that the standard practice of averaging or summing indicator scores hides important information regarding the relations between the original variables. Because the principal components (PCs) are uncorrelated, the scores associated with each PC encapsulate a unique aspect of the overall socioecological vulnerability represented by the original set of vulnerability indicators. However, since the components are statistically derived, it can be difficult to attribute meaning to a specific component. For example, their first PC, which they term "poverty and health vulnerability", includes infant mortality, poverty, agricultural constraints, and malnutrition, which is straightforward enough. But their third PC, termed "infrastructure poverty and population pressure vulnerability", combines population per net primary productivity, infrastructure poverty (a measure of population divided by night time lights), and travel time to major cities. It is hard to make sense of this except perhaps as a proxy for spatial isolation and population density.

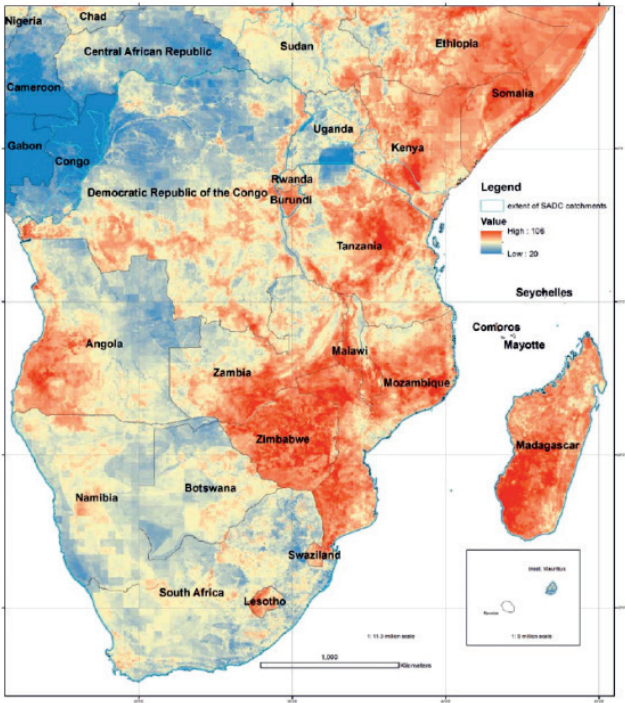

(a)

Source: Midgley et al. 2011.

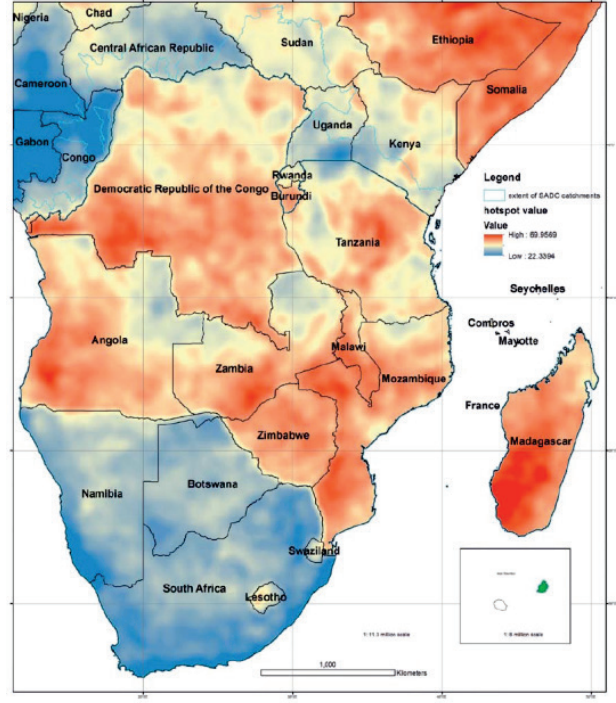

(b)

Figure 2.14: Vulnerability hotspots (a. 2008 and b. 2050).

Note: Red values indicate hotspots where people are most likely to be most in need of help adapting to climate stressors, while the blue areas indicate areas of resilience. 
Although the efforts are not directly comparable owing to differences in the underlying indicator sets, Figure 2.15 provides a comparison of the results by these two efforts that reveals broadly similar patterns but also some notable differences. For example, Midgley et al. find Zimbabwe and southern Zambia to be highly vulnerable but Abson et al. find them to be less so. Conversely, Abson et al. find most of the Congo and Angola to be highly vulnerable, but Midgley et al. find them to be less so. The figure serves to illustrate the fact that depictions of vulnerability patterns depend heavily on data and methods.

Liu et al. (2008) focus on hunger hotspots using multiple crop modeling outputs. They identify areas of high population density and current undernutrtion problems that are likely to see decreases in per capita calorie availability of $0-30 \%$ and $>30 \%$ (Figure 2.16). A major area of current and future vulnerability is the highlands of Ethiopia; Areas stretching from western Tanzania to Mozambique are projected to see $>30 \%$ declines in calorie intake, and the lakes region, northern Nigeria, and parts of southern Nigeria are considered currently vulnerable but without significant changes in future calorie intake.

Thornton et al. (2008) map hotspots of climate change and poverty in Africa using principle components analysis on 14 indicators measuring five livelihood capitals (Carney 1998): natural capital (e.g. soil degradation), physical capital (e.g., accessibility to markets), social capital (e.g., governance), human capital (e.g., malaria and HIV prevalence), and financial capital (e.g., agricultural GDP). Regions identified as most vulnerable include the Highlands of Ethiopia, southern Chad, southern Niger, and Rwanda and Burundi, followed by most of the rest of Africa, with only Guinea, southern Ghana, Namibia, and Zimbabwe and portions of South Africa near Johannesburg showing up as less vulnerable. The selection of Guinea and Zimbabwe as less vulnerable is puzzling, and may have to do with data limitations. 

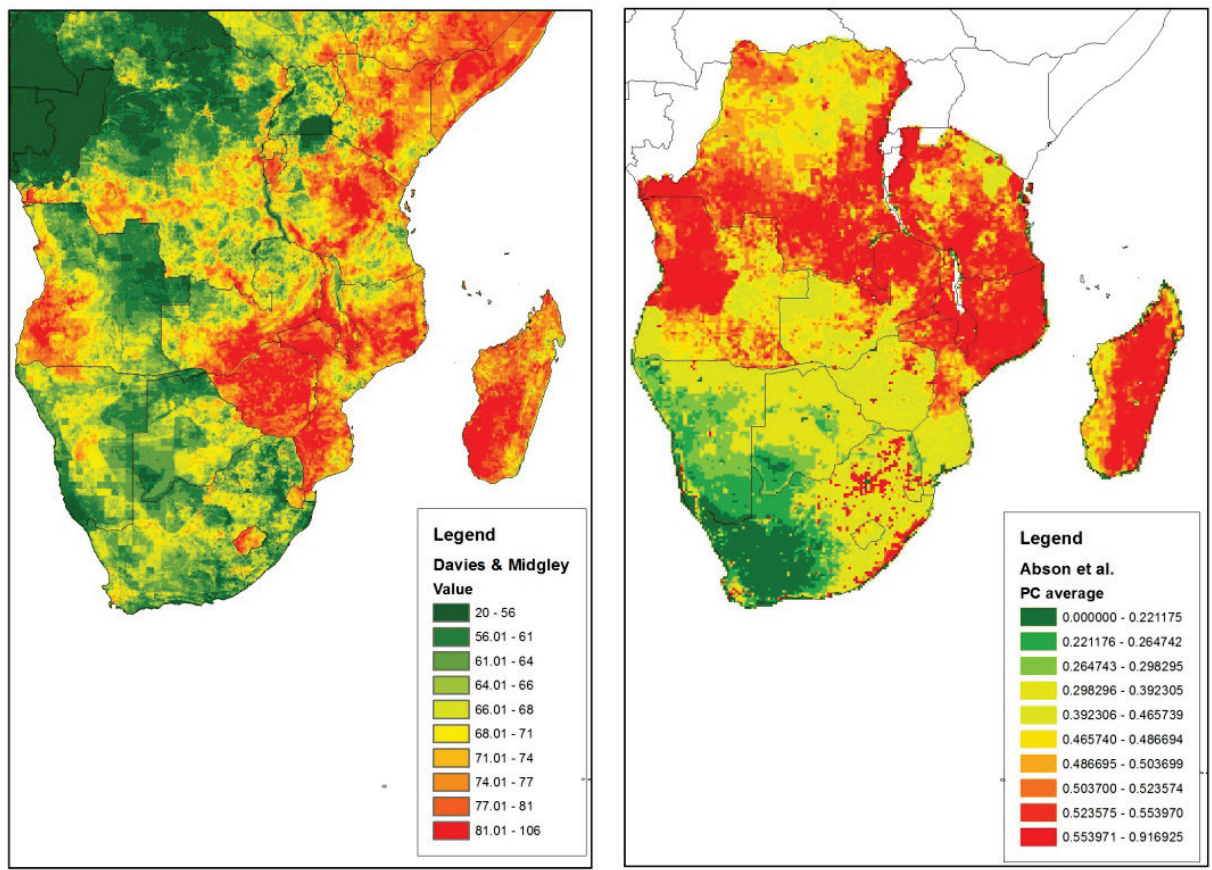

Sources: Davies \& Midgley 2010 and Midgley et al. 2011 (left) and Abson et al. 2012a (right).

Figure 2.15: Comparison of vulnerability maps by Midgely et al. and Abson et al.

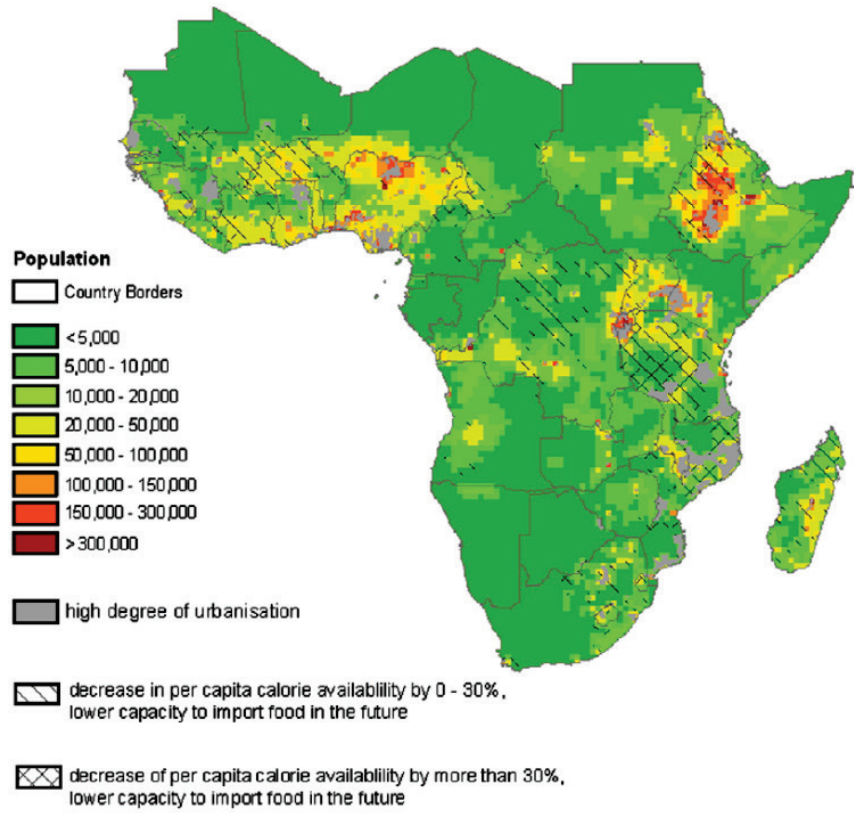

Source: Liu et al. 2008, Figure 13.

Figure 2.16: Number of people with current undernutrition problems in relation to future potential hotspots of food insecurity in the 2030s ower capacity to inport rood in the future 
Finally, Hagenlocher et al. (2013), in a climate-focused approach similar to that of Baettig et al.'s CCI, develop an innovative modeling approach using historical climatological and vegetation index data sets to delineate areas with relatively high climate change impacts in West Africa. Hotspots are identified as areas where temperature and precipitation trends are pronounced and drought and flood events over the past 24-36 years have been severe, with a focus on the rainy season from May to October. The map (Figure 2.17) reveals both the areas of high impacts, and the proportion of the impact that can be attributable to given impacts. For example, flood impacts dominate in the hotspots of Burkina Faso, Ghana, and southern Niger, whereas precipitation trends dominate in western Mauritania. The maps lack any reference to population vulnerability, but some hotspots do coincide with larger population centers, such as the flood hotspots in northern Nigeria (around Kano) and in southern Burkina Faso. The approach also does not differentiate between increasing and decreasing trends in precipitation, such that the rebound in precipitation following the great Sahelian droughts of the early 1970 s and 1980 s would be considered as contributing to climate hotspots in some regions. 


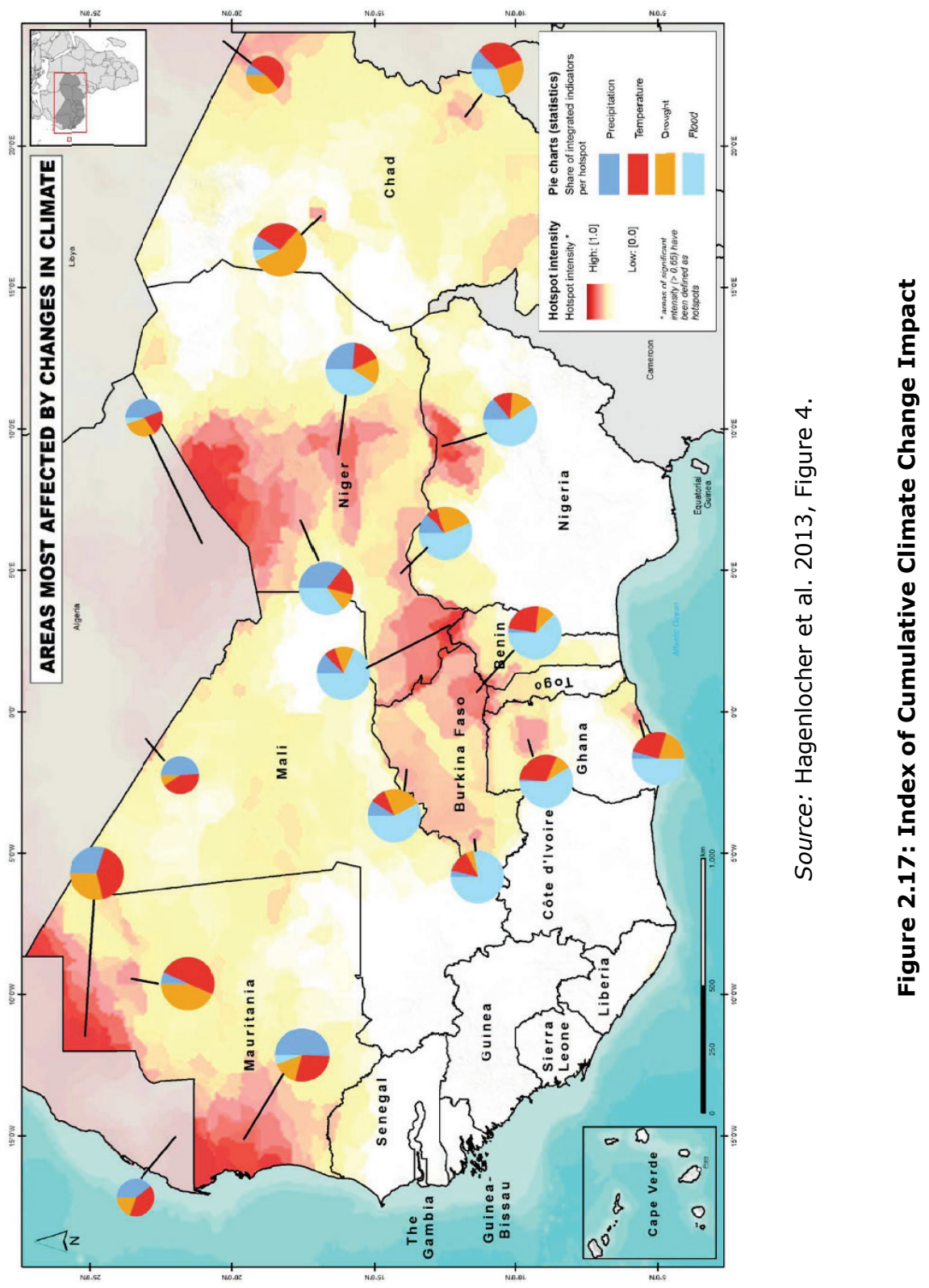

\subsubsection{Hotspots Map for Southeast Asia}

In a similar effort, Yusuf and Francisco (2009) sought to map vulnerability to climate change in Southeast Asia. They developed a vulnerability index following the IPCC definition, including natural hazards, population density as a proxy for human sensitivity, protected areas as a proxy for ecological 
sensitivity, and a number of variables for adaptive capacity. They did not incorporate GCM outputs or socioeconomic scenarios. The resulting vulnerability map (Figure 2.18) depicts areas of particularly high vulnerability in Laos, Cambodia, the Philippines, and the regions of Java and West Papua (former Irian Jaya) in Indonesia. The results appear to be largely driven by the Climate Hazard Index for all regions except Laos and Cambodia, where adaptive capacity is very low.

\subsubsection{Hotspots Maps for Europe}

The ESPON Climate (2011) mapping effort mapped potential impacts of climate change on Europe at the Nomenclature of Territorial Units for Statistics (NUTS) 3 level, which are approximately equivalent to US counties. The authors looked at physical impacts, such impacts on settlements, roads, railroads, airports, power plants, and harbors, as well as social impacts on populations, using proxies such as age and population density. Figure 2.19 depicts the map of potential vulnerability to climate change, which combines regional potential impacts with regional adaptive capacity. Impacts are calculated as exposure based on the difference between 1971-2000 and 2071-2100 based on eight climatic variables of the CCLM model for the SRES A1B scenario, plus inundation depth changes for a 100 year return flood event, change in 100 year return period coastal storm surge height, together with recent data on the physical, economic, social, environmental and cultural sensitivity to climate change. Adaptive capacity was calculated as a weighted combination of economic, infrastructural, technological and institutional capacity as well as knowledge and awareness of climate change. 


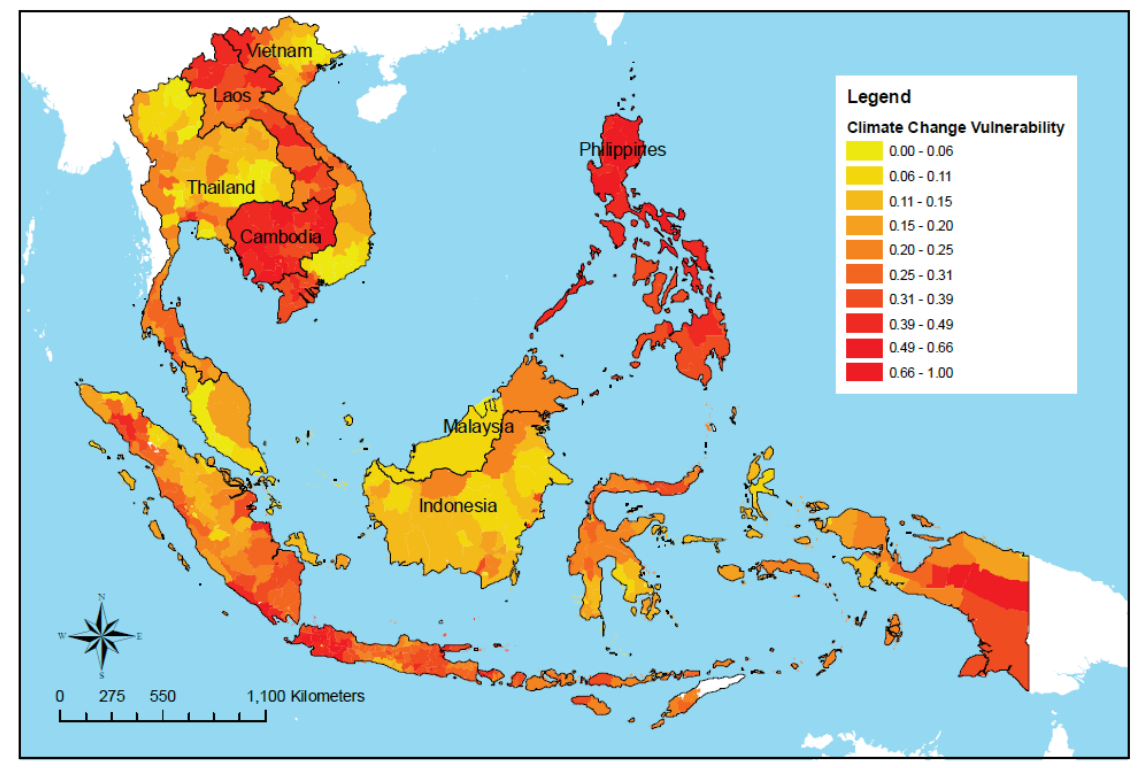

Source: Yusuf and Francisco 2009.

Figure 2.18: Climate Change Vulnerability for Southeast Asia

The results suggest high levels of vulnerability in much of southern Europe and medium vulnerability in selected coastal regions of France, Netherlands, and the UK. Some of these patterns are driven by increasing flood and surge risk along the coasts, but the broad pattern of vulnerability in southern Europe is driven most by projected hotter and drier climates combined with low adaptive capacity.

Schröter et al. (2005) focus on the vulnerability of ecosystem services to climate change impacts in Europe using multiple SRES scenarios out to the year 2080. They find that some changes reduce vulnerability, e.g., through the increase in growing days and more favorable agricultural conditions in northern latitudes, but most changes increase vulnerability, e.g., through declining soil fertility, declining water availability, and increasing risk of forest fires, especially in the Mediterranean and mountain regions. Their maps do not represent overall hotspots, but rather present information on changes to specific ecosystem services, such as changes to cropland areas and water stress. Here again, southern Europe appears to be most impacted across multiple scenarios.

\subsection{Discussion}

This paper reviewed a range of global and regional hotspots mapping efforts. While hotspots maps are issued with increasing regularity, there are a number of fundamental issues that need to be addressed. In this section I 
briefly assess data and methodologies, identify regions that are consistently identified as hotspots, address communication and design issues, and identify paths for future research. Issues around uncertainty, validation and risk communication relevant to hotspots mapping are addressed in Section 1.3.3 of Chapter 1.
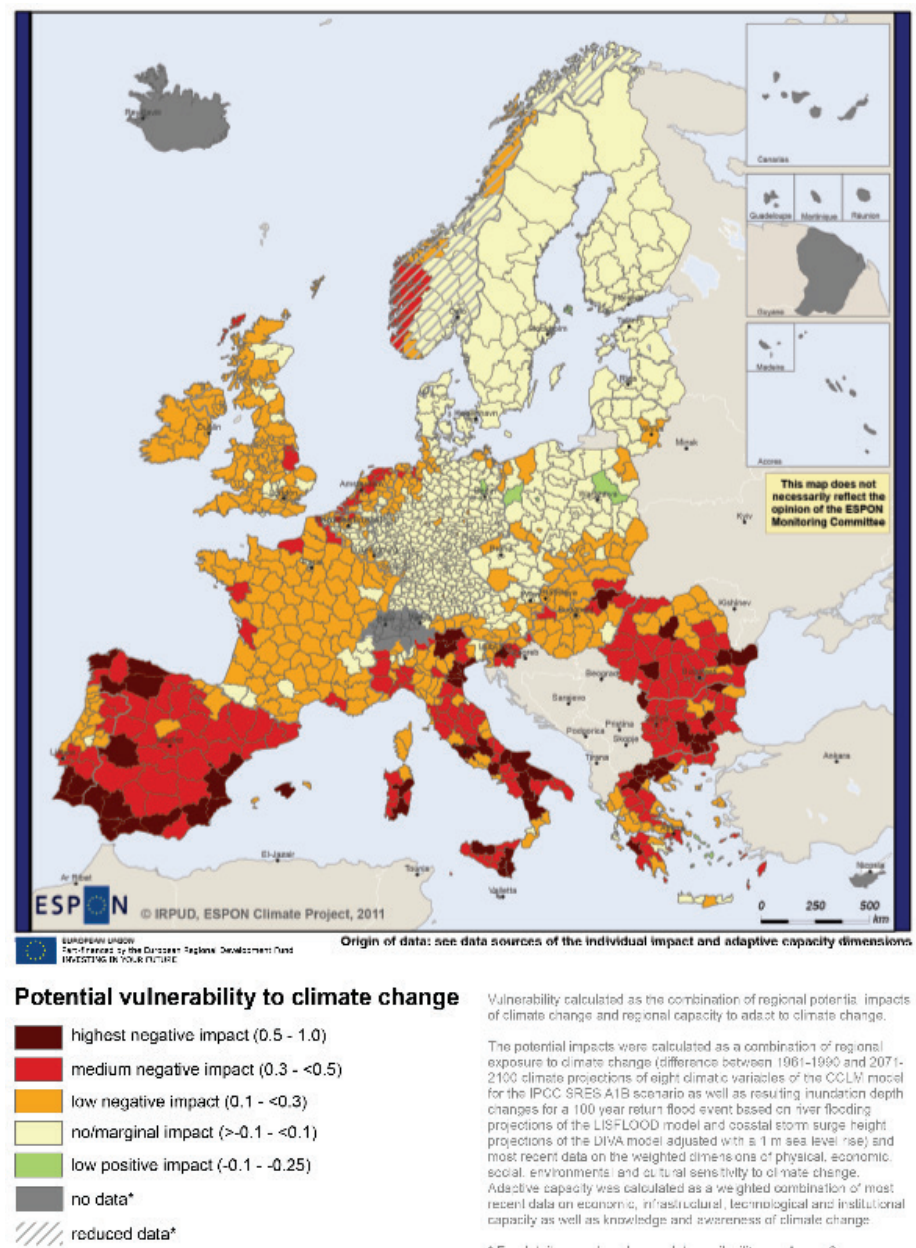

Source: ESPON Climate 2011, p.24

Figure 2.19: ESPON Europe assessment

\subsubsection{Data and methodologies}

There are a number of common conceptual and methodological approaches that are found across multiple mapping efforts. One is the frequent use of the IPCC conceptualization of vulnerability, which either directly or indirectly served as the basis for six of the efforts reviewed, although not all adequately addressed the three components. As already discussed (Chapter 
1 , Section 1.3), there remain challenges in data availability and mapping scales for a number of socioeconomic variables relevant to the mapping of sensitivity and adaptive/ coping capacity. Often, proxies such as poverty and malnutrition are used to measure social vulnerability, yet it is acknowledged in the literature that this is a multidimensional, time dependent and often complex concept that is difficult to capture in static maps (Adamo and de Sherbinin 2011, Kasperson et al. 2005). More fundamentally, the SREX framework (IPCC 2012) - which separates exposure and vulnerability - may yield better results for policy audiences since it translates more easily into a risk management approach.

Climate projections tend to be more common in hotspots studies of biophysical systems, especially as inputs to other models, and are rarely used for social or "general" vulnerability assessments (exceptions include Midgley et al. 2011, CARE and Maplecroft 2008). Apart from Busby et al. (2011), climate and security mapping efforts appear to be less sophisticated, relying to a greater extent on expert opinion (e.g., Schubert et al. 2007). Overall, there are strong disciplinary influences reflected in each of the approaches. The RCCI and CCI are entirely grounded in climate science, the CVI in ecology, the livelihood systems mapping in integrated assessment (Kok et al. 2010) and development practice (Warner et al. 2009, Thornton et al. 2008), and most agriculture and water hotspots maps are generated by modelers.

Many hotspots mapping efforts are affected by the spatial scale and uncertainties in the available global data sets. Kok et al. point out that there is a gap between local vulnerability assessment, which address contextspecific situations with more detailed data, and the kinds of analyses possible for global VAs, which are based on aggregated data and rather crude assumptions about the underlying mechanisms being assessed. Bridging this gap will prove to be difficult.

\subsubsection{Where are the hotspots?}

Based on the figures and Table 2.2, there are a number of regions that are found to be vulnerable across a range of climate impacts and systems, sectors, and groups. These include North Africa, the Sahel, the Horn of Africa, parts of southern Africa, Central America, and the Andes. In Asia, the picture is less consistent, but western China and Central Asia are fairly consistently identified, and often India as well. Parts of Europe, North America and South Asia are also found to be vulnerable to agricultural production declines. Many small islands states, particularly in Oceania and the Caribbean, are highly vulnerable to SLR and storm surge, but these islands rarely show up in global mapping efforts because they are too small to map adequately at global scales. A number of the data-driven GIS modeling efforts produce patterns 
that are not always intuitive, and the number of map outputs makes summarizing overall patterns difficult.

One obvious question is, Do the data-driven maps show patterns that would not have been identified in an expert assessment approach or based on a broad understanding of past patterns? This depends on the mapping efforts, but for the most part it appears that regions that have the lowest levels of economic development are typically found to be most at risk in global hotspots mapping assessments, which suggests that patterns are not radically different from what one might expect a priori. Indeed, many hotspots were already identified as having high vulnerabilities by the IPCC (Parry et al. 2007). However, the specific sub-regions identified vary from effort to effort, and the climate change exposure and SLR hotspots do include areas that are economically advanced because they are climate-driven.

\subsubsection{Map Design}

Maps are fundamentally a communication tool, answering the question, Where should I focus my attention? Maps have been proven particularly effective in risk communication (Dransch et al. 2010). Yet, some maps reviewed in this chapter are more effective than others in drawing attention to specific locations. For data driven maps, the "speckling" that results from isolated pixels showing up as hotspots is problematic from a policy communications perspective. A majority filter (moving window or spatial averaging) could reduce the speckling at the risk of some information loss (compare Figures 2.14a and 2.14b), and better convey uncertainties. The abrupt discontinuities across borders create problems for interpretation: they may be an artifact of using national level vulnerability and resilience indicators, or they may reflect real changes in on-the-ground vulnerability based on differing governance structures.

Reports by Busby et al. (2012), Warner et al. (2009 and 2012a), and Midgley et al. (2011) are professionally designed, and the maps are cartographically appealing. Busby provides map zooms for specific sub regions, which aids greatly in legibility (Figure 2.13). However, for most maps, their frequently small size and lack of contextual information (subnational boundaries, road networks, major cities) makes it difficult to identify the locations of hotspots. Some important areas such as small island states or major urban areas, where vulnerabilities are likely to be greatest, are often completely obscured on global scale maps. Maps zoomed to areas of vulnerability with greater contextual information could be used to address these concerns.

Finally, as mentioned in the previous section, researchers coming from the climate and integrated assessment communities tend to produce map arrays 
depicting multiple scenarios. Since the map arrays may be confusing, one approach commonly employed by the climate research community is to provide cross hatching of various densities on maps representing climate ensemble outputs, which indicates the percentage of scenarios that agree on the direction of change.

A broader issue is that the proliferation of hotspots mapping risks overloading decision makers with either too much or conflicting information (e.g., Figure 2.15). Furthermore, where identified hotspots do not conform to decision makers' mental models, it is an open question as to whether decision makers will accept results. This brings us to the topic of maps as tools for decision making.

\subsubsection{Hotspots maps as tools for decision making}

One common assumption is that hotspots maps hold out the potential for more "transparent" and data driven decision making with regards to adaptation funding allocations, much as indicators are presumed to distill complex information in ways that are useful to decision making (Abson et al. 2012). A common assertion by map authors is that their results will be useful to policy audiences.

Yet hotspots efforts tend to be plagued by a lack of specificity regarding who precisely constitutes the "policy audience". While aid agency clients may indeed use the maps to identify priority areas for investments (see Table 2.2 in Annex for funders), it seems unlikely that national or local policy makers will take up the maps as planning tools. Many country level decision makers distrust global/regional mapping efforts because they don't understand/accept the methods, or question data inputs if they are not from their own national agencies. There is little direct evidence that the maps actually influence investments or adaptation activities, but Preston et al. (2011) suggest that maps may serve as boundary objects that facilitate discourse.

More broadly, there is a risk, should the maps actually influence decisions, that quantification gives decision-makers the false impression that the information is more "objective" (Preston et al. 2011). Yet the framing of issues and selection of indicators cannot be presented as purely the result of objective scientific criteria. By reifying vulnerability and resilience, and relying on proxies, other qualitative aspects such as culture, power relations, and local ecological knowledge can be overlooked or downplayed (Adger 2006, Kasperson et al. 2005). Seemingly innocent and value neutral, maps could play an important role in framing societal responses to climate change and its impacts in ways that are surely not neutral. 
With increased attention and funding being devoted to adaptation, there is now a financial incentive for countries to portray themselves as highly vulnerable to climate impacts (Klein 2009). Yet, should donors use hotspots maps to guide investments, there is a potential to reward countries with poor governance should they be identified as the most vulnerable. Conversely, there is a moral hazard that countries could suffer funding "triage" if they are deemed overly vulnerable to climate impacts. For example, many small island states are identified as hotspots of vulnerability to sea level rise (McGranahan et al. 2007a), yet Barnett and Adger (2003) argue that warnings of sea level rise might dissuade companies and donors from investments, and, if internalized by local people, might lead to unsustainable practices such that the impacts of climate change materialize more through the "idea" of climate change than through actual climate vulnerabilities. The role of hotspots maps in political discourse and guiding decisionmaking deserves more attention.

\subsubsection{Suggestions for future research}

Some have suggested an alternative "hot systems" approach, which consider perturbations to socio-economic and ecological systems in disparate geographic locations (Shen et al. 2010). Similar to "syndromes" (Lüdeke et al. 2004), this approach would identify system characteristics across locations as well as teleconnections owing to "expanding markets and flows of resources, people, information and power relations", with a focus on "particular combinations of events and conditions in geographically disparate systems [that] can lead to ... crises" (p.15). While more complex than simply mapping local processes, there is no fundamental reason why the results of such "hot systems" approaches cannot be mapped. For example, Lüdeke et al. map global change syndromes in much the same way that hotspots have been mapped (Figure 2.19), and Kok et al. adopted aspects of this approach in their hotspots map (Figure 2.11). This would add sophistication to current efforts by better reflecting direct and indirect drivers of change and realworld teleconnections, through trade, migration and other linkages.

There are a number of other potentially fruitful areas for further research. A useful next step in this research would be to take spatial outputs of essentially similar hotspots mapping efforts, and overlay them to see if results are broadly similar (e.g., Figure 2.15). Another area for further research would be to interview decision makers at aid agencies in government agencies concerning the impact that the maps had on resource allocation decisions. Finally, it would be interesting to use eye-tracking software and other cognitive research tools being applied in the field of data visualization to understand how the human brain processes the information contained on the maps with a goal of improving their communication efficacy (Montello and Freundschuh 2005). 


\subsection{Conclusion}

This paper reviews a number of global and regional hotspots mapping efforts, assessing data and methods, the hotspots identified, and their efficacy as tools for risk communication and decision-making. Efforts to date can largely be characterized as supply-driven academic exercises rather than responding to demands from the policy community. Yet in a world where human security is potentially imperiled by temperature increases of $>4^{\circ} \mathrm{C}$ ( New et al. 2011), and where "loss and damage" has become part of the UN Framework Convention on Climate Change lexicon, demand for hotspots maps will likely increase as decision makers seek to identify where impacts will be greatest and what adaptation measures, if any, are possible.

The fact that only one of the hotspots mapping studies referenced the PNAS vulnerability framework (i.e., Kok et al. 2010) suggests that this framework is either not widely known, or that it is considered too complicated to implement in a spatial framework. Specifically, few efforts move beyond future climate stressors to examine other potential perturbations to the complex system, such as economic or population changes or potential evolutions in trade relations, institutions and governance structures. This may reflect the fact that these evolutions are largely unknowable compared to climate changes, which themselves have a large element of uncertainty. ${ }^{14}$ The multiple and interacting aspects of the social and environmental systems are probably too complex to render in a quantitative framework; Kok et al., for example, introduce qualitative aspects into their mapping in order to account for them. And the cross-scale interactions are very difficult to capture.

\footnotetext{
14 If the fall of the Berlin wall in 1989 and the Arab Spring in 2011 caught political analysts off guard, and the collapse of the U.S. housing market that led to the financial crisis in 2008 was not anticipated by most market analysts, then it stands to reason that any effort to model the future states of complex human-environment systems in a given location will be seriously hampered by uncertainties, particularly in the social sub-system. Perhaps this is why political scientists content themselves with hand drawn maps illustrating possible future trends (Figures 2.20 and 2.21).
} 


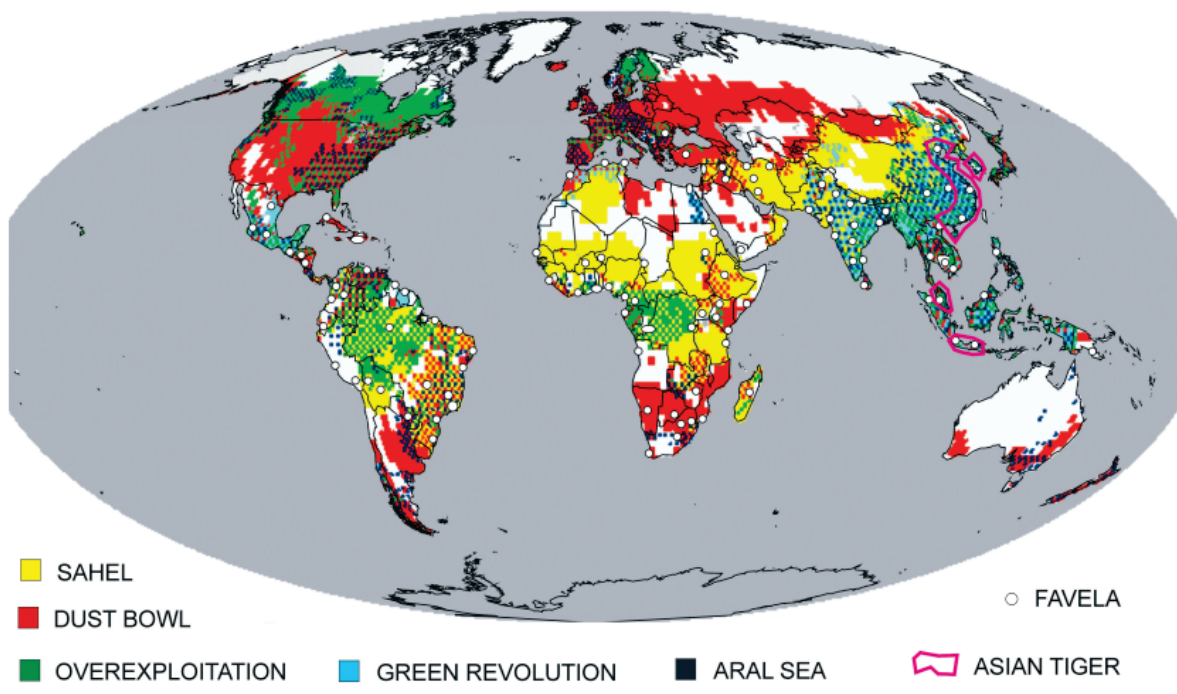

Figure 2. Global distribution of seven syndromes. Syndrome names are given in the legend. Simultaneous occurrence of more than one syndrome in a spatial map unit (2 degrees of latitude by 2 degrees of longitude) is symbolised by a chequered pattern combining the colours of the syndromes involved (the finest original resolution for a single syndrome is 0.5 by 0.5 degrees). The light grey land areas are either syndrome-free with respect to the seven investigated syndromes, or potential syndromes could not be identified because of significant gaps in data availability. While the indication of the Dust Bowl, the Green Revolution and the Asian Tiger Syndromes has global coverage, some gaps
exist for the other four syndromes due to absence of or unreliable data. This refers, for example, to all four syndromes with respect to Russia, exist for the other four syndromes due to absence of or unreliable data. This refers, for example, to all four syndromes with respect
to the Aral Sea and Sahel Syndromes in some regions of Africa and the Overexploitation Syndrome in parts of Central America.

Source: Lüdeke et al. 2004, Figure 2.

Figure 2.20: Global Distribution of Seven Syndromes of Global Environmental Change

Modeling efforts largely avoid theoretical frameworks altogether, or the frameworks and assumptions underlying the models are implicit, reflecting the physical science disciplinary training of their authors. The vulnerability hotspots efforts, on the other hand, mostly choose the simpler IPCC framework, which is contained within the overall PNAS framework. If creating models of dynamic and interacting human-environment systems is overly complicated, at least with the limited budgets and resources available to most hotspots mappers, then the utility of the PNAS framework would seem to be primarily in helping to identify key variables or questions to consider (see Kok et al. 2010:17-18) that might otherwise be overlooked (e.g., biophysical vulnerabilities or institutional factors), or in contextualizing the map outputs by providing a narrative concerning broader political, economic, historical or other considerations. We return to some of the issues of operationalization of the PNAS framework on Chapter 6. 


\section{Annex 2.1 Hotspots mapping based on expert opinion}

In this Annex I review a number of hotspots maps based on expert judgment, which use maps or spatial data to illustrate climate change impacts or to "tell a story".

Warner et al. (2009 and 2012a) represent a hybrid of expert judgment in the selection of hotspots and combinations of spatially explicit data for mapping. The maps in the report In Search of Shelter (Warner et al. 2009) highlight how climate impacts may adversely impact livelihoods, which in turn could precipitate human migration. They focus on several locations deemed to have high livelihood vulnerability and therefore susceptibility to increased migration, such as the semi-arid agricultural systems of the Sahel (Figure 2.18). The maps in the report Where the Rainfalls (Warner et al. 2012) complement field research in eight countries on rainfall variability and migration as a coping mechanism. The strength of these efforts is in their tailoring of representations of vulnerability to the specific regions of interest, acknowledging that the major issues facing each region will be different, and the use of well-designed maps to draw policymaker and media attention. A weakness is that it is not a systematic or quantitative assessment, and the regions identified as hotspots may not be the most important based on objective criteria. 


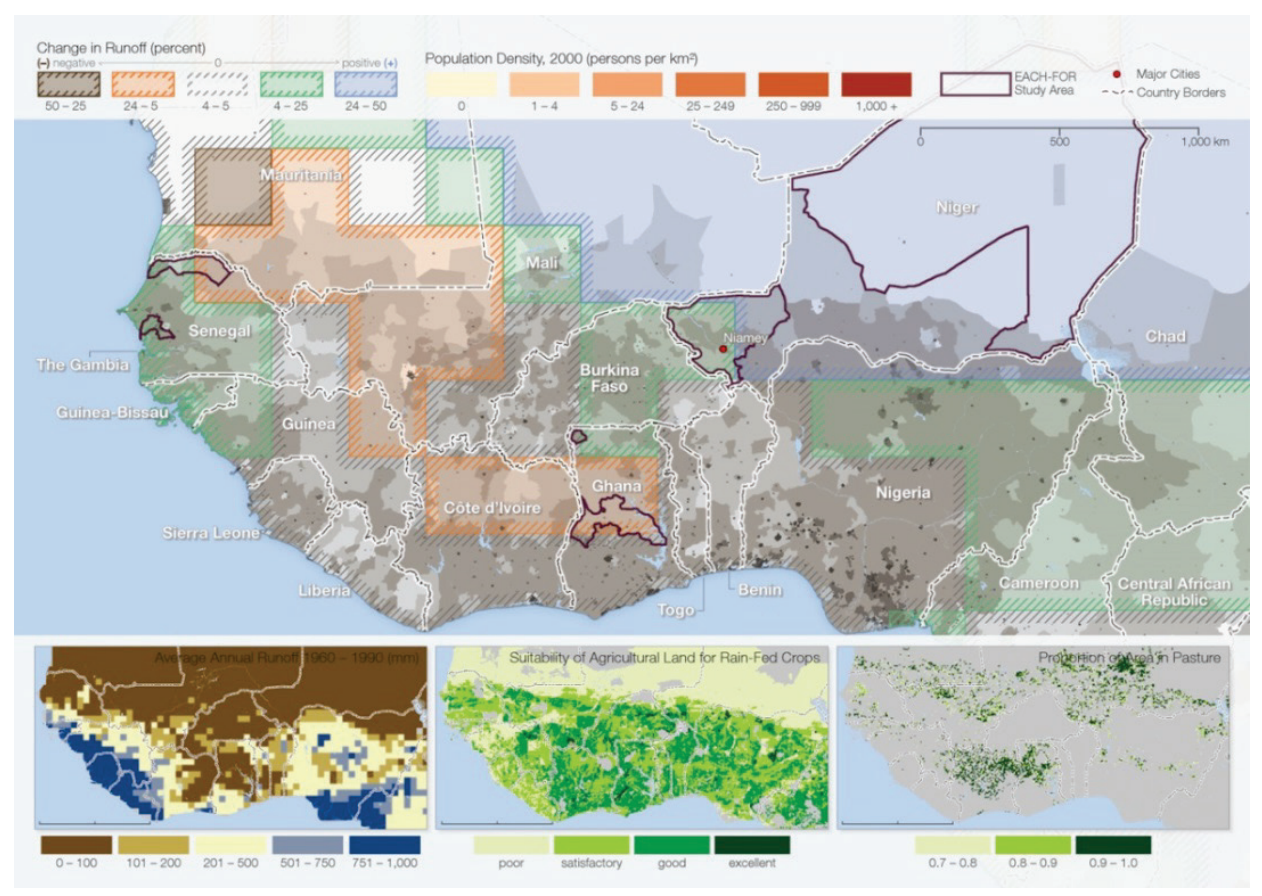

Source: Warner et al. 2009, p.6.

Figure 2.21: Rainfall runoff change and potential impacts on migration in the Sahel

In 2005 UNEP published a map depicting areas where climate impacts are likely to drive climate migration under the heading " 50 million climate refugees by 2010" (Figure 2.21). The map generated some controversy when The Wall Street Journal (WSJ 2011) pointed out that many areas predicted to be major sources of "climate refugees", such as coastlines, by 2010 were in fact areas of in-migration. Because they are based on expert judgment, such maps may be risky since they are assumed to be fabrications by climate skeptics. 


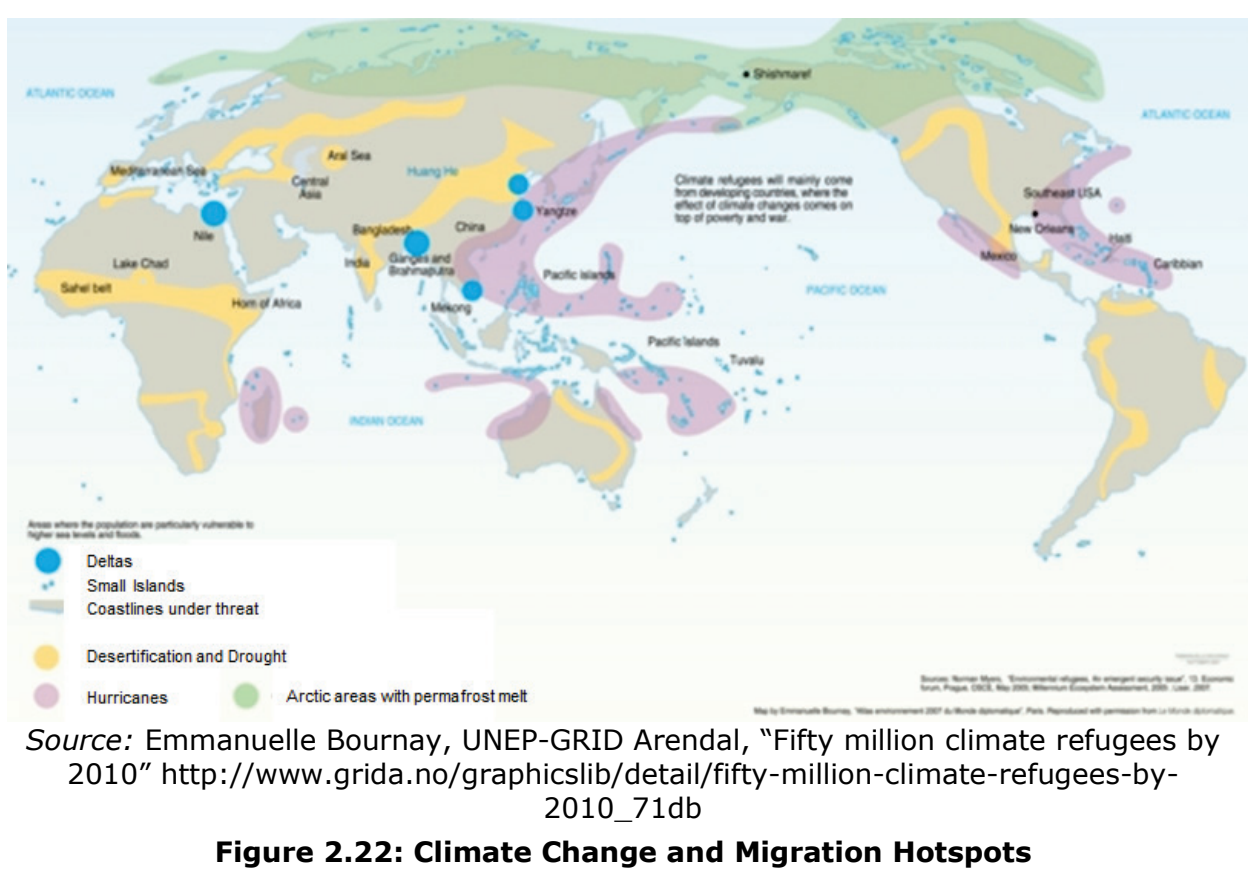

Expert judgment and "freehand" mapping has been widely used in climate security studies. For example, a report by Schubert et al. (2007) for the German Advisory Council on Global Change (WBGU) uses icons to identify regions at risk of water insecurity, declining food production, climate change increase in storm and flood disasters, and environment (Figure 2.22). The hotspots are schematically represented and provide a broad-brush, subjective assessment. According to the authors, the map "takes account of the social, political and economic conditions that determine the emergence of a conflict constellation in a given region; [it] summarizes the security risks arising from climate change for a set of regions selected as examples" (p.162).

Similarly, Scheffran and Battaglini (2011) identify climatic stressors that could result in conflict using a global map drawn in freehand to identify broad regions where climate change could result in security risks (Figure 2.23). Examples include droughts and general water scarcity (e.g., in the Mediterranean basin and western and central Asia), recurrent flooding (e.g., in coastal East Asia and parts of the Caribbean), loss of ecosystems and ecosystem services (e.g., across the arctic), extreme events (e.g., in Central America and Indonesia), and loss of coastal areas owing to SLR (e.g. in Oceania). Apart from illegibility and poor cartography, the map fulfills the purpose of distilling major issues. A weakness of both mapping efforts is the lack of underlying data and over-reliance on the authors' subjective assessments. 


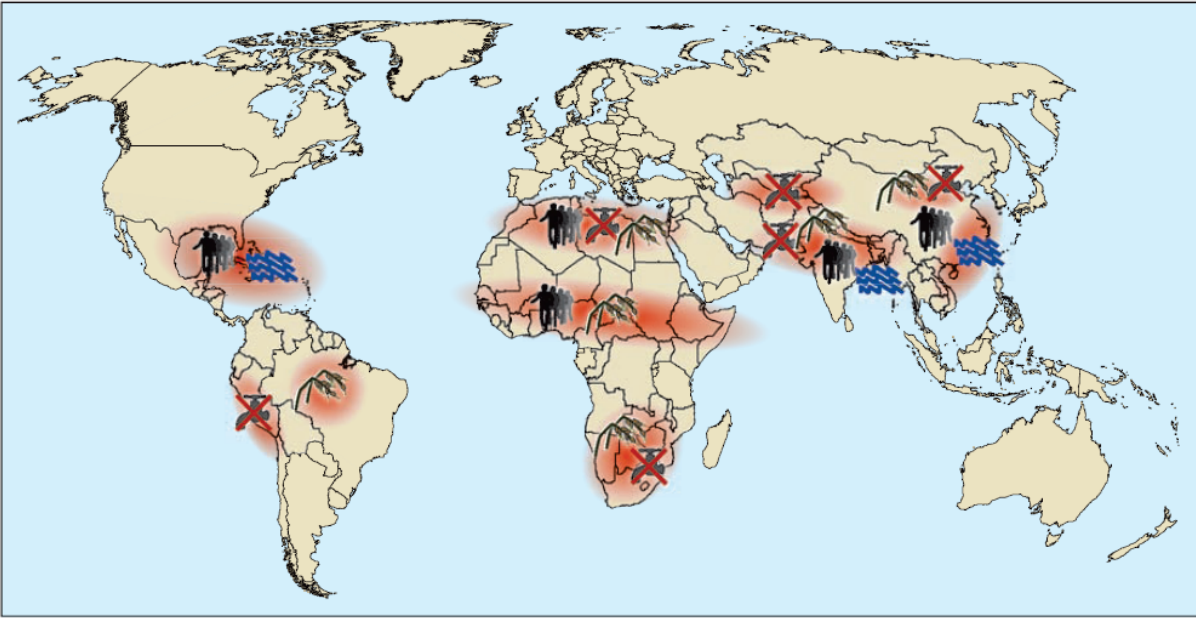

Conflict constellations in selected hotspots

Y. Climate-induced degradation

of freshwater resources

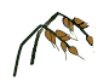

Climate-induced decline

in food production

Hotspot

Climate-induced increase

in storm and flood disasters

Environmentally-induced

migration

Source: Schubert et al. 2007, Figure 8.1-3

Figure 2.23: Security risks associated with climate change: Selected hotspots

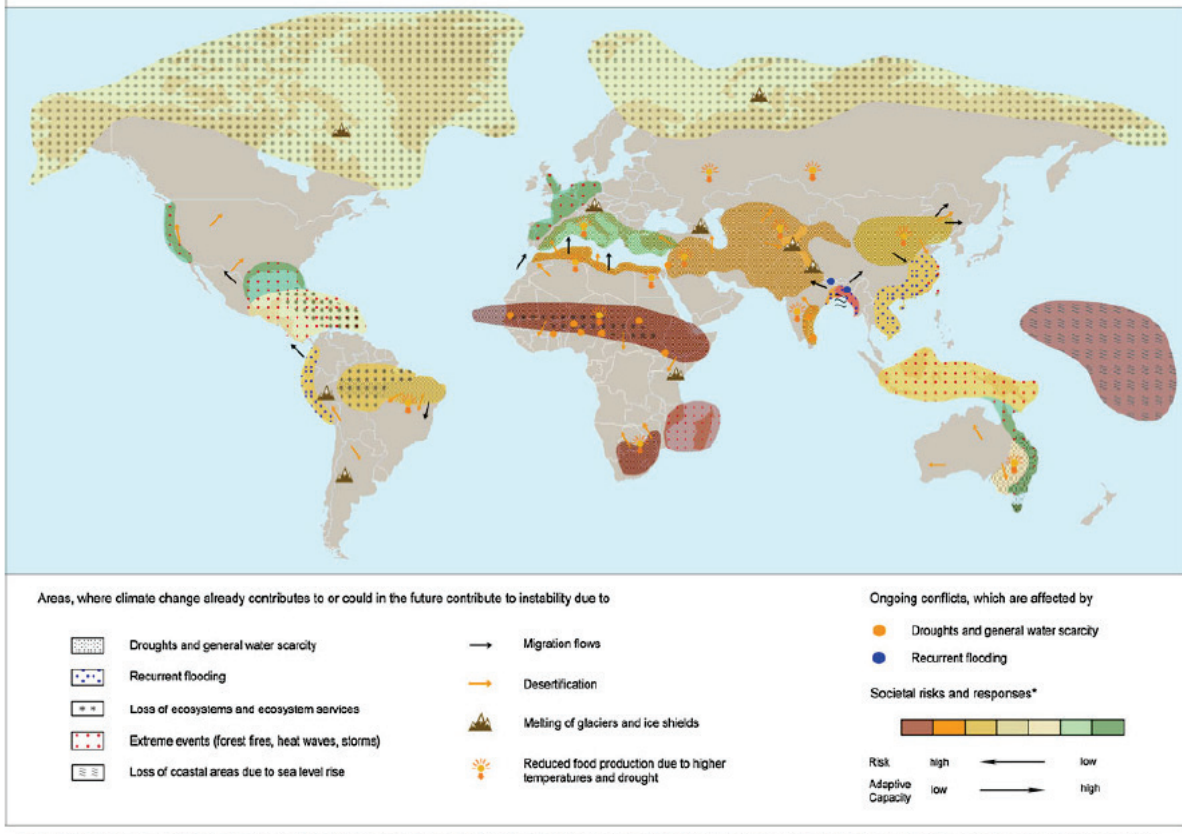

Source: Scheffran and Battaglini 2011, Figure 2.

Figure 2.24: Climate Change and Instability Hotspots 


\section{Annex 2.2 Summary table of global-scale hotspots mapping efforts}

Table 2.2: Summary table of global-scale climate change hotspots mapping efforts

\begin{tabular}{|c|c|c|c|c|c|}
\hline \multicolumn{2}{|l|}{ 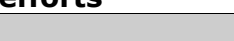 } & Giorgi 2006 & Baettig et al. 2007 & Samson et al. 2011 & McGranahan et al. 2007 \\
\hline \multicolumn{2}{|c|}{ Primary focus/foci } & $\begin{array}{l}\text { Climate change response } \\
\text { by region }\end{array}$ & $\begin{array}{l}\text { Increasing probabilities of } \\
\text { extreme warm/wet/dry } \\
\text { years }\end{array}$ & $\begin{array}{l}\text { Impacts on human } \\
\text { populations }\end{array}$ & Sea level rise \\
\hline \multicolumn{2}{|l|}{ Audience } & $\begin{array}{l}\text { Researchers (climate } \\
\text { scientists) }\end{array}$ & $\begin{array}{l}\text { Researchers and policy } \\
\text { makers }\end{array}$ & Researchers (ecologists) & Researchers (urban) \\
\hline \multicolumn{2}{|c|}{ Geographic scope } & Global & Global & Global & Coastal Areas \\
\hline \multicolumn{2}{|l|}{ Framework } & $\mathrm{n} / \mathrm{a}$ & $\mathrm{n} / \mathrm{a}$ & $\mathrm{n} / \mathrm{a}$ & $\begin{array}{l}\text { Focus on exposure and } \\
\text { sensitivity }\end{array}$ \\
\hline \multicolumn{2}{|l|}{ Methods } & $\begin{array}{l}\text { Multi-model ensembles for } \\
\text { several IPCC scenarios } \\
\text { were used to assess } \\
\text { changes in regional mean } \\
\text { precipitation, mean surface } \\
\text { air temperature, and in the } \\
\text { interannual variability in } \\
\text { precipitation and } \\
\text { temperature }\end{array}$ & $\begin{array}{l}\text { SRES scenarios for GCMS } \\
\text { were used to assess } \\
\text { changes in the probability of } \\
\text { warm, wet, and dry years, } \\
\text { and also by summer and } \\
\text { winter season }\end{array}$ & $\begin{array}{l}\text { Spatial representations of } \\
\text { population density and } \\
\text { climate are used together } \\
\text { with climate model } \\
\text { outputs, based on an } \\
\text { ecological niche model }\end{array}$ & $\begin{array}{l}\text { Overlay of coastal low elevation } \\
\text { band up to } 10 \mathrm{~m} \text { in elevation on } \\
\text { a population grid with urban } \\
\text { and rural identifiers }\end{array}$ \\
\hline \multicolumn{2}{|l|}{ Index } & $\begin{array}{l}\text { Regional Climate Change } \\
\text { Index (RCCI) }\end{array}$ & Climate Change Index (CCI) & $\begin{array}{l}\text { Climate-Demography } \\
\text { Vulnerability Index }\end{array}$ & None \\
\hline \multirow{6}{*}{$\begin{array}{l}\text { Regions } \\
\text { Identified }\end{array}$} & Africa & $\begin{array}{l}\text { North Africa (declines in } \\
\text { mean precipitation) }\end{array}$ & $\begin{array}{l}\text { All of sub-Saharan Africa, } \\
\text { coastal North Africa }\end{array}$ & Most regions & Alexandria \\
\hline & Asia & Northeastern Asia & $\begin{array}{l}\text { China, Southeast Asia, } \\
\text { Northeastern Asia }\end{array}$ & $\begin{array}{l}\text { Arabian Peninsula, } \\
\text { Southeast Asia }\end{array}$ & $\begin{array}{l}\text { Coastal cities including } \\
\text { Shanghai, Ho Chi Minh City }\end{array}$ \\
\hline & Europe & $\begin{array}{l}\text { Mediterranean (declines in } \\
\text { mean precip), North } \\
\text { Eastern Europe (increases } \\
\text { in winter precip and a } \\
\text { strong regional warming } \\
\text { relative to the global mean) }\end{array}$ & Spain, Italy, Arctic & None & Amsterdam, Hamburg, London \\
\hline & $\begin{array}{l}\text { Latin Am. \& } \\
\text { Caribbean }\end{array}$ & $\begin{array}{l}\text { Central America (decrease } \\
\text { in precip, increase in precip } \\
\text { variability) }\end{array}$ & Northern South America & $\begin{array}{l}\text { Central America, the } \\
\text { Amazon Basin }\end{array}$ & Buenos Aires, Rio De Janeiro \\
\hline & $\begin{array}{l}\text { North } \\
\text { America }\end{array}$ & $\begin{array}{l}\text { Northeastern quadrant } \\
\text { (Canada and US) }\end{array}$ & Arctic & None & Miami, New Orleans \\
\hline & Oceania & Not identified & None & Eastern Australia, SISes & Sydney, Melbourne \\
\hline \multicolumn{2}{|l|}{ Funder } & $\mathrm{N} / \mathrm{A}$ & $\begin{array}{l}\text { National Center of } \\
\text { Competence in Research, } \\
\text { Swiss NSF }\end{array}$ & $\begin{array}{l}\text { National Science and } \\
\text { Engineering Research } \\
\text { Council of Canada }\end{array}$ & $\begin{array}{l}\text { NASA Socioeconomic Data and } \\
\text { Applications Center }\end{array}$ \\
\hline
\end{tabular}


Table 2.2: Summary table of global-scale climate change hotspots mapping efforts (continued)

\begin{tabular}{|c|c|c|c|c|}
\hline \multirow{2}{*}{\multicolumn{2}{|c|}{ Primary focus/foci }} & $\begin{array}{l}\text { CARE \& Maplecroft and Thow \& } \\
\text { de Blois } 2008\end{array}$ & Erickson et al. 2011 & Fraser et al. 2012 \\
\hline & & Natural hazard vulnerability & Food production & $\begin{array}{l}\text { Soil moisture and agriculture as } \\
\text { it affects wheat and maize } \\
\text { productivity }\end{array}$ \\
\hline \multicolumn{2}{|c|}{ Target audience } & $\begin{array}{l}\text { Policymakers and humanitarian } \\
\text { actors }\end{array}$ & Agricultural research community & $\begin{array}{l}\text { Agricultural research } \\
\text { community }\end{array}$ \\
\hline \multicolumn{2}{|c|}{ Geographic scope } & The developing world & Tropical regions & Global \\
\hline \multicolumn{2}{|l|}{ Framework } & IPCC vulnerability framework & IPCC vulnerability framework & $n / a$ \\
\hline \multicolumn{2}{|l|}{ Methods } & & $\begin{array}{l}\text { Combination of climate scenario data, } \\
\text { important climate thresholds for } \\
\text { agriculture, data on natural resource } \\
\text { degradation, and indicators of food } \\
\text { availability, access, and utilization. }\end{array}$ & $\begin{array}{l}\text { Looks at change in growing } \\
\text { season soil moisture in relation } \\
\text { to adaptive capacity. Adaptive } \\
\text { capacity was modeled based on } \\
\text { socioeconomic variables that } \\
\text { have a high correlation with the } \\
\text { crop yield impacts of past } \\
\text { drought events. }\end{array}$ \\
\hline \multicolumn{2}{|l|}{ Index } & & $\begin{array}{l}\text { Maps are produced based on } \\
\text { combinations of high-low exposure, } \\
\text { sensitivity, and capacity }\end{array}$ & $n / a$ \\
\hline \multirow{6}{*}{$\begin{array}{l}\text { Regions } \\
\text { Identified }\end{array}$} & Africa & $\begin{array}{l}\text { Sahel, Horn, Central Africa, } \\
\text { Southern Africa }\end{array}$ & $\begin{array}{l}\text { Portions of the Sahel (rainfall variability) } \\
\text { and moist tropical West Africa and } \\
\text { Rwanda/Burundi (temperature } \\
\text { thresholds) }\end{array}$ & $\begin{array}{l}\text { Southern Africa (wheat and } \\
\text { maize) }\end{array}$ \\
\hline & Asia & $\begin{array}{l}\text { Central Asia, Afghanistan and } \\
\text { Pakistan, Myanmar, Mongolia, } \\
\text { Borneo }\end{array}$ & $\begin{array}{l}\text { Most of India (especially for rainfall } \\
\text { variability but also temperature } \\
\text { thresholds) }\end{array}$ & Western China (wheat) \\
\hline & Europe & & & Balkans (wheat and maize) \\
\hline & $\begin{array}{l}\text { Latin Am. } \\
\text { \& } \\
\text { Caribbean }\end{array}$ & $\begin{array}{l}\text { Andes, Northern Mexico, } \\
\text { Argentina }\end{array}$ & None & $\begin{array}{l}\text { Southern cone (wheat and } \\
\text { maize) }\end{array}$ \\
\hline & $\begin{array}{l}\text { North } \\
\text { America }\end{array}$ & & & U.S. great plains (wheat) \\
\hline & Oceania & & & None \\
\hline \multicolumn{2}{|l|}{ Funder } & $\begin{array}{l}\text { UN Office for the Coordination of } \\
\text { Humanitarian Affairs and CARE }\end{array}$ & $\begin{array}{l}\text { Consultative Group for International } \\
\text { Agricultural Research (CGIAR) with } \\
\text { funding from aid agencies }\end{array}$ & $\begin{array}{l}\text { UK National Environment } \\
\text { Research Council (NERC) }\end{array}$ \\
\hline
\end{tabular}


Table 2.2: Summary table of global-scale climate change hotspots mapping efforts (continued)

\begin{tabular}{|c|c|c|c|c|}
\hline \multicolumn{2}{|c|}{ (1) } & Kok et al. 2011 & Parish et al. 2011 & Döll 2009 \\
\hline \multicolumn{2}{|c|}{ Primary focus/foci } & $\begin{array}{l}\text { Vulnerability profiles based on } \\
\text { resource endowments, water, soil, and } \\
\text { development status }\end{array}$ & Water resources & Renewable groundwater resources \\
\hline \multicolumn{2}{|c|}{ Target audience } & Researchers (integrated assessment) & Researchers & Researchers \\
\hline \multicolumn{2}{|c|}{ Geographic scope } & Global & Global & Global \\
\hline \multicolumn{2}{|c|}{ Framework } & PNAS vulnerability framework & Unclear & Unclear \\
\hline \multicolumn{2}{|l|}{ Methods } & \begin{tabular}{|l|} 
Integrated assessment models, \\
geospatial data, and cluster analysis
\end{tabular} & GCMs coupled to hydrological models & $\begin{array}{l}\text { GCMs coupled to the WaterGap } \\
\text { hydrological model }\end{array}$ \\
\hline \multicolumn{2}{|l|}{ Index } & N/A & Water stress & $\begin{array}{l}\text { Vulnerability index (human } \\
\text { vulnerability to climate change } \\
\text { induced changes in freshwater } \\
\text { supply) }\end{array}$ \\
\hline \multirow{6}{*}{$\begin{array}{l}\text { Regions } \\
\text { Identified }\end{array}$} & Africa & $\begin{array}{l}\text { Extreme poverty in Sahel and Horn of } \\
\text { Africa }\end{array}$ & $\begin{array}{l}\text { North Africa (most scenarios), with } \\
\text { isolated spots in SS Africa }\end{array}$ & $\begin{array}{l}\text { North Africa, extreme western Africa } \\
\text { (Mauritania/Senegal), southwestern } \\
\text { Africa (Angola, Namibia, western } \\
\text { South Africa) }\end{array}$ \\
\hline & Asia & $\begin{array}{l}\text { Extreme poverty in Afghanistan; } \\
\text { Moderate to Extreme poverty in NW } \\
\text { China; Extreme overuse in Pakistan } \\
\text { and Western India, and in NE China }\end{array}$ & Eastern China (A2 scenario) & $\begin{array}{l}\text { Portions of Central Asia (the } \\
\text { "stans") and western China }\end{array}$ \\
\hline & Europe & None & None & Parts of southern Europe \\
\hline & Latin Am. \& Caribbean & Moderate poverty Andes & $\begin{array}{l}\text { Central America, Northeastern Brazil } \\
\text { (under A2 scenario) }\end{array}$ & $\begin{array}{l}\text { Northeastern Brazil, coastal Peru } \\
\text { and Chile }\end{array}$ \\
\hline & North America & $\begin{array}{l}\text { Marginal lands in West and Southwest } \\
\text { u.s. }\end{array}$ & West of the Great Lakes & $\begin{array}{l}\text { Ogalala aquifer in western Texas (in } \\
\text { two scenarios) }\end{array}$ \\
\hline & Oceania & $\begin{array}{l}\text { Marginal lands in West and Southwest } \\
\text { U.S., Marginal lands in Australia }\end{array}$ & None & $\begin{array}{l}\text { Western Australia (in most } \\
\text { scenarios) }\end{array}$ \\
\hline \multicolumn{2}{|l|}{ Funder } & $\begin{array}{l}\text { Netherlands Environmental } \\
\text { Assessment Agency (PBL) }\end{array}$ & $\begin{array}{l}\text { Oak Ridge National Laboratory, U.S. } \\
\text { Dept of Energy }\end{array}$ & Not listed \\
\hline
\end{tabular}

\subsection{References}

Abson, D.J., A.J. Dougill, and L.C. Stringer. 2012. Using Principal Component Analysis for information-rich socio-ecological vulnerability mapping in Southern Africa. Applied Geography, 35, 515-524.

Adamo, S.B., and A. de Sherbinin. 2011. "The Impact of Climate Change on the Spatial Distribution of Populations and Migration." Chapter in: Proceedings of the Expert Group Meeting on Migration, New York: UN Population Division.

Adger, N. 2006. Vulnerability. Global Environmental Change, 16:268-281.

Baettig, M.B., M. Wild, and D.M. Imboden. 2007. A climate change index: Where climate change may be most prominent in the 21st century. Geophysical Research Letters, 34, L01705

Barnett, J., S. Lambert, and I. Fry. 2008. The hazards of indicators: insights from the Environmental Vulnerability Index. Annals of the Association of American Geographers, 98(1):102-119.

Birkmann, J., D. Krause, N. Stiadi, D. Suarez, T. Welle, J. Wolfertz. 2011. World Risk Report. Bonn, Germany: UNU and IEHS.

Black, R., S.R.G. Bennett, S.M. Thomas, and J.R. Beddington. 2011. Migration as Adaptation. Nature, 478: 447-449. 
Busby, J.W., T.G. Smith, and K.L. White. 2011. Locating Climate Insecurity: Where are the most vulnerable places in Africa? Climate Change and African Political Stability Program Policy Brief No. 3.

CARE and Maplecroft. 2008. Humanitarian implications of climate change: Mapping emerging trends and risk hotspots. Geneva, Switzerland: CARE International.

Carney, D. 1998. Implementing the Sustainable Rural Livelihoods Approach. London, UK: Overseas Development Institute.

DARA. 2010. Climate Vulnerability Monitor 2010: The State of the Climate Crisis. Climate Vulnerable Forum.

Davies, R.A.G., and S.J.E. Midgley. 2010. Risk and Vulnerability Mapping in Southern Africa: A Hotspots Analysis. Cape Town, South Africa: OneWorld Sustainable Investments (Pty) Ltd.

de Sherbinin, A., K. Warner, and C. Ehrhart. 2011. Casualties of Climate Change, Scientific American, January 2011: 64-71.

De Stefano, L., J. Duncan, S. Dinar, K. Stahl, K. Strzepek, and A.T. Wolf. 2010. Mapping the Resilience of International River Basins to Future Climate Change-Induced Water Variability. Water Sector Board Discussion Paper Series No. 15. Washington DC: The World Bank.

Diffenbaugh, N. S., F. Giorgi, and J. S. Pal. 2008. Climate change hotspots in the United States, Geophysical Research Letters, 35, L16709.

Dilley, M., R.C. Chen, U. Deichmann, A. Lerner-Lam, and M. Arnold. 2005. Natural Disaster Hotspots. Washington, DC: World Bank.

Döll, P. 2009. Vulnerability to the impact of climate change on renewable groundwater resources. Environmental Research Letters, 4:035006. doi: $10.1088 / 1748-9326 / 4 / 3 / 035006$

Dransch, D., H. Rotzoll, and K. Poser. 2010. The contribution of maps to the challenges of risk communication to the public. International Journal of Digital Earth, 3(3):292-311. doi:10.1080/17538941003774668

Ericksen, P., P. Thornton, A. Notenbaert, L. Cramer, P. Jones, M. Herrero. 2011. Mapping hotspots of climate change and food insecurity in the global tropics. CCAFS Report no. 5. CGIAR Research Program on Climate Change, Agriculture and Food Security (CCAFS). Copenhagen, Denmark.

ESPON Climate. 2011. Climate Change and Territorial Effects on Regions and Local Economies. Applied Research 2013/1/4. Final Report, Version $31 / 5 / 2011$.

Fraser, E.D.G., E. Simelton, M. Termansen, S.N. Gosling, and A. South. 2012. "Vulnerability hotspots": Integrating socio-economic and hydrological models to identify where cereal production may decline in the future due to climate change induced drought. Agricultural and Forest Meteorology, in press. 
Füssel, H.-M. 2007. Vulnerability: A Generally Applicable Conceptual Framework for Climate Change Research. Global Environmental Change, 17:155-167.

Giorgi, F. 2006. Climate change hot-spots, Geophysical Research Letters, 33, L08707, doi:10.1029/2006GL025734.

Hagenlocher, M., S. Lang, D. Holbling, D. Tiede, and S. Kienberger. 2013. Modeling Hotspots of Climate Change in the Sahel Using Object-Based Regionalization of Multidimensional Gridded Datasets. IEEE Journal of Selected Topics in Applied Earth Observations and Remote Sensing. 7(1):229-234.

IPCC (Intergovernmental Panel on Climate Change). 2012. Managing the Risks of Extreme Events and Disasters to Advance Climate Change Adaptation. Field, C.B., et al. (eds.). Cambridge University Press, Cambridge, UK, and New York, NY, USA, 582 pp.

Kasperson R.E., K. Dow, E. Archer, D. Caceres, T. Downing, et. al. 2005. Vulnerable People and Places. Chapter 6 in: Millennium Ecosystem Assessment. Washington, DC: Island Press.

Klein, R.T. 2009. Identifying countries that are particularly vulnerable to the adverse effects of climate change: an academic or a political challenge? Carbon and Climate Law Review, 3:284-291

Kok, M.T.J., M.K.B. Lüdeke, T. Sterzel, P.L. Lucas, C. Walter, P. Janssen and I. de Soysa. 2010. Quantitative analysis of patterns of vulnerability to global environmental change. Den Haag/Bilthoven, Netherlands: Netherlands Environmental Assessment Agency (PBL).

Liu, J., S. Fritz, C.F.A. van Wesenbeeck, M. Fuchs, L. You, M. Obersteiner, H. Yang. 2008. A spatially explicit assessment of current and future hotspots of hunger in Sub-Saharan Africa in the context of global change. Global and Planetary Change, 64 (2008): 222-235.

Lüdeke, M.K.B., G. Petschel-Held, H.J. Schellnhuber. 2004. Syndromes of Global Change: The First Panoramic View. GAIA - Ecological Perspectives for Science and Society, 13(1):42-49.

McGranahan, G., D. Balk and B. Anderson. 2007a. The rising tide: assessing the risks of climate change and human settlements in low elevation coastal zones. Environment \& Urbanization, 19(1): 17-37.

McGranahan, G., D. Balk, and B. Anderson. 2007b. Low Elevation Coastal Zone (LECZ) Urban-Rural Population Estimates. Palisades, NY: NASA Socioeconomic Data and Applications Center. http://sedac.ciesin.columbia.edu/data/set/lecz-low-elevation-coastalzone

Midgley, S.J.E., R.A.G. Davies, and S. Chesterman. 2011. Climate Risk and Vulnerability Mapping: Status quo (2008) and future (2050). Report produced for the Regional Climate Change Programme for Southern Africa (RCCP), UK Department for International Development (DFID). 
Montello, D.R., and S. Freundschuh. 2005. "Cognition of Geographic Information". In: R.B. Mc.Master and E.L. Usery (eds.), A Research Agenda for Geographic Information Science. Boca Raton FL: CRC Press.

Myers, N. 1990. Threatened Biotas: Expanded Hot-Spots Analysis, The Environmentalist 10:243-256.

New, M., D. Liverman, H. Schroder, and K. Anderson. 2011. Introduction. Four degrees and beyond: the potential for a global temperature increase of four degrees and its implications. Philosophical Transactions of the Royal Society A 369:6-19.

Parry, M.L., O.F. Canziani, J.P. Palutikof, P.J. van der Linden and C.E. Hanson (eds). 2007. Climate Change 2007: Impacts, Adaptation and Vulnerability. Cambridge, UK: Cambridge University Press.

Parish, E.S., E. Kodra, K. Steinhauser, and A.R. Ganguly. 2012. Estimating future global per capita water availability based on changes in climate and population. Computers \& Geosciences, 42: 79-86.

Piontek, F., C. Müller, T.A.M. Pugh, et al. 2013. Multisectoral climate impacts in a warming world. Proceedings of the National Academy of Sciences. doi: $10.1073 /$ pnas.1222471110

Preston, B., E.J. Yuen, and R.M. Westaway. 2011. Putting vulnerability to climate change on the map: a review of approaches, benefits, and risks. Sustainability Science, 6:177-202.

Samson, J., D. Berteaux, B.J. McGill and M.M. Humphries. 2011. Geographic disparities and moral hazards in the predicted impacts of climate change on human populations. Global Ecology and Biogeography, doi: $10.1111 /$ j.1466-8238.2010.00632.x

Scheffran, J., and A. Battaglini. 2011. Climate and conflicts: the security risks of global warming. Regional Environmental Change, 11(Suppl 1):S27S39. doi:10.1007/s10113-010-0175-8

Schröter, D., W. Cramer, R. Leemans, et al.. 2005. Ecosystem Service Supply and Vulnerability to Global Change in Europe. Science, 310:1333-1337.

Schubert, R., H.J. Schellnhuber, N. Buchmann, A. Epiney, R. Grießhammer, M. Kulessa, D. Messner, S. Rahmstorf, and J. Schmid. 2007. Climate Change as a Security Risk. London: Earthscan and German Advisory Council on Global Change (WBGU).

Shen, X., T.E. Downing and M. Hamza (eds). 2010. Tipping Points in Humanitarian Crisis: From Hot Spots to Hot Systems. Studies of the University: Research, Counsel, Education (SOURCE) Publication Series of UNU-EHS, No. 13/2010.

Thornton, PK, PG Jones, T Owiyo, RL Kruska, M Herrero, V Orindi, S Bhadwal, P Kristjanson, A Notenbaert, N Bekele and A Omolo. 2008. Climate change and poverty in Africa: Mapping hotspots of vulnerability. AfJARE, $2(1)$ March 2008.

Thow, A., and M. de Blois. 2008. Climate change and human vulnerability: Mapping emerging trends and risk hotspots for humanitarian actors. 
Bath, UK and Geneva, Switzerland: Maplecroft, and CARE International.

Torres, R.R., D.M. Lapola, J.A. Marengo, M.A. Lombardo. 2012. Socio-climatic hotspots in Brazil. Climatic Change, 115:597-609.

UK Meteorological Office. 2009. The Impact of Global Temperature Rise above $4^{\circ} \mathrm{C}$. Accessed at http://www.metoffice.gov.uk/climatechange/guide/impacts/high-end/map on 15 April 2013.

UNISDR. 2009. Global Assessment Report on Disaster Risk Reduction. Geneva: United Nations.

Warner, K., T. Afifi, K. Henry, T. Rawe, C. Smith, and A. de Sherbinin. 2012. Where the rain falls : climate change, food and livelihood security, and migration. Bonn, Germany: UNU and CARE.

Warner, K., C. Erhart, A. de Sherbinin, S.B. Adamo, T.Chai-Onn. 2009. In search of Shelter: Mapping the effects of climate change on human migration and displacement. Bonn, Germany: UNU.

Wheeler, D. 2011. "Quantifying Vulnerability to Climate Change: Implications for Adaptation Assistance." Center for Global Development Working Paper 240, January 2011.

WSJ (Wall Street Journal). 2011. Climate Refugees, Not Found: Discredited by reality, the U.N.'s prophecies go missing. Wall Street Journal, 21 April 2011.

Yohe, G., E. Malone, A. Brenkert, M. Schlesinger, H. Meij, X. Xing, and D. Lee. 2006. Global Distributions of Vulnerability to Climate Change. The Integrated Assessment Journal, 6(3): 35-44.

Yusuf, A.A., and H. Francisco. 2009. Climate Change Vulnerability Mapping for Southeast Asia. Singapore: EEPSEA. 


\section{Chapter 3}

\section{The vulnerability of global cities to climate hazards $^{15}$}

15 This chapter was originally published as de Sherbinin, A., A. Schiller, and A. Pulsipher. 2007. The Vulnerability of Global Cities to Climate Hazards. Environment \& Urbanization, 19(1): 39-64, by SAGE Publications Ltd, All rights reserved. ( ) SAGE Publications Ltd. For more information please visit: http://eandu.sagepub.com. It has been revised and updated for the thesis. 


\subsection{Introduction}

Global cities are engines of economic growth and centers of innovation for the global economy and the hinterlands of their respective nations. The foundations of prosperity and prominence for most global cities lie in their long-standing commercial relationships with the rest of the world. Most global cities are located on or near the coast, which has facilitated trade and contributed to their wealth. They are also often located in low-lying areas near the mouths of major rivers, which served as conduits for commerce between interior agricultural and industrial regions and the rest of the world. As it happens, these locations place global cities at greater risk from current and projected climate hazards such as cyclones, high winds, flooding, coastal erosion and deposition, and sea-level rise (Nicholls 1995, Rosenzweig and Solecki 2001).

Global cities are also important centers of population concentration and growth. According to Brockerhoff (2000), just 25 years ago less than $2 \%$ of the global population resided in "megacities" of 10 million or more inhabitants. Today the proportion exceeds $4 \%$, and by 2015 it will top $5 \%$, when megacities will likely house 400 million people. The phenomenal growth rates that most low-income country megacities experienced from the $1960 \mathrm{~s}$ to the 1980 s have now somewhat tapered off, but because lower rates are being applied to higher population bases, the absolute numbers being added to their populations are still high. The fact that so many people reside in megacities near coastlines, and that these cities continue to grow, underscores the importance of assessing the vulnerability of such cities to coastal climate hazards.

Recent incidents have highlighted the vulnerability of urban areas in general to climate hazards. Hurricane Katrina in August 2005 effectively obliterated much of the Gulf Coast of Mississippi and flooded large portions of New Orleans, resulting in the evacuation of all residents and more than 1,000 deaths. The flooding was greatest in African-American neighborhoods (CIESIN 2005), and in the aftermath there were widespread accusations that the slow and ineffectual government response reflected a racial bias (Dyson 2006). In July 2005, Mumbai, India, was struck by a cyclone that dumped 94 centimeters of rain in 24 hours, also leaving more than 1,000 dead, mostly in slum settlements. In October 2012, Hurricane Sandy struck New York, leaving fewer casualties but resulting in an estimated $\$ 50-\$ 75$ billion in damages owing to an unprecedented storm surge.

Researchers at the Centre for Research on the Epidemiology of Disasters (CRED) have tracked an increase in almost all disasters, with the time trends for climate-related disasters, including floods, windstorms and droughts, 
showing the greatest increase, well above all geological hazards (CRED 2005) (see Chapter 5, Figure 5.1). There are two factors behind this rise in climaterelated disasters. One is regional increases in the severity and periodicity of hazard events (Easterling et al. 2000). For example, in the Atlantic and Pacific cyclone-generating areas, increased sea surface temperatures associated with global warming are responsible for an increase in the intensity and duration of tropical storms (although not necessarily an increase in their frequency) (Santer et al. 2006). The second factor - alluded to above - is the large and growing proportion of the world's population that is living in cities and towns near the coast (de Sherbinin et al. 2012), and which consequently is exposed to these hazards. Research by McGranahan et al. (2007) finds that more than 600 million people (or $10 \%$ of the global population) reside in coastal zones of less than $10 \mathrm{~m}$ elevation, and that $13 \%$ of them, or 77 million people, reside in megacities. This combination of increased hazards and exposure results in greater numbers of disasters that claim lives and cause major economic losses.

In the past decade climate policy has seen a steady evolution from an almost exclusive emphasis on mitigation to an increasing attention to adaptation. This is due in equal measure to the significant political and economic challenge of agreeing to and implementing greenhouse gas emissions reductions, and to the reality that the impacts of climate change are already being felt in many regions. Among other elements, risk assessment and disaster risk reduction plans are vital components of an adaptation strategy (e.g., Dickson et al. 2012, World Bank 2010). But to design these, we need a better understanding of which people and systems are vulnerable to what kind of climate hazards; also what makes them vulnerable, and where they are located.

This chapter applies the PNAS framework and the broad conceptual understanding of vulnerability presented in Chapter 1, Section 1.2. Some further considerations of this framework are briefly outlined in Section 3.2. In Section 3.3 I review the literature on urban spatial vulnerability assessment. In Section 3.4, we then apply the framework to an examination of three cities that are particularly vulnerable to multiple climate-related hazards: Mumbai (formerly Bombay) in India, Rio de Janeiro in Brazil, and Shanghai in China (Figure 3.1). Conclusions from this research are provided in Section 3.5. 

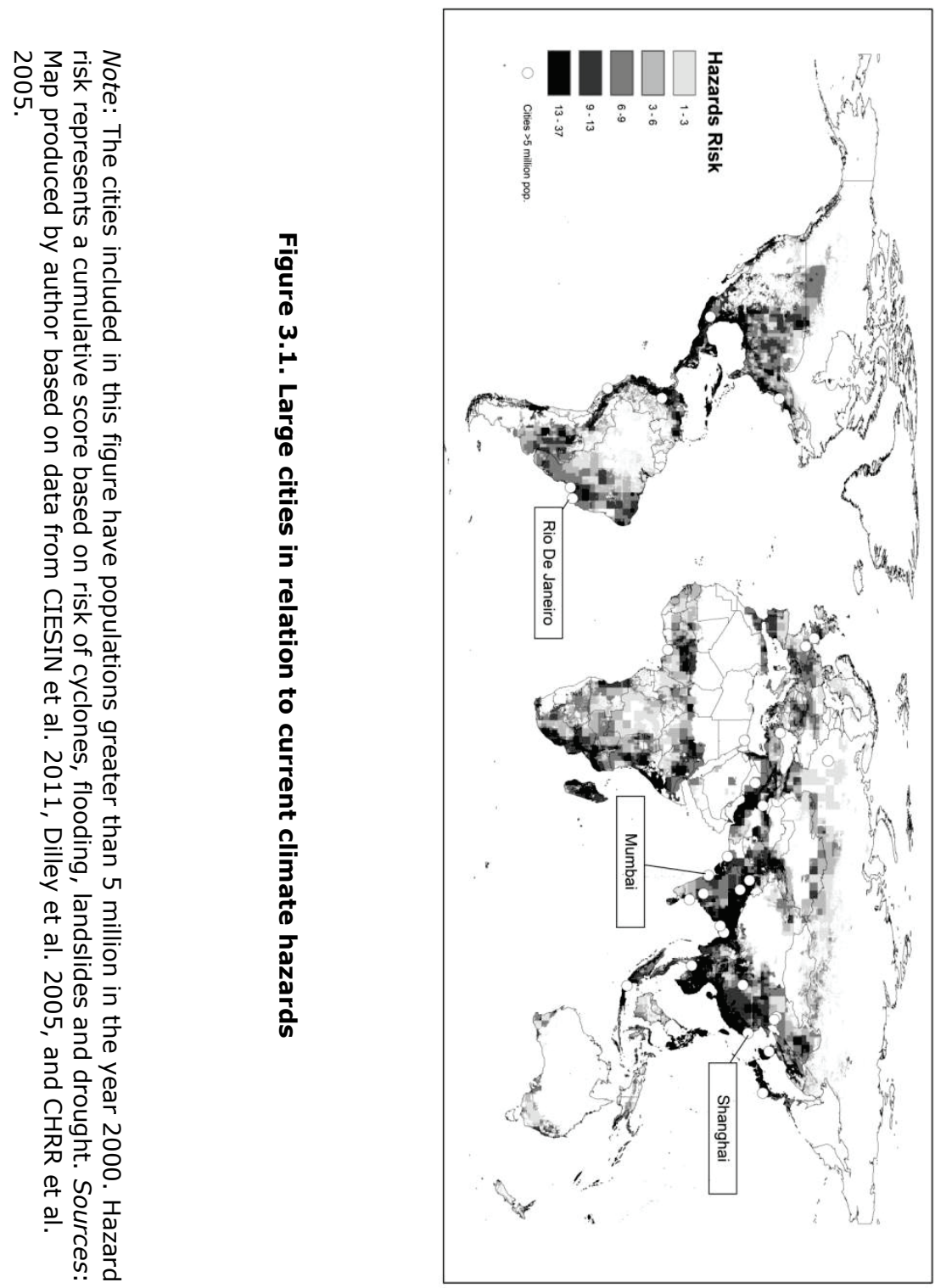

\subsection{Framing Vulnerability}

The concept of vulnerability originated in research communities examining risks and hazards, on the one hand, and entitlements, on the other (Adger 2006). The vulnerability concept emerged from the recognition by these research communities that a focus on perturbations alone (environmental, socioeconomic, technological) was insufficient for understanding the 
responses of, and impacts on, systems (social groups, ecosystems, places) exposed to such perturbations (Wisner et al. 2004, Liverman 1990). The vulnerability concept has been applied to cities by several authors, including Mitchell (1999), Pelling (2003), and Sanderson (2000). Multiple definitions and methods for measuring vulnerability have also been developed (e.g., Eakin and Luers 2006, SOPAC and UNEP 2005, Wisner et al. 2004).

In this chapter, the PNAS framework (Turner et al. 2003) is applied to better understand the vulnerabilities of three megacities to hazards resulting from climate change and variability. The framework addresses the vulnerability of interacting human-environment systems to multiple and synergistic stresses that emanate from within as well as from outside the system. Within this extended vulnerability framework, there is formal recognition that macroforces - broad-scale environmental and human systems within which the local system resides - come together to affect the local system and, simultaneously, influence the pressures that act upon it. Different pressures across scales come together in various sequences to create unique "bundles" of stress that affect local systems. A major hypothesis holds that when stresses or perturbations emanating from the environment coalesce with those arising from society, significant consequences can result. For example, economic depression reduces society's capability to develop or maintain preemptive coping measures to reduce the impacts of drought, such that the cooccurrence of drought and economic depression synergistically enlarges the vulnerability of the system. The risks resulting from such vulnerabilities emerge from multiple sources, and at different scales. These risks cascade through interacting human and environmental systems to create adverse consequences.

The framework proved useful in this work because it provides new insights into vulnerabilities because it considers multiple, synergistic stresses and perturbations on one side of the equation, and multiple, synergistic physical and social characteristics of the exposed system on the other. This enables us to conduct a "gap analysis" that identifies areas of exposure and vulnerability, and points to areas of greatest need for strengthened adaptive capacity and risk management.

\subsection{Spatial Approaches to Urban Climate Vulnerability Assessment}

This section provides a brief overview on spatial approaches for urban climate vulnerability assessment (VA). This is a large topic, worthy of a dissertation in its own right, so this is only intended to be a brief review of the literature.

It should be stated that urban-scale climate adaptation researchers tend to employ impact or risk assessment more often than vulnerability assessment 
(see Chapter 1, Section 1.3, and Chapter 6, Section 6.2 for definitions) (Rosenzweig et al. 2011a, Preston et al. 2007). This probably has to do with the desire on the part of local decision makers for data on the infrastructure at risk from extreme events of various magnitudes, the potential economic losses from those events, and the costs of mitigation activities. The largest proportion of this literature focuses on flood and storm surge risk (UNHABITAT 2013, Jha et al. 2012, Storch et al. 2011, Kit et al. 2011, Rosenzweig et al. 2011b, Hallegate et al. 2010, Lin et al. 2010, Nicholls et al. 2008, Kleinen and Petschel-Held 2007), though populations at risk to heat waves (Wilhelmi et al. 2004, Kinney et al. 2000) and drought (and attendant water scarcity) (McDonald et al. 2011) are also addressed in some risk assessments. That said, research on differential vulnerability to climate hazards in urban contexts is growing rapidly since the early work of the late 1990s and early 2000s (Romero-Lankao and Qin 2010, Pelling 2002, Pelling 1998).

Curtis et al. (2007) use census and public health data to explore the geography and characteristics of poverty in New Orleans prior to Hurricane Katrina, and the way in which the location and situations in which people live contribute to outcomes. They find that flood risk affected comparably well off and poorer communities almost equally, but that lower income communities lacked transportation options to evacuate. The most vulnerable residents were African Americans with pre-existing health conditions or children living at home, and with no personal vehicle. They conclude that vulnerability is spatially and socially complex, and that it is not sufficient to merely "map poverty."

Many urban-scale vulnerability assessments create social vulnerability indices, often modeled on the "SoVI" developed by Cutter et al. (2003). For example, de Sherbinin and Bardy (in prep.) created SoVIs using census data for New York and Mumbai, finding higher SoVI scores (higher vulnerability) in flood zones than in non-flood prone areas. Rygel et al. (2009) construct a SoVI for the city of Norfolk, Virginia (USA), and surrounding areas, experimenting with alternative aggregation methods, though they do not include hazard exposure. Moving beyond census-derived indicators, Ebert et al. (2009) tested the utility of lidar, optical satellite and GIS data to derive information on social vulnerability in Tegucigalpa, Honduras, by using physical proxy variables to describe aspects of social vulnerability. They argue that these data are more regularly updated than census data and can capture many of the same dimensions of vulnerability, as well as the exposure dimension such as steep slopes prone to landslides. There is a far broader literature on poverty and slum mapping in developing country urban areas (e.g., de Sherbinin et al. 2009, Sliuzas et al. 2008, Baud et al. 2008) that is beyond the scope of this brief review. 
Romero-Lankao et al. (2013) tested the hypothesis that there is a differential vulnerability to the health impacts of air pollution and temperature in three cities, Bogota, Mexico City, and Santiago (Chile). They analyzed temperature, air pollution, mortality and socioeconomic vulnerability data from the three study cities and found little evidence that areas experiencing greater environmental stressors or health impacts were more likely to have populations with high socioeconomic vulnerability. By contrast, assessment of differential vulnerability to urban heat stress by Uejio et al. (2011) in Phoenix and Philadelphia found that heat distress calls in the former and heat mortality in the latter were correlated with higher proportions of minority residents and lower housing values.

A range of vulnerability/resilience assessments have been carried out by the Asia Climate Change Research Network (ACCRN) which are notable for integrating climate stressors with land use, slum locations, and vulnerability and adaptive capacity indicators (ICRST 2012, Moench et al. 2011). The UN Population Fund (UNFPA) has also issued a volume that explores the use of census and other demographic data in the assessment of climate vulnerability at multiple scales, including urban scales (Martine and Schensul 2013), with one chapter focusing on urban centers in Malawi.

Some common issues with urban climate vulnerability assessment include a need for higher resolution spatial data for both exposure and the exposed elements. de Sherbinin and Bardy (in prep.) were able to obtain census data for more than 6,000 block groups covering New York City (averaging $~ 1,000$ inhabitants) but only 99 wards for Mumbai (averaging 120,000 inhabitants) (see Figure 3.4 below). The lack of access to high resolution census data in many developing countries obviously limits the spatial precision of VAs, although approaches to dasymetric mapping are increasingly being employed to model population distributions at a higher spatial resolution (Mantaay et al. 2007).

Fine scale spatial data for the built environment can be developed from high resolution remote sensing or aerial imagery (e.g., Kit et al. 2011), though it can be costly. A good overview on the development of land use and DEM data from remotely sensed imagery can be found in Taubenböck et al. (2011). While two dimensional maps may be useful for some purposes, for other purposes it is important to have a three-dimensional understanding of the built environment. Understanding flood risks, for example, requires more than a digital elevation model. Since water "finds its level", urban flood risk assessment requires a full understanding of underground drainage networks, as well as electrical conduits and metro lines (during Hurricane Sandy subway tunnels flooded throughout the southern tip of Manhattan). Similarly, 
vulnerability of urban neighborhoods to seismic hazards requires an understanding of building height as well as construction methods.

The World Bank has produced a guide to conducting urban resilience assessments (Prasad et al. 2010), though with little explicit mention of spatial approaches. A common issue with many vulnerability methods documents such as the World Bank guide and the PROVIA Guidance on Assessing Vulnerability, Impacts and Adaptation to Climate Change (2013) is that there is an implicit assumption that maps and spatial data will be used, but scant attention is paid to known issues with spatial data analysis and index construction described in Chapter 1, Section 1.3. The UNFPA volume partially fills this void, but additional guidance documents could usefully be written on approaches to urban spatial VA.

\subsection{The Case Studies}

We examine here three case studies of global coastal cities in light of climate hazards: Mumbai (formerly Bombay) in India, Rio de Janeiro in Brazil and Shanghai in China. Each of these cities has urban agglomerations in excess of 10 million people, the threshold that the United Nations applies to designate a "megacity", and they each represent important national and regional engines of economic development and innovation.

This chapter addresses current and future vulnerability to climate hazards. The respective sections provide baseline information on climate in each of the cities. To assess future vulnerability, we use standard sets of climate change and sea-level rise scenarios. Figure 3.2 provides projected temperature changes by season for reduced emissions ("sustainable path") and increased emissions ("business as usual") scenarios. ${ }^{16}$ Compared to temperature changes, precipitation changes are considered to be more difficult to accurately model, and therefore are not included here. Projections of sealevel rise due to melting land-based glaciers and polar ice caps range from 28 to $98 \mathrm{~cm}$ by 2100 (IPCC 2013). We adopt a common projected sea-level rise of $50 \mathrm{~cm}$ by 2050 , although local variations in land subsidence, storm surge, tides and bathymetry will affect the combined impact of sea-level rise and storm surge in each location (Parry et al. 2007).

\footnotetext{
${ }^{16}$ The study utilizes Canadian Climate Centre's B2 (emissions reduction) scenario and A2 (business as usual) scenario because these data were readily available from the NASA Goddard Institute for Space Studies, which ran the local temperature change estimates for us. They are generally consistent with B2 and A2 scenarios from the Hadley Centre, GISS and other models. The data were provided in 2001 and represent scenario data that contributed to the IPCC Third Assessment Report.
} 
These global cities are located in very different physical environments, which makes for interesting comparisons. The climate of Mumbai is tropical moist, Rio is sub-tropical wet and dry, and Shanghai is on the border between subtropical and warm-temperate. Shanghai is located at the mouth of a major river (the Yangtze), and all are coastal cities with significant areas just above sea level. Shanghai is subject to tropical cyclone landfalls at least once a year.

We focused on collecting data in the categories shown in Table 1 to explore climate hazard vulnerability for these three global cities. Note that data on stresses and perturbations include both climate and social components, some of which arise endogenously to the system. Likewise, system characteristics include elements of physical geography and built infrastructure, coupled with socioeconomic conditions that include what we term endowments, and coping abilities (both direct and indirect).

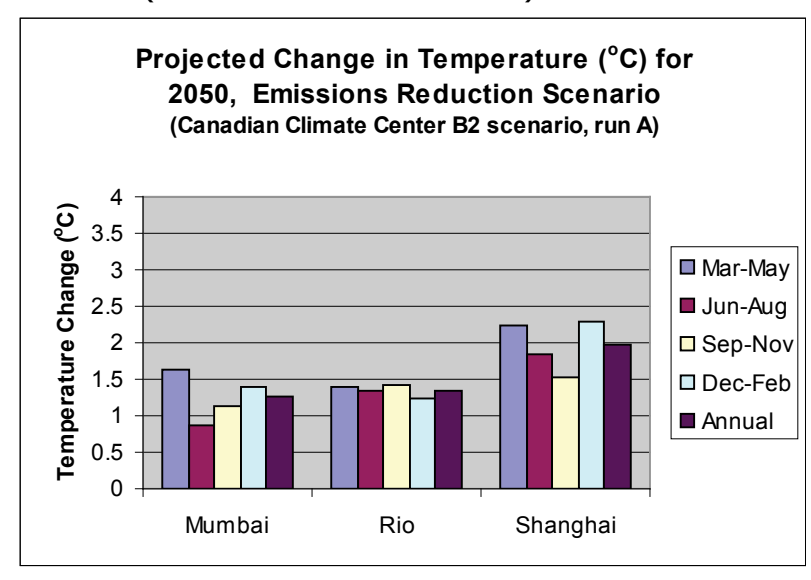

Source: Data courtesy of Richard Goldberg, Goddard Institute for Space Studies, New York, NY

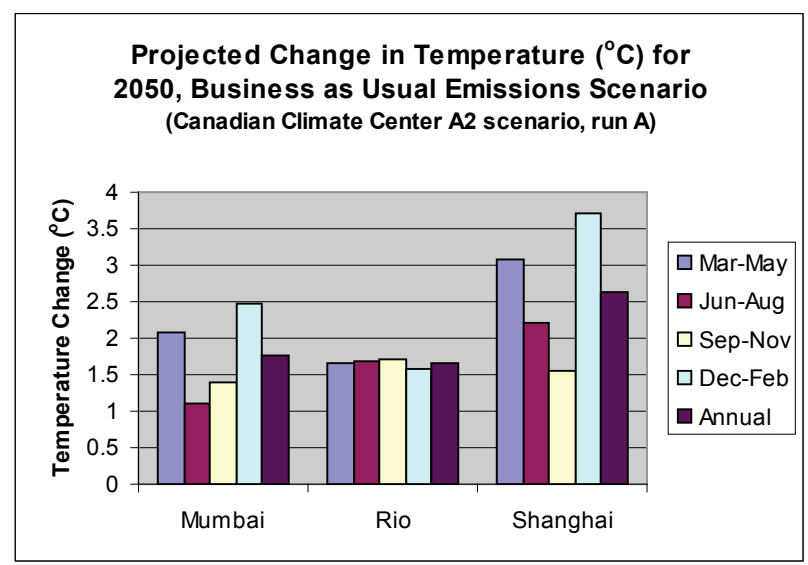

Figure 3.2: Projected changes in temperature by city and season 


\subsubsection{Mumbai}

Mumbai is the largest and most economically important city in India (Panda 2011). The city population is $12.5 \mathrm{~m}$ people, and the metropolitan area population is $18.4 \mathrm{~m}$ people (Census of India 2011), and it contributes to about $5 \%$ of India's GDP (Hallegate et al. 2010). Mumbai hosts India's largest stock exchange, its largest high-tech centre, the world's most prolific film industry, the world's largest metro-suburban rail system and Asia's largest squatter community. Across the bay from the old city, Navi Mumbai (New Mumbai) is taking shape as the world's largest totally planned city. Unfortunately, with its downtown located on a flood-prone, poorly drained peninsula composed largely of landfill, Mumbai is highly vulnerable to climate hazards, as demonstrated by the extensive monsoon flooding of July 2005 that caused more than $\$ 2$ billion in direct and indirect economic losses and killed more than 500 residents (Hallegate et al. 2010). Among the most vulnerable are the approximately one-half of the city's residents who live in squatter communities, many of which are located in low-lying areas without adequate sanitation or water supplies. Finally, these vulnerabilities are compounded by Mumbai's location on several seismic faults, as well as its unsanitary methods for raw sewage and industrial waste disposal into the waters and air surrounding Mumbai.

Table 3.1: Data collected to test the expanded vulnerability framework

\begin{tabular}{|c|c|c|c|c|}
\hline \multicolumn{2}{|c|}{ Stresses/perturbations } & \multicolumn{3}{|c|}{ System characteristics } \\
\hline \multirow{5}{*}{ Climate-related } & $\begin{array}{l}\text { Temperature } \\
\text { increases }\end{array}$ & \multirow{4}{*}{\multicolumn{2}{|c|}{ Physical environment }} & Topography/bathymetry \\
\hline & $\begin{array}{l}\text { Extreme } \\
\text { rainfall/flood }\end{array}$ & & & Geology \\
\hline & Drought frequency & & & Current/recent climate \\
\hline & Wind speeds & & & Wetlands/low-lying areas \\
\hline & Sea-level rise & \multirow{3}{*}{\multicolumn{2}{|c|}{ Infrastructure }} & Domestic water needs \\
\hline \multirow{3}{*}{ Socioeconomic } & Population growth & & & Industrial water needs \\
\hline & Economic downturn & & & Sanitation/waste disposal \\
\hline & Globalization & \multirow{14}{*}{ 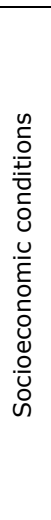 } & \multirow[t]{2}{*}{ Endowments } & Income/poverty rates \\
\hline & & & & Education \\
\hline & & & \multirow{5}{*}{$\begin{array}{l}\text { Direct coping } \\
\text { abilities }\end{array}$} & Health care \\
\hline & & & & Early warning systems \\
\hline & & & & Evacuation plans \\
\hline & & & & $\begin{array}{l}\text { Disaster management } \\
\text { plans }\end{array}$ \\
\hline & & & & Appropriate zoning \\
\hline & & & \multirow{7}{*}{$\begin{array}{l}\text { Indirect coping } \\
\text { (social capital) }\end{array}$} & Dykes or other armaments \\
\hline & & & & Building codes \\
\hline & & & & Percent migrants \\
\hline & & & & Crime rate \\
\hline & & & & Single-parent households \\
\hline & & & & Voter turnout \\
\hline & & & & $\begin{array}{l}\text { Households with secure } \\
\text { tenure }\end{array}$ \\
\hline
\end{tabular}




\section{Physical environment}

The Portuguese were first attracted to Mumbai, known then as Bom Bahia ("good bay" in Portuguese), for its excellent harbor and the opportunities for trade with several communities on islands within the harbor. The British gained control of Mumbai (then Bombay) from the Portuguese in 1661 and, as trade and population increased, the need for additional land led to the filling in, between 1784 and 1845, of the shallow waters and tidal mudflats connecting the original seven islands with rock and dirt from the island's own hilltops. Today, most of Mumbai city centre, which includes the stock exchange, the main train stations and train lines, and numerous high rises, is located on landfill. The inland suburbs, where most of the population now lives, are located at higher elevations. However, much new settlement (industrial, residential and commercial) has occurred along the coastal areas of Greater Mumbai, which are low lying and flood prone (Regional Plan for Mumbai Metropolitan Area 1996). In fact, Mumbai was found by the Organization for Economic Cooperation and Development to be the city with the highest exposure of population to flooding and other climate impacts worldwide (Nichols et al. 2008).

Mumbai's climate is tropical, with temperatures ranging between 16 and $33^{\circ} \mathrm{C}$. Temperature and rainfall are strongly affected by the Indian monsoon, which normally starts in June and ends around the middle of September. Approximately 2,500 $\mathrm{mm}$ of Mumbai's 2,700 mm of annual rainfall comes at this time, with flooding common when spells of heavy rainfall coincide with high tides or storm surges. On 26 July 2005, the city received an unprecedented $944 \mathrm{~mm}$ of rainfall in a 24-hour period, resulting in the most devastating floods in recent history.

\section{Built environment}

Mumbai has a diverse built environment with unique combinations of urban problems associated with its drainage system and its squatter communities, including building collapses, likely future water shortages and poor sewage disposal.

Drainage. Most landfill areas (i.e. most of the old city) are prone to flooding during the monsoon, especially when heavy rains combine with high tides or storm surges (Figure 3.3). Even in wealthy areas, drains are often blocked by trash and debris, and monsoon flooding often shuts down Mumbai's commuter rail lines, which are among the most heavily used in the world. Flooding of this type would likely increase with sea-level rise, necessitating major upgrades in the drainage systems and possibly an elevation of major rail lines. Projects are already underway to upgrade the drains that run alongside the rail lines and to demolish squatter communities also situated alongside rail lines that contribute to clogged drains. However, this work was 
not designed with sea-level rise in mind. A national study ranking India's coastal zones according to their vulnerability to sea-level rise found Mumbai to be the most likely to experience damage (TERI 1996).

Squatter communities. It is estimated that $55 \%$ of Mumbai's population lives in squatter communities, locally referred to as slums, roughly half of which are severely dilapidated. Many squatter structures are single storey and built of salvaged materials. Nevertheless, population densities for roughly one-half of Mumbai's squatter communities are estimated to be as high as 94,000 people per sq. $\mathrm{km}$, making it one of the most densely settled districts in the world. Mumbai's squatter communities suffer from inadequate access to potable water and sanitation. Public toilets are poorly maintained and at some distance from households, such that 1 in 20 people relieve themselves in open areas (World Bank 2006). ${ }^{17}$ As demonstrated in July 2005, even without sea-level rise, many squatter communities in Mumbai are already frequently flooded, as they are often located in low-lying coastal areas and along stream banks. Flooding is common even on the higher ground in Mumbai's squatter communities, as the large amount of refuse and debris in these areas tends to clog storm sewers, causing a backup of water that would otherwise run off or find its way into storm drains (Sharma 2000). Landslides are another threat to squatter communities that are near or on hillsides.

Historically, Mumbai authorities have dealt with the problems caused by squatter communities by demolishing them and forcibly relocating the inhabitants to new areas in the suburban fringe. Increasingly, nongovernmental organizations (NGOs) are organizing to meet the needs of squatter dwellers for better access to sanitation and water, but their efforts are still limited in scope and their impact is quite small, especially with regard to some of the squatter communities most vulnerable to sea-level rise and flooding. This is because funding from the Indian government cannot be used in violation of zoning regulations that prohibit residential development in coastal areas (Sharma 2000). While, in theory, restricting coastal zone settlements reduces settlement in vulnerable areas, in practice this has not deterred such settlement and has merely stalled efforts to make these areas less susceptible to damage and loss of life.

\footnotetext{
17 For example, in one slum, Simla Nagar on Malabar Hill, 6,000 people share 52 toilets, which works out to around 115 people per toilet (Sharma 2012). For some the walk to the toilet takes up to 20 minutes.
} 


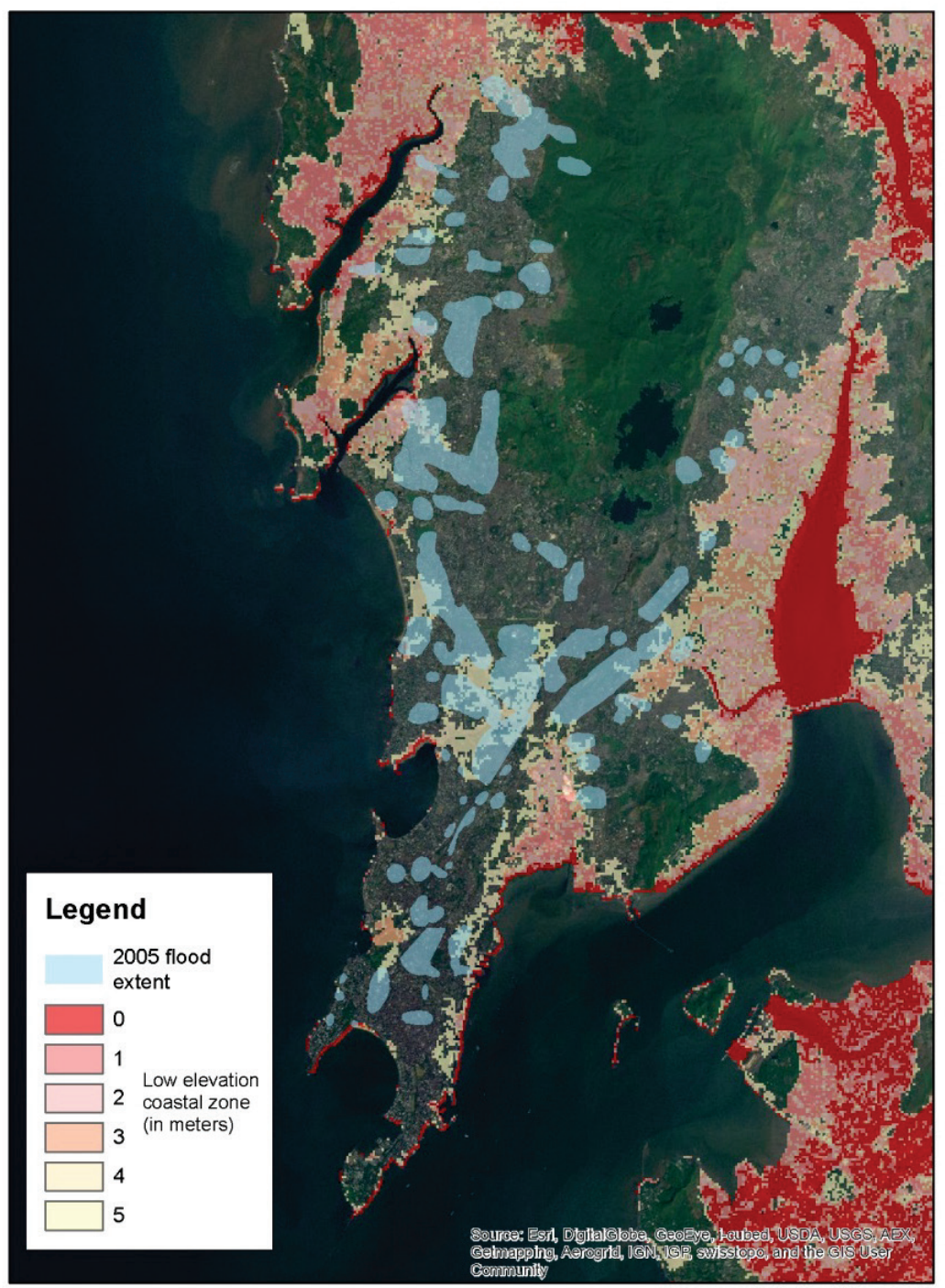

Source: map produced by author with flood extent data from Hallegatte et al. 2010 and low elevation coastal zone data from CIESIN. The author wishes to thank Stéphane Hallegatte for sharing the data.

Figure 3.3: Areas flooded by the July 2005 floods and potential coastal flooding from $1-5 \mathrm{~m}$ sea level rise

Drinking water/potable water capacity. Mumbai's water supply consists of several artificial rain-fed lakes located in the suburbs to the north of the old city. Their location on hills makes them less susceptible to impacts from sea-level rise, although their dependence on local rainfall (as opposed to canal systems or piping from other regions) means that increasing rainfall variability could threaten local supply. The World Bank's Bombay (Mumbai) 
Water Supply and Sewage Disposal projects, which were implemented between 1975 and 1995, increased the city's water supply from 984 to 2,460 million liters per day (World Bank 2006). Antiquation, leaking and partially unmetered water delivery are cited by the World Bank as major problems holding back improvement of the city's water system.

Pollution. Both air and water pollution have been identified as major problems in Mumbai. The World Bank describes Mumbai's air pollution as "severe" and, with regard to Mumbai's water pollution, states that "...about $75 \%$ of all sewage is untreated and discharged to local waterways and coastal waters, causing extensive environmental hazard" (World Bank 2006). The BOD load from Mumbai's domestic sewers alone has been estimated at 450 tons per day, while that from industries is about 24 tons per day. Most of the waste being discharged is either only partially treated or not treated at all, making Mumbai's river and coastal waters among the most polluted in the world (Dhage et al. 2006, Murthy et al. 2001). Phosphate-phosphorus concentrations in the coastal waters of Mumbai are at about 2.5 micromoles per liter and nitrate-nitrogen at 35 micromoles per liter. Massive algal blooms being fueled by these excessive nutrients in waste water discharge and the ensuing depletion of dissolved oxygen have led to steady degradation in water quality in most of Mumbai's estuaries and tidal creeks and near coastal waters.

\section{Socioeconomic conditions}

Endowments. While Mumbai has by far the largest concentration of wealth in India, it is unevenly distributed within the city. Per capita income, adjusted for purchasing power parity, is estimated to be three times the Indian average, or equal to US $\$ 8,400$ (Wikipedia: Mumbai), yet income distribution in the city is a major problem (Sharma 2000). Its vibrant economy means that unemployment rates are low, at 2.5\% among males and $8.3 \%$ among female in 2007 (Singh 2010). Figure 3.4 shows the location of the cities least vulnerable populations, located largely in Mumbai City District, and the wards with highest vulnerability, located in portions of the Suburban District. According to 2011 Census of India estimates, 62\% of all Mumbaikers live in informal slums such as Dharavi, one of the biggest slums in the world with almost 1 million residents. Dharavi, located in a flood prone area along the Mithi River near the Mumbai international airport, is found in the southernmost ward with the highest vulnerability (Figure 3.4).

Direct coping. Mumbai is the headquarters for the State of Maharashtra Disaster Management Plan. An emergency operations center (central control room) in Mumbai is the main hub for a network connected to a variety of sophisticated technologies aimed at emergency planning and disaster management. Multi-hazard response plans, financed by the UK's Department 
for International Development, are also in place in Mumbai as well as in six other centers across the state. There are multi-hazard response plans in place for each district, including risk assessment and vulnerability analysis with reference to earthquakes, floods and cyclones, epidemics, road accidents, fires, and chemical and industrial disasters. These systems also contain a multi-hazard response structure, capability analysis, inventory of resources, mitigation strategies, and a directory of personnel and institutions in the districts with their contact addresses, telephone and fax numbers (Maharashtra State Disaster Management Plan undated). Revi (2005) laments, however, that despite identifying flood risks and pinpointing vulnerable slums, no systematic action had been taken in the five years since the plan's development to mitigate the risk. Moreover, the ongoing landfill projects of various Mumbai development authorities suggest that a prevention-oriented approach to disaster avoidance and reduction is lacking. ${ }^{18}$

18 For example, suggestions to develop an early warning system for monsoon flooding based on text messaging were not pursued by the Mumbai Metropolitan Regional Development Authority (Greenough personal communication). 


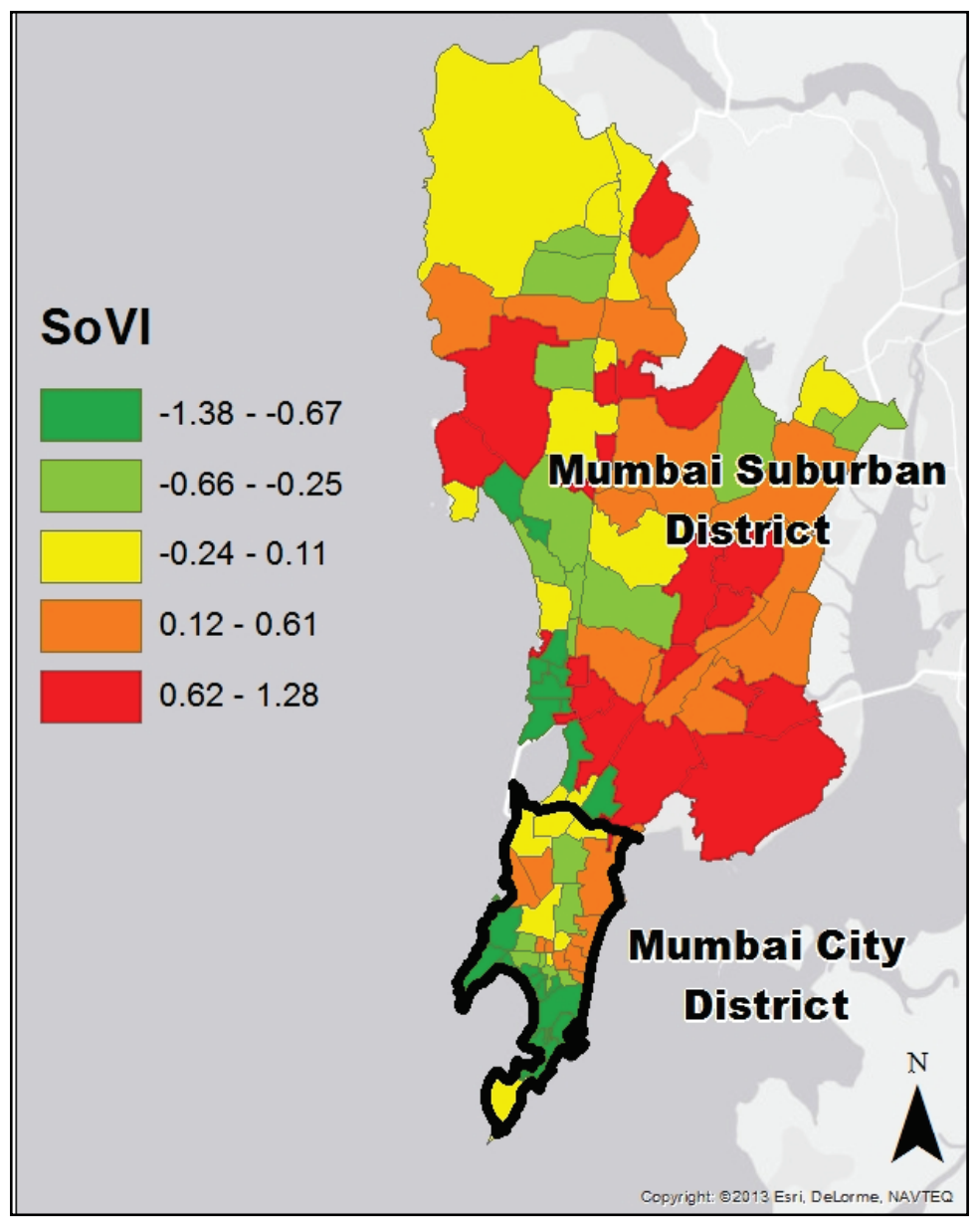

Source: de Sherbinin and Bardy, in preparation.

Figure 3.4: Social Vulnerability Index for Mumbai (2001)

Regulations are in place that prohibit the location of new industries in the old center city. This has been done in order to reduce congestion and pollution, and to discourage further dense settlement in this old portion of the city that has an antiquated built environment. These regulations have an added and, as yet, unappreciated benefit of decreasing settlement on landfill areas that are susceptible to flooding and potential shifting due to sea-level rise and increased storm frequency. However, some of the new settlements to which industries and people are being relocated are also in low-lying coastal areas that may be similarly susceptible to sea-level rise and storm surges.

Indirect coping. Despite its many chaotic qualities, Mumbai is socially highly organized, a quality that mitigates some of the city's vulnerability to natural hazards. The internationally known squatter organization, the 
National Slum Dwellers Federation (NSDF), is based in Mumbai. The NSDF received the prestigious Scroll of Honor from the United Nations Human Settlements Program for its work in the collective design and construction of low-cost houses and toilets, improving environmental sanitation in ways that can help mitigate the disease impact during and after flooding (UNDP 2001). The NSDF has more than 90 housing projects that are either built or underway, providing housing for more than 35,000 households (UN Millennium Project 2005). The NSDF and similar organizations in Mumbai have built strong partnerships between poor communities, NGOs and various levels of government (SPARC 2001).

Despite the existence of slum federations, Revi (2005) decries the "institutionalization of disparity" in Mumbai, citing a decline in the quality of law enforcement and justice institutions and a rise in organized crime and terror networks. He cites the income disparity, one manifestation of which is the over-priced land market that contributes to the spread of informal settlements, as a significant vulnerability.

Another important aspect of Mumbai's social support system is the city's ability to garner resources from abroad. As the wealthiest and most cosmopolitan city in India, and as the center of India's film industry (the world's largest in terms of output), Mumbai looms large in the minds of Indians living abroad. This community is recognized throughout India as a key to the country's overall development, and Mumbai's unique ability to broadcast its problems and needs to this community abroad may prove an important factor in reducing the impacts of climate hazards on the city. This may be especially true in the case of dramatic perturbations, such as sealevel rise and associated flooding, which could threaten Mumbai's status as the leading city of India.

\section{Likely future climate hazards and overall vulnerability assessment}

The Canadian Climate Centre's A2 (business as usual) and B2 (sustainable path) scenarios predict an average annual temperature increase of $1.75^{\circ} \mathrm{C}$ and $1.25^{\circ} \mathrm{C}$, respectively, by 2050 (Figure 3.2). This increase is similar to that predicted for Rio but lower than increases in Shanghai. Mumbai is predicted to have an average annual decrease in precipitation of $2 \%$ for the A2 scenario and an increase of $2 \%$ for the B2 scenario. The predicted sealevel rise of $50 \mathrm{~cm}$ by 2050 could prove seriously damaging for Mumbai.

Potential impacts of precipitation extremes. The A2 (business as usual) scenario may engender water shortages in Mumbai, given the city's complete dependence on locally stored rainfall for its water supply. The fact that both scenarios predict a decrease in rainfall during the first part of the year (January-August) suggests that droughts will become more common in the 
MMR, although predicted reductions during the monsoon season are less dramatic. Furthermore, both scenarios show an increase in rainfall from September to November, which may mitigate water shortages from reduced monsoons. If droughts do increase in severity, this could trigger migrations from surrounding agricultural areas (a common occurrence during drought years), which could tax the city's resources in the context of multiple climate change impacts. Hallegatte et al. (2010) estimate the total economic losses including infrastructure for the July 2005 event were between $\$ 690 \mathrm{~m}$ and $\$ 1.9 \mathrm{~b}$, and that reduced return periods for major floods will have significant economic consequences.

Coastal/marine issues. A 1996 a Tata Energy Research Institute (TERI) study put the cost to Mumbai of a one-meter sea-level rise at US\$71 billion (TERI 1996). The study concluded that US $\$ 24 \mathrm{~m}$ invested in protection against sea-level rise would reduce the economic impact by about US\$33b dollars. The predicted rise in sea level of $50 \mathrm{~cm}$, together with storm surges, would render uninhabitable the coastal and low-lying areas where many squatter communities are located. Moreover, shifting would likely occur in the sub-surface of the landfill areas, resulting in many buildings becoming uninhabitable due to structural instability. Mumbai's landfill areas contain a mixture of high value commercial properties, such as the stock exchange, important public facilities, such as the main train stations and train lines, numerous high value residential high-rises and a number of squatter communities. The few hills, formerly islands, that were not leveled to create the landfill that the majority of the city was built on, comprise mostly upscale residential areas long-prized for their relative immunity to flooding. These areas lack the commercial potential to take up slack should the landfill areas go into decline. However, provided that sea-level rise occurs gradually, and is recognized early enough, Mumbai might be able to mitigate damage, perhaps by shifting much of the old city to the adjacent suburbs or to Navi Mumbai.

Overall vulnerability. What emerges from using the extended vulnerability framework is the identification of a set of stresses and perturbations that collectively converge to create great "stress bundles" for Mumbai. An example is the convergence of extreme rainfall and floods. Mumbai's various characteristics of topography (flat), geology (unconsolidated fill material), numerous wetlands and flood-prone areas, the city's building conditions (not meeting building codes, squatter dwellings, previously flood-damaged buildings), poor sanitation and poor waste treatment and removal capabilities together create a particular "bundle" of stresses that "collides" with the set of socio-environmental conditions of Mumbai, such that vulnerabilities emerge for the system. 
In addition, a "stress bundle" composed of population (large and growing), projected sea-level rise, and economic stresses converge to create some particularly problematic issues for Mumbai. This is because of a set of characteristics for Mumbai that include the lack of dykes and other coastal armaments for dealing with sea-level rise, weak disaster preparedness at the scale of sea-level rise, building conditions (not meeting building codes, squatter dwellings, previously flood-damaged buildings), and low incomes that do not allow the city to improve building conditions to the level required, nor to better develop and fund disaster preparedness. Mumbai is thus facing threats that local authorities have very little ability to control, dampen or mitigate. This suggests that a reinforcing spiral could emerge for this set of issues, where increasing population comes together with sea-level rise and a stressed economy to further damage already weak buildings, undermine efforts to improve disaster preparedness and build coastal armaments; and these, in turn, further erode the economy while sea-level rise marches on. Mumbai's informal coping capacities, as a result of notably strong social networks and cooperation, emerge as important parts of Mumbai's resistance and resilience in the face of stresses. These informal coping systems are expected to help reduce vulnerabilities to some degree for both sets of issues that emerge from this preliminary analysis. Yet, by themselves, these informal coping capacities appear quite inadequate to meet the challenges from climate hazards and population size and growth that now face Mumbai.

Mumbai's overall vulnerability appears to be high, and this is confirmed by the number of reports focusing on Mumbai's flood vulnerability and risk to sea level rise (Hallegatte et al. 2010, Nichols et al. 2008). While the city is relatively prosperous compared to the rest of India, and it does have an elaborate disaster management plan in place, the challenges posed by climate change, especially flooding and sub-surface shifting in landfill areas, are unlikely to be met effectively. In particular, sub-surface shifting of the type that Mumbai might face could well overwhelm the adaptive abilities of any city, and particularly one with some of the other critical issues that Mumbai now faces.

\subsubsection{Rio de Janeiro ${ }^{19}$}

Rio de Janeiro is a city of just over 10 million people located on the southeastern coast of Brazil, and covers an area of 1,171 square km. Guanabara Bay, where Rio is situated, faces almost due south. Rio is the

\footnotetext{
19 This section has been updated with some more recent research which was presented in de Sherbinin, A., and D. Hogan. 2011. "Box 3.1 Climate Proofing Rio de Janeiro, Brazil", in Chapter 3 of Rosenzweig et al. (eds), Climate Change and Cities: First Assessment Report of the Urban Climate Change Research Network. Cambridge: Cambridge University Press.
} 
second most populous city in Brazil, after São Paulo, and ranks second only to São Paulo in industrial production. This erstwhile capital of Brazil is known for its beautiful beaches and the granite hills that rise dramatically from sea level to more than $1,000 \mathrm{~m}$. Yet, as flooding and landslides in April 2010 and January 2011 have demonstrated, Rio de Janeiro and the surrounding region continue to be at high risk of climate impacts. Approximately 200 deaths were attributed to the April 2010 floods and landslides, and several thousand people were made homeless, while 450 died in mudslides in the state of Rio de Janeiro in early 2011. Rio also faces significant environmental sustainability challenges stemming from unregulated settlement in hazardous areas, sewage disposal and industrial wastes. Efforts will need to be made to "climate proof" the metropolitan region, increasing its resilience to floods induced by climate change and variability.

\section{Physical environment}

Rio's dramatic topography has made it more prone to certain types of hazard. When the Portuguese discovered Guanabara Bay in 1501, the coastal mountains were carpeted in thick Atlantic rainforest. As this protective covering has been progressively stripped away to make room for settlements, the thin soils have become prone to landslides, and the granite and gneiss bedrock has been left exposed to weathering, making it more prone to decomposition and erosion.

The coastline in this area was characterized by lagoons, estuaries and lowlying coastal marshes, many of which have been filled in (Figure 3.5). The flat topography of low-lying areas, combined with a lack of drainage, has continued to result in flooding during the summer rainy season (JanuaryMarch). The few remaining lagoons, mangroves and marshes have been affected by sedimentation, reducing their absorptive capacity during extreme rainfall events. Ninety\% of mangroves surrounding Guanabara Bay have been removed, and intense sedimentation has resulted in the need for dredging to maintain shipping lanes. Rio's beaches, a major tourist asset, are subject to intense erosion during storms (with up to five meters recession), but usually recover quickly through the deposition of sand laterally along the coast (Muehe personal communication). Significant resources are also expended on beach nourishment following intense erosion.

The climate in Rio is moderated by the coastal effect, its southern exposure, and the mountain ranges to the north. The mountain ranges block cooler northeasterly winds during the winter months and enhance orographic precipitation during the summer months, when winds are predominantly southwesterly. Rio experiences wet summers (December-March), with an average temperature range of $24-26^{\circ} \mathrm{C}$, and dry winters (June-September), with an average temperature range of $20-22^{\circ} \mathrm{C}$ (Figure 3.6). Maximum 
temperatures rarely exceed $42^{\circ} \mathrm{C}$. From year to year, precipitation ranges between 1,200 and 1,500 mm, and evaporation between 800 and 1,200 mm. Rio has never been impacted by tropical cyclones, although this may change. The first recorded South Atlantic hurricane reached land in the state of Santa Catarina in March 2004, suggesting that what was once thought to be a meteorological impossibility is no longer so, with global warming-induced increases in regional sea surface temperatures (UK Met Office 2004). The city receives a strong El Niño-Southern Oscillation (ENSO) signal, and during El Niño years the city receives higher than normal precipitation during the summer months. During one recent El Niño year, 1988, the city was affected by severe floods as a result of two intense periods of rainfall in early February that produced a total of $480 \mathrm{~mm}$ of rain, one-third the annual total rainfall. Flooding in early 2011 was precipitated by $288 \mathrm{~mm}$ of rainfall in a 24-hour period.

\section{Built environment}

Rio's peculiar geography, and the circumscribed nature of suitable building sites, has spawned two kinds of response. One is the construction of high-rise apartments close to the coastline (e.g. Copacabana, Ipanema and Leblon) and in flood-prone areas further inland; the other is unregulated construction on steep slopes, particularly on the Tijuca mountain range. The unregulated construction of favelas (shanty towns) has a long history, and stems from the invasion of both private and public urban lands by poor urban squatters who become de facto (and in some cases de jure) owners of plots of land (Fernandes 2000). Many favelas have evolved over time from ramshackle collections of wooden shacks lacking even the most basic amenities to organized communities of largely concrete housing with cemented walkways, electricity, plumbing, sewerage and other services. 


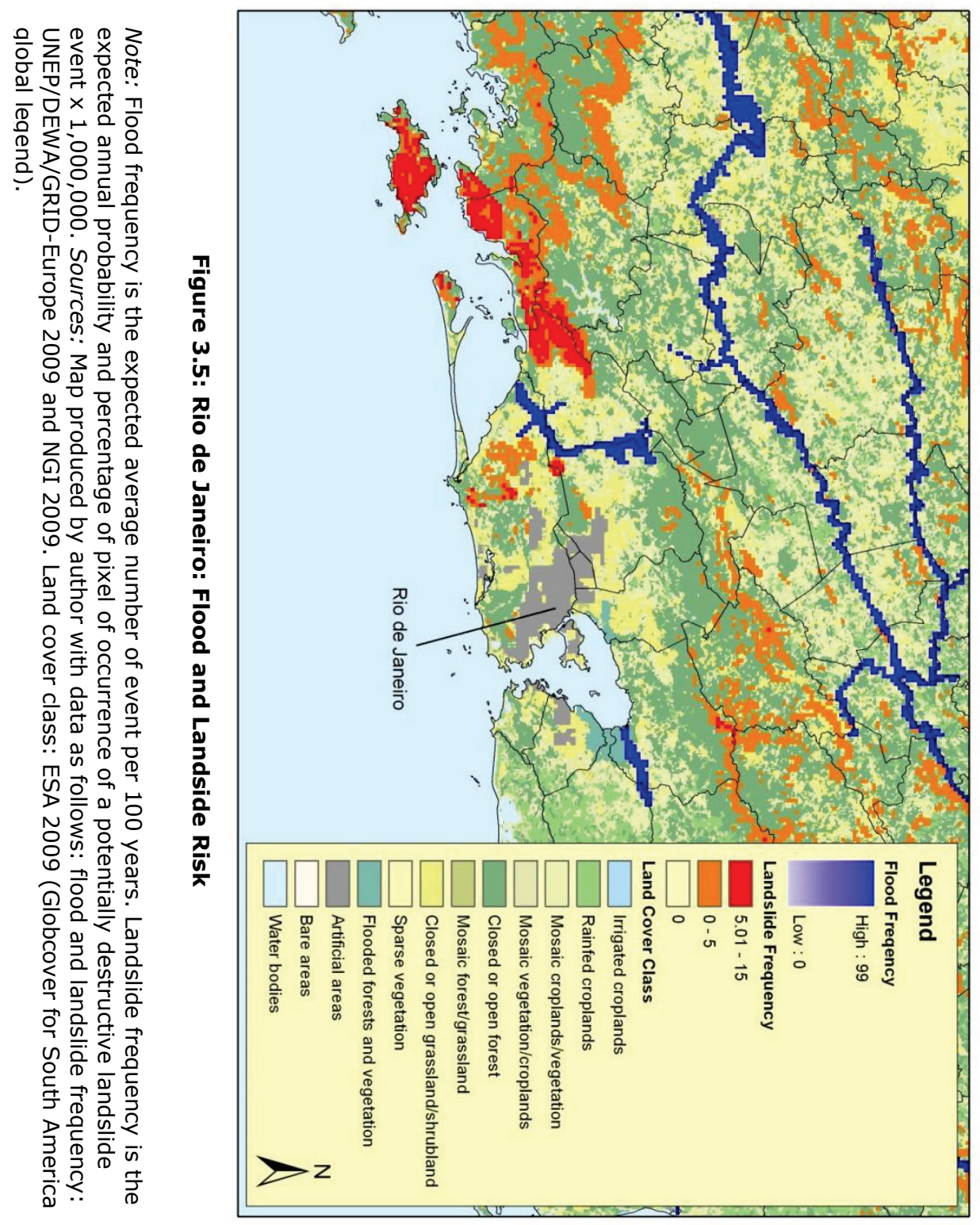

Although favelas have always suffered during rainy seasons, the paving of walkways has had the effect of increasing runoff to the point where water is often ankle or knee deep between the houses. Runoff from communities on steep hillsides, including Petropolis and favelas on the Maciço da Tijuca massif, are channeled down cemented and quasi-natural watercourses to the narrow coastal lowlands, where they join canals whose limited flow capacity causes frequent flooding. In 2010, the Morro do Bumba slum built on a 
former garbage dump in Niteroi collapsedowing to super-saturated soils and slid downhill, burying homes and killing more than 200 people. By contrast, the Baixada Fluminense, a large marshy lowland somewhat removed from the steeper parts of the city, has had reasonably adequate drainage since the 1930s (Cunha and Miller Santos 1993).
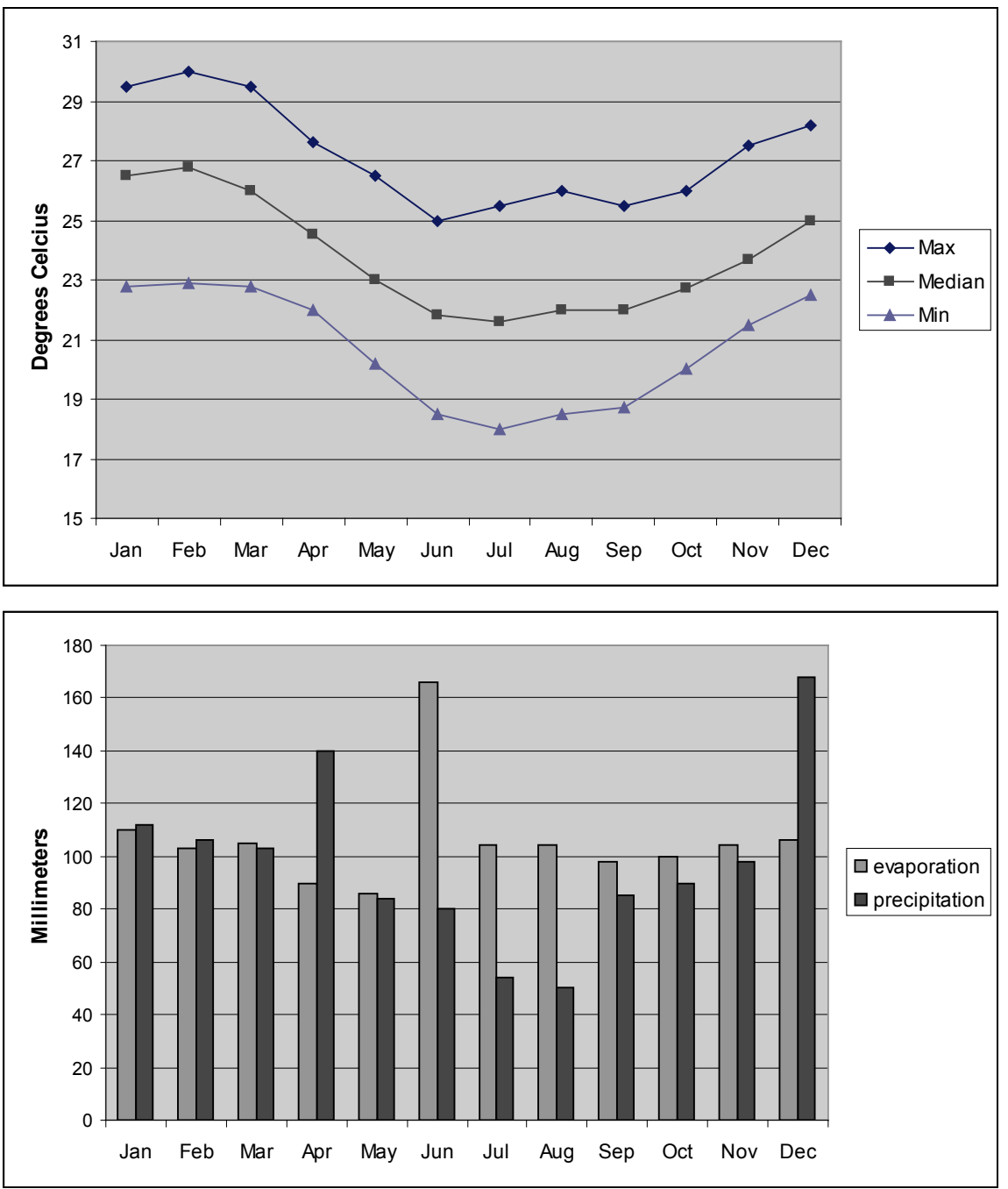

Figure 3.6: Temperature (top) and hydrographs (bottom) for Rio de Janeiro

Note: Temperature does not vary significantly through the year. In contrast, the hydrograph shows that precipitation is greatest in April and December, whereas potential evapo-transpiration greatly exceeds rainfall from June through August (the southern hemisphere winter months). Source: Instituto Nacional de Meteorologia (INMET) 
In terms of services, the city has a reasonably clean and reliable water supply that is piped in from rivers in the state of Minas Gerais to the north. Over $84 \%$ of the population is supplied with water. Eighty-three percent have their own sanitary installations. Ninety-four percent of the population has access to electricity supply at home. Electricity is largely generated by Brazil's major hydroelectric facilities, which supply $92 \%$ of the country's electricity needs. Droughts, such as one in 2001, have periodically led to electricity shortages throughout the country.

Waste disposal is a significant problem. Trash disposal for favelas remains haphazard, with several tons per day ending up in rivers and drainage channels, blocking channels during peak flow (Baptista de Araújo 1994). The Iguacu and Estrela rivers, which drain the bay's watershed, are often anoxic owing to waste emissions (Kreimer et al. 1993).

Guanabara Bay is surrounded by a mix of industrial and residential land uses. As the second largest industrial zone in the country, it has a large number of industries, oil terminals, and shipyards, in addition to two oil refineries. Petrobras, the Brazilian oil company, has numerous off-shore drilling platforms near Rio, and uses Rio as its primary distribution point. A giant causeway crosses the bay, leading to Niteroi, and two airports are located just above sea level on the margins of the bay.

\section{Socioeconomic conditions}

Endowments. Although Rio's product per capita is roughly double the national average, its income distribution is highly skewed. The existence of pockets of extreme poverty side-by-side with some of the most affluent neighborhoods is characteristic of the city. Rocinhas, among the oldest and largest of Rio's favelas, clings precariously to the steep slopes of the Tijuca mountain range just above Gavea, one of the city's wealthiest neighborhoods. It is estimated that 1.1 million people live in favelas, or $20 \%$ of the municipality's population.

According to the 2010 census, the population of Rio metropolitan area is $12.4 \mathrm{~m}$, with $6.3 \mathrm{~m}$ residing in the municipality (IBGE 2010). Population density in the latter is 4,640 persons per square $\mathrm{km}$, but densities in the smaller administrative units of the metro area are between 8,000 and 12,000 persons per square $\mathrm{km}$, indicating that some parts of the city have significant population concentrations. Although rapid population growth of $3.8 \%$ was predicted for the $1990 \mathrm{~s}$, census figures suggest that the rate may have been slower. Corrêa do Lago notes that the metro area received 758,000 migrants between 1970 and 1980, but that between 1980 and 1991 the number had decreased by $24 \%$ to 573,000 (Correa do Lago 1999). It is possible that 
continued declines in migration account for the somewhat lower than expected overall population growth.

Direct coping. The state of Rio de Janeiro has a 15,000 member Civil Defense, which includes the fire department, emergency medical services, sea rescue services and the community relief department. Brazil's State Environmental Engineering Foundation (FEEMA) is responsible for coastal monitoring and land use zoning in the state. Baptista de Araújo (1994) urges more micro-planning for disaster management such as occurred under the Rio Reconstruction Project, which was implemented in the wake of the 1988 floods.

In terms of zoning, until recently there was little effort to segregate industrial or waste disposal activities from residential areas. This could result in potential vulnerabilities, particularly should flooding lead to the dispersion of pollutants to surrounding areas. New regulations have been put in place that restrict building in hazard-prone areas. Efforts to "regularize" favelas have also been underway for several years, with various government programmes to undertake cadastral surveys, grant deeds to de facto owners and provide basic infrastructure. These same plans limit the further expansion of favelas in flood-prone or steeply sloped areas.

Indirect coping. There are several issues that weaken Rio's indirect coping capacity. These include official corruption and political tensions between federal, state and municipal governments; and large migrant communities with low security of tenure, decreasing levels of social cohesion and low levels of education.

Rio has a large migrant population from the poorest parts of Brazil's arid northeast region. The fact that many of them do not have personal experience with mudslides or mass wasting may account for their building practices. Migrants move up hillsides in search of new land, consistently eating away at the vegetation cover on the slopes above the favelas, despite government efforts to cordon off such areas to prevent further development. Improved local environmental knowledge and an understanding of slope dynamics might cause favela dwellers to reconsider such activities.

Rio de Janeiro has invested more than US\$600m in its Programa Favela Bairro to improve access to basic infrastructure, health and education for half a million of its poorest residents (UNHABITAT 2006). In terms of social cohesion, the favelas do have some rudimentary organization, including neighborhood watches and self-improvement societies. The level of cohesion had declined until recently as the levels of drug-related crime and violence increased, but the recent pacification campaign begun in 2010 , an effort to 
clean up the favelas using paramilitary Pacification Police Units, has had some success in reducing the dominance of drug traffickers and restoring public order.

Riots in Rio and other major cities in June 2013 were sparked by increased bus fares and massive investments in the World Cup stadiums. The riots exposed continuing disparities in access to adequate health and education, and concerns among the urban poor that their voices are not being heard.

\section{Likely future climate hazards and overall vulnerability assessment}

The Canadian Climate Centre's A2 (business as usual) and B2 (sustainable path) scenarios predict roughly equal average annual temperature increases of $1.5^{\circ} \mathrm{C}$ by 2050 (Figure 3.2 ). This increase is about the same as that predicted for Mumbai, but is lower than that for Shanghai. Unlike the other cities, the same approximate $1.5{ }^{\circ} \mathrm{C}$ increase is predicted across all four seasons. As mentioned earlier, projected precipitation changes are less reliable, although Canadian A2 and B2 scenarios suggest declines of $7 \%$ and $2.5 \%$, respectively. Sea-level rise, as mentioned earlier, is predicted to be in the order of $50 \mathrm{~cm}$ by 2050 .

Potential impacts of precipitation extremes. Given the potential decreases in precipitation during winter and/or spring, it is likely that these seasons will suffer from increased drought. Summer months may also experience drought, as evapo-transpiration increases due to increased temperatures with no offsetting increases in precipitation. Drought conditions could precipitate two kinds of problem. One is water scarcity, particularly if the droughts extend into the Paraíba River basin in Minas Gerais, from where Rio obtains the majority of its water. The other is electricity shortages, as were recently experienced throughout the country in 2001.

Although average precipitation during the summer rainy season may decline, increases in sea surface temperature and in the severity of El-Niño/Southern Oscillation (ENSO) events could result in periodic flooding of the kind encountered during February 1967, and again in February 1988. The 1967 floods were even more extreme than those in $1988-1,985 \mathrm{~mm}$ fell over two days (83\% higher than average annual rainfall) (Baptista de Araújo 1994). Generally, precipitation extremes are expected to increase in severity with climatic change, and these will have adverse impacts on Rio, given that the city already experiences extreme flooding on a 15-20 year basis.

Coastal/marine issues. Rio does not suffer from subsidence, so this will not exacerbate sea-level rise. However, should sea-level rise be coupled with more extreme coastal storms, there is significant likelihood of increased beach erosion, which will affect nourishment costs and could ultimately 
impact the tourism sector of the economy (Schnack 1993). However, Muehe indicates that it is unlikely that high-rise apartment buildings in Copacabana and Ipanema will be directly impacted by a rise in sea level of $50 \mathrm{~cm}$, even in the event of storm surges (Muehe personal communication).

As mentioned above, Guanabara Bay has lost most of its coastal mangroves, and significant portions of coastal marshes have been filled in. The potential for mangroves or marshes to retreat inland with rising sea level is impeded by the concentrated development along the coast. This will reduce the capacity of the few remaining wetlands to act as buffers during storm surges.

Rising water temperatures may precipitate algae blooms in Guanabara Bay, especially if no effort is made to treat discharges into the bay.

Overall vulnerability. We find that there are three stress bundles that are particularly troublesome for Rio de Janeiro. Each converges with a particular set of system characteristics to produce vulnerabilities that result from gaps in Rio's socio-ecological system and which do not allow it to withstand, respond or cope effectively with these predicted stress bundles.

Temperature increases come together with drought to put stress on Rio's drinking water supply. In addition, problems with governance exist that could further hinder the city in developing more robust potable water storage and delivery systems. Extreme and unpredictable rainfalls and floods converge with projected sea-level rise to increase stresses which will be difficult for Rio to handle owing to the city's topography (narrow coastal shelf backed by steep mountains subject to mass erosion), poor building conditions, the lack of secure land tenure for a notable portion of the city's population, poverty coupled with large income inequalities, high rates of crime that reduce social trust, and large problems with sanitation systems and sewage disposal.

Lastly, sea-level rise converges with the tourism-based economy of a beach city to create a third stress bundle of great importance to Rio de Janeiro. Because of Rio's characteristically narrow beach, which is backed by steep slopes and mountains, modest increases in sea level will likely magnify sand erosion. In addition, Rio has no dykes or other armaments that could protect the beach from modest sea-level rise, or even from great storm surges. This situation illuminates a gap between the stress bundle and Rio's ability to resist or cope with it. Because of Rio's economic dependence on beach tourism, such damage will likely have reciprocal effects on the economy, thus creating additional stress on the city.

Based on this preliminary assessment, we conclude that Rio suffers from a significant ongoing vulnerability to climate hazards, particularly flooding and 
landslides. Although civil defense institutions have been set up to cope with natural disasters, underlying structural problems, including political clientelism (Geddes and Neto 1992) and spatial segregation based on income, render the city vulnerable to climate hazards. Little in the way of concrete flood protection infrastructure has been set up in the wake of the 1988 floods (Allen 1994). It is possible to speak of highly vulnerable subpopulations living in favelas and near waterways, and relatively less vulnerable upper classes living in high-rise apartments in locations less susceptible to inundation. At the same time, climatic changes are predicted that will likely increase the severity of intense rainfall events and raise sea level.

Although the economy of Rio de Janeiro is relatively robust, significant portions of GDP will be required for relief and reconstruction if floods similar to those in 1967, 1988 and 2010/2011 become more frequent. Unless more concerted efforts are made to prepare for climate hazards, the city will remain vulnerable. Efforts are needed upgrade slums, limit settlement on steep slopes and unstable locations, relocate some settlers on some slopes, revegetate hillsides, create more green verges near waterways for water absorption, and improve drainage systems in low-lying areas. Part of this will entail cleaning and maintenance of existing waterways and canals. A number of more specific suggestions for climate proofing are provided in the volume by Gusmão et al. (2008).

\subsubsection{Shanghai}

Shanghai ("on the sea" in Chinese) is one of the world's largest seaports and a major industrial and commercial center of the People's Republic of China. It is located at $31^{\circ} 41^{\prime}$ latitude north and $121^{\circ} 29^{\prime}$ longitude east. Bordering Jiangsu and Zhejiang provinces to the west, Shanghai is washed by the East China Sea to the east and Hangzhou Bay to the south. North of the city, the Yangtze River (or Changjiang) pours into the East China Sea. The municipality covers $6,185 \mathrm{sq}$. km, which includes the city itself, surrounding suburbs and an agricultural hinterland. It is also China's most populous urban area, with a 2010 municipal population of 23 million (NBS 2011), up a remarkable $40 \%$ from $16.5 \mathrm{~m}$ inhabitants in the year 2000 .

\section{Physical environment}

With the exception of a few hills in the southwest corner, most of the Shanghai area is flat and is situated on the alluvial plain of the Yangtze River delta. Shanghai's elevation is only 3-5 meters above sea level and averages four meters. There are no high mountains in the surrounding area, and the Jiangshuai and Huabei plains extend northwards. Cold air masses from the 
north and moist, warm air from the south meet and mix above Shanghai with no topographical hindrance (Zhang and Wang 1998).

Geologically, the Shanghai area lies in the northeast section of the southern Changjiang land mass. Since the beginning of the quaternary era, this area has undergone tectonic subsidence and global marine transgressions and regressions. With the exception of the west, where there are several scattered stripped kops (igneous Mesozoic rocks), most of the area is covered by unconsolidated sediments, including fluvial, lacustrine and littoral facies that range in thickness from 100-150 meters in the west to 350-400 meters in the east (Xu and Tao 1998).

Being located at the mouth of the Yangtze River, the Shanghai region is very much the product of riverine and marine processes. The evolution of the landscape has been deeply influenced by local hydrodynamics, especially tidal flows and runoff. The Yangtze is a major river, with a yearly discharge of $9.24 \times 10^{11}$ cubic meters, and carries an annual sediment load of $4.86 \times 10^{8}$ tons. These sediments feed the delta's continued seaward expansion. The basin drains a humid region, with an average annual precipitation greater than $1,000 \mathrm{~mm}$, rising to $2,000 \mathrm{~mm}$ in certain localities (Milliman and Mei-e 1995).

The Shanghai area experiences a sub-tropical monsoon climate. Frequent summer and autumn typhoons bring not only rainstorms that greatly increase surface runoff, but also cause storm surges in coastal areas. Both significantly modify the geomorphic evolution of the coastal area, as illustrated by typhoon Number 14 that occurred in 1981. This typhoon created high tidal flats while simultaneously strongly scouring middle and low tidal flats along the local coast. Waves produced by strong northeast winds can also cause significant coastal erosion, which lowers the surface of the tidal flats and promotes shoreline recession.

\section{Built environment}

The Construction Ministry utilizes a uniform system of classifying urban land use by housing quality. In the central districts of Shanghai, residential land use occupies $30.1 \%$ of the area, and a high proportion of overall land use is in high quality residential quarters, while poor-quality residential quarters (code R4) are declining as a percentage over time. The proportion of land devoted to industrial and warehouse use is $22 \%$.

The Huangpu River is Shanghai's main source of water. There are over 30 waterworks in Shanghai, 11 of which are located in the urban district along the Huangpu River. Five million tons of tap water are supplied to the urban district every day. Each suburban county also has one or two waterworks. 
Water resources are used in three significant ways in Shanghai, namely industry, agriculture and public water use, in a ratio of 3:6:1. The province consumes 12.6 billion cubic meters per year (SGLIS 2012), which is about one quarter of available water.

One of the serious water resource problems is the over-exploitation of groundwater resources in the surrounding agricultural lands, which has caused significant subsidence (Nichols 1995, Milliman and Mei-e 1995). Since 1921, groundwater has been exploited on a large scale and the city has sunk, on average, more than $1.8 \mathrm{~m}$ (Springer 2012). Because recharge is slow, the water table has fallen and soil moisture has dropped, leading to compression. This process of subsidence has encouraged greater intrusion of seawater into Shanghai's waterways, thus decreasing their quality. Since 1965, the level of groundwater exploitation has been reduced, and aquifer-recharging projects have been carried out. As a result, subsidence was reduced to as little as a few $\mathrm{mm}$ a year; however, since 1984, with the development of new industry in suburban counties, the exploitation of groundwater has increased again, with inadequate controls. By 2014 it is hoped that the China South-North Water Transfer Project will supply one-third of the city's water needs, thus buying more time (Springer 2012).

\section{Socioeconomic conditions}

Endowments. Shanghai has 17.8 million residents in the city proper and an average population density of 6,845 persons per sq. $\mathrm{km}$. Owing to stringent application of the "one child" family planning policy, in 1993 Shanghai was the first area in China to report a negative natural growth rate (births minus deaths). The city registered a negative population growth rate of -1.9 per thousand in 2000, based on a birth rate of 5.3 per thousand and a mortality rate of 7.2 per thousand. However, rapid rates of in-migration more than make up for declining fertility.

Perhaps the biggest single endowment is the city's burgeoning economy, coupled with its pre-eminent status as China's financial capital. Thus, whatever the threats that may exist in the way of subsidence and sea-level rise, the government of China and the local authorities are likely to make whatever investments are required in order to build coastal defenses.

Direct coping. In August 1998, China experienced devastating floods when the Yangtze River overflowed, causing more than 3,000 deaths, affecting 223 million people, displacing 16 million people, flooding 25 million hectares of crop land and causing US\$ 36 billion worth of damage (Abramovitz 1999, NOAA 1999). Heavy rainfall in 1999 also caused flooding, although less extensive. In October 2013 Typhoon Fitow dumped the highest rainfall to hit Shanghai in 52 years and battered floodwalls along the Huangpu River, which 
saw some breaches, but economic losses were minimal, suggesting that city planners and disaster management officials have learned from the past (Jian et al. 2013). Among other flood prevention strategies, the government has undertaken dyke construction and massive afforestation and reforestation campaigns in the Yangtze River basin to reduce runoff and prevent flooding and landslides.

Shanghai has a Municipal Civil Defense Office, which cooperates with the Public Security and Fire Protection agencies. In addition, 284 streets and counties have civil defense organizations which, in turn, organize communities into volunteer civil defense teams (China Fire undated). In 2005, China's central government instituted the Emergency Management Office (EMO), which is responsible for emergency planning, natural disasters, technological accidents, social security concerns, and recovery and reconstruction activities (Bai 2010). Different levels of emergency lead to the engagement of appropriate levels of the EMO and government.

Indirect coping. Shanghai's population, at close to 23 million, includes a mix of relatively affluent and poor populations, including an increasing number of migrants from rural hinterlands. Many of these reside outside the city's flood walls (Springer 2012). Official statistics do not provide a clear picture of income and wealth distribution, or measures of social cohesion in Shanghai. However, broader trends in China suggest that disparities are increasing in urban areas, that urban unemployment is rising, and that the hukou system of household registration is limiting access to benefits (McGranahan and Tacoli 2006). ${ }^{20}$ While inequalities may be rising and social cohesion may be low in areas settled predominantly by migrants, official efforts have been made to involve citizens in disaster response.

Given Shanghai's negative natural population growth, low birth rates could engender population aging, and a growing elderly population could imply vulnerability to heat stress. On the other hand, high immigration means that population is receiving a steady influx of 20-30 year olds. As of the 2000 census, 3.8 million migrants resided in the city.

\section{Likely future climate hazards and overall vulnerability assessment}

Temperature changes for Shanghai suggest that the city will be the most severely affected of the three cities considered here, with average annual temperature increases of between 2 and $2.5^{\circ} \mathrm{C}$. This will have an impact on evapo-transpiration and, consequently, on the moisture balance. In the 30 years from 1978-2007, Shanghai saw a remarkable interannual increase of

${ }^{20}$ A hukou, or household registration record, officially identifies a person as a resident of an area, and includes identifying information such the name of the person, date of birth, the names of parents, and name of spouse, if married. 
urban heat island intensity owing to a combination of urban expansion and global warming, increasing at a mean rate of $0.75^{\circ} \mathrm{C} / 10$ years (Zhang et al. 2010).

Temperature changes will also likely lead to more severe extra-tropical storms and consequent flooding. However, the greatest issue of immediate concern for Shanghai is flood defenses in response to subsidence, sea-level rise and the likelihood that future extreme precipitation will cause flooding from the Yangtze.

Overall vulnerability. As in Mumbai and Rio, severe flooding has tested Shanghai. Perhaps given the magnitude of the city's losses in the late 1990s, the government has taken a genuine interest in long-term disaster planning, perhaps accounting for the lack of deaths and minimal losses from Typhoon Fitow. The municipality has also engaged citizens in "volunteer" civil defense networks, which presumably means that citizens know what to do in the event of disaster and are prepared to take action.

Nonetheless, several key bundles of stress converge to create specific vulnerabilities for Shanghai that emerge out of gaps in the city's ability to resist and cope with these stresses. First, sea-level rise along with increasing severity and frequency of heavy rains and floods come together with Shanghai's topography (level and low lying), geology (unconsolidated), land subsidence due to groundwater withdrawal, many wetlands and flood-prone areas, the inability of many buildings to withstand shifting land and water damage due to their poor condition, sanitation and waste disposal systems that are near capacity, and relatively modest income levels. This mix is likely to produce significant vulnerabilities for a large proportion of the city's residents, the city's built infrastructure and the Shanghai region's economy.

Second, Shanghai's population is already large and continues to grow rapidly. When this massive trajectory comes together with projected sea-level rise and increasing water use by the city, this exacerbates land subsidence, puts greater numbers of people in harm's way from climate hazards and coastal erosion, and places people in greater concentration within areas that are likely increasingly flood prone. This set of circumstances may lead to a diminishing capacity for Shanghai to cope with such stresses because of its burgeoning population on already vulnerable lands, and a greater draw down of groundwater, causing densely populated lands to subside while sea level continues to rise. This could lead to increases in direct mortality, economic downturn and, potentially, large-scale disease outbreaks. On the other hand, as noted above, Shanghai's wealth means the city has a high adaptive capacity. Resources will likely be invested in technological solutions even if such solutions fail to address root causes of vulnerability. 
Third, Shanghai's temperature increases and ageing native population suggest an increased mortality risk from heat-related illnesses in the absence of adaptation measures such as tree planting, air conditioning or cooling centers (Wilhelmi et al.. 2012).

\subsection{Discussion and Conclusions}

The foregoing sections provide a snapshot of vulnerabilities to climate-related hazards in three global cities. The aim here was not to assess definitively the vulnerability of each of these cities but instead, to apply a selection of data identified by the vulnerability framework in order to better understand multiple, synergistic stresses and perturbations on one side of the equation, and multiple, interacting physical and social characteristics of the exposed human-environment system on the other side. Vulnerabilities that may have been hidden with simple "summations" of stresses when compared with "summations" of vulnerabilities, were instead highlighted with this process. ${ }^{21} \mathrm{~A}$ novelty of this work is the application of a more traditional approach to vulnerability assessment - using scenario-based models to assess likely climate impacts, or a "top-down" approach - coupled with more recent advances in vulnerability mapping through "bottom-up" assessments (e.g., Adger 1999). The result is something of a hybrid, which facilitates an understanding of likely future climate impacts while assessing the resilience of the current socio-ecological system in the face of bundles of stresses that are partly related to climate impacts and partly related to fragilities in the system itself.

From a policy perspective, there are few easy prescriptions for reducing vulnerability and better preparing for future climate hazards, at least in the case of the low-income country cities we describe above. Among other things, this may be attributed to the following factors ${ }^{22}$ :

- Disasters are an unequally distributed public "bad" that is more likely to affect poorer, more vulnerable sub-populations with the least political influence. Mitigation measures, by contrast, are a public "good" that require substantial investment and adequately functioning institutions.

\footnotetext{
${ }^{21}$ We found some parts of the extended framework currently beyond our ability to gather appropriate data. This was particularly true when we tried to identify data on informal coping abilities for Shanghai. Informal coping, as we defined it, relies on surrogate measures of social cohesion, cooperation and social safety net. Such data, even though they are surrogate measures for such characteristics, were impossible to collect for Shanghai, and difficult to collect for Mumbai and Rio de Janeiro. While the extended framework includes much richness, it simultaneously begs for better data for the framework to be used to its full potential.
}

22 Selected elements of this list are derived from Di John (2001). 
- Low tax collection capacity and low incomes constrain the resources available to government to make necessary infrastructural or institutional investments. Government resources themselves may become highly contested through political maneuvering (as in the case of Brazil).

- The wealthy and more influential classes may simply choose to "exit" from political decision-making processes rather than voice their concern over the lack of disaster preparedness. "Exit" means that they opt out of public resources and, instead, choose to invest in their own capability set (e.g. purchasing a well-built home in a safe location, insurance policies, or private education and health care).

- Adaptation measures are difficult to implement because they require long time horizons, whereas politicians typically operate on short-term horizons. Incentives need to be intelligently designed so that politicians, officials and the private sector find it in their interest to build less riskprone equitable cities (Revi 2005).

- If vulnerability mitigation/prevention measures are expensive, there may exist a "moral hazard" on the part of state decision makers, as they may assume that the international relief community will come to their assistance in the event of a significant natural disaster. Thus, to act means committing scarce public resources for a medium- or even lowprobability future event, whereas to "wait and see" if disaster strikes, and later claim that the disaster could not be foreseen, shifts the financial burden onto international agencies.

The difficulties in preparing adequately for future climate change-related vulnerabilities cannot be under-estimated. Given these political and institutional issues, it is worth considering how communities themselves, through micro-planning or other efforts at collective organization (Goethert and Hamdi 1988), might develop plans and infrastructure necessary to reduce their vulnerability to natural disasters in contexts in which governments either lack the resources or are unwilling to consider investments in preparedness (Pelling 2002). ${ }^{23}$ Many efforts to improve local environments, such as enhanced drainage and improved waste disposal, also reduce vulnerabilities to disasters and their consequences (such as the spread of disease).

\subsection{References}

Abramovitz, J. 1999. "Natural Disasters: At the Hand of God or Man?" Environmental News Network, 23 June 1999. Accessed at

\footnotetext{
23 In some instances, community preparedness is directly supported by the government, as in the case of Cochin in the state of Kerala, India (Alungal 2006). See also adaptation planning approaches presented by ACCRN, http://www.accrn.org.
} 
http://www.enn.com/enn-features-archive/1999/06/062399/

disaster_3932.asp on 29 October 2001.

Adger, N. 2006. Vulnerability. Global Environmental Change, 16:268-281.

Adger, N. 1999. Social vulnerability to climate change and extremes in coastal Vietnam. World Development, 27(2): 249-269.

Allen, E. 1994. "Political Responses to Flood Disaster: The Example of Rio de Janeiro," in Disasters, Development and Environment, Ann Varley (ed.), New York: John Wiley \& Sons, Ltd.

Bai, V. 2010. "Emergency Management in China". In: D.A. McIntire (ed.), Comparative Emergency Management: Understanding Disaster Policies, Organizations, and Initiatives from Around the World. Washington DC: FEMA. Accessed at http://training.fema.gov/EMIWeb/edu/ CompEmMgmtBookProject.asp on 31 December 2013.

Baptista de Araújo, S. 1994. Rio de Janeiro and Natural Disasters, STOP Disasters, No. 21, Sept-Oct 1994.

Baud, I., N. Sridharan, and K. Pfeffer. 2008. Mapping Urban Poverty for Local Governance in an Indian Mega-City: The Case of Delhi. Urban Studies, 45(7):1385-1412. doi: 10.1177/0042098008090679

Brockerhoff, M. 2000. "An Urbanizing World," Population Bulletin, Vol. 55, No. 3, September 2000.

Census of India. 2011. Metropolitan area population," accessed at http://www.census2011.co.in/urbanagglomeration.php on 26 May 2013.

China Fire. (undated). "New Disaster Assistance Management Help Residents Away from Misadventure," accessed at http://eng.chinafire.com/news/domestic/New\%20Disaster\%20Assistance\%20Managem ent.htm on 30 October 2001.

CHRR (Center for Hazards and Risk Research/Columbia University CIESIN (Center for International Earth Science Information Network/Columbia University), The World Bank, and UNEP/GRID-Geneva (United Nations Environment Programme Global Resource Information Database Geneva). 2005. Global Cyclone Hazard Frequency and Distribution. Palisades, NY: NASA Socioeconomic Data and Applications Center (SEDAC). http://sedac.ciesin. columbia.edu/data/set/ndh-cyclonehazard-frequency-distribution

CIESIN (Center for International Earth Science Information Network), IFPRI (International Food Policy Research Institute), The World Bank, and CIAT (International Center for Tropical Agriculture). 2011. Global Rural-Urban Mapping Project, Version 1 (GRUMPV1): Settlement Points. Palisades, NY: NASA Socioeconomic Data and Applications Center (SEDAC). http://sedac.ciesin. columbia.edu/data/set/grump-v1settlement-points.

CIESIN (Center for International Earth Science Information Network), Columbia University. 2005. Katrina Hazard Mapping Project. Distributed 
by the NASA Socioeconomic Data and Applications Center (SEDAC). Accessed at http://sedac.ciesin.columbia.edu/katrina2005.html on 30 September 2005.

Corrêa do Lago, L. 1999. "Divisão Sócio-Espacial e Mobilidade Residencial: Reprodução ou Alteração das Fronteiras Espaciais?," Instituto de Pesquisa e Planejamento Urbano e Regional, Universidade Federale do Rio de Janeiro (IPPUR/UFRJ).

CRED (Centre for Research on the Epidemiology of Disasters). 2005. Are natural disasters increasing? CRED CRUNCH, August 2005.

Cunha, L. R., and M. Miller Santos. 1993. "The Rio Reconstruction Project: The First Two Years," in Towards A Sustainable Urban Environment: The Rio de Janeiro Study, World Bank Discussion Paper 195, Washington, DC: World Bank.

Curtis, A., J.W. Mills, and M. Leitner. 2007. Katrina and Vulnerability: The Geography of Stress. Journal of Health Care for the Poor and Underserved, 18 (2007): 315-330

Cutter S. L., B.J. Boruff, W.L. Shirley et al. 2003. Social vulnerability to environmental hazards. Social Science Quarterly, 84:242-261

de Sherbinin, A., and G. Bardy. (in preparation). Assessing social vulnerability to floods in two coastal megacities: New York City and Mumbai.

de Sherbinin, A., M. Levy, S.B. Adamo, K. MacManus, G. Yetman, V. Mara, L. Razafindrazay, B. Goodrich, T. Srebotnjak, C. Aichele, and L. Pistolesi. 2012. Migration and Risk: Net Migration in Marginal Ecosystems and Hazardous Areas. Environmental Research Letters. 7 045602. Available at http://dx.doi.org/10.1088/1748-9326/7/4/045602.

de Sherbiniin, A., A. Rahman, A. Barbieri, J.C. Fotso, and Y. Zhu (eds.). 2009. Urban Population-Development-Environment Dynamics in the Developing World: Case Studies and Lessons Learned. Paris: Committee for International Cooperation in National Research in Demography (CICRED).

Dhage, S.S., et al. 2006. Marine water quality assessment at Mumbai West Coast. Environmental International, 32: 149-158.

Di John, J. 2001. "An Institutionalist Political Economy Perspective of Risk and Vulnerability," presentation at a joint World Bank/Columbia University workshop on Assessment of High Risk Disaster Hotspots, Palisades, NY, 6-7 September 2001.

Dickson, E., J. Baker, and D. Hoornweg. 2012. Urban Risk Assessment. Washington DC: The World Bank.

Dilley, M., R.S Chen, U. Deichmann, A. Lerner-Lam and M. Arnold. 2005. Natural Disaster Hotspots: A Global Risk Analysis, Washington, DC: World Bank.

Dyson, M. 2006. Come Hell or High Water: Hurricane Katrina and the Color of Disaster, New York, NY: Basic Civitas. 
Eakin, H., and A. Luers. 2006. Assessing the vulnerability of socioenvironmental systems. Annual Review of Environment and Resources, 31:365-94. doi: 10.1146/annurev.energy.30.050504.144352

Easterling, D R, J L Evans, P Y Groisman, T R Karl, K E Kunkel and P Ambenje. 2000. Observed variability and trends in extreme climate events: a brief review. Bulletin of the American Meteorological Society 81(3): 417-425.

Ebert, A., N. Kerle, and A. Stein. 2009. Urban social vulnerability assessment with physical proxies and spatial metrics derived from air- and spaceborne imagery and GIS data. Natural Hazards, 48:275-294

ESA (European Space Agency). 2009. Globcover. Accessed at http://due.esrin.esa.int/globcover/ on 21 October 2010.

Fernandes, E. 2000. The Legalisation of Favelas in Brazil: Problems and Prospects. Third World Planning Review, 22(2): 167-188.

Geddes, B., and A.R. Neto. 1992. Institutional Sources of Corruption in Brazil. Third World Quarterly, 13(4): 641-661.

Goethert, R. and N. Hamdi. 1988. Making Microplans. A Community-based Process in Design and Development. London UK: Intermediate Technology Publications.

Greenough, G. 2013. Harvard School of Public Health. Personal communication on 16 January 2013.

Gusmão, P.P., P. Serrano do Carmo, and S.B. Vianna. 2008. Rio Proximos 100 Anos. Rio De Janiero: Instituto Municipal de Urbanismo Pereira Passos.

Hallegate, S., F. Henriet, A. Patwardhan, K. Narayanan, S. Ghosh, et al. 2010. Flood Risks, Climate Change Impacts and Adaptation Benefits in Mumbai: An Initial Assessment of Socio-Economic Consequences of Present and Climate Change Induced Flood Risks and of Possible Adaptation Options. OECD Environment Working Papers No. 27. Accessed at http://dx.doi.org/10.1787/19970900 on 27 May 2013.

ICRST (Indore City Resilience Strategy Team). 2012. Final Report on city resilience strategy, Indore, G.K. Bhat, V.P. Kulshreshtha, U.A. Bhonde, U. Rajasekar, A.K. Karanth, and M.K. Burvey (eds). TARU Leading Edge Pvt. Ltd.

IBGE (Instituto Brasileiro de Geografia e Estatistica). 2010. Web site accessed at http://www.ibge.gov.br/home/estatistica/populacao/ censo2010/ on 15 May 2013.

IPCC (Intergovernmental Panel on Climate Change). 2013. Working Group I contribution to the IPCC 5th Assessment Report, "Climate Change 2013: The Physical Science Basis". Draft report issued 7 June 2013. Accessed at http://www.climatechange2013.org/images/uploads/ WGIAR5_WGI-12Doc2b_FinalDraft_Chapter13.pdf on 30 December 2013. 
Jha, A.K., R. Bloch, and J. Lamon. 2012. Cities and Flooding. Washingont, DC: The World Bank and GFDRR.

Jian, Y., M. Yue and H. Min. 2013. Heaviest rain for 52 years floods streets and homes in Shanghai. Shanghai Daily. 9 October 2013. Accessed at http://www.shanghaidaily.com/Metro/society/Heaviest-rain-for-52years-floods-streets-and-homes-in-Shanghai/shdaily.shtml on 31 January 2013.

Kinney, P.L., D. Shindell, E. Chae, and B. Winston. 2000. Climate Change and Public Health: Impact Assessment for the NYC Metropolitan Region. White paper for the Metropolitan East Coast Assessment. Accessed at http://metroeast_climate.ciesin.columbia.edu/reports/health.pdf on 3 January 2013.

Kit, O., M. Lüdeke, and D. Reckien. 2011. "Assessment of Climate ChangeInduced Vulnerability to Floods in Hyderabad, India, Using Remote Sensing Data", In: K. Otto-Zimmermann (ed.), Resilient Cities: Cities and Adaptation to Climate Change - Proceedings of the Global Forum 2010, Local Sustainability 1, Dortrecht, NL: Springer Science+Business Media. DOI 10.1007/978-94-007-0785-6_4

Kleinen, T., G. Petschel-Held . 2007. Integrated assessment of changes in flooding probabilities due to climate change. Climatic Change, 81(3-4), 283-312

Kreimer, A., T. Lobo, B. Menezes, M. Munasinghe, R. Parker, and M. Preece. 1993. "Rio de Janeiro - In search of Sustainability," In Towards $A$ Sustainable Urban Environment: The Rio de Janeiro Study, World Bank Discussion Paper 195, Washington, DC: World Bank.

Lin, N., K.A. Emanuel, J.A. Smith, and E. Vanmarcke. 2010. Risk assessment of hurricane storm surge for New York City. Journal of Geophysical Research, 115, D18121

Liverman, D. 1990. "Vulnerability to Global Environmental Change." In Understanding Global Environmental Change: the Contributions of Risk Analysis and management, edited by R.E. Kasperson et al. Worcester, MA: Clark University, The Earth Transformed Program, 27-44.

Maharashtra State Disaster Management Plan. (undated). Accessed at http://mdmu.maharashtra.gov.in/pages/State/statedmpShow.php on 20 September 2006

Maantay, J.A., A.R. Maroko, and C. Herrmann. 2007. Mapping Population Distribution in the Urban Environment: The Cadastral-based Expert Dasymetric System (CEDS). Cartography and Geographic Information Science, 34(2): 77-102.

Martine, G., and D. Schensul (eds.). 2013. The Demography of Adaptation to Climate Change. New York, London and Mexico City: UNFPA, IIED and El Colegio de México.

McDonald, R.I., P. Green, D. Balk, B.M. Fekete, C. Revenga, M. Todd, and M. Montgomery. 2011. Urban growth, climate change, and freshwater 
availability. Proceedings of the National Academy of Sciences. 108(15):6312-6317, doi: 10.1073/pnas.1011615108

McGranahan, G., D. Balk and B. Anderson. 2007. The rising tide: assessing the risks of climate change and human settlements in low-elevation coastal zones, Environment \&Urbanization, 19(1): 17-37.

McGranahan, G., and C. Tacoli. 2006. "Rural-urban migration in China: policy options for economic growth, environmental sustainability and equity", Working Paper No 12, Rural-Urban Interactions and Livelihoods Strategies Series, London: IIED.

Milliman, J. D., and R. Mei-e. 1995. "River Flux to the Sea: Impact of Human Intervention on River Systems and Adjacent Coastal Areas," in Climate Change Impact on Coastal Habitation, D. Eisma (ed.). Boca Raton, FL: Lewis Publishers.

Mitchell, J.K. (ed.). 1999. Crucibles of Hazard: Megacities and Disasters in Transition, Tokyo: UN University Press.

Moench, D., S. Tyler, and J. Lage. 2011. Catalyzing Urban Climate Resilience: Applying Resilience Concepts to Planning Practice in the ACCCRN Program, Boulder CO: Institute for Social and Environmental Transition.

Muehe, D. 2001. Professor, Department of Geography, Federal University of Rio de Janeiro. Personal communication, 22 August 2001.

Murthy, R.C., Y.R. Rao, and A. Inamdar. 2001. Integrated coastal management of Mumbai metropolitan region. Ocean \& Coastal Management, 44: 355-369.

NBS (National Bureau of Statistics). 2011. Communiqué of the National Bureau of Statistics of People's Republic of China on Major Figures of the 2010 Population Census[1] (No. 2). Accessed at http://www.stats.gov.cn/english/newsandcomingevents/ t20110429_402722516.htm on 20 June 2013.

NGI (International Centre for Geohazards). 2009. Frequency of landslides triggered by precipitations. In: ISDR, Global Assessment Report on Disaster Risk Reduction. Geneva, Switzerland: United Nations.

Nicholls, R. J. et al. 2008. Ranking Port Cities with High Exposure and Vulnerability to Climate Extremes: Exposure Estimates, OECD Environment Working Papers, No. 1, OECD Publishing. Accessed at http://dx.doi.org/10.1787/011766488208 on 27 May 2013.

Nicholls, R. 1995. Coastal Megacities and Climate Change. GeoJournal, Vol. 37, No. 3, pp. 369-379.

NOAA/OGP (National Oceanographic and Atmospheric Administration/Office of Global Programs). 1999. National Oceanographic and Atmospheric Administration, Office of Global Programs Climate Information Project archives, 27 December 1999, accessed online at http://www.cip.ogp.noaa.gov/Library/weekly/1999/12.27.99.html on 24 Sept 2001. 
Panda, A. 2011. Climate Change Risks \& Adaptation: Indian Mega Cities. The India Economy Review, Volume VII, 1 January 2011.

Parry, M.L., O.F. Canziani, J.P. Palutikof, et al. 2007. Impacts, Adaptation and Vulnerability. Contribution of Working Group II to the Fourth Assessment Report of the Intergovernmental Panel on Climate Change. M.L. Parry, O.F. Canziani, J.P. Palutikof, P.J. van der Linden and C.E. Hanson (Eds.). Cambridge, UK: Cambridge University Press.

Pelling, M. 2003. The Vulnerability of Cities: Natural Disaster and Social Resilience, London: Earthscan.

Pelling, M. 2002. Assessing urban vulnerability and social adaptation to risk: Evidence from Santo Domingo. International Development Planning Review, 24 (1):59-76.

Pelling, M. 1998. Participation, social capital and vulnerability to urban flooding in Guyana. Journal of International Development, 10:469-486.

Prasad, N., F. Ranghieri, F. Shah, Z. Trohanis, E. Kessler, and R. Sinha. 2010. Climate Resilient Cities: A Primer on Reducing Vulnerabilities to Disasters. Washington DC: World Bank.

Preston, B. L., D. Abbs, B. Beveridge, C. Brooke, R. Goddard, G. Hunt, M. Justus, P. Kinrade, I. Macadam, T. G. Measham, K. McInnes, C. Morrison, J. O'Grady, T. F. Smith \& G. Withycombe. 2007. Spatial Approaches for Assessing Vulnerability and Consequences in Climate Change Assessments In Proceedings of MODSIM 2007: International Congress on Modelling and Simulation. Christchurch, NZ: Modelling and Simulation Society of Australia and New Zealand.

PROVIA (Programme on Vulnerability, Impacts and Adaptation). 2013b. PROVIA Guidance on Assessing Vulnerability, Impacts and Adaptation to Climate Change. Nairobi, Kenya: United Nations Environment Programme (UNEP).

Regional Plan for Mumbai Metropolitan Area, 1996-2011, accessed at http://theory.tifr.res.in/bombay/amenities/housing/masterplan.html, 19 September 2006

Revi, A. 2005. Lessons from the deluge: priorities for multi-hazard risk mitigation. Economic and Political Weekly, 40(36): 3911-3916.

Romero-Lankao, P., H. Qin and M. Borbor-Cordova. 2013. Exploration of health risks related to air pollution and temperature in three Latin American cities. Social Science \& Medicine, 83:110-118

Romero-Lankao, P., and H. Qin. 2010, Conceptualizing urban vulnerability to global climate and environmental change, Current Opinion in Environmental Sustainability, 3(3): 142-149, http://dx.doi.org/10.1016/j.cosust.2010.12.016.

Rosenzweig, C., W.D. Solecki, S.A. Hammer, and S. Mehrotra (eds). 2011a. Climate Change and Cities: First Assessment Report of the Urban Climate Change Research Network. Cambridge: Cambridge University Press. 
Rosenzweig, C., W. D. Solecki, R. Blake, M. Bowman, C. Faris, V. Gornitz, R. Horton, K. Jacob, A. LeBlanc, R. Leichenko, M. Linkin, D. Major, M. O'Grady, L. Patrick, E. Sussman, G. Yohe, and R. Zimmerman. $2011 \mathrm{~b}$. Developing coastal adaptation to climate change in the New York City infrastructure-shed: Process, approach, tools, and strategies. Climatic Change, 106:93-127

Rosenzweig, C., and W.D. Solecki, 2001. Climate Change and a Global City. Environment, 43(3): 8-18.

Rygel, L., D. O'Sullivan, and B. Yarnal. 2006. A Method for constructing a social vulnerability index: An application to hurricane storm surges in a developed country. Mitigation and Adaptation Strategies for Global Change, 11: 741-764.

Sanderson, D. 2000. Cities, disasters and livelihoods. Environment \& Urbanization, 12(2): 93-102.

Santer, B.D., T.M.L. Wigley, P.J. Gleckler, C. Bonfils, M.F. Wehner, et al. 2006. Forced and unforced ocean temperature changes in Atlantic and Pacific tropical cyclogenesis regions. Proceedings of the National Academy of Science 103: 13905-13910.

Schnack, E.J. 1993. "The Vulnerability of the East Coast of South America to Sea Level Rise and Possible Adjustment Strategies," in Climate and Sea Level Change: Observations, Projections and Implications, R.A. Warrick, E.M. Barrow, and T.M.L. Wigley (eds.), Cambridge, UK: Cambridge University Press.

Sharma, V.K. 2000. Problems of Marine Ecosystems And Sustainability of Coastal Cities: A Focus on Mumbai, India. Indian Journal of Environmental Health, 42(2): 82-91.

Singh, D.P. 2010. Employment Situation in Mumbai: An analysis. Paper presented at Global Labour Conference, Berlin, September 14-16, 2010.

SGLIS (Shanghai Government Legislative Information Service). 2012. Shanghai to Initiate Toughest Water Resource Management System. Accessed at http://www.shanghailaw.gov.cn/fzbEnglish/page/ news21645.htm on 2 September 2013.

Sliuzas, R., G. Mboup, and A. de Sherbinin. 2008. "Expert Group Meeting on Slum Identification and Mapping." Report of a meeting held 21-23 May 2008 at ITC in Enschede, Netherlands.

SOPAC (Pacific Islands Applied GeoScience Commission) and UNEP. 2005. Building Resilience in SIDS: The Environmental Vulnerability Index, SOPAC and UNEP.

SPARC (Society for the Promotion of Area Resource Centres). 2001. "SPARC and its work with the National Slum Dwellers Federation", accessed online at http://www.sparcindia.org/documents/alliance.html on 23 June 2001. 
Springer, K. 2012. Soaring to Sinking: How Building Up Is Bringing Shanghai Down. Time. Accessed at http://science.time.com/2012/05/21/soaringto-sinking-how-building-up-is-bringing-shanghaidown/\#ixzz2p6Q2BU1k on 31 January 2013.

Storch, H., N. Downes, and H. Rujner. 2011. "A scenario-based approach to assessing the exposure and flood risk of Ho Chi Minh City's urban development strategy in times of climate change", In W. Pillmann, S. Schade, and P. Smits (eds.). EnviroInfo 2011: Innovations in Sharing Environmental Observations and Information. Ispra, Italy: Shaker Verlag.

Taubenböck, H., M. Wurm, M. Netzband, H. Zwenzner, A. Roth, A. Rahman, and S. Dech. 2011. Flood risks in urbanized areas - multi-sensoral approaches using remotely sensed data for risk assessment. Natural Hazards Earth Systems Science, 11: 431-444.

TERI (Tata Energy Research Institute). 1996. The Economic Impact of a One Metre Sea Level Rise on the Indian Coastline: Method and Case Studies. Report submitted to the Ford Foundation.

Turner, B. L., R. E. Kasperson, P. A. Matson, J. J. McCarthy, R. W. Corell, L. Christensen, N. Eckley, J. X. Kasperson, A. Luers, M. L. Martello, C. Polsky, A. Pulsipher \& A. Schiller. 2003. A framework for vulnerability analysis in sustainability science. Proceedings of the National Academy of Sciences, 100:8074-8079.

Uejio, C., O. Wilhelmi, J. Samenow, J. Golden, and J. Mills. 2011. Intra-Urban Spatial Patterns of Societal Vulnerability to Extreme Heat. Health \& Place, 17: 498-507.

UK Meteorological Office. 2004. "Catarina hits Brazil: South Atlantic hurricane breaks all the rules," UK Meteorological Office, accessed at http://www.metoffice.com/sec2/sec2cyclone/catarina.html, 21 September 2006

UNDP (United Nations Development Program). 2001. Press Release, accessed online at http://www.undp.org.in/NEWS/PRESS/press138.htm on 23 June 2001.

UNEP/DEWA/GRID-Europe. 2009. Flood frequency. In: ISDR, Global Assessment Report on Disaster Risk Reduction. Geneva, Switzerland: United Nations.

UNHABITAT. 2013. Flood Risk Assessment, Strategies and Actions for Improving Flood Risk Management in Kampala. Nairobi, Kenya: UNHABITAT.

UNHABITAT. 2006. State of the World's Cities, London, UK: Earthscan.

UN Millennium Project. 2005. A Home in the City, Task Force on Improving the Lives of Slum Dwellers. London: Earthscan.

Wikipedia. Mumbai. Accessed at http://en.wikipedia.org/wiki/Mumbai on 20 June 2013 
Wilhelmi, O.V., A. de Sherbinin, and M. Hayden. 2012. "Exposure to Heat Stress in Urban Environments" In: Crews, K., and B. King (eds.), Ecologies and Politics of Health. Oxon, UK: Routledge.

Wilhelmi, O.V., K.L. Purvis and R.C. Harriss. 2004. Designing a geospatial information infrastructure for the mitigation of heat wave hazards in urban areas. Natural Hazards Review, 5(3): 147-158.

Wisner, B, P Blaikie, T Cannon and I. Davis. 2004. At Risk: Natural Disasters, People's Vulnerability and Disasters. London: Routledge.

World Bank. 2010. Climate risks and adaptation in Asian coastal megacities. A Synthesis Report. Washington, D.C.: World Bank.

World Bank. 2006. The Mumbai Slum Sanitation Program: Partnering with Slum Communities for Sustainable Sanitation in a Megalopolis. Washington DC: World Bank and Cities Alliance. Accessed at http://esa.un.org/iys/docs/san_lib_docs/ WSP-Mumbai.pdf on 20 June 2013.

Xu, S. and J. Tao. 1998. "The Geomorphology of Shanghai", in The Dragon's Head: Shanghai, China's Emerging Megacity, H.D. Foster, D. Chuenyan Lai, and N. Zhou (eds). Vancouver: Canadian Western Geographical Series.

Zhang, K., R. Wang, C. Shen, and L. Da. 2010. Temporal and spatial characteristics of the urban heat island during rapid urbanization in Shanghai, China. Environmental Monitoring and Assessment, 169:101112.

Zhang, C. and Y. Wang. 1998. "The Climate of Shanghai", in The Dragon's Head: Shanghai, China's Emerging Megacity, H.D. Foster, D. Chuenyan Lai, and N. Zhou (eds). Vancouver: Canadian Western Geographical Series. 


\section{Chapter 4}

\section{Climatic, Biophysical, and Socioeconomic Factors Affecting Malnutrition in Sub-Saharan Africa $^{24}$}

\footnotetext{
24 This chapter was originally published as de Sherbinin, A. 2009. "The Biophysical and Geographical Correlates of Child Malnutrition in Africa" Population, Space and Place, 17(1): 27-46 (reprinted with permission from John Wiley and Sons). It has been revised and updated for this thesis. I am indebted to the work of Adam Storeygard, formerly of CIESIN and now an Assistant Professor of economics at Tufts University, who compiled the sub-national underweight data utilized in this analysis. I am also grateful for the comments on an earlier draft provided by Maria Muñiz, Sébastien Oliveau, Christian Webersik, and Anita Makri, and for comments made on the draft manuscript by two anonymous reviewers.
} 


\subsection{Introduction}

This chapter introduces a quantitative approach to identifying the biophysical and geographical correlates of child malnutrition in Africa. Vulnerable regions are identified a priori on the basis of child malnutrition levels, which can be considered an outcome variable that reflects local-level vulnerabilities. As mentioned in Section 1.3, because vulnerability is an emergent phenomena, meaning that it emerges from complex system dynamics, it cannot be directly measured. One approach to this problem is to measure outcomes, such as economic losses or mortality from natural disasters. In this chapter, using inductive methods similar to those described by Hinkel (2011), I seek to identify the correlates of malnutrition that can help to elucidate underlying causal mechanisms that contribute to vulnerability. Climate variables emerge from this analysis as potentially important determinants. Consistent with the PNAS framework, the analysis explicitly adopts a coupled humanenvironment system approach by incorporating a series of biophysical, geographical, and socioeconomic indicators into a multivariate regression analysis. The analysis identifies exposure to drought hazard as among the primary correlates of vulnerability, and piped water availability, a measure of income (piped water is a relative luxury in Africa), as a measure of resilience. The analysis is unable to operationalize the broader historical or political economy contexts, and cannot fully capture the dynamic elements of the PNAS framework owing to data gaps or the difficulty of incorporating such factors as culture and history in a multivariate quantitative model.

Climate variability and change is expected to have especially negative impacts on Africa (Busby et al. 2011, Davies and Midgley 2010, Parry et al. 2007). It is also generally recognized that the Green Revolution - a package of genetically improved seeds, fertilizers and pesticides - greatly increased agricultural output and reduced hunger in all developing regions except subSaharan Africa (Evenson and Gollin 2003). Though South Asia has, on average, higher rates of child malnutrition, sub-Saharan Africa not only has the second highest rates but it is the only region whose rates are increasing (Sanchez et al. 2005, Chopra and Darton-Hill 2006). ${ }^{25}$ A number of reasons have been put forward to explain the persistence of hunger in Africa,

\footnotetext{
25 Child malnutrition and hunger are used here interchangeably. Several studies cited in this section make use of data on stunting (low height-for-age) and wasting (low weight-for-height) of children 0 to 5 years of age. The data analyzed in this paper are for the percent of children ages 0 to 5 who are underweight. Children are defined as underweight if their weight-for-age z-scores are two standard deviations below the median of the NCHS/CDC/WHO International Reference Population. I utilize this measure of malnutrition for two primary reasons: (i) data on underweight prevalence is available for all sub-national units in Africa but such is not the case of stunting and wasting, and (ii) the target for the Millennium Development Goals specifies reducing the prevalence of hunger as measured by the percent of children who are underweight.
} 
including the continent's reliance on low-productivity rainfed agriculture, its poor soils, climatic variability, dependence on food aid and cheap imports (which undercuts farmer productivity), poorly developed markets, high transport costs, and the prevalence of diseases such as malaria and diarrhea which affect the physiological uptake of nutrients (Chopra and Darton-Hill 2006, Sanchez et al. 2005, African Green Revolution undated). In this chapter, I test a number of these explanations by examining the covariates of child malnutrition across 367 subnational units using geospatial data sets covering a range of concerns: the constraints to agricultural production due to poor soils, hilly terrain, arid climates, recurrent drought, and accessibility to markets, on the one hand, and health problems such as diarrhea and malaria, which may affect child hunger, on the other.

Child malnutrition is a symptom of food insecurity and broader societal vulnerabilities. According to the UN Food and Agriculture Organization (FAO), "food insecurity exists when people are undernourished as a result of the physical unavailability of food, their lack of social or economic access to adequate food, and/or inadequate food utilization" (FIVIMS undated). Figure 4.1 depicts the distal and proximate determinants of nutritional status, illustrating the complex mix of factors that lead to malnutrition. A number of indirect determinants of malnutrition, such as natural resource endowments and environmental conditions, are rarely tested owing to the fact that the surveys that measure child nutritional status seldom collect such data. Most of the literature on child malnutrition focuses on household-level determinants that are more easily measured by such surveys. Among household-level variables, household income has been found to have a significant impact on malnutrition, as does the education level of parents, and household size and composition (Charmargagwala et al. 2005). Other factors that have been found to be significantly correlated with levels of malnutrition are urban/rural status (malnutrition is higher in rural areas), access to utilities such as safe water and electricity, and access to health services. Finally, the ability of the body to utilize food is affected by the health status of the child, and diarrheal disease in particular is found to increase the risk of malnutrition (Brown 2003).

Prior work on the relationship between geographic/biophysical variables and hunger is limited. A study of the geography of food insecurity in developing countries utilizing national-level data found that food availability was not a significant determinant of malnutrition, but that poverty rates were (Smith et al. 2000). This confirms findings by Sen (1981) that local food availability is secondary to household poverty in determining access to food (and presumably nutritional outcomes), especially in times of drought or famine when the poorest households draw on all their livelihood assets and still cannot afford to buy food. Webb (1998) utilized data for 501 provinces in 45 
countries to examine the relationship of a number of contextual factors to malnutrition, among which were variegated topography, dry marginal lands, and distance from the capital. The first two were found to be significantly correlated with stunting at the .10 level, but the latter was not. However, wasting (a measure of acute short-term malnutrition) was found to be significantly correlated with distance from the capital and road density $(\mathrm{km}$ per $\mathrm{km}^{2}$ ), suggesting, according to Webb (p.6), that "time-bound epidemics or price shocks are made more acute by a lack of access to wider markets or health services."

Balk et al. (2005) studied the correlates of child malnutrition for 19 countries in Africa using Demographic and Health Survey (DHS) individual-level data, and for 43 countries in Africa, Asia and Latin America using data on rural children aggregated to subnational units. ${ }^{26}$ One of the strengths of their work is that both household (e.g., maternal and child characteristics and household socioeconomic status) and environmental factors were incorporated into the models. In the full model for Africa they found sandy soils, too long and too short growing seasons, percent pasture land and distance to port were positively correlated with underweight status, whereas percent tree cover was negatively correlated (all variables significant at the .05 level or higher). For the 43 country analysis, in the full model without country dummies they found all of the following variables were positively correlated with malnutrition: sandy soil, malaria exposure, population density, the fraction of territory occupied by small urban areas, and medium intensity conflicts since 1975. Taken separately (without the household variables), the environmental variables predicted $23 \%$ of the variance in underweight status, with sandy soil positively correlated, and fraction of territory with trees and average food production negatively correlated. Unlike the individual-level analysis, exceptionally long and short growing seasons turned out to be significantly negatively correlated with child malnutrition. ${ }^{27}$

\footnotetext{
26 Their outcome variable was the average weight-for-age z-score, which is highly correlated with the outcome variable in this study, the percentage of children underweight (Pearson's correlation coefficient of 0.96 ). The study only considers children in the age bracket of 1-3 years of age, because below age 1 accurate anthropometry is difficult to obtain, and for several countries anthropometry for children above age 3 did not exist.

27 One reason for this put forward by the authors is that they averaged conditions across the entire subnational unit rather than the portions that are most populated and therefore likely to correspond to the survey areas. Thus, growing seasons may not correspond accurately to where the survey respondents actually live, if for example, the unit is arid in one portion and sub-humid in another. To account for this I removed portions of units populated at 2 persons per sq. $\mathrm{km}$. or below.
} 
In a related work, Balk et al. (2004) used DHS clusters to examine the degree to which spatial factors help to explain patterns of infant and child mortality in West Africa. They found that although spatial factors such as proximity to urban areas, population density, and farming systems have an overall modest effect on both infant and child mortality when the usual demographic and household characteristics are included, they do explain much of the country-specific variation in mortality. Distance of the DHS cluster to the coast was found to have an independent effect, beyond urban residence; the risk of infant death is about 30\% greater at the 90th percentile of the coastal distance distribution than at the 10th percentile. Tree crops were found to be the optimal farming system, with about 30\% and $20 \%$ lower risk of child and infant death, respectively, than other systems. A direct and consistent effect of rainfall was not found, but it was determined that children living in areas with the shortest growing seasons, classified as arid and semi-arid, had 15\% and 12\% higher risks of death, respectively, than children in the optimal range. They posit that environmental factors, while exerting some influence directly on mortality, may also be mediated through individual and household-level factors - in other words, geographical and environmental factors have a direct effect on household income, wealth, education, and other factors that are known to affect infant and child mortality.

Nubé and Sonneveld (2005) analyzed the geographical distribution of underweight children in Africa, examining both the rates and the absolute numbers of children suffering from malnutrition. Although they offer some conjectures about the cause of the observed patterns, such as higher rates of malnutrition being associated with high population densities and soil depletion in the Horn of Africa and agronomic and climatic conditions in West Africa, they do not undertake any kind of quantitative analysis. They cite an earlier West Africa study by Curtis and Hossain (1998) in which aridity zones are suggested to have an impact on child nutritional status.

The work of Webb and particularly Balk et al. (2005) represent significant advances in our understanding of the geographic and biophysical correlates of hunger, and notably these advances have been made possible thanks to increasingly sophisticated of spatial analysis tools (e.g., geographic information systems). However, neither study explicitly addresses the impact of spatial autocorrelation on OLS regression models or take measures to correct for it. Spatial autocorrelation (SA) measures the extent to which an occurrence of an event in one unit constrains or makes more likely an event in a neighboring unit. Like serial autocorrelation in time series data, the 
events are not independent, which violates Gauss-Markov assumptions. ${ }^{28}$ This means that estimated coefficients are biased and inconsistent and that the standard errors are artificially deflated, leading to type I errors (improper rejection of null hypothesis). The approach utilized here to account for spatial autocorrelation will be taken up in the results section.

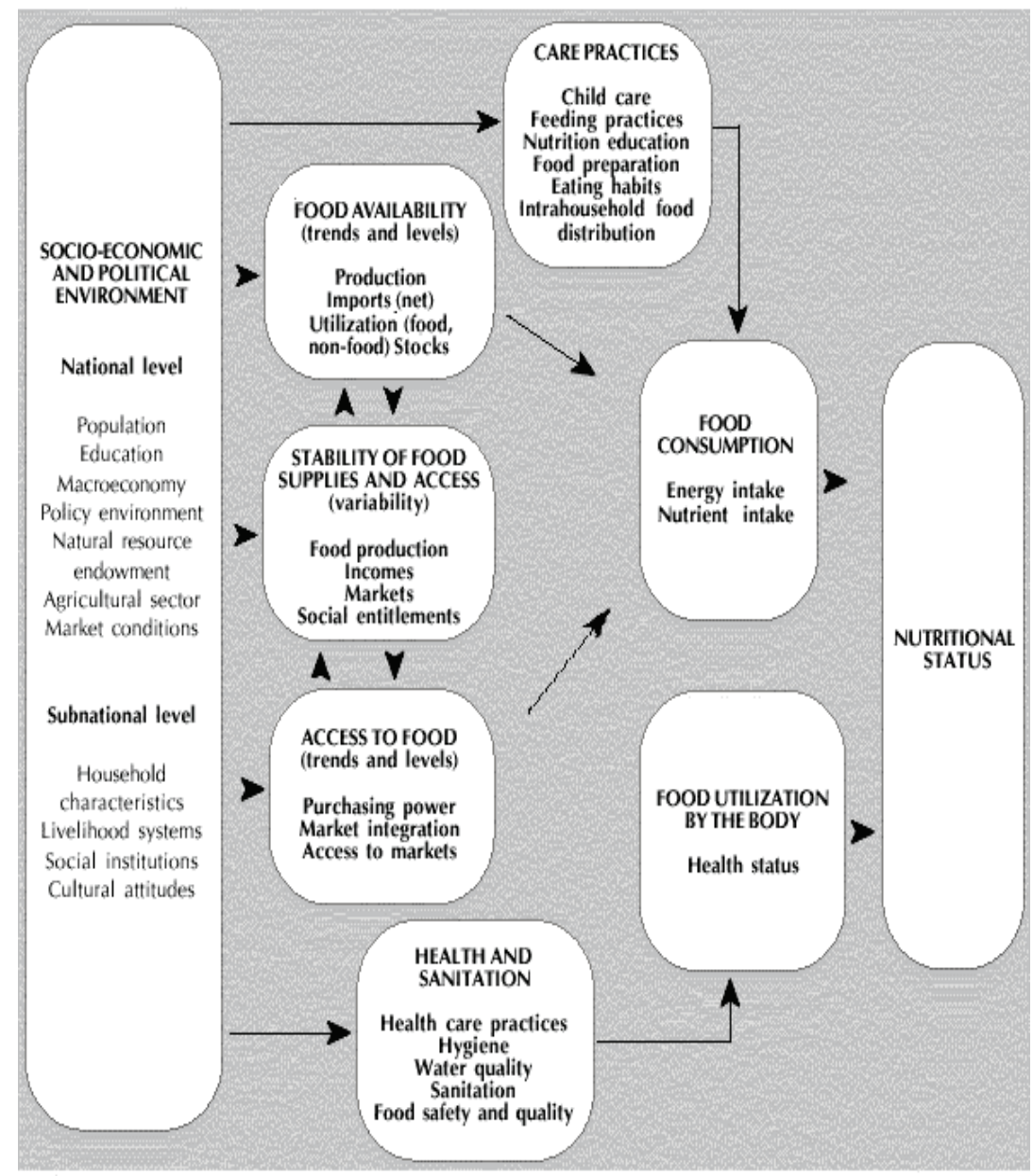

Source: FIVIMS undated.

Figure 4.1: Conceptual framework for understanding the causes of malnutrition

28 If SA is present it can be demonstrated that the assumptions of OLS regression are violated because, just as with time series autocorrelation, the residuals are correlated with themselves. This violates the Gauss-Markov assumption of independence in the error terms. If errors are not independent the regression parameter estimates are not BLUE (i.e., Best Linear Unbiased Estimator). According to Voss et al. (2006), "statistica inference is therefore unreliable because (1) the estimated regression parameters are biased and inconsistent, or (2) standard errors of the parameter estimates are biased." 
This chapter explicitly seeks to introduce the indirect but often overlooked variables that provide the context for household level child malnutrition dynamics. The primary question that I seek to answer is, when controlling for income and health and accounting for spatial autocorrelation, to what degree do biophysical and socioeconomic variables explain spatial variation in vulnerability, as measured by child malnutrition rates? I hypothesize that these factors do indeed predict, at a significant level, patterns of vulnerability. Specifically, I examine a number of biophysical and geographic variables and hypothesize the following relationships:

1. Arid areas will have higher levels of malnutrition than those with more ample rainfall.

2. Drought prone areas will have higher levels of malnutrition than regions with more predictable rainfall regimes.

3. Mountainous and topographically variegated regions will have higher malnutrition than lower lying and flatter regions.

4. Regions with high soil, terrain and climate constraints to agriculture will have higher levels of malnutrition than regions with lower constraints.

5. Isolated areas with poor road networks will have higher levels of malnutrition than areas with good accessibility.

6. Higher population density areas, a surrogate for levels of urbanization, will have lower levels of malnutrition than lower density areas.

7. Malaria-ridden areas will have higher levels of malnutrition than areas with low malaria endemicity.

8. Areas with high diarrhea prevalence will have higher malnutrition than areas with low diarrhea prevalence.

If indeed biophysical, geographical and health variables, which are the "environment" side of the coupled human-environment system, play an important role in determining patterns of hunger in Africa, then policies need to be directed towards mitigating the effects of these constraints so that hunger can be reduced and ultimately eradicated. The implications of this analysis for development policy and climate adaptation are taken up in the concluding section.

\subsection{Methods}

Data on the percent of children underweight were assembled from Demographic and Health Survey (DHS), Multiple Indicator Cluster Survey (MICS), and Africa Nutrition Database Initiative (ANDI) data. ${ }^{29}$ These data were aggregated to the lowest spatial unit for which they are still statistically robust. For many countries this is the provincial or first administrative level,

29 The data were assembled by CIESIN for the Millennium Project Hunger Task Force (Sanchez et al 2005). 
but in other countries the units may encompass sub-national regions of two or more provinces. Box 4.1 provides detail on the methodology utilized to compile the map of the percent of children underweight by sub-national units in Africa, and Figure 4.2 provides the map.

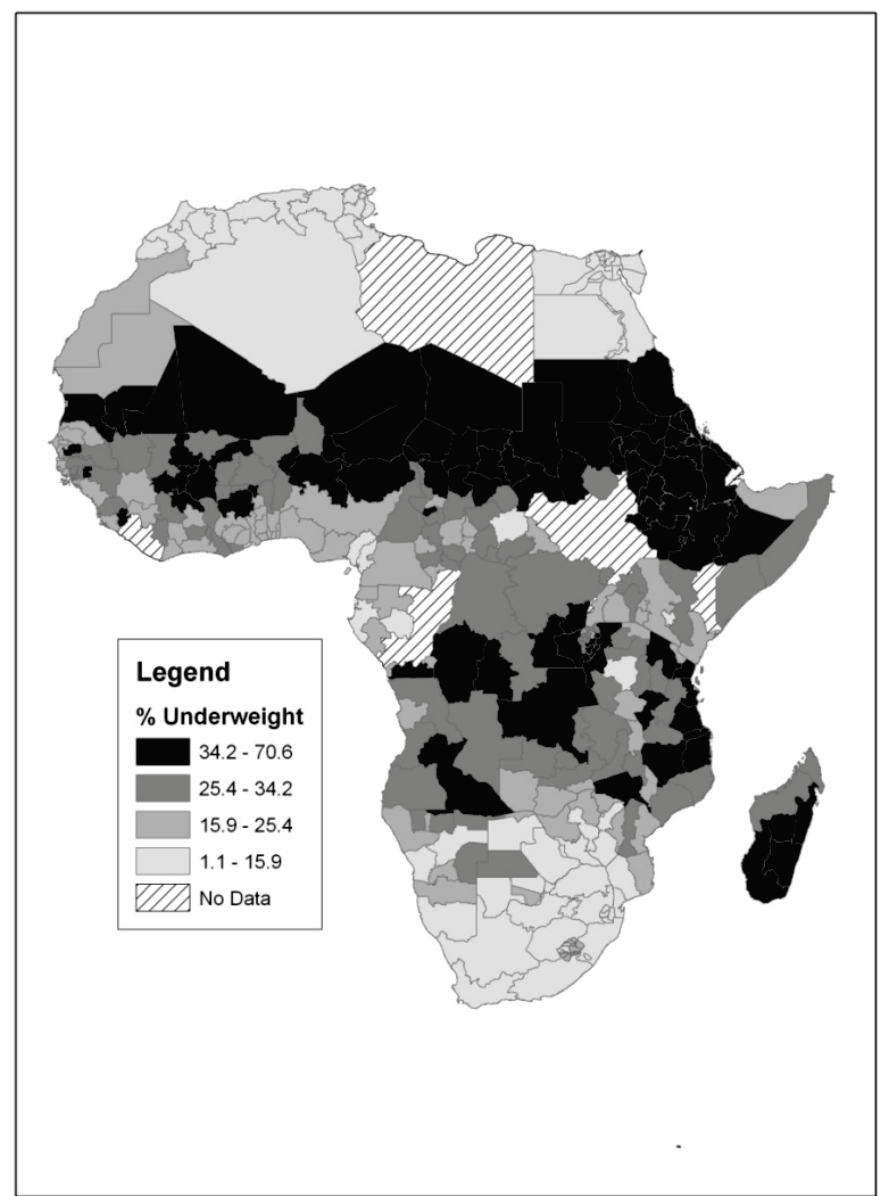

Figure 4.2: Percent of children underweight by subnational region (19922002)

Underweight data are missing for Liberia, Libya, southern Sudan, western Somalia, and the Republic of Congo; corresponding data on diarrheal disease prevalence and piped water are missing for Libya. The date of the underweight data ranges from 1992-2002, with a mean of 1999 and a mode 
of $2000 .^{30}$ There are 367 sub-national units (SNUs) with underweight data for Africa.

Data for all the biophysical and geographical variables were assembled from gridded data sources and aggregated, utilizing a geographic information system (GIS), to obtain mean, maximum, and standard deviation values for the same sub-national units (see Box 4.2 for details). ${ }^{31}$ Thus, the units of analysis for the study are the 367 sub-national units for Africa. The following biophysical, geographical and health variables were tested. Source information on the variables is found in Table 4.1.

1. Rainwater Runoff: Runoff is the proportion of precipitation that is left after evapotranspiration and the soil moisture deficit are satisfied. This is a better measure of water availability than precipitation alone. Because most small holder farmers are dependent on rainfed agriculture, it is important to include a measure of water availability.

2. Number of Drought Incidents (1980-2000): Drought is defined as precipitation less than $75 \%$ of the median for 3 months or more. Whereas runoff reflects long-range moisture availability, drought reflects deviations from the mean that can have significant impacts on agriculture production. This can also be thought of as a measure of the inter-annual variability in rainfall.

3. Average Elevation: Average elevation above sea level is measured in meters. Mountain areas in some sub-regions of Africa correspond to high productivity areas (more moderate climates and possibly volcanic soils), but in others they may correspond to lower productivity, particularly if slopes are steep and soils are easily erodable. ${ }^{32}$

4. Agricultural Constraints: Soil, terrain and climate constraints to agriculture. Approximately $80 \%$ of Africans are employed in the agricultural sector, so it is important to explicitly include measures of

\footnotetext{
${ }^{30}$ The fact that the data are from different years does not in itself pose a problem for this analysis, since most of the independent variables are time invariant at the temporal scale of decades. It would have been desirable to obtain average values of percent underweight for two or more years spanning a decade, since unusual events such as prolonged droughts or civil wars could affect levels of child malnutrition for any given survey year. However, comparable data are not available over time at the subnational level.

31 The roads layer was converted to a grid by buffering the poly-lines to $2 \mathrm{~km}$ on each side and then gridding the data at $1 \mathrm{~km}$ resolution.

32 I also tested the standard deviation of elevation, which would reflect either significant altitude differences within an SNU (e.g. a highland and lowland within a unit) or undulating terrain. However, this variable was highly correlated with average elevation $(r=.559)$ and, in any case, proved to be insignificant in all the models I tested.
} 
land suitability for agriculture. This ordinal variable ranges from 0 , for no constraints, to 7, for maximum constraints.

5. Accessibility: Proportion of the SNU's territory that is within $2 \mathrm{~km}$ of a paved or improved road. Accessibility is an important measure of market access and trade, but also can serve as a proxy for level of urbanization and government service provision.

6. Population Density: This is the average population density, and would reflect either the rural population density or the degree of urbanization, depending on the SNU.

7. Malaria Transmission Index: This is a measure of malaria endemicity. Malaria is a major health concern in Africa, claiming almost 900 thousand lives per year (WHO/UNICEF 2005), and thus any analysis that did not control for its effects would be missing a major factor affecting food utilization. This variable has a theoretical minimum of 0 , for no transmission, and a theoretical maximum of 37 , for very high levels of transmission.

8. Percent of Children with Diarrhea in the Past Two Weeks: This is a standard measure of the prevalence of diarrheal disease. The literature clearly shows that the health status of the child affects food utilization, and diarrheal disease directly affects the ability of a child to assimilate any food consumed (Haddad et al. 1998) (see also Figure 4.1). ${ }^{33}$

\footnotetext{
33 The data for diarrheal disease prevalence and piped water access were available for the same units as the data on child malnutrition, except in a few cases. For Uganda, data on piped water but not diarrhea prevalence were available at the subnational level, so I simply applied the national level diarrhea disease rate from the 2000-01 DHS for all four SNUs. For Namibia, there were more sub-national units in the underweight data set than for the diarrhea and piped water data set, and in the case of Tunisia, the opposite was the case, so I spatially matched the units. In the case of Namibia, I repeated the diarrhea and piped water values across more than one SNU in the malnutrition data set. In the case of Tunisia, I calculated the mean of diarrhea and piped water values for the corresponding malnutrition SNUs.
} 


\section{Box 4.1: Steps utilized to create the underweight data}

1. DHS and MICS data were aggregated to the spatial units at which the surveys report, based on raw data where it was available, and published reports otherwise. These spatial units are typically equivalent to first level administrative regions or aggregations thereof.

2. Geospatial boundary files that match those spatial units were located or created in order to match the reporting regions of the surveys as closely as possible. In many cases, the survey reports contained maps detailing the survey regions. Elsewhere, matches were purely name-based.

3. An analysis of the relationship between the proportions of children underthree and under-five who are underweight was carried out for all countries for which we had data for both age groups. It was determined that there is very close to a $1: 1$ relationship (within 2\%) between the two measures, so where data was available only for children under age 3, they were treated as equivalent to data for children under age 5.

4. Based on steps 1-3, a map was compiled of the proportion of children underweight using the spatial units available.

\section{Box 4.2: Steps utilized to create the independent variables}

1. All data were converted to a $1 \mathrm{~km}$ (30 arc seconds) grid, although the nominal input resolution varied from 30 arc seconds up to 2.5 degrees (see Table 1).

2. Using CIESIN's Global Rural-Urban Mapping Project's $1 \mathrm{~km}$ population grid (CIESIN et al. 2004), portions of sub-national hunger units were removed from consideration because they are thinly populated $(<2$ persons per $\mathrm{km}^{2}$ ). This step was taken to ensure that under-populated areas, where surveys were unlikely to have collected data, would not affect the zonal statistics produced in step 3.

3. In ArcGIS zonal statistics were produced for the remaining areas (populated at $>2$ persons per $\mathrm{km}^{2}$ ) of each sub-national hunger unit rendering means, medians, and standard deviations for each variable.

4. Data were exported to SPSS for data checking and cleaning and for logging of skewed variables, and then to Geoda for spatial regression. 
Table 4.1: Description of variables

\begin{tabular}{|c|c|c|c|}
\hline Code & Description & Source* & Native Resolution \\
\hline $\begin{array}{l}\text { Uw } \\
\text { Biophysic }\end{array}$ & $\begin{array}{l}\% \text { of children underweight } \\
\text { bles }\end{array}$ & DHS, MICS, and ANDI ${ }^{34}$ & SNUs** \\
\hline Runoff & $\begin{array}{l}\text { Mean rainwater runoff (in } \\
\text { millimeters) }\end{array}$ & $\begin{array}{l}\text { UNH/GRDC Runoff Data } \\
\text { (Fekete et al. 2000) }\end{array}$ & 0.5 degree \\
\hline Drought & $\begin{array}{l}\text { Mean number of droughts } \\
1980-2000\end{array}$ & $\begin{array}{l}\text { Brad Lyon, IRI Columbia } \\
\text { University }\end{array}$ & 2.5 degrees \\
\hline Elevation & Mean elevation (in meters) & SRTM Data & 30 arc sec. \\
\hline \multicolumn{4}{|c|}{ Agricultural Variables } \\
\hline Agconst & $\begin{array}{l}\text { Mean agricultural constraints } \\
\text { (index: } 1=\text { no constraints, } 7 \\
=\text { high constraints) }\end{array}$ & $\begin{array}{l}\text { FAO/IIASA GAEZ Study } \\
\text { (Fischer et al. 2000) }\end{array}$ & $5 \mathrm{~min}$. \\
\hline \multicolumn{4}{|c|}{ Geographic Variables } \\
\hline Access & $\begin{array}{l}\text { Proportion of SNU that is } \\
\mathrm{w} / \text { in } 2 \mathrm{~km} \text { of a road }\end{array}$ & VMap0 Roads & $1: 1 \mathrm{~m}$ \\
\hline Popdens & $\begin{array}{l}\text { Population density in the } \\
\text { portion of the SNU above a } \\
\text { density of } 2 \text { persons } / \mathrm{km} 2\end{array}$ & SEDAC'S GRUMP & $1 \mathrm{~km}$ \\
\hline \multicolumn{4}{|l|}{ Health } \\
\hline$\overline{\text { Malaria }}$ & $\begin{array}{l}\text { Mean malaria transmission } \\
\text { index in the SNU (index: } 0= \\
\text { no transmission; } 38=\text { high } \\
\text { trans.) }\end{array}$ & Kiszewski et al. 2004 & 0.5 degrees \\
\hline Diarrhea & $\begin{array}{l}\% \text { of children with diarrhea } \\
\text { in the past } 2 \text { wks }\end{array}$ & DHS and MICS & SNUs** \\
\hline \multicolumn{4}{|c|}{ Income Variables } \\
\hline Gdppc & GDP per capita (2000) & CIA World Fact Book & National \\
\hline Pctpiped & $\begin{array}{l}\% \text { of households with piped } \\
\text { water }\end{array}$ & DHS and MICS & SNUs** \\
\hline
\end{tabular}

* Sources: DHS = Demographic and Health Surveys, MICS = Multiple Indicator and Cluster Surveys, ANDI = Africa Nutrition Database Initiative, UNH = University of New Hampshire Global Water Systems Program, GRDC = Global Runoff Data Center, IRI = International Research Institute for Climate and Society, SRTM = NASA's Shuttle Radar Topography Mission, FAO $=$ Food and Agricultural Organization of the UN, IIASA = International Institute for Applied Systems Analysis, GAEZ = Global Agroecosystem Zone Assessment, VMap0 = Vector Smart Map Version 0, CIESIN's GRUMP: Center for International Earth Science Information Network, Global Rural-Urban Mapping Project.

$* *$ SNUs $=$ Sub-National Units

Two "control" variables related to income were utilized in this analysis: gross domestic product (GDP) per capita, and a proxy variable measuring the percentage of households with access to piped water. Data for gross domestic product per capita were not available at the sub-national level, but I include it nevertheless because, according to the literature, income is an important determinant of malnutrition. Piped water as a percent of total supply is a useful proxy for income as well as urbanization, since only better off and more urban households are likely to have this amenity. It should be noted that piped water can also have health effects on malnutrition by improving water quality, reducing disease, and thereby increasing food uptake by the body.

34 The completed data set on Global Subnational Prevalence of Child Malnutrition, v1 $(1990-2002)$ is available for Africa and other developing country regions (see CIESIN 2005). 
The data assembled here, particularly the geographic and biophysical data, are not without shortcomings. Data on rainwater runoff and agricultural constraints are subject to uncertainty due to measurement errors. The Digital Chart of the World (DCW) roads data are incomplete for much of Africa (Nelson et al. 2006). Data on drought incidence, elevation, and malaria transmission are marginally better, but still have an unknown level of error. Another issue that cannot be addressed in this study is that, even with the use of sub-national units rather than national-level aggregates, it must be understood that the average value for a given unit may not accurately represent the conditions prevailing where the majority of children are surveyed. This is particularly the case, for example, of units straddling climatic zones such as sub-humid to arid. It can be expected that the majority of the population will reside in the sub-humid zone, whereas the average rainfall runoff value may be quite low because the majority of the unit is in the arid climatic zone. To partially compensate for this, I only averaged the values of the geographic and biophysical variables over that portion of the unit that is populated at greater than 2 persons per square $\mathrm{km}$. Notwithstanding the shortcomings of the data, as a first approximation at continental and regional scales of analysis, I feel these measures are robust and represent important but often overlooked determinants of malnutrition that can help to illuminate policy options as well as to guide future research using better, more spatially disaggregated data.

Maps of some of the biophysical, geographic, and health variables aggregated to sub-national units can be found in Figure 4.3. Most variables approximated a normal distribution, but four variables required log transformations owing to highly skewed distributions. These included runoff, elevation, population density and the malaria transmission index.

\subsection{Results}

Table 4.2 shows descriptive statistics for each of the variables. The dependent variable, percent of children underweight, ranges from $1 \%$ (for South Sinai, Egypt) to $70.6 \%$ (for Kanem, Tchad), with a mean of about $25 \%$ and a standard deviation of $13 \%$. Mean runoff - that portion of precipitation which runs off the land after evapotranspiration and the soil moisture deficit is met - ranges from 0 (for large portions of arid and semi-arid Africa) to 2,444 mm (for Conakry, Guinea) (Figure 3a). Over the twenty year period 1980-2000, the average SNU experienced approximately 4 droughts, although Northern Kordufan, Sudan, experienced a maximum for the continent of 12.3. The belt of highest drought incidence is largely in the Sahel and sub-humid areas (Figure 3b). Mean elevation for populated areas of the sub-national units is 673 meters, with a standard deviation of 579 meters. The maximum elevation unit, at $2,708 \mathrm{~m}$, is Mokhotlong, Lesotho. Agricultural 
constraints are quite high across most units, with a mean of 5.6 out of 7 (maximum constraints), and a standard deviation of less than one. Similarly, access to roads is quite poor in Africa; even considering only the more densely settled portions of each unit, on average only $30 \%$ of the populated area is within 2 kilometers of a road. Population density is also low compared to many other continents, ranging from only 2.6 persons per square $\mathrm{km}$ in the most arid zones to 6,436 persons in the most urbanized SNU, Bangui, Central Africa Republic, with an average of 323 persons per square $\mathrm{km}$. Malaria is well known to be a significant problem in Africa, and this is borne out by the data; the average malaria transmission index is 10 out of 38, with a standard deviation of 9 . Diarrhea is quite prevalent, with an average of one in five children in these units having had an episode of diarrhea in the past two weeks. Apart from northern and southern Africa, GDP per capita is low, averaging only $\$ 2,400$. Finally, across all SNUs an average of only $40 \%$ of households has piped water. 

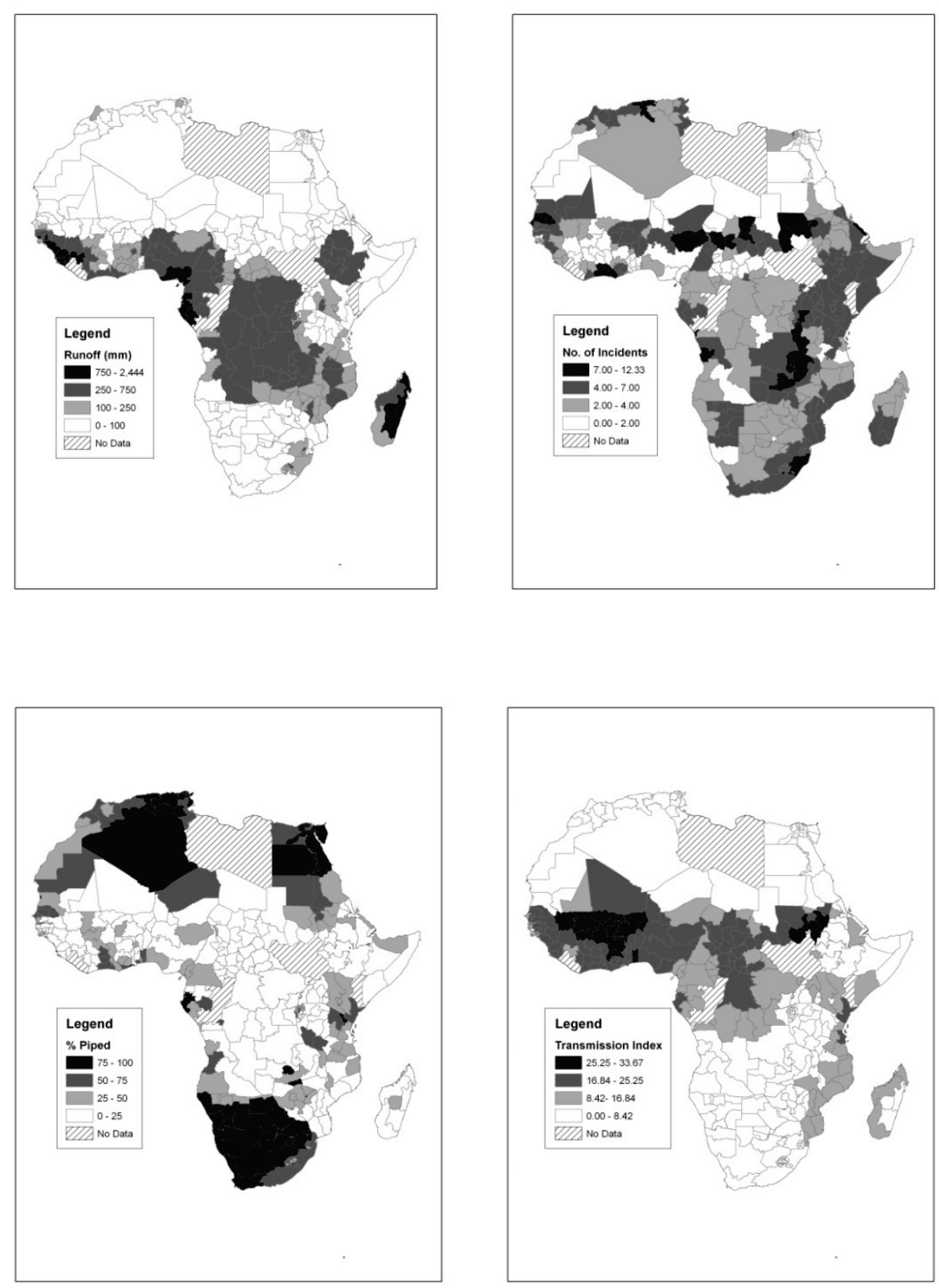

Figure 4.3: Biophysical, Geographic, and Health Variables: (a) Runoff ( $\mathrm{mm})$, (b) Drought Incidence 1980-2000, (c) \% of Households with Piped Water, and (d) Malaria Transmission Index 
Table 4.2: Descriptive statistics

\begin{tabular}{|c|c|c|c|c|}
\hline Variable Name & Min. & Max. & Mean & Std. Dev. \\
\hline$\%$ of Children Underweight (uw) & 1.1 & 70.6 & 25.1 & 13.2 \\
\hline Mean runoff (runoff) & 0.0 & 2444.0 & 228.6 & 354.6 \\
\hline Mean drought frequency (drought) & 0.0 & 12.3 & 3.9 & 2.3 \\
\hline Mean elevation (elevation) & 3.2 & 2708.4 & 673.4 & 579.9 \\
\hline Mean agricultural constraints (agconst) & 0.7 & 7.0 & 5.6 & 0.9 \\
\hline Proportion of SNU within $2 \mathrm{~km}$ of a road (access) & 0.0 & 1.0 & 0.3 & 0.2 \\
\hline Population Density (persons per sq. km) (podens) & 2.6 & $6,436.6$ & 323.4 & 847.8 \\
\hline Mean malaria transmission index (malaria) & 0.0 & 33.7 & 10.4 & 9.3 \\
\hline $\begin{array}{l}\% \text { of children with diarrhea in past } 2 \text { weeks } \\
\text { (diarrhea) }\end{array}$ & 0.6 & 49.1 & 19.7 & 8.7 \\
\hline GDP per capita (gdppc) & 500.0 & $10,700.0$ & $2,413.9$ & $2,427.7$ \\
\hline$\%$ of households with piped water (pctpiped) & 0.0 & 100.0 & 40.2 & 30.9 \\
\hline
\end{tabular}

$\mathrm{N}=367$

The correlation matrix (Table 4.3) shows a number of significant correlations between the independent variables and the proportion of children in the unit that are underweight, most of them in the expected direction. Those that are significant and have the expected sign include drought frequency $(+)$, mean elevation $(+)$, accessibility to roads $(-)$, population density $(-)$, the malaria transmission index $(+)$, diarreal disease prevalence $(+)$,GDP per capita $(-)$, and piped water (-). The last two income variables are strongly correlated, at $r=-.540$ and $r=-.661$, respectively. Surprisingly, runoff is positively related to child malnutrition at the .01 level, which partly reflects the low rates of malnutrition in highly arid North Africa and relatively arid but prosperous parts of southern Africa. There is also an insignificant but positive relationship between agricultural constraints and child malnutrition.

Table 4.3: Correlation matrix of all variables

\begin{tabular}{|c|c|c|c|c|c|c|c|c|c|c|c|}
\hline & 3 & 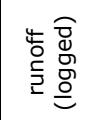 & $\begin{array}{l}\text { 듬 } \\
\text { 음 } \\
\text { 옴 }\end{array}$ & 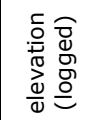 & $\begin{array}{l}\overleftrightarrow{\dddot{n}} \\
\check{0} \\
\stackrel{0}{\sigma}\end{array}$ & 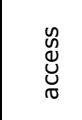 & 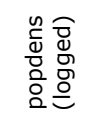 & 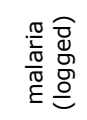 & $\begin{array}{l}\frac{\pi}{0} \\
\stackrel{1}{1} \\
\frac{1}{L} \\
\frac{10}{0}\end{array}$ & $\begin{array}{l}\text { ஜn } \\
\text { ত̆ }\end{array}$ & 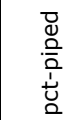 \\
\hline & 1.000 & $.207^{* *}$ & $.165^{* *}$ & $.246^{* *}$ & .033 & $-.403^{* *}$ & $-.396^{* *}$ & $.429^{* *}$ & $.487^{* *}$ & $-.540^{* *}$ & $-.661^{* *}$ \\
\hline off (log) & $.207^{* *}$ & 1.000 & $.105^{*}$ & $.124^{*}$ & $-.409^{* *}$ & $-.263^{* *}$ & -.075 & $.322^{* *}$ & $.315^{* *}$ & $-.440^{* *}$ & $-.434^{* *}$ \\
\hline ught & $.165^{* *}$ & $.105^{*}$ & 1.000 & $.142^{* *}$ & $-.198^{* *}$ & -.098 & -.084 & .025 & .084 & -.021 & -.047 \\
\hline vation (log) & $.246^{* *}$ & $.124^{*}$ & $.142^{* *}$ & 1.000 & .004 & $-.422^{* *}$ & $-.287^{* *}$ & $-.273^{* *}$ & .066 & .067 & $-.163^{* *}$ \\
\hline onst & .033 & $-.409^{* *}$ & $-.198^{* *}$ & .004 & 1.000 & .097 & -.019 & $-.062^{*}$ & $-.166^{* *}$ & .079 & $.112^{*}$ \\
\hline$\overline{\text { ess }}$ & $-.403^{* *}$ & $-.263^{* *}$ & \begin{tabular}{|l|}
-.098 \\
\end{tabular} & $-.422^{* *}$ & .097 & 1.000 & $.540^{* *}$ & $\begin{array}{l}-.096 \\
\end{array}$ & $-.231^{* *}$ & $.283^{* *}$ & $.415^{* *}$ \\
\hline dens (log) & $-.396^{* *}$ & -.075 & -.084 & $-.287^{* *}$ & -.019 & $.540^{* *}$ & 1.000 & $-.320^{* *}$ & $-.332^{* *}$ & .084 & $.529^{* *}$ \\
\hline laria (log) & $.429^{* *}$ & $.322^{* *}$ & .025 & $-.273^{* *}$ & -.062 & -.096 & $-.320^{* *}$ & 1.000 & $.367^{* *}$ & $-.452^{* *}$ & $-.543^{* *}$ \\
\hline rrhea & $.487^{* *}$ & $.315^{* *}$ & .084 & .066 & $-.166^{* *}$ & $-.231^{* *}$ & $-.332^{* *}$ & $.367^{* *}$ & 1.000 & $-.408^{* *}$ & $-.507^{* *}$ \\
\hline $\mathrm{spc}$ & $-.540^{* *}$ & $-.440^{* *}$ & -.021 & .067 & .079 & $.283^{* *}$ & .084 & $-.452^{* *}$ & $-.408^{* *}$ & 1.000 & $.608^{* *}$ \\
\hline$\overline{\text { piped }}$ & $-.661^{* *}$ & $-.434^{* *}$ & -.047 & $-.163^{* *}$ & $.112^{*}$ & $.415^{* *}$ & $.529^{* *}$ & $-.543^{* *}$ & $-.507^{* *}$ & $.608^{* *}$ & 1.000 \\
\hline
\end{tabular}

** Correlation is significant at the 0.01 level (2-tailed).

* Correlation is significant at the 0.05 level (2-tailed). 
The strongest correlations are among the income variables, especially the piped water variable, and a number of the independent variables. For piped water access, accessibility and population density are positively correlated, whereas runoff, malaria endemicity, and diarrhea prevalence are strongly negatively correlated, and elevation is moderately negatively correlated. This suggests that higher income and more urbanized SNUs are more accessible and densely settled, suffer from less malaria and diarrheal disease, and are at lower elevations. The malaria transmission index and GDP per capita are negatively correlated $(r=-.452)$, confirming the hypothesis of Sachs and Malaney (2002) that malaria endemicity affects economic performance and represents a significant barrier to poverty alleviation efforts. Interestingly, population density is also negatively correlated $(r=-.320)$, suggesting that malarial areas are associated with lower population densities, and may have even been avoided for dense settlement. None of the bi-variate correlations among the independent variables approach 0.80 , which would raise concerns about multi-collinearity among the variables.

The results of an ordinary least squares (OLS) regression model are found in Table 4.4. As can be seen, all the independent variables except the log of population density are found to be significantly correlated with child malnutrition. The results are not surprising, insofar as the dependent and independent variables are spatially autocorrelated. Spatial autocorrelation (SA) can be thought of as the extent to which the occurrence of an event in a given unit constrains, or makes more probable, the occurrence of an event in a neighboring unit (Anselin 1988). It is more likely that units with high levels of malnutrition will be surrounded by units with similarly high levels of malnutrition, and that units with low malnutrition will be surrounded by units with similarly low levels.

Table 4.4: Ordinary Least Squares model results

\begin{tabular}{|l|c|r|r|}
\hline \multirow{2}{*}{$\begin{array}{l}\text { Dependent Variable: \% of Children } \\
\text { Underweight }\end{array}$} & \multicolumn{2}{|l|}{ Unstandardized Coefficients } & $\begin{array}{l}\text { Standardized } \\
\text { Coefficients }\end{array}$ \\
\cline { 2 - 4 } & \multicolumn{1}{|l|}{ B } & \multicolumn{1}{l|}{ Std. Error } & Beta \\
\hline Constant & 7.688 & 5.401 & \\
\hline Log of Average Runoff & $-1.135^{* * *}$ & .245 & -.204 \\
\hline Average No. of Drought Incidents ('80-'00) & $.691^{* * *}$ & .195 & .124 \\
\hline Log of Average Elevation & $2.069 * * *$ & .397 & .223 \\
\hline Average Agricultural Constraints & $1.268^{*}$ & .564 & .086 \\
\hline Proportion of area within 2km of a road & $-7.825^{*}$ & 3.186 & -.113 \\
\hline Log of Population Density & .462 & .425 & .056 \\
\hline Log of Average Malaria Transmission & $2.197 * * *$ & .529 & .197 \\
\hline$\%$ of children with diarrhea in past 2 weeks & $.275^{* * *}$ & .061 & .183 \\
\hline GDP per capita & $-.001 * * *$ & .000 & -.244 \\
\hline$\%$ of households with piped water & $-.148 * * *$ & .025 & -.352 \\
\hline
\end{tabular}

$* \mathrm{p}<.05, * * \mathrm{p}<.01, * * * \mathrm{p}<.001$

$\mathrm{R}^{2}=.58$, Log likelihood $=-1296.3$

$\mathrm{N}=367$ 
Figure 4.2 illustrates the high degree of spatial clustering of child malnutrition in Africa. Units with a high percentage of malnourished children are generally surrounded by similar units, and SNUs with low malnutrition are similarly spatially clustered. In Figure 4.4, the average percent of children underweight of all SNUs bordering a given unit (known as "queen contiguity") are transformed into $z$-scores (standard deviations from the mean), as are the values for the given unit. The given unit's $z$-score is represented on the $X$ axis, whereas the average $z$-score for neighboring units is on the $Y$ axis. As can be seen these are highly correlated; in fact, the Moran's $I$, which is similar to the Pearsonian correlation coefficient, is +0.628 , indicating high levels of positive spatial autocorrelation in the dependent variable. Most of the independent variables demonstrate similar patterns of non-random spatial clustering (see Figure 4.3). This presents particular problems for OLS regression, which assumes independence among observations. The result is that estimated coefficients are biased and inconsistent, and residuals/standard errors are artificially deflated leading to type I errors - an incorrect rejection of the null hypothesis that there is no statistical relationship (Voss et al. 2006).

A telltale sign of spatial autocorrelation in OLS model results is the spatial clustering of residuals, as found in Figure 4.5. Here we find clusters of SNUs in the eastern Sahel stretching through Ethiopia, in Madagascar, and in southern Africa where the OLS model under-predicts child malnutrition, and other clusters in North Africa, Central Africa, Uganda, and southeastern Africa where the model over-predicts malnutrition. The Moran's $I$ for the residuals is $0.421(p<0.001)$, indicating that the standard regression estimates cannot be trusted. 


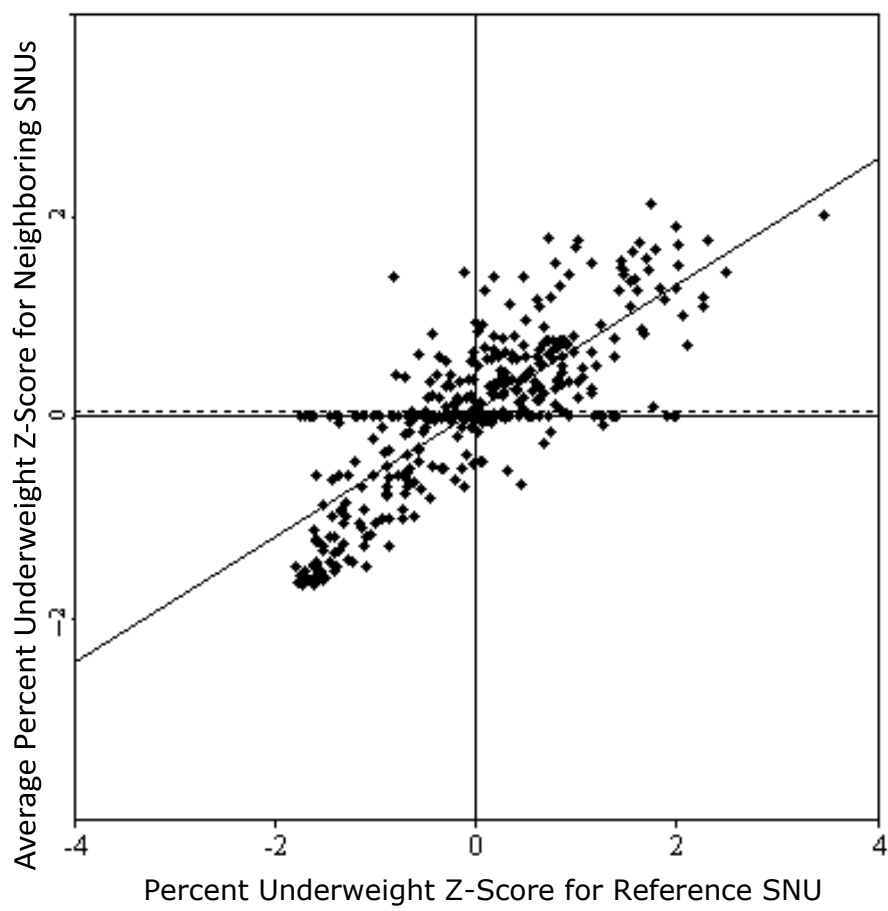

Figure 4.4: Moran's I for the dependent variable (Moran's $I=0.628$ ) 


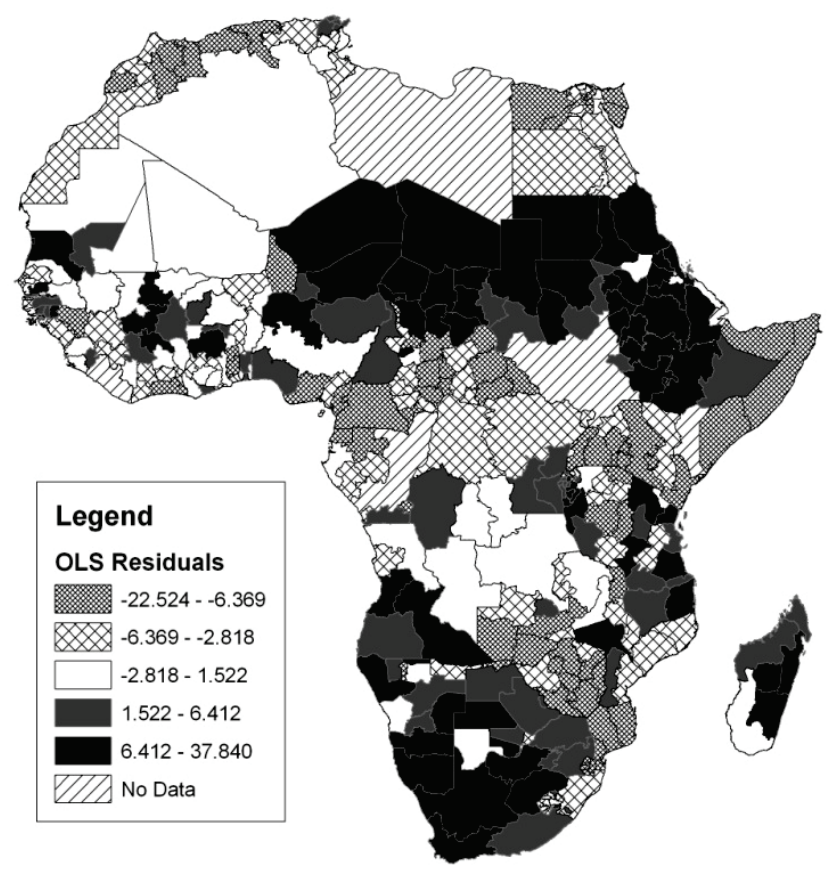

Figure 4.5: Map of the Residuals for the OLS Regression Model

To correct for SA, following diagnostics described in Anselin (2005: 199-200), I ran a spatial error model with first order queen contiguity. ${ }^{35}$ According to Voss et al. (2006, p.382):

"Under this specification, spatial autocorrelation in the dependent variable results from exogenous influences. Portions of the spatial autocorrelation may be "explained" by the included independent variables (themselves spatially autocorrelated) and the remainder is specified to derive from spatial autocorrelation among the disturbance terms. The latter is assumed to occur because of one or more relevant spatially autocorrelated variables is omitted from the design matrix, $\mathrm{X}$. Said another way, it is, in part, the error structure that is the vehicle by which spatial autocorrelation appears in the vector, y."

The results of the spatial error (SE) model are presented in Table 4.5. Overall, the model has a pseudo R-square of 0.79 , indicating that the independent variables in the model explain approximately three-quarters of

35 I also ran a Spatial Lag model. Results for this model resulted in a lower log likelihood $(-1,219)$ and a lower R-squared $(0.75)$ than the spatial error model, suggesting the spatial error model is a better fit. 
the variation in underweight status in the sub-national units. Also, the log likelihood increased from the OLS model's $-1,296$ to $-1,195$. Figure 4.6 shows that the problem of spatial autocorrelation among the residual terms is largely solved by this model. The amount of spatial clustering of the residuals is reduced (i.e. the residuals appear to be more randomly distributed), and the Moran's $I$ of the SE residuals is reduced from 0.421 to -0.197 , indicating that the model produces slight negative spatial autocorrelation among the residuals. Figure 4.7 shows that the spread of the residuals is substantially reduced in the SE model when compared to the OLS model, which is another sign that the SE model has succeeded in correcting for spatial autocorrelation among the variables. Importantly, many of the highly significant variables in the OLS model are no longer significant in the spatial error model. Only two independent variables remain highly significant $(p<0.001)$ : drought frequency and the percentage of households with piped water. The health variable, incidence of diarrhea in the past two weeks, is reduced from highly significant to significant $(p<0.05)$. Per capita GDP is on the cusp of being significant $(p<0.10)$. A number of the coefficients also change signs, although none of the affected variables are significant.

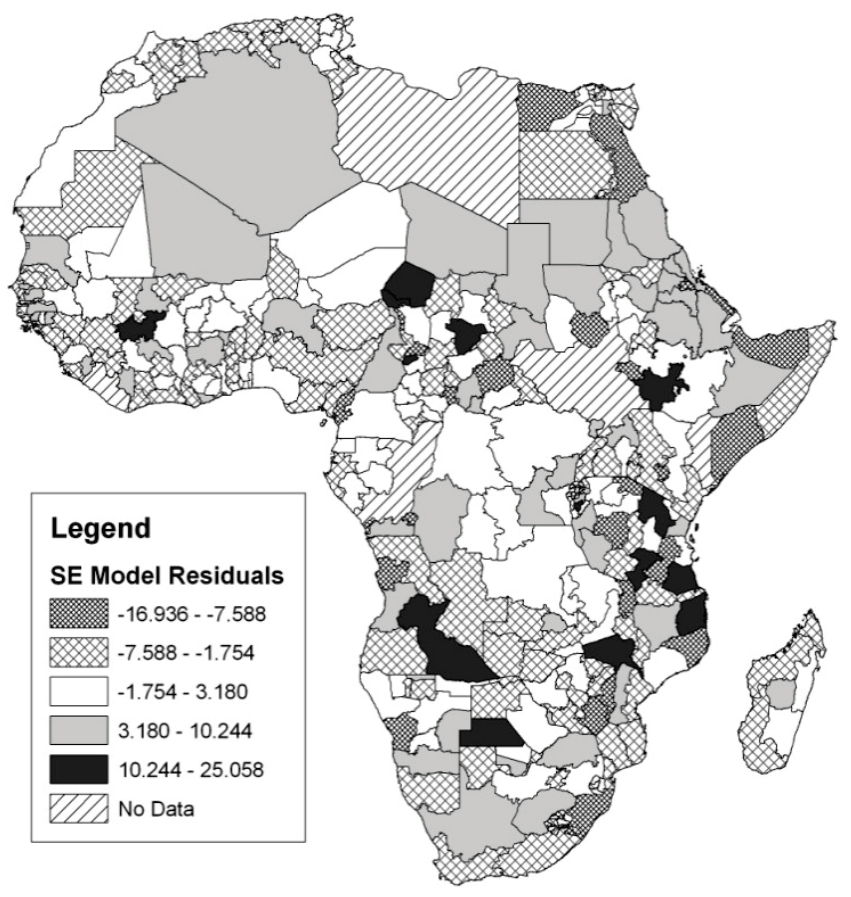

Figure 4.6: Map of Residuals for the Spatial Error Model 


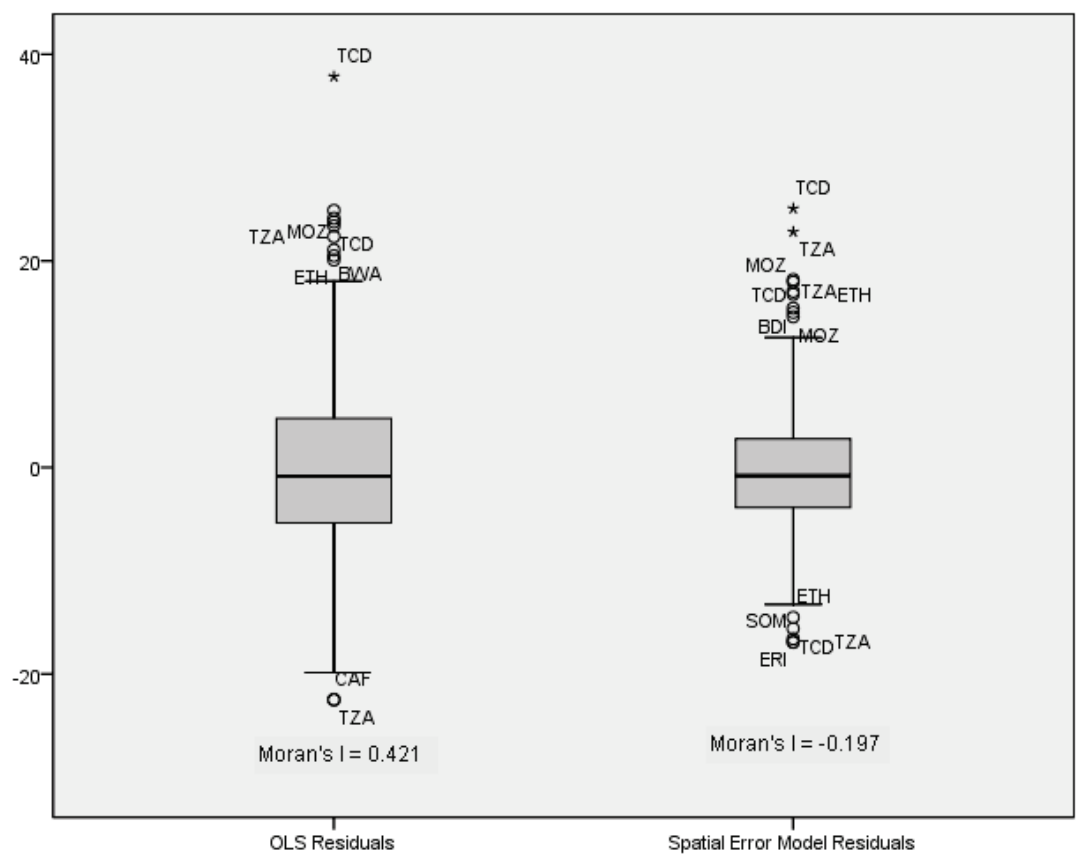

ISO-3 Codes: $\mathrm{TCD}=$ Chad, $\mathrm{TZA}=$ Tanzania, $\mathrm{MOZ}=$ Mozambique, BWA $=$ Botswana, $\mathrm{CAF}=$ Central African Rep., $\mathrm{BDI}=$ Burundi, $\mathrm{SOM}=$ Somalia, $\mathrm{ERI}=$ Eritrea

Figure 4.7: Boxplot of OLS and SE Model Residuals (Labels Represent Country ISO-3 Codes)

Table 4.5: Spatial error model results

\begin{tabular}{|l|c|c|}
\hline Dependent Variable: \% of Children Underweight & Coefficient & $\begin{array}{l}\text { Change in } \\
\text { Sign from OLS }\end{array}$ \\
\hline Constant & $26.2077 * * *$ & \\
\hline Log of Average Runoff & 0.2296 & Yes \\
\hline Average No. of Drought Incidents (1980-2000) & $0.6994^{* * *}$ & \\
\hline Log of Average Elevation & -0.3128 & Yes \\
\hline Average Agricultural Constraints & 0.4245 & \\
\hline Proportion of area within 2km of a road & -4.1806 & \\
\hline Log of Population Density & -0.3606 & Yes \\
\hline Log of Average Malaria Transmission & -0.5173 & Yes \\
\hline$\%$ of children with diarrhea in past 2 weeks & $0.1119^{*}$ & \\
\hline GDP per capita & -0.0006 & \\
\hline$\%$ of households with piped water & $-0.1096 * * *$ & \\
\hline Lambda (autoregressive error term) & $0.9831 * * *$ & \\
\hline
\end{tabular}

$* \mathrm{p}<.05, * * \mathrm{p}<.01, * * * \mathrm{p}<.001$

$\mathrm{R}^{2}=.79$

Log likelihood $=-1194.9$

$\mathrm{N}=367$ 


\subsection{Discussion}

The spatial error model reduced the number of significant variables substantially, although it would be going too far to suggest that the independent variables that were eliminated are irrelevant to the understanding patterns of child malnutrition in Africa. What is more likely is that one of the most significant variables in the spatial model, the percentage of households with piped water, serves as a proxy for a number of issues relevant to climate resilience and overall wellbeing. As discussed earlier, firstly piped water represents an income variable, insofar as only more affluent households in Africa are likely to have this form of water supply. The majority of households obtain water from wells (communal or private), public spigots, or open water bodies. Secondly, piped water represents a proxy for the level of urbanization in an SNU, since water works are largely an urban phenomenon in Africa. Lastly, piped water exerts a direct health effect, is strongly negatively correlated with diarrhea disease prevalence ( $r=-.507)$, and hence serves to improve food assimilation.

The fact that piped water serves as a "stand in" of sorts for a number of the variables in this analysis is confirmed both by its high correlations with other independent variables in the correlation matrix (Table 4.3), and what happens to the significance of other variables when this variable is removed from the SE model. Population density, an alternative measure of urbanization, becomes highly significant, as does per capita GDP. Diarrheal disease prevalence is no longer significant at the .05 level, but at the .10 level.

It is no great surprise that child malnutrition is negatively correlated with urbanization levels and income. Isolated regions that are less connected to markets are more likely to suffer from malnutrition than more highly urbanized and accessible regions. Isolated regions have been described as "spatial poverty traps" in the literature, and they are marked by low market penetration and lack of health services (Hyman et al. 2005, Scott 2006).

In terms of the biophysical and agricultural variables, only one variable, drought prevalence, trumps all others. The fact that average water availability, as represented by runoff, is not highly correlated with malnutrition may be explained by the fact that agricultural systems including transhumant and pastoralist systems - in semi-arid regions are largely adapted to low water availability, but that shocks to the system in the form of drought have greater impacts on livelihoods by periodically depleting households of resources (de Sherbinin et al. 2008). Drought obviously also operates directly on child malnutrition, by reducing harvests and food availability, and may exercise an indirect effect through the mother's workload. Nankhuni and Findeis (2006) posit that natural resource scarcity 
impacts upon a mother's work time allocation for child care, which presumably would have an impact on child nutrition.

The fact that water availability (runoff) is not significant may also be explained by regional patterns of development levels that appear to suggest little correlation between economic development and water availability. Northern Africa and southern Africa are both relatively water scarce but, by continental standards, highly developed. On the other hand, some of the most water abundant regions, such as Sierra Leone, the Democratic Republic of Congo, Angola, and northern Madagascar, all have relatively high child malnutrition rates ( $>30 \%$ underweight status). These countries are mired in chronic poverty and, in the first three instances, have experienced persistent conflict.

Thus, it appears the overall abundance of water per se does not give a region any particular advantages in terms of food security and climate resilience. Diarrheal disease prevalence is positively correlated with runoff, suggesting that some combination of parasite abundance and under-developed water delivery infrastructure (which is negatively correlated with runoff) might be contributing to malnutrition via diarrheal disease prevalence (de Sherbinin 2003).

The fact that elevation proved to have an inconclusive association with child malnutrition is not entirely surprising. Although highland areas such as Ethiopia, parts of the Great Lakes region, Southern Angola, and eastern Madagascar are high elevation $(>1,000 \mathrm{~m})$ hunger "hotspots", there are vast swaths of the Sahel that have very high child malnutrition and are situated at low elevations. The low elevation coastal areas have generally very low levels of child malnutrition, except in the cases of Tanzania and northern Mozambique.

The fact that high agricultural constraints (soil, terrain, and climate) are insignificant in the SE model and barely significant in the OLS model may suggest that the data set inadequately captures the real constraints to agriculture. Soil maps of Africa are notoriously poor and out of date, having been based on a very sparse sampling frame, and a major effort is underway (the Africa Soil Information System or AfSIS) to improve the quality of soils data for the continent (Sanchez et al. 2009). Terrain constraints, i.e. steep slopes, are of secondary importance in the African context (when compared to Central America, the Andes, or the Himalayas), and the major climate constraint is already captured in the drought variable.

In terms of the geographic variables (proportion of the SNU that is within $2 \mathrm{~km}$ of roads and population density), as discussed above, these variables 
may be captured by the piped water variable. Furthermore, as stated earlier, the roads data in the Digital Chart of the World (DCW) are known to be incomplete for a number of countries. An improved roads data set has recently become available (CIESIN and ITOS 2013), although the inconsistencies in road density across countries might result in greater errors than simply relying on DCW.

The lack of significance for malaria prevalence in the SE model when compared to standard OLS model (in which malaria was found to be highly significant) is somewhat surprising. It may be that because malaria is so highly spatially clustered (Figure 4.3d), in a belt from West Africa to Ethiopia, that the spatial error model reduces its relative influence.

Overall, the SE model confirms a number of findings from earlier studies. The piped water variable, a proxy for income, accessibility, and child health, was found to be negatively correlated with malnutrition, confirming prior studies in which these factors were found to be significant. Unlike the Webb and Curtis and Hossain studies, drylands or aridity per se were not found to be significant determinants of child malnutrition, though differences in country selection make comparisons difficult. Unlike Webb, elevation, which is related to topography, was not found to be positively correlated with malnutrition. The Balk et al. (2005) study found sandy soils and malaria exposure to be positively correlated with malnutrition, neither of which is confirmed by this study (if soil constraints are correlated with sandy soils, which is uncertain). Yet Rice et al. (2000) find that undernutrition is a significant contributor to susceptibility to malaria, which may explain the strong bivariate relationship found in Table $3(r=.429, p<0.01)$.

Overall, while differences in methods and units of analysis in this study make direct comparisons with earlier studies difficult, it can certainly be said that inadequate consideration of spatial autocorrelation in earlier studies may have resulted in biophysical/geographic variables being considered significant determinants (or correlates) of malnutrition when in fact they were not. On the other hand, as Voss et al. (2006) point out, spatial models of the kind presented in this chapter carry with them some ambiguity in terms of interpretation. This is particularly the case where pairwise correlations among the dependent and independent variables are strong and highly significant as in the case of malaria, for which piped water cannot be said to serve as a "stand in" - yet spatial models find them to be insignificant.

Ultimately, this analysis seems to support Balk et al.'s (2004) suggestion that while environmental factors may affect vulnerability directly, they are more likely to be mediated through individual and household-level factors such as household income, wealth, education, and other factors that are known to 
affect malnutrition. Hence, the household level variables that act as surrogates for urbanization, income, and levels of education (piped water and diarrhea incidence) are found, ultimately, to predict most of the child malnutrition, with the robust finding that controlling for these factors, frequent droughts represent a significant additional shock to household food security.

One contribution this study makes is the introduction of data from DHS and MICS surveys into spatial climate vulnerability assessment. These data have not been adequately exploited in spatial $\mathrm{VA}$, a point I return to the concluding chapter (Chapter 6).

\subsection{Recommendations for Development Policy and Climate Adaptation}

The results suggest, within the limits imposed by this kind of continental scale analysis, that a number of the biophysical, geographical, and health variables that one might expect to have a strong independent impact on malnutrition are found to be insignificant when controlling for income and urbanization (piped water) and child health (piped water and diarrhea). The outstanding exception to this statement is drought prevalence, which has a strong independent impact on child malnutrition outcomes, a proxy for vulnerability, even controlling for income and urbanization levels.

Drought is a persistent problem in many parts of Africa, and it is projected to increase in frequency and intensity in the context of climate change (IPCC 2012, McElroy and Baker 2012, Parry et al. 2007). According to the IPCC Working Group II fourth assessment regional report on Africa (Boko et al. 2007), drought has already been on the rise since the 1970s. The authors state that "Increased interannual variability has ... been observed in the post1970 period, with higher rainfall anomalies and more intense and widespread droughts reported" (p.436). There are three principal ways to cope with drought and climate variability: temporary or permanent out-migration, increasing water storage for irrigation during deficit periods, and the relatively recent approach of index insurance.

Migration has been a long-standing adaptation mechanism for subsistence famers and pastoralists in Africa when confronted with drought (Tacoli 2009). For this reason researchers have asserted that migration hardly constitutes a failure of adaptation to a changing climate (Gemenne 2013, Foresight 2011). Migration has been particularly high out of the drylands and drought stricken regions of Africa over the period from 1970-2000 (de Sherbinin et al. 2012). Whether migration has increased in recent years owing to greater drought frequency remains an open research question, but one which is being tested 
by field research in a number of African countries (Warner et al. 2012, Kniveton et al. 2011, Henry et al. 2004).

In terms of water storage, a study by Brown and Lal (2007) found that the seasonal water holding capacity of most African countries, an important measure of resilience to drought, is largely inadequate, and that, furthermore, this capacity was highly correlated with GDP growth and foreign direct investment. Another found that the drought mortality risk in Africa is higher than on any other continent, and indeed, that African drought mortality accounted almost half of all hazard related mortality from 19802000 study (Dilley et al. 2005). Africa is one of the few world regions where dam density is very low (Lehner et al. 2011) and an increase in dams and irrigation infrastructure is still needed. Of course dams are not without social and environmental impacts (Scudder 2005), and in Africa they can have significant health impacts, such as the spread of guinea worm, bilharzia and shistosomiasis. Yet, given the climate variability in vast swaths of Africa, the continent's frequent droughts and famine, its dependence on agriculture as an economic mainstay, and its untapped potential for irrigated agriculture, not to mention the likelihood of climate change-induced drying, finding appropriate means to exploit existing water resources and to increase the area under irrigation would seem to be a priority.

Another adaptation strategy is index insurance. While the use of index insurance is still in its infancy, it is being applied with some success among small holder agriculturalists in several parts of Africa (Hellmuth et al. 2009). The idea is to create an insurance policy indexed to rainfall (rather than actual loss) that pays out to farmers when the index (e.g., a drought index) is exceeded. Index insurance has the advantage of low transaction costs and rapid payments, since it eliminates the need for claims and for field- or satellite-based crop loss inspections and it reduces the moral hazard found in common insurance schemes whereby farmers may have a perverse incentive to maximize crop losses. And because farmers often avoid costly technologies such as fertilizers and improved seeds because they fear crop losses to drought, index insurance can remove a barrier to agricultural innovations that would result in greater food security.

In the African context this is particularly important. Although some have suggested that African soils are inherently inferior, Sanchez (2002) argues that African soils are not poor, but that instead the continent has suffered from decades of soil depletion as a result of low-input agriculture. According to the findings of the Millennium Project Hunger Taskforce, a number of measures are required (Sanchez and Swaminathan 2005, p.357-358): Applying appropriate combinations of mineral and organic fertilizers, using leguminous green manures and agroforestry fertilizer trees, returning crop 
residues to the soil, and using improved methods of soil conservation can restore soil health and double or triple yields of the cereal staple crop. Making mineral fertilizers available at affordable prices and using them efficiently remain major challenges. As an emergency short-term measure, targeted subsidy programs should be designed to supply mineral and organic fertilizers (as seeds) to farmers.

Although other variables fell out of the spatial error model either because of data gaps or because they turned out to be statistically insignificant, this does not mean they are unimportant. Malaria, for example, is preventable yet is a major killer in Africa, and malnutrition has been found to increase susceptibility to the malaria parasite (Rice et al. 2000). A major recommendation of the Millennium Project's Poverty Task Force was the distribution of treated bed nets (Madamombe 2005).

\subsection{Assessment of strengths and weaknesses}

Spatial analyses of this sort are not without weaknesses. Studies of this kind tend to be highly scale dependent (Balk et al. 2005), and thus any relationships observed at the continental scale could easily wash out at a finer scale of analysis such as sub-regions within countries. The measures I utilize are relatively coarse in terms of their spatial scale (some are measured only in half-degree grid cells that would completely absorb the smaller SNUs) and subject to error. Thus, in planning policy or programmatic interventions it is vital to rely on localized assessments of malnutrition that attempt to disentangle the multiple drivers (e.g. Teller et al. 2005). This study may have benefited from household level variables such as average education levels of household heads, though the piped water proxy is likely be very highly correlated. Finally, other variables that might have been introduced include conflict prevalence, though an assessment of the dates of the surveys in relation to conflict events suggests that most surveys were not conducted in post-conflict situations.

Despite the weaknesses, spatial analyses of this type already represent a quantum leap from earlier analyses based on national-level statistics that ignored the effects of spatial autocorrelation. Analyses such as this one can help targeting areas in need of intervention that have not benefited from improved agricultural technologies (Hyman et al. 2005). Furthermore, by identifying where environmental constraints to agriculture may be important factors in predicting child malnutrition, it can help to pinpoint regions where ecological approaches to increasing agricultural productivity could boost yields and improve child survival rates (DeClerck et al. 2006, Sanchez and Swaminathan 2005). Indeed, for the Millennium Villages Project the map of child underweight status that underpins this analysis together with 
information on agroecological zones was used to identify regions in need of interventions. Villages were then selected within these "hunger hotspots" to receive a package interventions identified by the Millennium Project (Millennium Villages undated). Overall, this study confirms the findings of Hyman et al. (2005, p.453) that "poverty mapping facilitates assessments of the role of environmental factors on the broad spatial pattern of poverty and food security", and that "spatial statistics can enhance our understanding of geographic and neighborhood effects on poverty and food security outcomes."

\subsection{References}

African Green Revolution. Undated. African Agriculture: Constraints. Accessed at http://www.africangreenrevolution.com/en/ african_agriculture/constraints/ on 5 July 2008.

Anselin, L. 2005. Exploring Spatial Data with GeoDa: A Workbook. Center for Spatially Integrated Social Science. Accessed at http://www.csiss.org on 5 July 2008.

Anselin, L. 1988. Spatial Econometrics: Methods and models. Kluwer, Dordrecht.

Balk, D., T. Pullum, A. Storeygard, F. Greenwell, and M. Neuman. 2004. A Spatial Analysis of Childhood Mortality in West Africa. Population, Space and Place, 10: 175-216.

Balk, D., A. Storeygard, M. Levy, J. Gaskell, M. Sharma, and R. Flor. 2005. Child hunger in the developing world: An analysis of environmental and social correlates. Food Policy, 30: 584-611.

Boko, M., I. Niang, A. Nyong, C. Vogel, A. Githeko, et al. 2007. Africa. Climate Change 2007: Impacts, Adaptation and Vulnerability. Contribution of Working Group II to the Fourth Assessment Report of the Intergovernmental Panel on Climate Change, M.L. Parry, O.F. Canziani, J.P. Palutikof, P.J. van der Linden and C.E. Hanson, Eds., Cambridge University Press, Cambridge UK, 433-467.

Brown, C., and U. Lal. 2007. "Climate and economic development in Africa." Presentation made at the International Research Institute for Climate and Society Monthly Seminar, 19 December 2007, Palisades, NY.

Brown, K.H. 2003. Diarrhea and malnutrition. Journal of Nutrition, 133(1): 328S-332S.

Busby, J.W., T.G. Smith, and K.L. White. 2011. Locating Climate Insecurity: Where are the most vulnerable places in Africa? Climate Change and African Political Stability Program Policy Brief No. 3.

CIESIN (Center for International Earth Science Information Network)/ Columbia University. 2005. Poverty Mapping Project: Global Subnational Prevalence of Child Malnutrition. Palisades, NY: NASA Socioeconomic Data and Applications Center (SEDAC). Available at 
http://sedac.ciesin.columbia.edu/data/set/ povmap-global-subnationalprevalence-child-malnutrition.

CIESIN (Center for International Earth Science Information Network)/ Columbia University, and Information Technology Outreach Services (ITOS) University of Georgia. 2013. Global Roads Open Access Data Set, Version 1 (gROADSv1). Palisades, NY: NASA Socioeconomic Data and Applications Center (SEDAC). http://dx.doi.org/10.7927/ H4VD6WCT.

CIESIN (Center for International Earth Science Information Network)/ Columbia University; International Food Policy Research Institute (IFPRI); The World Bank; and Centro Internacional de Agricultura Tropical (CIAT). 2004. Global Rural-Urban Mapping Project (GRUMP), Alpha Version: Population Density Grids. Palisades, NY: Socioeconomic Data and Applications Center (SEDAC), Columbia University. Available at http://sedac.ciesin.columbia.edu/gpw. (Downloaded August 2005).

Charmargagwala, R., M. Ranger, H. Waddington, and H. White. 2005. The Determinants of Child Health and Nutrition: A Meta-Analysis. Accessed at: http://Inweb18.worldbank.org/oed/oeddoclib.nsf/ InterLandingPagesByUNID/F5D232968229166085256ED00066155F on 7 September 2007.

Chopra, M., and A. Darton-Hill. 2006. Responding to the crisis in SubSaharan Africa: The role of nutrition. Public Health Nutrition. 9(5): 544-550

Curtis, S.L., and M. Hossain. 1998. The effect of aridity zone on child nutritional status, West Africa spatial analysis prototype exploratory analysis. Calverton, Maryland: Macro international, Inc.

Davies, R.A.G., and S.J.E. Midgley. 2010. Risk and Vulnerability Mapping in Southern Africa: A Hotspots Analysis. Cape Town, South Africa: OneWorld Sustainable Investments (Pty) Ltd.

DeClerck, F., J.C. Ingram, and C.M. Rumbaitis del Rio. 2006. The role of ecological theory and practice in poverty alleviation and environmental conservation. Frontiers in Ecology and the Environment. 4(10): 533540.

de Sherbinin, A., M. Levy, S.B. Adamo, K. MacManus, G. Yetman, V. Mara, L. Razafindrazay, B. Goodrich, T. Srebotnjak, C. Aichele, and L. Pistolesi. 2012. Migration and Risk: Net Migration in Marginal Ecosystems and Hazardous Areas. Environmental Research Letters, 7045602. http://dx.doi.org/ 10.1088/1748-9326/7/4/045602.

de Sherbinin, A., L. VanWey, K. McSweeney, R. Aggarwal, A. Barbieri, et al. 2008. Household Demographics, Livelihoods and the Environment. Global Environmental Change, 18: 38-53.

de Sherbinin, A. 2003. "Relationship Between Physical Water Availability and Development Indicators in Africa." Poster presented at the Open Science Conference of the Global Water Science Project, Portsmouth, 
NH, 7-9 October 2003. Accessed at http://www.ciesin.columbia.edu/ pdf/desherbinin_GWSP.pdf on 7 July 2008.

Dilley, M., R.S. Chen, U. Deichmann, A. Lerner-Lam, et al. 2005. Natural Disaster Hotspots: A Global Risk Analysis. Washington, DC: World Bank, $132 \mathrm{pp}$.

Evenson, R.E., and D. Gollin. 2003. Assessing the Impact of the Green Revolution, 1960-2000. Science, 300: 758-762.

Fekete, B., C.J. Vörösmarty, and W. Grabs. 2000. UNH/GRDC Composite Runoff Fields v.1.0. Available from http://www.grdc.sr.unh.edu/ (accessed 5 September 2005).

Fischer, G., H. van Velthuizen, F. Nachtergaele, and S. Medow. 2000. Global Agro-Ecological Zones (Global-AEZ) [CD-ROM], Food and Agriculture Organization and the International Institute for Applied Systems Analysis (FAO/IIASA), Rome. Accessed at http://www.fao.org/ag/AGL/agll/gaez/ on 5 September 2005.

FIVIMS (Food Insecurity and Vulnerability Information and Mapping Systems). Undated. Available at http://www.fivims.net/.

Foresight Migration and Environmental Change. 2011. Final Project Report. London: The Government Office for Science.

Gemenne, F. 2013. Migration doesn't have to be a failure to adapt. Chapter 22 in: J. Palutikof, S.L. Boulter, A.J. Ash, M. Stafford Smith, et al. (eds), Adaptation Policy. New York: John Wiley \& Sons. http://dx.doi.org/10.1002/ 9781118529577.ch22

Haddad, L., S. Bhattaraia, M. Immink, and S. Kumarc. 1998. Estimating the interactions between household food security and preschool diarrhea. Food Policy, 23(3-4):241-261.

Hellmuth ,M.E., D.E. Osgood, U. Hess, A. Moorhead, and H. Bhojwani (eds). 2009. Index insurance and climate risk: Prospects for development and disaster management. Climate and Society No. 2. International Research Institute for Climate and Society (IRI), Columbia University, New York.

Henry, S., B. Schoumaker, C. Beauchemin. 2004. The impact of environmental conditions on migration in Burkina Faso: an eventhistory analysis, Population and Environment, 25(5):423-460

Hinkel, J. 2011. Indicators of vulnerability and adaptive capacity: Towards a clarification of the science-policy interface, Global Environmental Change, 21:198-208.

Hyman, G., C. Larrea, and A. Farrow. 2005. Methods, results and policy implications of poverty and food security mapping assessments. Food Policy. 30: 453-460

IPCC (Intergovernmental Panel on Climate Change). 2012. Managing the risks of extreme events and disasters to advance climate change adaptation. In A Special Report of Working Groups I and II, C.B. Field (ed.). Cambridge: Intergovernmental Panel on Climate Change. 
Kiszewski, A., A. Mellinger, A. Spielman, et al. 2004. A global index representing the stability of malaria transmission. American Journal of Tropical Medicine and Hygiene, 70(5): 486-498.

Kniveton, D., C. Smith, and S. Wood. 2011. Agent-based model simulations of future changes in migration flows for Burkina Faso. Global Environmental Change, 21( Supplement 1): S34-S40.

Lehner, B., C. Reidy Liermann, C. Revenga, C. Vorosmarty, B. Fekete, P. Crouzet, P. Doll, M. Endejan, K. Frenken, J. Magome, C. Nilsson, J.C. Robertson, R. Rodel, N. Sindorf, and D. Wisser. 2011. Global Reservoir and Dam Database, Version 1 (GRanDv1): Dams, Revision 01. Palisades, NY: NASA Socioeconomic Data and Applications Center (SEDAC). http://sedac.ciesin.columbia.edu/data/ set/grand-v1-damsrev01.

Madamombe, I. 2005. Africans push to tame malaria. Africa Renewal, 18(4): 4.

McElroy, M., and J. Baker. 2012. Climate Extremes: Recent Trends with Implications for National Security. Cambridge, Mass.: Harvard University.

Millennium Villages. Undated. Accessed at http://www.millenniumvillages.org/ on 7 July 2008.

Nankhuni, F., and J. Findeis. 2006. "Child Malnutrition and the Environment: How Women's Work in Collecting Environmental Goods Affect Children's Health in Malawi." Paper presented at the 2006 annual meeting of the Population Association of America, Los Angeles, CA, 30 March-1 April, 2006.

Nelson, A., A. de Sherbinin, and F. Pozzi. 2006. Towards development of a high quality public domain global roads database. CODATA Science Journal, 5: 223-265. Accessed at http://www.jstage.jst.go.jp/article/ dsj/5/0/223/_pdf on 7 September 2007.

Nubé, M., B. Sonneveld. 2005. The geographical distribution of underweight children in Africa. Bulletin of the World Health Organization. 83(10): 764-770.

Parry, M.L., O.F. Canziani, J.P. Palutikof, et al. 2007. Technical Summary. Climate Change 2007: Impacts, Adaptation and Vulnerability. Contribution of Working Group II to the Fourth Assessment Report of the Intergovernmental Panel on Climate Change. M.L. Parry, O.F. Canziani, J.P. Palutikof, P.J. van der Linden and C.E. Hanson (Eds.). Cambridge, UK: Cambridge University Press, pp. 23-78.

Rice, A.L., L. Sacco, A. Hyder, and R.E. Black. 2000. Malnutrition as an underlying cause of childhood deaths associated with infectious diseases in developing countries. Bulletin of the World Health Organization. 78: 1207-1221.

Sachs, J., and P. Malaney. 2002. The economic and social burden of malaria. Nature. 415: 680-685. 
Sanchez, P., S. Ahamed , F. Carré, A. Hartemink, J. Hempel, J. Huising, P. Lagacherie, A. McBratney, et al. 2009. Digital Soil Map of the World. Science. 325: 680-681.

Sanchez, P., M.S. Swaminathan, P. Dobie, and N. Yuksel. 2005. Halving Hunger: It Can Be Done. Report of the Millennium Project Task Force on Hunger. Sterling, VA: Earthscan.

Sanchez, P., and M.S. Swaminathan. 2005. Cutting World Hunger in Half. Science. 307: 357-359.

Sanchez, P. 2002. Soil Fertility and Hunger in Africa. Science. 295: 2019-20.

Scott, L. 2006. Chronic Poverty and the Environment: A Vulnerability Perspective. Chronic Poverty Research Centre Working Paper No. 62. Overseas Development Institute, London, UK.

Scudder ,T. 2005. The future of large dams: dealing with social, environmental, institutional and political costs. Earthscan: London, xvii $+389 \mathrm{pp}$.

Sen, A. 1981. Poverty and famine: An essay on entitlement and deprivation Image, Oxford, New York: Oxford University Press, 1981. xi + 257 pp.

Smith, L.C., A.E. El Obeid, and H.H. Jensen. 2000. The geography and causes of food insecurity in developing countries. Agricultural Economics, 22: 199-215.

Tacoli, C. 2009. Crisis or adaptation? Migration and climate change in a context of high mobility. Environment and Urbanization, 21(2):513525.

Teller, C., A. Yitna, and A. Keffene. 2005. "The demography of hunger: population-land pressure and vulnerability/resilience to food/nutrition insecurity in 16 drought-prone districts of Ethiopia." Paper presented at the XXVth International Population Conference, Tours, France, 17-24 July 2005.

Voss, P.R., D.D. Long, R.B. Hammer, and S. Friedman. 2006. County Child Poverty Rates in the U.S.: A Spatial Regression Approach. Population Research and Policy Review. 25(4): 369-391.

Warner, K., T. Afifi, K. Henry, T. Rawe, C. Smith, and A. de Sherbinin. 2012. Where the Rain Falls: Climate Change, Food and Livelihood Security, and Migration. Bonn, Germany: United Nations University and CARE.

Webb, P. 1998. "Isolating Hunger: Reaching People in Need Beyond the Mainstream." Paper Prepared for the World Food Programme, Rome, Italy.

World Health Organization (WHO) and United Nations Children's Fund (UNICEF). 2005. World Malaria Report 2005. Geneva: WHO. 


\section{Chapter 5}

\section{Climate Change: Three Hotspots of Human Mobility ${ }^{36}$}

\footnotetext{
36 This chapter was originally published as de Sherbinin, A., K. Warner, and C. Ehrhart. 2011. "Casualties of Climate Change," Scientific American, January 2011: 64-71, which itself was a policy-oriented synthesis of Warner, K., C. Erhart, A. de Sherbinin, S.B. Adamo, T. Chai-Onn. 2009. In search of Shelter: Mapping the effects of climate change on human migration and displacement. Bonn, Germany: United Nations University, CARE, and CIESIN-Columbia University. The work was updated and revised for this thesis. Additional material is drawn from de Sherbinin, A., M. Levy, S.B. Adamo, K. MacManus, G. Yetman, V. Mara, L. Razafindrazay, B. Goodrich, T. Srebotnjak, C. Aichele, and L. Pistolesi. 2012. Migration and Risk: Net Migration in Marginal Ecosystems and Hazardous Areas. Environmental Research Letters, 7045602. http://dx.doi.org/ 10.1088/1748-9326/7/4/045602.
} 


\subsection{Introduction}

Recent research and policy attention has focused on the potential for climate change and other environmental change processes to become significant drivers of displacement and migration (Oliver-Smith and de Sherbinin 2014, de Sherbinin et al. 2012, Warner et al. 2012, Black 2011a and 2011b, Adamo and de Sherbinin 2011, Warner et al. 2009). Black et al. (2011a), drawing on extensive research compiled for the UK Government's Foresight Project on Global Environmental Change and Migration (Foresight 2011), find that while migration decision-making in the past was mostly driven by economic or other concerns, there is good reason to believe that environmental factors will increasingly influence migration.

Although environmental change has long played a role in human migration (Lamb 1995), the rapidity of projected climate change is a major cause for concern. Climate is the envelope in which all human activities occur. Agricultural systems, human settlements, culture and countless other variables are shaped by climate, and the relative stability of the climate system since the last ice age has created "sweet spots" for human habitation (Samson et al. 2011). Within that relative stability, however, even minor climate disruptions have led to population movements, as people seek better living conditions and more stable livelihoods (Lamb 1995). For example, increased climate variability from AD 250-600 coincided with the demise of the Western Roman Empire and the turmoil of the so-called "Migration Period", which featured the Barbarian invasions (Büntgen et al. 2011), and the drought of the American Dust Bowl displaced 2.5 million people from the mid-West (Reuveny 2007). The latter was an ecological catastrophe precipitated as much by bad land management practices as it was by drought, illustrating the fact that climatic factors rarely operate in isolation.

In today's more densely settled world, likely climatic changes such as higher rainfall variability, greater frequency of extreme events (such as droughts and floods), and long term shifts in temperature and precipitation could have dramatic impacts on human migration (Adamo and de Sherbinin 2011, Warner et al. 2009). These changes, along with melting glaciers and icesheets, sea level rise and ocean acidification, will result in major disruptions to ecosystems that supply our basic needs. They could also trigger a massive increase in migration flows-though it should be emphasized that the precise magnitude and direction of those flows remains uncertain (Gemenne 2011).

Many of the impacts of climate change on migration are mediated by ecosystems and the livelihoods that are based on their services. With a probable global average warming in the neighborhood of $2-4^{\circ} \mathrm{C}$ this century, changing temperature and precipitation patterns and sea-level rise will 
significantly alter ecosystems (New et al. 2011), perhaps even causing the disappearance of some climate types and the emergence of altogether new ones (Williams et al. 2007). These will have major effects on human populations as ecosystem services - especially the provisioning and regulating services - are key providers of life's basic needs (Reid et al. 2005). Any change in their characteristics has the potential of affecting livelihoods, income, and migration trends (Warner et al. 2009, Corvalan et al. 2005), and may also lead to civil or interstate conflict, which itself is a precursor to population displacements (McElroy and Baker 2012, WBGU 2007, Campbell et al. 2007).

The concern for migration and displacement have been dealt with in a number of reports of the Intergovernmental Panel on Climate Change (IPCC), starting with the first report in 1990, which suggested that the greatest effect of climate change on society could be human migration, especially involuntary forms of displacement and relocation (OSCE 2005). In 2007, the IPCC's Fourth Assessment Report highlighted the significance of already established migrant networks and patterns as part of the inventory of adaptation practices, options and capacities available to face climate change impacts (Adger et al 2007). In 2012, the IPCC special report on climate extremes (SREX) concluded, albeit with "medium evidence/medium confidence", that:

"If disasters occur more frequently and/or with greater magnitude, some local areas will become increasingly marginal as places to live or in which to maintain livelihoods. In such cases, migration and displacement could become permanent and could introduce new pressures in areas of relocation" (IPCC 2012:16).

In international policy circles, discussion of "climate refugees" (this term has problems that will be addressed below) has most often centered on the plight of low-lying small island states threatened by rising sea levels (Biermann and Boas 2010). This is an emotive issue, particularly for those who risk losing not only a culture and a way of life, but their very homeland, as lands are submerged or reconfigured by shifting currents. By the end of this century many low lying island states could disappear under certain sea level rise scenarios (Gronewald 2011), and a number of South Pacific states are seeking reparations while also calling on the international community to ease immigration restrictions to make it easier for their citizens to relocate. The potential loss of these states is a profound political and legal issue (Tol and Verheyen 2004).

Yet, the largest volume of outmigration from rising seas and increasingly intense storm surge will not be from small island states. In India alone, 
approximately 4.5 million people would be displaced by a one-meter sea level rise in the absence of sea wall construction or other adaptation responses (CIESIN 2012). In combination with retreating Himalayan glaciers, reduced snow pack, and changes in Asian monsoon rainfall patterns, the potential for environmental disruption, conflict and large scale migration on the subcontinent should be taken seriously (Faris 2009). Climate models suggest an increase in total monsoon rainfall but a decrease in the frequency of rain, implying more intense rainfall in fewer days (Greene et al. 2011). Shifts in the seasonality of river flows (as winter snowpack declines and glaciers shrink), coupled with these potentially disruptive changes in rainfall patterns, would affect the agricultural livelihoods of several hundred million rural Asians and the food supplies of an equal number of Asian urbanites (Warner et al. 2009). Devastating floods in Pakistan in 2010 and in India in June 2013 may be the harbinger of things to come.

While it may take decades for the impacts of glacier melting and sea level rise to be felt, the increase in climate-related natural disasters is already a fact. Climate related disasters-storms, floods, landslides triggered by precipitation, extreme heat events, droughts, and wildfires-increased in frequency 2.3 times when comparing the decade of the $1980 \mathrm{~s}$ to the $2000 \mathrm{~s}$, or from 1,416 to 3,332 events (CRED 2013). Even accounting for possible changes in reporting over time (Gall 2013), this is an extraordinary increase. Figure 5.1 shows the breakdown of events in terms of frequency from 19902009, with flood and storm by far the most prevalent. The UN Office for the Coordination of Humanitarian affairs estimated that in 2008 there were a total of 20 million displaced persons from climate-related disasters, more than four times the number of conflict-displaced people (OCHA and IDMC 2009). Research shows that most displaced persons return to their homes after disaster events, but depending on the magnitude or frequency of disruption, some portion will relocate permanently (IPCC 2012). For example, of the some 1.5 million people displaced by Hurricane Katrina (Renaud et al. 2007), most returned to New Orleans, though the city population as of the 2010 decennial census (at 343,829) is $29 \%$ lower than the population in the year 2000 (Krupa 2011). Many resettled in Houston or other southern cities, or outside the region entirely. 


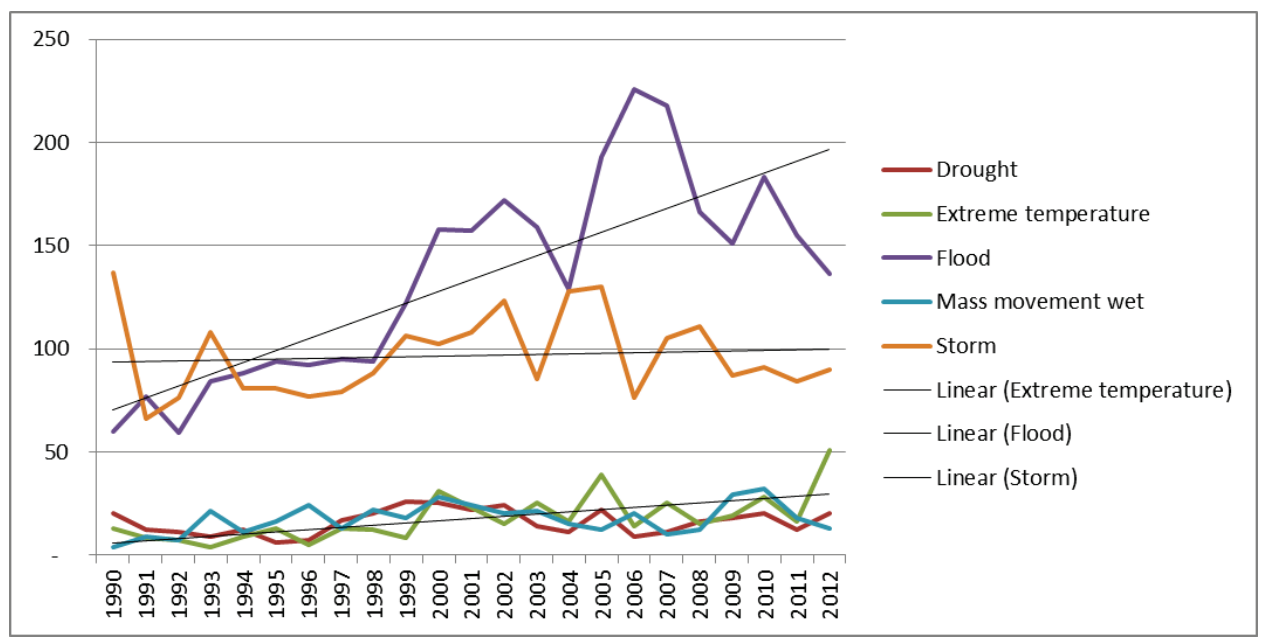

Figure 5.1: Frequency of Climate-Related Natural Disasters by Year, with Trend Lines

Note: To be classified as a disaster, at least one of the following four criteria must be met: (1) ten or more people reported killed, (2) one hundred or more people reported affected, (3) a declaration of a state of emergency, and (4) a call for international assistance. Source: CRED 2013.

This chapter focuses on three regions in which human migration and displacement due to climate variability and change are already taking place. The evidence presented is from the European Commission's Environmental Change and Forced Migration Scenarios project (EACH-FOR), a global study on environmentally-induced migration (EACH-FOR 2009), and from a mapping exercise led by the author. The primary focus is on the maps that illustrate the combination of climate, biophysical, and social factors that may increase risk of migration in the study areas. The maps are used to "tell a story" that complements the results of the EACH-FOR research, while providing additional contextual information to readers. This is the approach to spatial vulnerability assessment described in Chapter 1 (Section 1.3) and Chapter 2 (Annex 2.1), where maps are used as a tool for policy communication. ${ }^{37}$ For this reason, this chapter is written in less academic language and with greater emphasis on policy recommendations than the other chapters comprising this dissertation.

The first case study is from Mexico and Central America, where rainfall variability has had significant impacts on traditional cropping systems, where tropical storms and cyclones have displaced thousands, and where projections show that further drying is likely to take place. The second is

${ }^{37}$ For additional examples of climate change vulnerability maps developed for policy communications, see the UK Met Office map (Figure 2.3, Chapter 2), maps available through www.wheretherainfalls.org, and UNEP (2011). 
from Mozambique, where a combination of catastrophic floods and periodic droughts has caught rural populations in a double bind. Projections of precipitation are difficult to make, but most global climate models foresee increasing rainfall in northern Mozambique while southern Mozambique will likely be affected by the expansion of sub-tropical dryland areas. The last case is the Mekong Delta, where floods are already a common phenomenon to which delta inhabitants are well habituated. However, the scale of those floods in recent years has surpassed historic precedent; and the low-lying areas are facing potentially catastrophic impacts from projected sea level rise.

This research was primarily guided by the sustainable livelihoods framework (Carney 1998a and b), which is appropriate for the assessment of vulnerability in largely rural subsistence agricultural systems. The framework described five capitals deployed by natural-resource dependent households: Natural capital (e.g., assets such as water, soil, timber and non-timber forest products), social capital (e.g., interpersonal networks, membership in groups, access to wider institutions of society), human capital (e.g., formal and informal education, local ecological knowledge, the ability to work, and good health), physical capital (e.g., land, tools, oxen, roads, markets), and financial capital (e.g., cash savings, supplies of credit, or regular remittances and pensions) (de Sherbinin et al., 2008). While the framework is best suited to local scale participatory mapping, it can also, when used in conjunction with the concept of ecosystem services (Reid et al., 2005), guide the selection of data layers to be used in meso-scale maps (countries or regions) depicting livelihood assets that may be impacted by climatic changes.

The PNAS framework was not explicitly used, but elements of it are clearly reflected in the maps that were developed insofar as they address the following:

- Multiple interacting perturbations and stressors/stresses (e.g., cyclones and secular drying trends in Mexico; floods and droughts in Mozambique; floods and sea level rise in the Mekong);

- Coupled socio-ecological systems, with particular reference to rainfed subsistence agriculture; and

- The sensitivity of different systems to stressors.

In addition, in the analysis we considered the system resilience and the consequences of poor system recovery in the form of out-migration. It is unclear at this stage whether and how the systems are restructuring after adaptation. Migration appears to be a more or less permanent response to changing conditions in each case, though circular migration appear to be occurring in the Mozambique and Mekong cases, with migrants returning for periods to migration source areas. 
It should be stated up front that the actual migration impact of climateinduced changes will depend on a complex mix of factors, including "push" and "pull" factors and "intervening obstacles" (Lee 1966). Push factors are conditions in the region of origin that may cause a migrant to leave home, such as a weak economy, political instability, environmental degradation, limited natural resource availability or lack of entitlement to key resources. Migrants may also be influenced by anticipated changes in conditions in the region of origin. Pull factors are conditions (or perhaps as importantly, perceptions about conditions) in destination areas-such as job availability, higher wages, political stability, and resource availability-that attract migrants. Climate change impacts can affect both push and pull factors, though it is more likely to act as a push factor (Black et al. 2008). Intervening obstacles (or factors - since they can be negative or positive) hinder or facilitate migration, such as ease of transportation, family connections, and-in the case of international migration-policies in receiving countries and historic, economic, and social/cultural ties between source and destination countries. Given that most migration is likely to be internal (Adamo and de Sherbinin 2011), some of these intervening obstacles are of secondary importance. Yet, for that portion which is international, current flows may see an increase or a decrease depending on the responses of receiving countries. ${ }^{38}$

\subsection{Data and Methods}

The maps in the In Search of Shelter report (upon which this chapter is based) represented the presentation, at scales ranging from continental to small islands, of geospatial datasets such as population (size, density, and distribution), hydrology (Asian river basins, highly populated river deltas), projected sea level rise ( 1 and 2 meters), agriculture (rain-fed agricultural land and areas in pasture), projected changes in runoff, and cyclones. A complete list of data sources used in the three case studies listed here can be found in Table 5.1. These databases were mapped using ArcGIS version 9.3 with a focus on the map design and cartographic representation (see below). The map layers portray different facets of vulnerability (exposure to climate variability and change and the sensitivity of the exposed systems) that could be considered part of the context that shapes migration decisions.

\footnotetext{
38 Then Nansen Initiative is promoting interstate dialog in regions that are deemed to be hotspots of likely future transboundary migration such as Oceania, Central America, and South Asia.
} 
Table 5.1: Data Sets Used in the Maps

\begin{tabular}{|c|c|c|}
\hline Component & Variable & Source \\
\hline \multirow{6}{*}{ Climate } & $\begin{array}{l}\text { Sea Level Rise } \\
\text { (Coastal } \\
\text { Elevation) }\end{array}$ & $\begin{array}{l}\text { Jarvis, A., H.I. Reuter, A. Nelson, and E. Guevara. } 2008 . \\
\text { Hole-filled SRTM for the globe Version 4, CGIAR-CSI SRTM } \\
90 \mathrm{~m} \text { Database. http://srtm.csi.cgiar.org }\end{array}$ \\
\hline & Historical Runoff & $\begin{array}{l}\text { Fekete, B., C. Vorosmarty, and W. Grabs. 2000. UNH/GRDC } \\
\text { Global Composite Runoff Fields v1.0. Accessed at } \\
\text { http://www.grdc.sr.unh.edu/ }\end{array}$ \\
\hline & $\begin{array}{l}\text { Percent Change in } \\
\text { Runoff by } 2080\end{array}$ & $\begin{array}{l}\text { Nohara, D., A. Kitoh, M. Hosaka and T. Oki. 2006. Impact of } \\
\text { climate change on river runoff. Journal of Hydrometeorology, } \\
\text { 7:1076-1089. }\end{array}$ \\
\hline & Cyclone Frequency & $\begin{array}{l}\text { Dilley, M., R.S Chen, U. Deichmann, A. Lerner-Lam and M. } \\
\text { Arnold. 2005. Natural Disaster Hotspots: A Global Risk } \\
\text { Analysis, Washington, DC: World Bank. }\end{array}$ \\
\hline & Flood Extent & $\begin{array}{l}\text { MODIS-derived flood extent shape files from the Dartmouth } \\
\text { Flood Observatory. }\end{array}$ \\
\hline & $\begin{array}{l}\text { Drought } \\
\text { Frequency }\end{array}$ & $\begin{array}{l}\text { Xie, P. and P. A. Arkin, 1996: Analyses of Global Monthly } \\
\text { Precipitation Using Gauge Observations, Satellite Estimates, } \\
\text { and Numerical Model Predictions. J. Climate, 9, } 840-858 ; \\
\text { and Xie, P. and P. A. Arkin, 1997: Global Precipitation: A 17- } \\
\text { Year Monthly Analysis Based on Gauge Observations, Satellite } \\
\text { Estimates and Numerical Model Outputs. BAMS, 78, 2539- } \\
255 . \\
\text { Available through the International Research Institute for } \\
\text { Climate and Society (IRI) Data Library }\end{array}$ \\
\hline \multirow{2}{*}{$\begin{array}{l}\text { Exposed } \\
\text { Systems }\end{array}$} & $\begin{array}{l}\text { Rainfed } \\
\text { Agricultural Lands }\end{array}$ & $\begin{array}{l}\text { FAO (Food and Agriculture Organization of the United } \\
\text { Nations). 2007. Combined suitability of currently available } \\
\text { land for pasture and rainfed crops (low input level) (FGGD). } \\
\text { Obtained from GeoNetwork. }\end{array}$ \\
\hline & Croplands & $\begin{array}{l}\text { Ramankutty, N., A.T. Evan, C. Monfreda, and J.A. Foley. } \\
\text { 2010. Global Agricultural Lands: Croplands, 2000. Palisades, } \\
\text { NY: NASA Socioeconomic Data and Applications Center } \\
\text { (SEDAC). http://sedac.ciesin.columbia.edu/data/set/aglands- } \\
\text { croplands-2000. }\end{array}$ \\
\hline \multirow{2}{*}{$\begin{array}{l}\text { Population } \\
\text { and } \\
\text { Settlements }\end{array}$} & Population Density & $\begin{array}{l}\text { CIESIN (Center for International Earth Science Information } \\
\text { Network/Columbia University), IFPRI (International Food } \\
\text { Policy Research Institute), The World Bank, and CIAT (Centro } \\
\text { Internacional de Agricultura Tropical). 2011. Global Rural- } \\
\text { Urban Mapping Project, Version 1 (GRUMPV1): Population } \\
\text { Density Grid. Palisades, NY: NASA Socioeconomic Data and } \\
\text { Applications Center (SEDAC). } \\
\text { http://sedac.ciesin.columbia.edu/data/set/grump-v1- } \\
\text { population-density. }\end{array}$ \\
\hline & Urban Areas & $\begin{array}{l}\text { CIESIN (Center for International Earth Science Information } \\
\text { Network/Columbia University), IFPRI (International Food } \\
\text { Policy Research Institute), The World Bank, and CIAT (Centro } \\
\text { Internacional de Agricultura Tropical). 2011. Global Rural- } \\
\text { Urban Mapping Project, Version } 1 \text { (GRUMPV1): Urban Extents } \\
\text { Grid. Palisades, NY: NASA Socioeconomic Data and } \\
\text { Applications Center (SEDAC). } \\
\text { http://sedac.ciesin.columbia.edu/data/set/grump-v1-urban- } \\
\text { extents. }\end{array}$ \\
\hline
\end{tabular}


Map production was overseen by the author, and involved a team at the Center for International Earth Science Information Network (CIESIN), Columbia University, including demographer Susana Adamo, GIS analyst Tricia Chai-Onn, and graphic designer Andrés Gonzalez. The process involved a number of steps (Figure 5.2), beginning with a thorough reading of the case studies in order to identify the most important variables affecting migration in each case. For example, the Mexico and Central American cases clearly showed that declining rainfall and increasingly long drought intervals were affecting agricultural production in ways that made migration an attractive option, on the one hand, while tropical cyclones and storms were important factors in influencing displacement, on the other. Thus, spatial data sets were chosen from the IPCC (Nohara et al. 2006) and the World Bank Natural Disaster Hotspots project (Dilley et al. 2005, CHRR et al. 2005) that reflected likely changes in rainfall runoff (water availability) and cyclone risk, respectively. Data sets related to rainfed agriculture (FAO 2007) and baseline rainfall runoff during the climate normal period (1960-1990) (Fekete et al. 2000) were also selected to illustrate current vulnerabilities. Finally, all maps included population density for the year 2000 as a backdrop (CIESIN 2009b), and many included a circa 2000 delineation of urban areas (CIESIN 2009a), to give a sense of populations at risk of various hazards.

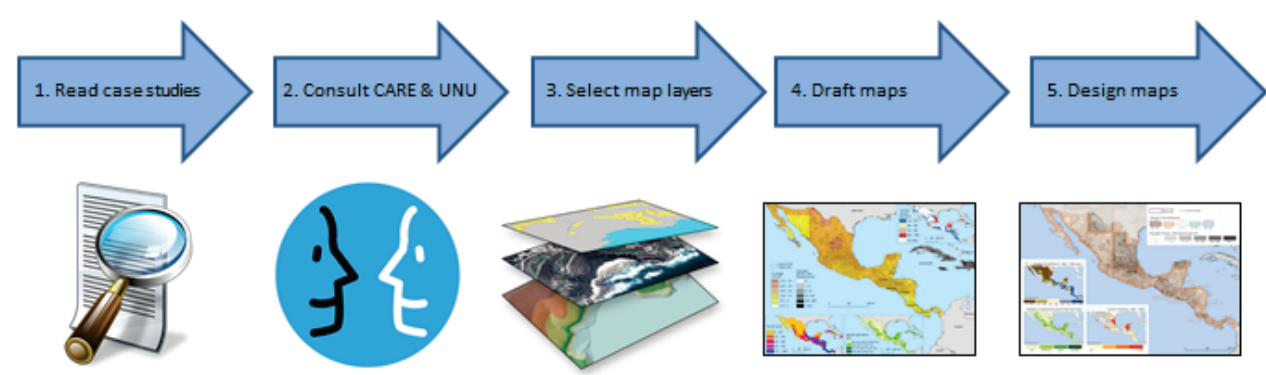

Figure 5.2: Map Production Process

The project involved a number of internal meetings and teleconferences with co-authors Koko Warner (UNU) and Charles Ehrhart (CARE) to identify the map layers that would best provide the context for, and illustrate the issues related to, the findings from the EACH-FOR studies. ${ }^{39}$ An additional objective of UNU and CARE counterparts was to demonstrate that the issues faced in a particular case study area were not unique to that area, such that findings

\footnotetext{
39 The original report included reports of field studies in Egypt's Nile Delta, Bangladesh's Ganges Delta, Tuvalu, Maldives, and West Africa's Sahel, as well as a broader map covering the river systems that rise in the Himalayas. The report did not include the Mozambique case study, which is described in this chapter.
} 
might be seen to have broader applicability. ${ }^{40}$ All map production work (basic cartographic representation) was performed in ArcGIS version 9.3, while zonal statistics were performed for some variables (e.g. land area and population in low elevation coastal zones) in ArcGIS with the Spatial Analyst extension. Maps were exported in Adobe Illustrator format for final map design in Adobe Illustrator. A number of cartographic issues arose during the design stage, such as how best to represent the coarse gridded data set representing projected runoff change. We decided at the time to represent the grid boxes rather than to smooth the results and generalize the boundaries, a decision that in retrospect was not optimal, because it tended to imply a high level of confidence in the model results as well as an abrupt discontinuities between neighboring grid cells. Issues surrounding cartographic representation are dealt with in greater detail in Chapter 6 (Section 6.2.4). For the final report the author developed box text accompanying each map set that sought to guide the readers on how to interpret the maps, and providing some technical explanations for data sets such as runoff.

One issue that needed to be addressed was the choice of models and scenarios used to illustrate future climate parameters, as well as the specific variables (e.g. temperature or precipitation) of greatest interest. While recognizing that changing temperatures will have wide-ranging ramifications for many tropical and subtropical regions, especially where temperatures may exceed tolerances for specific crops, the team felt that the impact of temperature changes will take longer to unfold and that precipitation change is likely to have greater short-term impacts on livelihoods. Once that decision was made, additional choices presented themselves. In the maps presenting drying trends, we chose to use data on projected changes in runoff by Nohara et al (2006) published in the IPCC Fourth Assessment Report (AR4) Working Group 2 synthesis report. These data were produced using an ensemble of climate models, and correspond broadly to the pattern of changing precipitation minus evaporation found in other ensemble modeling approaches. ${ }^{41}$ Ensembles are generally more reliable than single model runs, since they average out the extremes. Runoff change was chosen rather than change in precipitation alone, or precipitation minus evaporation $(P-E)$, because runoff represents the water that runs off the land (after soil moisture recharge and evapotranspiration are accounted for) and that is effectively

\footnotetext{
40 Extrapolating from spatially delimited case studies in order to generalize findings is a classic problem in geography (e.g., Parker et al. 2008).

41 See, for example, projections of precipitation minus evaporation to 2040 using a 19 model ensemble mean, by Vecchi, G.A., R. Seager, and N. Naik, produced by Princeton University's Geophysical Fluid Dynamics Laboratory, available at http://www.Ideo.columbia.edu/res/div/ocp/drought/science.shtml.
} 
available for a range of human purposes (domestic, industrial and agricultural use), and also for aquatic ecosystems, which are important for freshwater fisheries. Whether one uses runoff or $\mathrm{P}-\mathrm{E}$, global patterns are broadly similar: (1) wet areas are getting wetter; (2) dry areas are getting drier; and (3) subtropical dry zones are expanding poleward.

In terms of sea level rise, the IPCC AR4 projected potential eustatic (meaning produced by the melting glaciers rather than thermal expansion) sea level rise of $0.8-1 \mathrm{~m}$ this century. However, some research suggests that the upper bound for sea level rise this century may be closer to $2 \mathrm{~m}$ (Parris et al. 2012, Pfeffer et al. 2008). For this reason, we provided $1 \mathrm{~m}$ and $2 \mathrm{~m}$ bands for each delta area.

\subsection{The Case Studies}

\subsubsection{Mexico and Central America}

Mexico and Central America are home to almost 10 million farmers, many of whom are barely managing to meet their basic needs by growing traditional staples (corn, beans and squash) on steep hillsides. Like farmers anywhere, they depend on predictable rainfall in moderate amounts. Too little, and their plants wither and die; too much all at once, and the soil washes down gullies, carrying with it crops and their livelihood. Sometimes, countries can be hit by droughts and tropical storms in the same year. In July 2001, Honduras went through a drought that affected a quarter million people. In October, a tropical storm affected 86,000 (CRED 2009). Just three years earlier, Hurricane Mitch devastated the region, triggering mudslides and floods to an extent rarely seen even in this hazard prone region. Disasters like these can set countries back decades in terms of infrastructure and development.

The great majority of migrants to the United States come from poor rural areas, many of whom have found their rural livelihoods too precarious. Although soil depletion, deforestation and unemployment are among the factors that drive migration-along with the pull of higher wages in the U.S.climatic factors are certainly important. In Tlaxcala, Alscher (2008) found that market liberalization in the 1990s and declining rainfall led to lower farm incomes. This pushed some to leave. In one interview, a farmer described migration as a last resort: "My grandfather has worked on our lands, my father-and so do I. But times have changed...the rain is coming later now, so that we produce less. The only solution is to go away, at least for a while [to the United States]" (p.25).

Tlaxcala is projected to see a 10-20 percent decline in rainfall runoff in association with climate change (Nohara et al. 2006). In an area that 
currently receives the rainfall of Kansas (700mm annually) but with considerably higher evaporation, this could mean rain-fed agriculture will no longer be viable. Water storage and irrigation is often an alternative in such water stressed regions. But in Tlaxcala, as in most of the region, mountainous topography means that irrigation is only practical in some river valleys. The state counts 4,250 hectares under irrigation, as compared to 1.2 million hectares in Kansas. ${ }^{42}$

Most of the region's irrigation occurs on the coastal plains, such as those in Jalisco and Sinaloa - major agricultural states that collectively produce almost $18 \%$ of the country's agricultural GDP. But these states are due to see a 25 to $50 \%$ decline in water availability by 2080 (Nohara et al. 2006), which will deplete their reservoirs and could lay waste to their agricultural productivity.

Along with projected long term declines in rainfall, climatologists predict more intense tropical storms over the coming century. In 1998, Hurricane Mitch set a benchmark in terms of ferocity, but many other storms have left their mark. Hurricane Stan in 2005 set off major mudslides in Guatemala and Mexico, and Tropical Storm Noel in 2007 flooded up to $80 \%$ of the state of Tabasco while displacing some 500,000 people. The evidence for long-term migration due to natural hazards is slim; most displacement is short-term and local. But as extreme events become a more regular phenomenon, some may be tempted to give up and move.

\footnotetext{
42 See http://www.conagua.gob.mx and http://www.kgs.ku.edu/HighPlains/atlas/atisct.htm.
} 


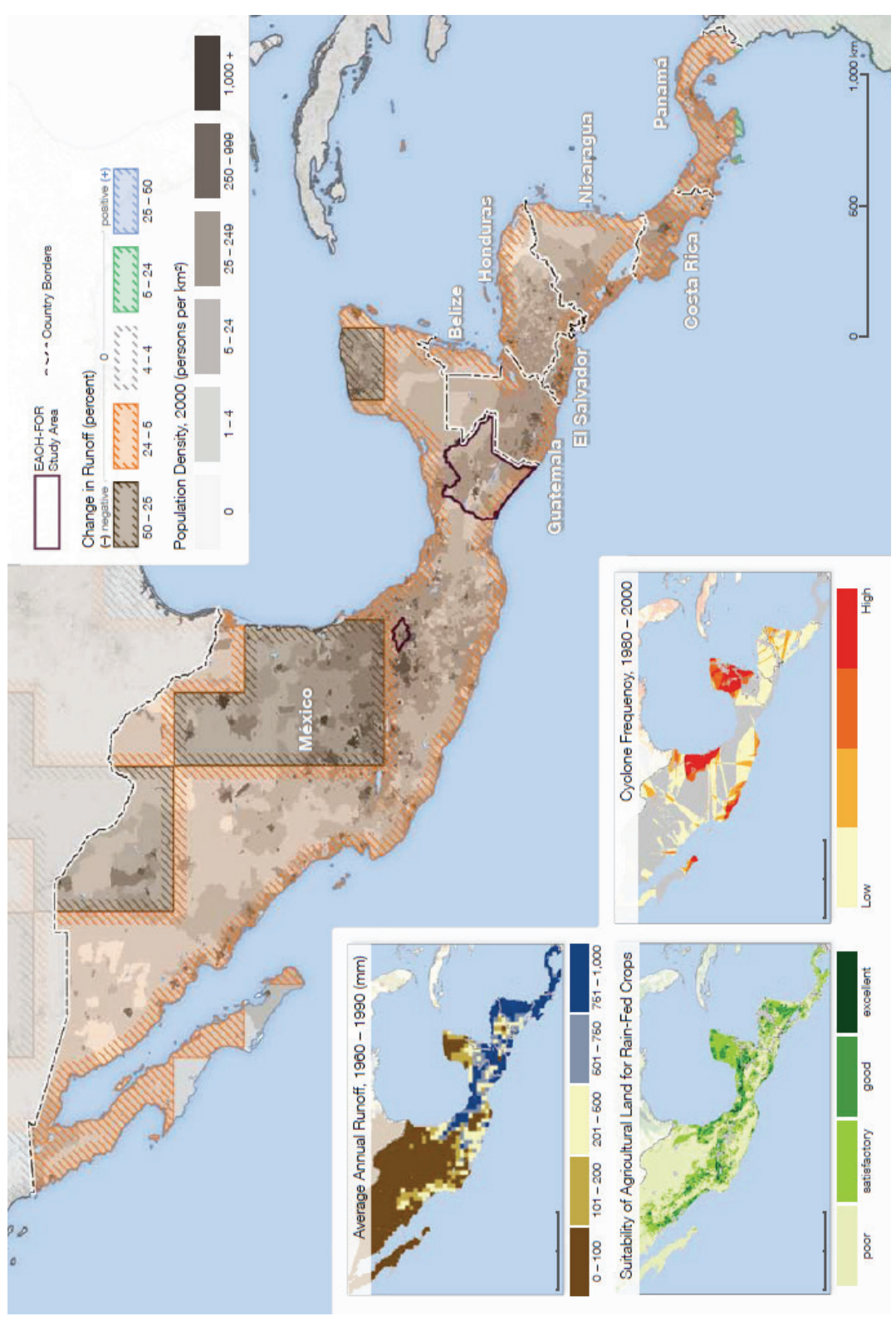

Figure 5.3: Projected Changes in Rainfall Runoff in Mesoamerica by 2080

What does this map tell us? The main map depicts projected changes in runoff by 2080 (Nohara et al. 2006). Runoff is a measure of water availability and represents the amount of rainfall that runs off the land surface after accounting for evaporation, plant transpiration, and soil moisture replenishment. Mexico and Central America will be widely affected by declines. The map also outlines the Mexican states of Tlaxcala and Chiapas, where EACH-FOR conducted research (Alscher 2008). The bottom left inset 
map shows average annual runoff for the 1960-1990 period, a baseline against which future declines will be applied (Fekete et al. 2000). The bottom right inset map shows lands suited for rain-fed agriculture (FAO 2007), which will be particularly affected by progressive drying in the region. Circular, temporary and seasonal migration has traditionally been a means of coping with climate variability in these areas, and permanent internal and international migration out of areas dependent on rain-fed agriculture is a distinct possibility. The inset on the upper right depicts cyclone frequency in the 1980-2000 period (CHRR et al. 2005). Some models show the number of category 4 and 5 hurricanes increasing in the Caribbean.

Where ties to the land are important, temporary or seasonal migration have long been important coping mechanisms and are likely to be so under climate change. Recognizing that, as in the past, most future migration is likely to be towards the United States and Canada, one approach that may be worth considering is the provision of temporary work visas following climate disasters such as drought or flooding. Such an approach was taken after the earthquake of January 2011 in Haiti (de Sherbinin et al. 2011). Migrant remittances can help local economies recover faster, and offer an adaptation mechanism that can help individual households to better weather the coming storms. As for the longer term, regional planners may need to plan for declines in rainfall that will affect major cropping areas and develop water saving irrigation technologies and alternative livelihoods for those farmers now depending on rain-fed agriculture.

\subsubsection{Mozambique: The Double Blow of Flooding and Drought}

Mozambique, a country of 777,000 sq. km (about the size of France and the UK combined), lies along Africa's east coast between Tanzania in the north and South Africa in the south. The country has a history of migration and government-sponsored resettlement that is tied to the government's socialist past and to a 15-year civil war, from 1977-1992, during which five million people were displaced. In the four years following the end of the war, some $1.6 \mathrm{~m}$ Mozambicans were repatriated from Malawi, Zimbabwe, South Africa, and Tanzania.

Although the civil war is behind them, a new kind of displacement is now afflicting Mozambique. In 2000, 2001, and 2007 the country experienced disastrous flood events in the Zambezi and Limpopo river basins that displaced hundreds of thousands of people. ${ }^{43}$ The floods of the past decade affected approximately 1 million people living in the Zambezi River valley. The floods of 2007 alone displaced over 100,000 people, half of whom were

43 The country has experienced flood cycles in the past, from the 1960 s to the early 1980s (INGC 2009); the difference in impacts could be owing to increased population densities in flood prone areas. 
evacuated to temporary "accommodation centers". In 2007 another storm, Cyclone Favio, increased the number of homeless people in Mozambique following the flooding of the Zambezi River. During the flooding, affected people lost their homes and livelihoods as well access to medical facilities, sanitation and safe drinking water (Stal 2008). Such double and triple blows greatly hinder communities' abilities to recover, since many people's limited assets have been literally swept away.

International humanitarian aid following the 2001 floods was unprecedented. In subsequent years, the government encouraged resettlement away from dangerous flood plains by providing incentives such as infrastructure in a work-for-assistance program. In exchange for making bricks, the government promised to pay for other construction materials and technical assistance for houses and multi-purpose community buildings. Stal (2008), who studied areas around the Zambezi River, conducted interviews with displaced people living in resettlement centers who indicated that before the last decade movement out of the flood plain had occurred periodically to avoid floods, but that they had never contemplated moving permanently.

Some out-migration was spontaneous, but resettlement was government orchestrated. The relocation plan moved villages together to minimize the impact on social networks. The flood-safe areas are prone to drought and resettlement has contributed to other issues like deforestation, soil erosion and water scarcity (Stal 2008). Yet, though the environment is less productive, the propensity of people to move on is partly mitigated by a lack of clear alternatives and dependence on government-provided infrastructure and services. NGOs offer training for farming techniques suited to the drought-prone conditions, but many able-bodied people leave the resettlement areas during the planting and harvesting season to work their traditional fields in the flood plains, leaving children and the elderly behind. 


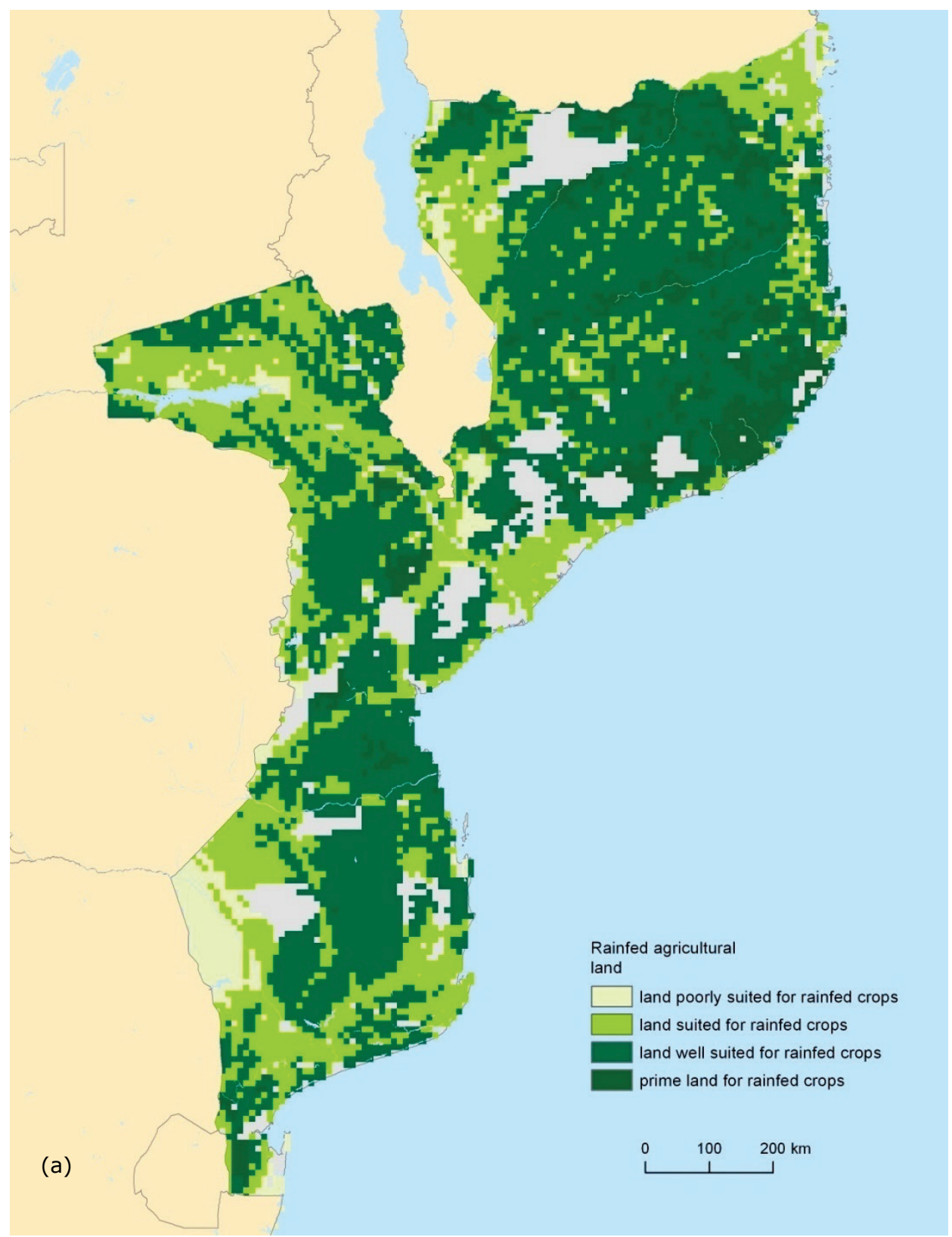

Figure 5.4 (a): Factors Contributing to Climate Vulnerability in Mozambique 


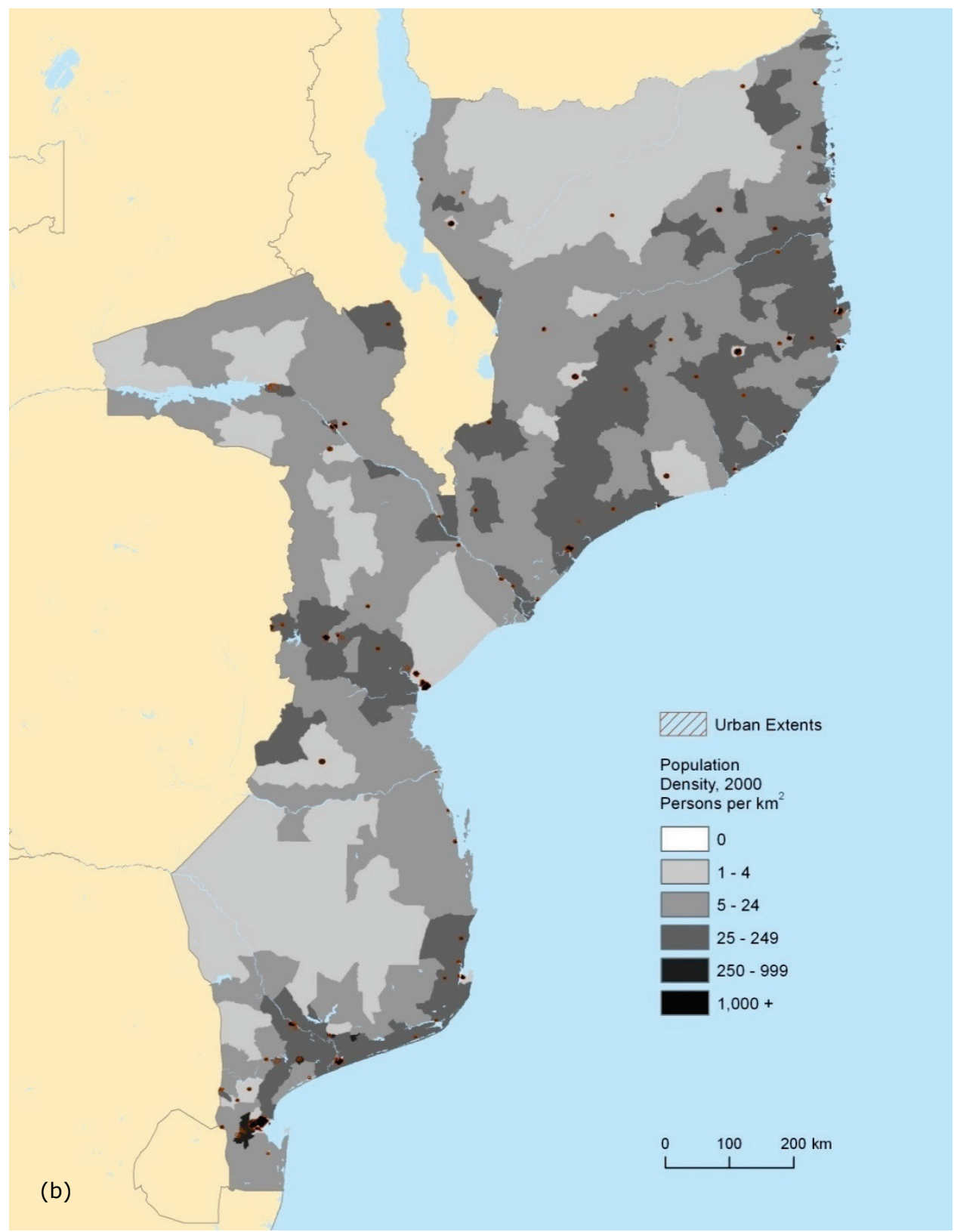

Figure 5.4(b): Factors Contributing to Climate Vulnerability in Mozambique 


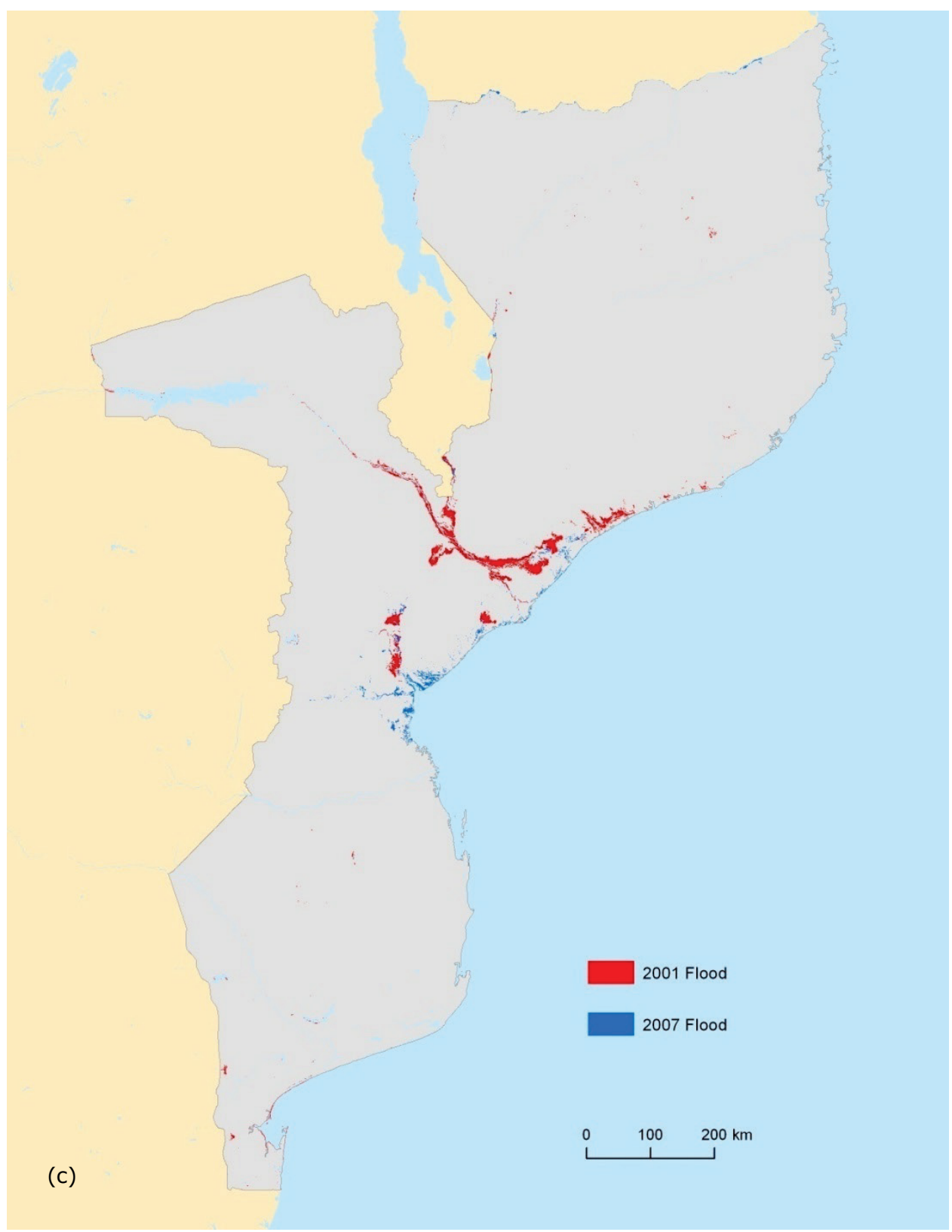

Figure 5.4(c): Factors Contributing to Climate Vulnerability in Mozambique 


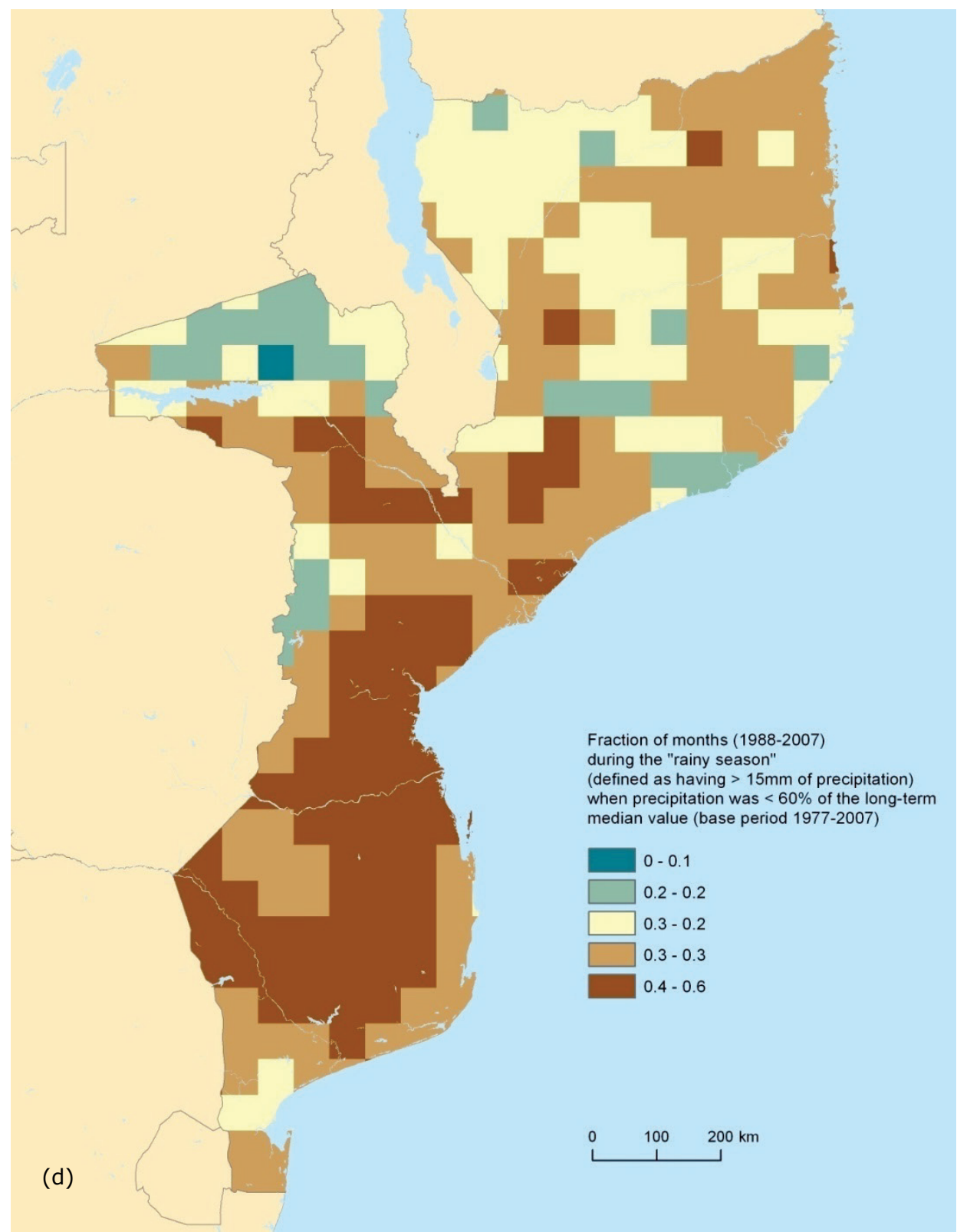

Figure 5.4(d): Factors Contributing to Climate Vulnerability in Mozambique

What do the maps tell us? Map (a) describes the distribution of rainfed agriculture in Mozambique (FAO 2007). As in many countries of Africa, a large proportion of the population is subsistence farmers dependent on rainfed agriculture which is particularly susceptible to climatic extremes. Map (b) presents the population distribution and urban extents based on CIESIN's Global Rural-Urban Mapping Project (CIESIN et al. 2011a and 2011b). More densely settled areas generally have more favorable 
agricultural conditions. Map (c) depicts the 2001 and 2007 floods along the Zambezi (north), Pungwe (middle), and Revue rivers (south), based on data from the Dartmouth Flood Observatory. Map (d) depicts the fraction of rainy season months (with precipitation $>15 \mathrm{~mm}$ ) in the period $1988-2007$ when precipitation was $<60 \%$ of the long term mean (base period 1977-2007). This map, depicting the relatively high frequency of droughts in Mozambique's south, was developed by Brad Lyon using the IRI Climate Data Library, available at http://iridl.Ideo.columbia.edu/.

Resettled people remain heavily dependent on governmental and international aid, since areas in which they are relocated are not selfsustaining in terms of infrastructure (e.g. schools and health clinics) and frequent crop failure is still the norm. Without humanitarian assistance, experts and interviewees suggest that people may need to migrate longer distances or across borders (Stal 2008). The main destinations will most likely be Maputo and South Africa, since economic prospects in other cities and neighboring countries such as Zimbabwe are not nearly so bright. While a Gallup Poll in 2009 (Esipova and Ray 2009) found that 38\% of Africans would like to move permanently to another country, most to Europe and North America, the likelihood that poor Mozambicans will find their way beyond the continent is very slim owing to their poverty and lack of established communities overseas.

The irony in Mozambique is that the country can be simultaneously hit by drought and flood - as happened in 2007, when the southern portion of the country suffered a drought even as the Zambezi farther north was overflowing its banks. Climate models suggest that rainfall levels in Mozambique may increase in the north while they decrease in the south (Nohara et al. 2006). Even areas that will receive increased overall rainfall could be affected by drought, since the country is likely to be affected by more dry spells and a prolonged dry season owing to changes in precipitation patterns and temperature increases that contribute to evapotranspiration (INGC 2009). Although land-use change in upstream areas is an important contributor to flood vulnerability, another major factor will be the spacing and intensity of rainfall; further intensification of rainfall events will increase the likelihood of a repetition of the catastrophic flooding that was repeated throughout this decade. Unfortunately, climatologists project even greater variability in this century (IPCC 2012), with climate see-sawing between extremes of drought and flood, leaving countries like Mozambique at the mercy of increasingly unpredictable weather patterns.

\subsubsection{The Mekong: Flooding and the Threat of Sea Level Rise}

Major floods are also a contributing factor to displacement in the Mekong Delta of Vietnam, but the delta has the added vulnerability of sea level rise. The Vietnamese portion of the Mekong Delta is home to 18 million people, or 
22 percent of Vietnam's population. It provides 40 percent of Vietnam's cultivated land surface and produces more than a quarter of the country's GDP. Half of Vietnam's rice is produced in the Mekong Delta, 60 percent of its fish-shrimp harvest, and 80 percent of Vietnam's fruit crop. Ninety percent of Vietnam's total rice exports come from the Mekong (Dun 2009).

Flooding plays an important role in the economy and culture of the area. People live with and depend on flood cycles, but within certain bounds. For example, flood depths from one-half to three meters are considered part of the normal flood regime upon which rice cultivation depends. These are socalled "nice floods" by Vietnamese living in the delta. Higher floods challenge coping capacities and often have harrowing effects on local livelihoods.

In recent decades, both the frequency and magnitude of floods exceeding the four-meter mark have increased. Dun (2009) conducted interviews with 32 migrants from the delta in Phnom Penh, Cambodia, one of whom noted, "Flooding sometimes threatened our lives. So we came here to find another livelihood." Another said, "My family had crop fields but in recent years, floods occurred very often so the crop was not stable" (p.17).
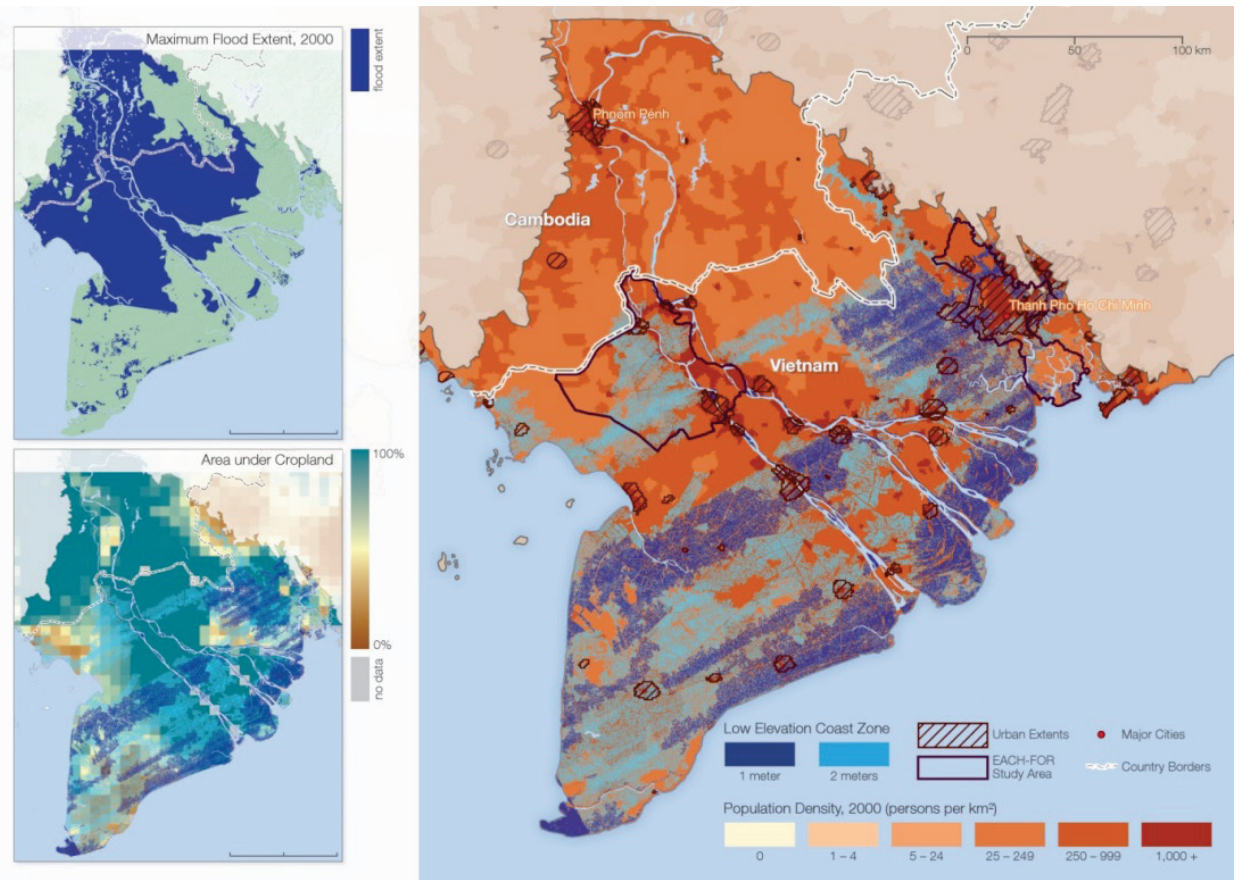

Figure 5.5: Mekong Sea Level Rise Vulnerability

What does this map tell us? The main map depicts areas of sea level rise at 1 and 2 meters (dark and light blue, respectively) based on SRTM data (Jarvis et al. 2008) 
overlaid on a population density map with urban extents delineated (CIESIN et al. 2011a and 2011b)..$^{44}$ It also shows the regions of the EACH-FOR study areas. The upper left inset map shows the area flooded in the year 2000 when unusually widespread monsoon floods deluged nearly 800,000 sq. $\mathrm{km}$ of land in Cambodia, Vietnam, Thailand, and Laos. These data are from the Dartmouth Flood Observatory. The inset map below it shows the distribution of agricultural lands (Ramankutty et al. 2010). The delta has 3 million ha of agricultural lands, of which 1.4 million ha would be inundated by a 2 meter sea level rise. Resettlement programs are already underway in some areas of the delta, and could become more widespread under certain sea level rise scenarios.

Natural hazards, the stress placed on the environment due to rapid socioeconomic development in Vietnam and upstream South-east Asian countries, and the threats posed to Vietnam by climate change places the country's natural resources and those who depend upon them for their livelihoods in a precarious position. In the face of environmental stressors, people in the Mekong Delta adapt in various ways. One adaptation mechanism is migration, and since most economic growth is occurring in urban areas, that generally means a move to cities.

For its part, the government in Vietnam has a program known as "living with floods." As part of this program, agencies are encouraging a shift from rice culture to aquaculture and, along the Mekong River's main stem in An Giang province, are moving people away from the river. Almost 20,000 landless and poor households in this province are targeted for relocation by 2020 . Households are selected for resettlement based on a number of factors related to the risk of natural calamities (flooding, landslides) and riverbank erosion. People scheduled for relocation are generally landless, have nowhere else to move if their houses collapse, and are too poor to move to urban areas. For these people, social networks - the fabric of relationships with family, friends, and employers - are all important. Although the "residential clusters" are generally within a mile of their former homes, resettlement can tear the social fabric, leading to joblessness and a sense of isolation.

Based on a spatial analysis using NASA Shuttle Radar Topography Mission (SRTM) elevation data (Figure 5.4), a one meter sea level rise could result in the displacement of more than 7 million residents in the delta (including Cambodian portions), and a two meter rise would double that to 14 million or 50 percent of delta residents. At that level, even parts of Ho Chi Minh City and a number of other cities would be under water. Though a two meter rise in this century is beyond what is generally considered likely, abrupt climate change could create so-called "tipping points" in which the land-based

44 SRTM absolute average vertical errors are in the range of 3.5-8m (Gorokhovich and Voustianiouk 2006), with higher accuracy in flatter areas. 
glaciers of Greenland and West Antarctic melt much more quickly than currently anticipated. In this event, a two meter rise might occur by 2100 (Pfeffer 2008). Under those circumstances, the Vietnamese strategy of "living with floods" would be put to an extreme test, and many delta residents would be forced to flee to urban areas further north and in Cambodia. Yet, the same lands that employ the farmers also feed the urban areas, begging a host of other questions related to the region's food security.

\subsection{Policy considerations: How best to safeguard those displaced?}

While each of the case studies addresses issues related to climate-related displacement and migration, the policy ramifications are different in each case. In each case there are policies that relate to climate adaptation and migration that need to be put in place. In Mexico and Central America, adaptation mechanisms include investments in improved seed varieties and agricultural methods that are more climate-resilient (Eitzinger et al. 2012) and improved disaster risk reduction and response (Nansen Initiative 2013). Mechanisms for addressing disaster-related displacement include granting temporary protection status, complementary protection, or humanitarian visas (Nansen Initiative 2013, de Sherbinin et al. 2011). In the longer term, it is anticipated that climatic and other factors inducing migration to the U.S. will continue to grow (Feng et al. 2010), and apart from adaptation responses and border control it seems likely that migratory streams will increase.

For Mozambique, as mentioned the government has already put in place both adaptation and resettlement responses. The central government has also empowered the district level to carryout disaster risk reduction activities, and community-based approaches are being piloted (Kienberger 2012). While the government has been very proactive, it seems likely that migratory streams to South Africa will continue to grow in response to precarious livelihoods and climate variability. Finally, for the Mekong, the government has taken a similarly pro-active approach by moving communities to dykes and cluster resettlement sites, but as with the other two cases, it seems likely that future displacement and increased rural-urban migration is all but inevitable as floods become more unpredictable, water levels rise, and saline intrusion affects coastal districts (de Sherbinin 2014, Oxfam 2008).

A debate exists in international law about the legitimacy of conferring the term "refugee" on people displaced by climate change. Many refugee organizations and legal scholars have argued against a broadening of the definition employed by the UN Convention Relating to the Status of Refugees (1951), which refers only to individuals who have a "well-founded fear of being persecuted for reasons of race, religion, nationality, membership of a 
particular social group or political opinion." McAdam (2012) doubts whether governments that have already failed to fully live up to this UN Convention would be willing to expand the definition further to include potentially millions of "climate refugees."

A case of Tuvaluans appealing for refugee status in New Zealand is telling. The Refugee Status Appeals Authority responded: "This is not a case where the appellants can be said to be differentially at risk of harm amounting to persecution due to any one of these five grounds. All Tuvalu citizens face the same environmental problems and economic difficulties living in Tuvalu. Rather, the appellants are unfortunate victims, like all other Tuvaluan citizens, of the forces of nature leading to the erosion of coastland and the family property being partially submerged at high tide, ${ }^{\prime \prime 5}$ Although New Zealand has issued visas to an increasing number of islanders under its Pacific Access Category, established in 2002, this was not a response to environmental changes.

While conferring refugee status on those displaced by climate change may be problematic, forced migration and displacement due to the impacts of climate change is poised to become the international community's defining - and potentially overwhelming - humanitarian challenge in coming decades.

In terms of policy responses, the first and most urgent priority must be to reduce the greenhouse gas emissions that drive climate change, while acknowledging that a certain amount of change is "locked in" based on historical emissions. When people are forced to move, whether due to sea level rise or extreme events that grow in frequency and intensity, the international community will need to put protections in place for these migrants and displaced people (Oliver-Smith and de Sherbinin 2014, McAdam 2012) ${ }^{46}$ Ways must be found to ensure that human movements are orderly and peaceful, and that affected peoples have a voice in shaping their own mobility and (re)settlement (de Sherbinin et al. 2011). Special consideration must be taken of social dynamics and the particular needs of some of the most vulnerable and marginalized groups in societies worldwide.

Some may consider it paradoxical that many residents of small island states don't want to be considered refugees. Most refugees want to leave their countries owing to a fear of persecution, but Pacific Islanders love their countries and are loath to emigrate to those countries that they blame for the

\footnotetext{
45 See http://www.refworld.org/pdfid/4d08cf7f2.pdf, p.3.

${ }^{46}$ See also Nansen Principles, www.regjeringen.no/upload/UD/Vedlegg/Hum/nansen prinsipper.pdf. Conflict- related migration and resettlement offers a partial analog, an issue explored in greater by Martin et al. (2014).
} 
climate problem in the first place. This gets to a critical issue: many of tomorrow's climate migrants will not want to leave, but may be forced to do so owing to a lack of secure livelihoods in their home communities. This reality led the UK Government's Foresight on Migration and Environmental Change (2011) to speak of "trapped populations" that are at significant risk of climate impacts yet lack the financial means to move out of harm's way (Black et al. 2011a). The international community will need to partner with developing country governments to help communities to adapt to the changing climate. Research has found that diversification of livelihood strategies and government investment in disaster risk management decreases the likelihood of migration, regardless of poverty status (e.g., Warner et al 2012).

\subsection{References}

Adamo, S., and A. de Sherbinin. 2011 "The impact of climate change on the spatial distribution of populations and migration." In Proceedings of the Expert Group Meeting on Population Distribution, Urbanization, Internal Migration and Development. Edited by United Nations. Population Division: UNDESA.

Adger, W.N., S. Agrawala, and M.M.Q. Mirza. 2007. Assessment of adaptation, practices, options, constraints and capacity. In: M. Parry (ed), Climate Change 2007: Impacts, Adaptation and Vulnerability. Contribution of Working Group II to the Fourth Assessment Report of the Intergovernmental Panel on Climate Change. Cambridge: IPCC and Cambridge University Press.

Alscher, S. 2008. Mexico Case Study Report: Environmental Factors in Mexican Migration. EACH-FOR (Environmental Change and Forced Migration Scenarios) Project Report D2.6.2.4.

Biermann, F., and I. Boas. 2010. Preparing for a Warmer World: Towards a Global Governance System to Protect Climate Refugees. Global Environmental Politics, 10.

Black, R., S.R.G. Bennett, S.M. Thomas, and J.R. Beddington. 2011 a. Migration as Adaptation. Nature, 478: 447-449.

Black, R., D. Kniveton, and K. Schmidt-Verkerk. 2011b. Migration and climate change: towards an integrated assessment of sensitivity, Environmental Planning A, 43:431

Black, R., D. Kniveton, R. Skeldon, D. Coppard, A. Murata, and K. SchmidtVerkerk. 2008. Demographics and Climate Change: Future Trends and their Policy Implications for Migration, Working Paper T-27, Development Research Centre on Migration, Globalisation and Poverty, University of Sussex, Brighton.

Büntgen, U., W. Tegel, K. Nicolussi, M. McCormick, et al. 2011. 2500 Years of European Climate Variability and Human Susceptibility. 
Scienceexpress, January 2011, http://dx.doi.org/10.1126/science.1197175.

Campbell, K. M., J. Gulledge, J.R. McNeill, et al. 2007. The Age of Consequences: The Foreign Policy and National Security Implications of Global Climate Change. Washington, DC: Center for Strategic and International Studies and Center for New American Security.

Carney, D. 1998a. "Sustainable rural livelihoods: What contribution can we make?" In: D. Carney (ed.), Department for International Development's Natural Resources Advisers' Conference, July 1998. London: DFID.

Carney, D. 1998b. Implementing the Sustainable Rural Livelihoods Approach. London, UK: Overseas Development Institute.

CHRR (Center for Hazards and Risk Research/Columbia University CIESIN (Center for International Earth Science Information Network/Columbia University), The World Bank, and UNEP/GRID-Geneva (United Nations Environment Programme Global Resource Information Database Geneva). 2005. Global Cyclone Hazard Frequency and Distribution. Palisades, NY: NASA Socioeconomic Data and Applications Center (SEDAC). http://sedac.ciesin.columbia.edu/data/set/ndh-cyclonehazard-frequency-distribution.

CIESIN (Center for International Earth Science Information Network)/Columbia University. 2012. Low Elevation Coastal Zone Urban-Rural Population and Land Area Estimates, v.2 (Alpha). Palisades, NY: NASA Socioeconomic Data and Applications Center (SEDAC).

CIESIN (Center for International Earth Science Information Network)/Columbia University, IFPRI (International Food Policy Research Institute), The World Bank, and CIAT (Centro Internacional de Agricultura Tropical). 2011a. Global Rural-Urban Mapping Project, Version 1 (GRUMPv1): Population Density Grid. Palisades, NY: NASA Socioeconomic Data and Applications Center (SEDAC). http://sedac.ciesin.columbia.edu/data/set/grump-v1-populationdensity.

CIESIN (Center for International Earth Science Information Network/Columbia University), IFPRI (International Food Policy Research Institute), The World Bank, and CIAT (Centro Internacional de Agricultura Tropical). 2011b. Global Rural-Urban Mapping Project, Version 1 (GRUMPV1): Urban Extents Grid. Palisades, NY: NASA Socioeconomic Data and Applications Center (SEDAC). http://sedac.ciesin.columbia.edu/data/ set/grump-v1-urban-extents.

Corvalan, C., S. Hales, and A. McMichael. 2005. Ecosystems and Human Well-being: Health Synthesis. A Report of the Millennium Ecosystem Assessment. Geneva: World Health Organization. 
CRED (Center for Research on the Epidemiology of Disease). 2013. EM-DAT: The OFDA/CRED International Disaster Database, Université catholique de Louvain. Queried on 4 July 2013, Data version 12.07.

CRED (Center for Research on the Epidemiology of Disease). 2009. EM-DAT: The OFDA/CRED International Disaster Database, Université catholique de Louvain. Created on 16 November 2009, Data version 12.07.

de Sherbinin, A. 2014. "Mekong Delta and Three Gorges Dam: World's First Climate Change Resettlements?" State of the Planet Blog, 6 March 2014. Available at: http://blogs.ei.columbia.edu/2014/03/06/themekong-delta-and-three-gorges-dam/.

de Sherbinin, A., M. Levy, S.B. Adamo, K. MacManus, G. Yetman, V. Mara, L. Razafindrazay, B. Goodrich, T. Srebotnjak, C. Aichele, and L. Pistolesi. 2012. Migration and Risk: Net Migration in Marginal Ecosystems and Hazardous Areas. Environmental Research Letters. 7045602. http://dx.doi.org/10.1088/1748-9326/7/4/045602.

de Sherbinin, A., M. Castro, F. Gemenne, M.M. Cernea, S. Adamo, P. M. Fearnside, G. Krieger, S. Lahmani, A. Oliver-Smith, A. Pankhurst, T. Scudder, B. Singer, Y. Tan, G. Wannier, P. Boncour, C. Ehrhart, G. Hugo, B. Pandey, and G. Shi. 2011. Preparing for Resettlement Associated with Climate Change. Science, 334: 456-457. Accessed at http://dx.doi.org/10.1126/science.1208821 on 4 July 2013.

de Sherbinin, A., L. VanWey, K. McSweeney, R. Aggarwal, A. Barbieri, S. Henry, L. Hunter, W. Twine, and R. Walker. 2008. Household Demographics, Livelihoods and the Environment. Global Environmental Change, 18(1): 38-53.

Dilley, M., R.S Chen, U. Deichmann, A. Lerner-Lam and M. Arnold. 2005. Natural Disaster Hotspots: A Global Risk Analysis, Washington, DC: World Bank.

Dun, O. 2009. Viet Nam Case Study Report: Linkages between flooding, migration and resettlement. EACH-FOR (Environmental Change and Forced Migration Scenarios) Project Report D 2.3.2.2.

EACH-FOR (Environmental Change and Forced Migration Scenarios). 2009. Synthesis Report. Report D.3.4. of the EACH-FOR project.

Eitzinger, A., Läderach, P., Rodriguez, B., Fisher, M., Rizo, L., and Ocon, S. (2012). Tortillas on the roaster: Central American maize-bean systems and the changing climate. CIAT final technical report. Cali, Colombia: International Center for Tropical Agriculture (CIAT).

Esipova, N., and J. Ray. 2009. 700 Million Worldwide Desire to Migrate Permanently. Gallup World. Accessed at http://www.gallup.com/poll/124028/700-Million-Worldwide-DesireMigrate-Permanently.aspx on 22 November 2011.

FAO (Food and Agriculture Organization of the United Nations). 2007. Combined suitability of currently available land for pasture and rainfed crops (low input level) (FGGD). Obtained from GeoNetwork. 
Faris, S. 2009. The Last Straw. Foreign Policy, July/August 2009 issue.

Fekete, B., C. Vorosmarty, and W. Grabs. 2000. UNH/GRDC Global Composite Runoff Fields v1.0. Accessed at http://www.grdc.sr.unh.edu/ on 29 June 2013.

Feng, S., A.B. Krueger, and M. Oppenheimer, 2010. Linkages among climate change, crop yields and Mexico-US cross-border migration. Proceedings of the National Academy of Sciences, 107(32), 1425714262.

Foresight Migration and Environmental Change. 2011. Final Project Report. London: The Government Office for Science.

Gall, M. 2013. "Measuring Disaster Losses is Not As Explicit as Climate Change." Perspectives on Loss and Damage: Society, Climate Change and Decision-Making, Conference hosted by UNU-EHS, Bonn, 25-27 February 2013.

Gemenne, F. 2011. Why the numbers don't add up: A review of estimates and predictions of people displaced by environmental changes. Global Environmental Change, 21, Supplement 1: S1-S130.

Gorokhovich, Y., Voustianiouk, A. 2006. Accuracy assessment of the processed SRTM-based elevation data by CGIAR using field data from USA and Thailand and its relation to the terrain characteristics. Remote Sensing of Environment, 104:409-415.

Greene, A.M., A.W. Robertson, P. Smyth and S. Triglia. 2011. Downscaling projections of Indian monsoon rainfall using a nonhomegneous hidden Markov model, Quarterly Journal of the Royal Meteorological Society 137:347-359. http://dx.doi.org/10.1002/qj.788

Gronewold, N. 2011. "Island Nations May Keep Some Sovereignty if Rising Seas Make Them Uninhabitable," The New York Times, 25 May 2011,

INGC (Mozambique National Institute for Disaster Management). 2009. Main report: INGC Climate Change Report: Study on the impact of climate change on disaster risk in Mozambique. INGC, Mozambique

IPCC (Intergovernmental Panel on Climate Change). 2012. Managing the Risks of Extreme Events and Disasters to Advance Climate Change Adaptation. A Special Report of Working Groups I and II of the Intergovernmental Panel on Climate Change. Cambridge and New York: Cambridge University Press.

Jarvis, A., H.I. Reuter, A. Nelson, and E. Guevara. 2008. Hole-filled SRTM for the globe Version 4, CGIAR-CSI SRTM 90m Database. Accessed at http://srtm.csi.cgiar.org on 8 April 2009.

Kienberger, S. 2012. Spatial modelling of social and economic vulnerability to floods at the district level in Búzi, Mozambique. Natural Hazards, 64:2001-2019. http://dx.doi.org/10.1007/s11069-012-0174-9

Krupa, M. 2011. "New Orleans' official 2010 census population is 343,829, agency reports". New Orleans Times Picayune, 3 February 2011. 
Lamb, H.H. 1995. Climate, History and the Modern World. London, New York : Routledge.

Lee, E.S. 1966. A Theory of Migration. Demography, 3(1):47-57.

Martin, S., S. Weerasinghe, and A. Taylor. 2014. What is crisis migration? Forced Migration Review, 45:5-9.

McAdam, J. 2012. Climate Change, Forced Migration, and International Law. Oxford: Oxford University Press.

McElroy, M., and J. Baker. 2012. Climate Extremes: Recent Trends with Implications for National Security. Cambridge, Mass.: Harvard University.

Nansen Initiative. 2013. "Disasters and Cross-Border Displacement in Central America: Emerging Needs, New Responses." Conclusions: Nansen Initiative Regional Consultation, San Jose, Costa Rica 2-4 December 2013.

New, M., D. Liverman, H. Schroder, and K. Anderson. 2011. Four degrees and beyond: the potential for a global temperature increase of four degrees and its implications. Philosophical Transactions of the Royal Society A, 369 (1934) 6-19. http://dx.doi.org/10.1098/rsta.2010.0303

Nohara, D., A. Kitoh, M. Hosaka and T. Oki. 2006. Impact of climate change on river runoff. Journal of Hydrometeorology, 7:1076-1089.

OCHA (Office for the Coordination of Humanitarian Affaris) and IDMC (International Displacement Monitoring Centre), and NRC (Norwegian Refugee Council). 2009. Monitoring disaster displacement in the context of climate change. Geneva: IDMC.

Oliver-Smith, A., and A. de Sherbinin. 2014. "Something Old and Something New: Resettlement in the Twenty First Century." In: S. Martin et al. (eds). Crisis Migration. Oxon, UK: Routledge.

OSCE (Organization for Security and Co-operation in Europe). 2005. Background paper for Session III of the 13th Economic Forum. Vienna, OSCE. The Secretariat. http://www.osce.org/eea/14861 .

Oxfam. 2008. Viet Nam: Climate Change, Adaptation and Poor People. London, UK: Oxfam.

Parker, D.C., B. Entwisle, R.R. Rindfuss, L.K. Vanwey, S.M. Manson, E. Moran, L. An, P. Deadman, T.P. Evans, et al. 2008. Case studies, cross-site comparisons, and the challenge of generalization: comparing agent-based models of land-use change in frontier regions. Journal of Land Use Science. 3(1): 41-72. http://dx.doi.org/ $10.1080 / 17474230802048151$

Parris, A., P. Bromirski, V. Burkett, D. Cayan, M. Culver, J. Hall, R. Horton, K. Knuuti, R. Moss, J. Obeysekera, A. Sallenger, and J. Weiss. 2012. Global Sea Level Rise Scenarios for the US National Climate Assessment. NOAA Tech Memo OAR CPO-1. 37 pp. 
Pfeffer, W., J. Harper, and S. O'Neel. 2008. Kinematic constraints on glacier contributions to 21st-century sea-level rise. Science, 321(5994): 13401343.

Ramankutty, N., A.T. Evan, C. Monfreda, and J.A. Foley. 2010. Global Agricultural Lands: Croplands, 2000. Palisades, NY: NASA Socioeconomic Data and Applications Center (SEDAC). http://sedac.ciesin.columbia.edu/data/set/aglands-croplands-2000.

Reid, W.V., H.A. Mooney, A. Cropper, D. Capistrano, S.R. Carpenter, K. Chopra, et al. 2005. Ecosystems and Human Well-being: Synthesis. Washington, DC: Island Press.

Renaud, F., J.J. Bogardi, O. Dun, and K. Warner. 2007. "Control, Adapt or Flee." UNU-EHS InterSecTions No. 5/2007. Accessed at http://www.ehs.unu.edu/article/read/345 on 1 January 2014.

Reuveny, R. 2008. Ecomigration and violent conflict: case studies and public policy implications. Human Ecology, 36:1-13, http://dx.doi.org/10.1007/s10745-007-9142-5.

Samson, J., D. Berteaux, B.J. McGill and M.M. Humphries. 2011. Geographic disparities and moral hazards in the predicted impacts of climate change on human populations. Global Ecology and Biogeography, http://dx.doi.org/10.1111/j.1466-8238.2010.00632.x

Stal, M. 2008. Mozambique Case Study Report. EACH-FOR (Environmental Change and Forced Migration Scenarios) Project Report D2.4.2.2.

Tol, R.S.J., and R. Verheyen. 2004. State Responsibility and Compensation for Climate Change Damages: A Legal and Economic Assessment. Energy Policy, 32(9):1109-1130.

UNEP (United Nations Environment Programme). 2011. Climate Change, Conflict and Migration in the Sahel. Geneva: UNEP.

Warner, K., T. Afifi, K. Henry, T. Rawe, C. Smith, and A. de Sherbinin. 2012. Where the Rain Falls: Climate Change, Food and Livelihood Security, and Migration. Bonn, Germany: United Nations University and CARE.

Warner, K., C. Erhart, A. de Sherbinin, S. Adamo, and T. Chai-Onn. 2009. In Search of Shelter: Mapping the Effects of Climate Change on Human Migration and Displacement. Bonn, Germany: United Nations University, CARE, and CIESIN-Columbia University.

WBGU (German Advisory Council on Global Change). 2007. Climate Change as Security Risk. Berlin: WBGU.

Williams, J.W., S.T. Jackson, and J.E. Kutzbach. 2007. Projected distributions of novel and disappearing climates by 2100. Proceedings of the National Academy of Sciences, 104(14): 5738-5742.

Xie, P. and P. A. Arkin. 1997. Global Precipitation. BAMS, 78, 2539-255.

Xie, P. and P. A. Arkin, 1996. Analyses of Global Monthly Precipitation Using Gauge Observations, Satellite Estimates, and Numerical Model Predictions. Journal of Climate, 9, 840 -858. 
Chapter 6

Conclusions 


\subsection{Introduction}

This chapter assesses the strengths and weaknesses of the different approaches described in the previous chapters (Section 6.2) and the utility of the PNAS framework (Section 6.3), and point to ways forward in spatial VA research (Section 6.4). We conclude by returning to the question implied in the thesis title, Is vulnerability measurable and therefore mapable? (Section 6.5). ${ }^{47}$

\subsection{Assessment of Spatial VA Approaches}

The proceeding chapters describe a wide array of spatial approaches for assessing vulnerability at scales ranging from individual cities (Chapter 3) to continents (Chapter 4 ) to the entire world (Chapter 2). There are certainly a wider array of approaches available for spatial VA than those presented in these chapters (see Chapter 1, Section 1.3 for an overview), so the chapters cannot be seen to be fully representative of all the approaches available. Still, a return to the guiding questions in Table 1.1 and a review of their strengths and weaknesses is appropriate. Here we evaluate the approaches primarily on their ability to guide policy, since a strong rationale for adopting spatial approaches to vulnerability assessment is to target the allocation of resources for adaptation and disaster risk reduction responses (see Chapter 2, Section 2.1).

\subsubsection{Chapter 2: Climate change hotspots mapping}

Chapter 2 sought to answer two main questions: Which regions are most affected by climate change past and future?, and, What improvements can be made to the practice of hotspots mapping? The chapter provides a list of regions in Table 2.2 that are likely to be more severely affected by climate change in terms of both exposure to climate and overall vulnerability, with Africa and South Asia showing up as particularly vulnerable in most global assessments. Improvements in the practice of hotspots mapping were discussed, including cartographic and design elements, better treatment of uncertainties in map results, and greater evaluation of use in decisionmaking. Regarding the latter, questions remain about the utility of mapping hotspots and their influence in policy development and the targeting of adaptation projects that can really only be answered through extensive interviews with end users. Although the literature on geospatial tools in decision support is extensive, there is less literature on this in the field of climate vulnerability and hotspots mapping. As mentioned in the chapter, while assertions of the utility of hotspots maps for decision-making are widespread, there are very few examples of serious monitoring and

${ }^{47}$ For this chapter, "we" refers to A. de Sherbinin, M. van Maarseveen, and R. Sliuzas. 
evaluation of their use. An evaluation of the use of bush fire vulnerability maps by local governments in Australia (Preston et al. 2009) is one of the few to seriously consider this issue. Follow up interviews with staff at the Mali mission of the U.S. Agency for International Development regarding the use of maps developed by de Sherbinin et al. (2014a) found that the maps were influential in decisions to target resources to a highly climate-vulnerable province in northern Mali where other aid agencies had less of a presence.

Turning to strengths and weaknesses, the chapter represents a metaanalysis, and hence does not make use of a spatial VA method per se. Instead, it reviews the most commonly used approaches for global- to regional-scale hotspots identification, and includes an assessment of the pros and cons of the different approaches. Given the diverse approaches and the differing thematic coverage it is difficult to evaluate the methods as a whole. However, it is worth noting some of the primary differences between the spatial VA and impact (or risk) assessment approaches. These are not "hard and fast" distinctions, but rather generalizations that relate to conceptual understandings, approaches, and the overall goals of an assessment.

Vulnerability mapping or assessment, per the IPCC definition provided in Chapter 1 (Section 1.2), helps to illuminate multiple drivers of vulnerability and how the broader human-environment system behaves in response to climate stressors (Preston et al. 2007). Both the thematic and geographic foci tend to be relatively broad, with systems often being defined in terms of "livelihoods" or "wellbeing" over relatively large areas. Although the term "VA" has sometimes been used to refer to any kind of climate change assessment (Soares et al. 2012), it is useful for analytical purposes to distinguish it from impact assessment. The latter often entails modeling the response of specific systems (e.g., infrastructure or crops) to specific stressors (e.g., increased flood exposure, temperature change, or precipitation extremes). Although these systems may exhibit sensitivity and to some degree adaptive capacity (e.g., farmers may have greater or lesser abilities to adapt), the goal of the assessment is generally a quantitative measurement of the scale of impact (e.g., number of people affected or likely damage from climate change impacts) and possibly the costs of adaptation.

Preston et al. (2007 and 2009) address a number of the pros and cons of spatial VA versus impact assessment. The vulnerability approach is "conducive to diagnosing the various factors and interactions that contribute to vulnerability and climate risk as a means of generating thought regarding processes that affect risk and its management" (2007:262). In the spatial index approach, multiple data layers are integrated in a spatial indexing approach, in which each component of vulnerability contributes to the overall score for a given location. This can spur a "complex systems" approach to 
understanding the system. On the other hand, because they are more open ended and comprehensive, it may be difficult to identify the precise contributions of the different indicators that account for the spatial patterns on the maps, and it is challenging to validate the maps against objective data. Spatial VAs also do not generally yield cost estimates of likely losses or adaptation responses, which are of interest to decision-makers. Their primary use in policy making is identification of regions requiring adaptation assistance, often with ancillary information on population or existing donor interventions.

Impact assessment, on the other hand, is often scenario-based (e.g., projected changes in temperature or rainfall, or scenarios of extreme rainfall or storm surge events), and may focus on the return periods of extreme events or on likely system responses to changes in rainfall or temperatures over time. ${ }^{48}$ They are generally focused on narrowly defined systems, such as a specific sector (e.g. transportation, energy, or water supply infrastructure, or on specific crops). Because they are more narrowly focused and can provide estimates of the costs of impacts and potential adaptation options, they are attractive in decision-making contexts. Modeling also tends to lend itself more readily to uncertainty assessment than VA approaches because multiple scenarios based on different assumptions, adaptation responses (e.g. seed varieties or planting dates in crop models), or underlying data inputs can be compared side-by-side. However, requirements for both data and technical expertise are quite high. Furthermore, while there may be a predisposition to desire quantitative assessments on the part of stakeholders, there are challenges in accounting for endogenous social and environmental change (e.g., population growth or development) within impact assessment models given sometimes high uncertainty in future development paths. Of the hotspots maps reviewed in Chapter 2, the agricultural, water resource, and multi-sectoral assessments can be characterized as impact assessments. Which approach is most desirable depends in large part on the context and the decision making needs of the users, and the time and funding available to carry out the assessment. Depending on the tool/model used, ${ }^{49}$ spatial impact assessments tend to take longer, have more stringent data requirements, and have higher costs than spatial VAs.

\footnotetext{
48 While climate scenarios are certainly used in VA approaches, the focus tends to be less on relative risk under different future scenarios, and alternative vulnerability aggregations under future scenarios is not a primary focus of attention.

49 Some, such as the Dynamic Interactive Vulnerability Assessment (DIVA) model, include prepackaged data and are relatively easy to use (Hinkel et al. 2012), though they may not be easily adapted to local contexts or specific assessment needs.
} 
As mentioned above, the usefulness of global/regional hotspots maps for policy development is an open question. It is likely that where maps consistently represent certain regions as more vulnerable that this shapes perspectives of policy makers and may be used to target resources at high levels, but inputs are often so coarse that it is unlikely that they are used for national-level planning. Tailored country-level or sub-national assessments may have greater policy traction. For example, results of the Mali vulnerability mapping (de Sherbinin et al. 2014a) were used by USAID to prioritize the Mopti Region owing to high vulnerability levels and large populations. The USAID mission also requested high resolution versions of the base maps depicting the untransformed data, suggesting that transparency is needed if decision makers are to trust and use the model outputs. The practice of providing detailed indicator profiles with source information, justifications for inclusion, and statistical transformations applied is important for credibility among end users, and is found in a number of the hotspots mapping efforts reviewed (e.g., Davies and Midgley 2010, Thow and DeBlois 2008). It is clear that decision making with regard to the allocation of adaptation funding is moving ahead whether it is informed by data or not (Klein 2009); thus provision of maps developed using best practices (i.e., methodological transparency, uncertainty assessment, and sensitivity analysis) for targeting of resources represents an advance, even if the maps represent only one datum in a larger matrix.

\subsubsection{Chapter 3: The vulnerability of global cities to climate hazards}

Chapter 3 sought to answer the question, What is the interplay of biophysical and human factors influencing the vulnerability of coastal megacities to climate hazards? Underlying this broad question is a more narrow question, Which of the two sets of factors is most important in the cities studied? The response is that it is almost impossible to disentangle the relative contributions of the two when discussing complex coupled socio-ecological systems. That said, one can argue that certain "given" biophysical factors (e.g., flat topography and low elevation in a cyclone prone area like Shanghai and torrential rains and steep topography in a landslide prone area like Rio De Janeiro) already put a city in a higher vulnerability category regardless of the human responses. It is clearly the combination of the "given" factors with human responses, in the form of dykes in the case of Shanghai and the lack of enforcement of zoning regulations in Rio De Janeiro, that underpin the vulnerability of these cities to climate risks. In addition, there is the degree of social capital/cohesion (e.g., slum dweller organizations in Mumbai) and the empowerment and capacity of populations to respond to risks (e.g., community disaster response drills in Shanghai (Sha 2011)). The precise 
combination of contributing factors, either positively or negatively influencing vulnerability, varies from city, which makes this topic extremely interesting.

In terms of strengths and weaknesses, the analysis of the three cities-Rio De Janeiro, Mumbai and Shanghai-was not strictly speaking a spatial VA, but it did include a strong awareness of the geographic context of each city and how that context influences their relative vulnerabilities. Spatial data were useful but not central to the assessment. This approach is frameworkdriven but eclectic in its use of data and information. The assessments conducted by the Asia Climate Change Research Network (ACCRN) are similar in this regard (e.g., ICRST 2012), with a strong overarching framework that drives data gathering and assessment (Moench et al. 2011). Map illustrations are used liberally, but no attempt is made to combine data layers to map vulnerability hotspots.

The strength of this approach is in its complex systems understanding, but its weakness is in that very complexity; decision makers may have a difficult time identifying the precise actions to take. While the originally published paper on which Chapter 3 is based is widely cited (192 citations according to Google Scholar as of March 2014), and Figure 3.1 has appeared in World Bank and UNHABITAT reports (Dickson et al. 2012, UNHABITAT 2011), the majority of citations are in the academic literature, and it is not clear that the article influenced any decisions. On the other hand, the ACCRN reports (e.g., Report on City Resilience Strategy, Indore (ICRST 2012)), which include a range of vulnerability related maps, directly engaged city stakeholders who endorsed the results, and therefore could be said to have had a strong impact (Tyler et al. 2014). Furthermore, in contrast to standard risk/impact assessments, the consideration of a wider set of variables-including informal institutions, social capital and inequality of access to endowments-helps draw attention to economic disparities and malfunctioning political/institutional systems that strongly influence vulnerability in ways that a standard engineering/modeling approach to risk/impact assessment does not. There is a strong value in this, though because findings may be politically "inconvenient", they may not always be acted upon (See Chapter 3 , Section 3.5 for further discussion). ${ }^{50}$

\footnotetext{
50 Ranganathan (2012) finds a pattern of blame-shifting in the wake of urban flooding in India, in which blame is shifted away from the political and economic structures that allow people to move into areas and from those who would be responsible for putting in place flood prevention infrastructure (e.g. highly educated engineers and civil servants), and towards those who are blamed for "encroaching" on flood prone areas (e.g. lower and lower middle classes). No amount of data or maps will necessarily trigger action to mitigate the floods.
} 


\subsubsection{Chapter 4: Climatic, biophysical and socioeconomic factors affecting malnutrition}

Chapter 4 sought to answer two questions: Which biophysical and socioeconomic variables best explain the spatial variation in vulnerability, as measured by child malnutrition rates?, and How does spatial autocorrelation affect results and how do results of a spatial error model compare to standard OLS regression? The answer to the first question is relatively straightforward, namely drought frequency and the prevalence of diarrhea in the two weeks prior to the survey were positively correlated and the percentage of households with piped water was negatively correlated. Climate variability as measured by drought frequency is found to be a strong predictor, although data on the precise incidence of drought leading up to the survey were not collected as part of this research. It is likely that it acts through food availability, household wealth, or some other intermediate variable. The research also showed that the OLS tended to lead to deflation of standard errors, with a much larger suite of variables found to be highly correlated with child malnutrition (9 out of 10 variables). For reasons described in the chapter (Section 4.3), results of the spatial error model are found to have more validity.

The approach used in Chapter 4 represented an inductive approach to understanding vulnerability by investigating the correlates of the outcome indicator, child malnutrition. Consistent with the understanding of vulnerability as a product of the complex socio-ecological system, the study included socioeconomic variables ranging in scale from individual to household to country level and biophysical variables summarized at the level of subnational units. The strength of the approach is the adoption of a quantitative and outcome based approach to vulnerability mapping. A common weakness in spatial VA is that the indicators-what Hinkel (2011) terms the "indicating variables", i.e., that point towards vulnerability-are simply theorized as having a strong impact on vulnerability. This leads to a catch-all approach to indicator identification, in which anything hypothesized as having the remotest connection to vulnerability is thrown into the mix (e.g., Midgley et al. 2011). A more thorough regression-based assessment of which indicators are and which are not correlated with vulnerability can help in thinning the pool of indicators. Of course, correlation is not causation, and one must be careful not to rule out the importance of an indicator in all locations or at every given scale based on a relatively coarse resolution continental scale analysis (see discussion of scale and MAUP issues in Chapter 1, Section 1.3.2), a subject addressed in Section 4.6.

In terms of its relevance for decision-making, Section 4.5 of the chapter outlines a number of policy recommendations, and we would argue that these 
kinds of quantitative and statistically rigorous assessments are useful tools in support of decision making. Yet the academic impact of the original article upon which the chapter was based has been limited, including only six citations listed in Google Scholar (two of which are self-citations). All of the citations are in the academic literature rather than in publications typically accessed by policy audiences. This does not necessarily mean that the article was not read by a policy maker or that it did not have some influence on policy; but given the technical nature of the article, the chances seem somewhat remote. It could be that quantitative and inductive assessments at finer spatial resolutions, e.g., at the city level (e.g., Baud et al. 2008), would have findings more easily transferable for decision-making purposes.

\subsubsection{Chapter 5: Climate change - three hotspots of human mobility}

The central question addressed in this chapter was: How can maps be used to illustrate the climate and other factors that influence human mobility? Based on the three case studies presented in the chapter, together with the author's experience in developing similar maps for In Search of Shelter (Warner et al. 2009), Where the Rainfalls (Warner et al. 2012a), and Evidence from the Frontlines of Climate Change (Warner et al. 2012b), it is evident that by integrating multiple climatic, biophysical and socioeconomic drivers, maps have a strong capability of communicating the multiple forces contributing to vulnerability. While non-climatic factors most often predominate in migration decision-making, this does not mean that climatic factors are irrelevant (e.g., Henry et al. 2004, McLeman and Smit 2006). A challenge, however, is in the representation of climatic variables produced by climate models at spatial scales that are relevant while also conveying uncertainty, an issue taken up again in Section 6.4.4.

The chapter highlights the "map illustration" approach to the use of spatial information for spatial VA. Unlike the spatial index or the spatial regression approaches, no effort is made to quantify degrees of vulnerability, but rather the maps serve to complement a narrative, to tell a story. Although no research has been conducted as to the ways in which such maps may influence policy, there is a widespread assumption that map illustrations represent an important tool for conveying information in an easily digestible form for policy makers (Preston et al. 2011). With the advent of info-graphics and data visualization, with their graphically attractive data and map representations (Figure 6.1 ), the ability to represent information or highlight key findings (while removing extraneous information) has grown substantially.

While map illustrations have their strengths, they, like any approach used to drive a message home, could be used in uncritical ways to reinforce 
narratives that may not be fully true. For example, the map illustration of the major rivers flowing out of the Himalayas in one of the reports that contributed to Chapter 5, In Search of Shelter (Warner et al. 2009), could be interpreted in such a way as to suggest that glacier retreat in the Himalayas is an immediate threat to livelihoods in the region that could trigger mass migration. ${ }^{51}$ Yet a subsequent study by the U.S. National Academies of Science concludes, "While glacier melt contributes water to the region's rivers and streams, retreating glaciers over the next several decades are unlikely to cause significant change in water availability at lower elevations, which depend primarily on monsoon precipitation and snowmelt" (press release for NAS 2012). Bigger threats to water resources in Asia are extensive extraction of groundwater resources (Tiwari et al. 2009), population growth (Vorosmarty et al. 2000), and shifts in water-use patterns (Meinzen-Dick and Appasamy 2002).

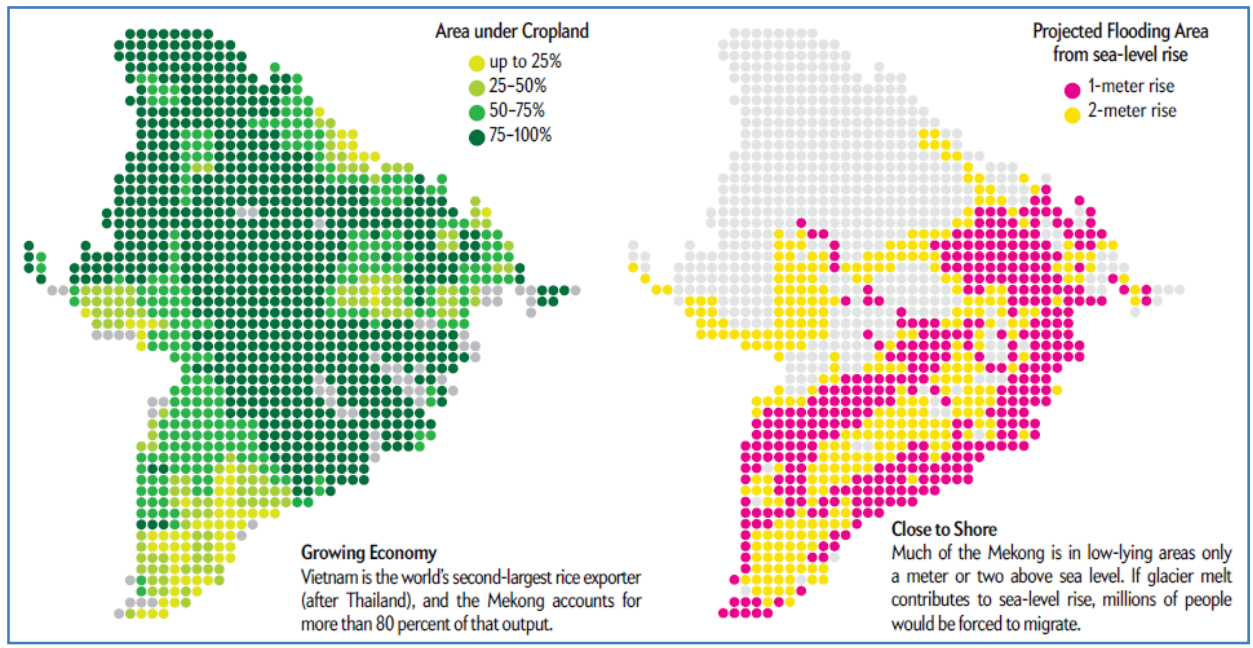

Source: de Sherbinin et al. 2011, p.37.

Figure 6.1: Designer's Representation of Selected Maps in Figure 5.5

Interest in the potentially deceptive uses of cartography is not new. Monmonier, in How to Lie with Maps, writes:

Map users generally are a trusting lot: they understand the need to distort geometry and suppress features, and they believe the cartographer really does know where to draw the line, figuratively as well as literally. As with many things beyond their full understanding, they readily entrust map-making to a priesthood of technically

\footnotetext{
51 Much in the way Figure 2.21 and its title " 50 million climate refugees by 2010 " could be uncritically accepted by readers as meaning that the highlighted areas would be sources of 50 million migrants by 2010 .
} 
competent designers and drafters working for government agencies and commercial firms. (1991:1)

He goes on to point out, however, that many map designers are not trained in cartography, and few users consider the map's power as a tool of subtle propaganda. Similarly, Harley (1989:1) writes that "we often tend to work from the premise that mappers engage in an unquestionably 'scientific' or 'objective' form of knowledge creation." Preston et al. (2011:178), echoing these sentiments, warn that the benefits of vulnerability mapping and the power of maps "has cultivated a bias regarding their inherent utility." Yet this discussion can equally be applied to statistical evidence, which have also been known to be manipulated in the service of political agendas.

This critique of map representation is certainly not limited to the "maps as illustrations" approach, but there is little doubt that special care needs to be taken that these maps, constructed with the explicit goal of policy communication, are couched with enough context for the reader to be able to adequately assess the uncertainties. For example, in the figure text accompanying the Himalayan glacier map (Warner et al. 2009:5), it is clearly stated that "Reductions of river flows will affect irrigated areas, but the potential for migration out of agricultural areas is hard to predict, and will depend on adaptation responses such as dam construction and more efficient irrigation technologies."

Overall, and bearing in mind the critiques, map illustrations clearly have a strong ability to attract the attention of policy makers, but the degree to which they influence decision making remains an open question (see Section 6.4.5). Anecdotal evidence suggests that the maps were important in influencing the UNFCCC's Cancun agreement, in which language was inserted to promote "measures to enhance understanding, coordination and cooperation with regard to climate change induced displacement, migration and planned relocation", and in the development of the UNFCCC Loss and Damage work program (McGray personal communication). There are growing efforts to creatively use graphics for climate communications (e.g., Figure 2.3, UNEP and ECLAC 2010), and incipient efforts to develop cartographic guidelines for risk communications (Dransch et al. 2010), climate science, and uncertainty (Kaye et al. 2012). The latter is particularly relevant not just for the communication of uncertainty in climate scenarios but also for the communication of uncertainty in vulnerability maps more broadly.

\subsection{Assessment of the PNAS Framework}

Having assessed the different approaches to spatial VA represented in Chapters 2-5, we turn now to an assessment of the PNAS framework. We 
begin with a general assessment of the framework, and then proceed to a specific assessment of the utility of the framework in the context of this dissertation. We provide the PNAS framework figure from Chapter 1 again here for ease of reference (Figure 6.2).

\subsubsection{General assessment}

There are a growing number of frameworks used in climate change spatial VA and allied fields such as disaster risk reduction (DRR), disaster risk management (DRM), climate risk and adaptation assessment, and livelihood security and development research (de Sherbinin 2014). Examples include Bohle's vulnerability framework (Bohle 2001), the ISDR framework (UNISDR 2004), the BBC framework (Birkmann 2006), the SREX framework (IPCC 2012), and the MOVE Framework (Birkmann et al. 2013). Ultimately, each framework needs to be evaluated on the basis of how well it guides research and illuminates key system dynamics and complexity while also yielding results useful for policy responses.

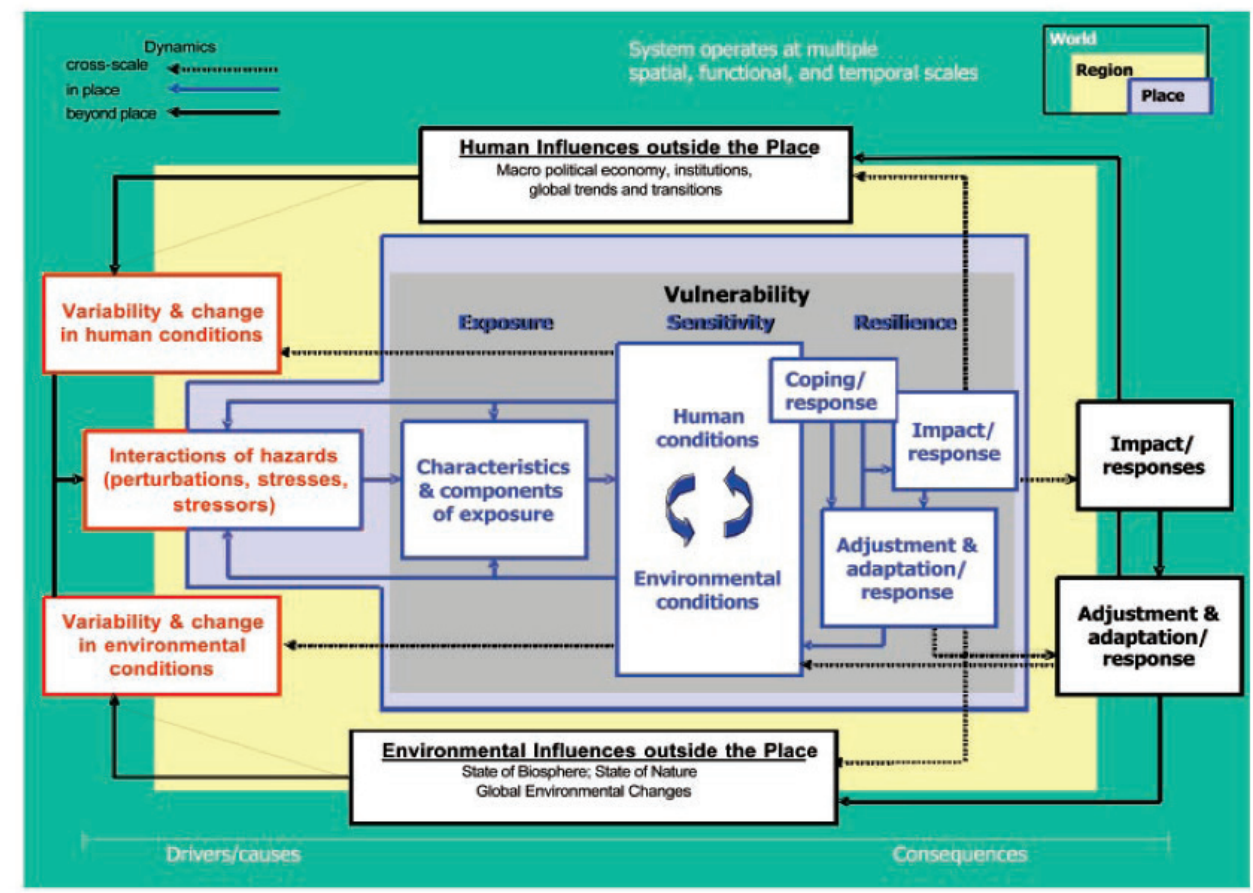

Source: Turner et al. 2003a.

Figure 6.2: The PNAS Extended Vulnerability Framework Apart from the ISDR framework, the PNAS framework has arguably attracted greater attention (as measured by numbers of citations) than the other frameworks listed above. However, as discussed in the introduction, the PNAS framework does not readily lend itself to quantitative vulnerability 
assessment (or modeling) because of the nested scales and the complexity of the interactions among elements of the coupled socio-ecological system. Eakins and Luers (2006) find that the applications of the framework that PNAS team provide in a companion Proceedings of the National Academy of Sciences article (Turner et al. 2003b) are focused on processes and interactions rather than indicators of vulnerability:

Although both qualitative and quantitative data are used in the illustrative assessments explored for this model (e.g., satellite data, soil quality data, climate data, demographic and economic data, as well as data collected in interviews, surveys, and focus groups), the integration of the data and the overall system's analysis is largely qualitative. The final outcome of the analysis is not necessarily the identification of present or future impacts on the system, or the identification of particularly vulnerable populations, but rather the illumination of the processes and interactions that are generating vulnerable conditions. (Eakin and Luers 2006: 383)

This is consistent with the use of the framework in Chapter 3, where it was explicitly used to guide the gathering of data and information on characteristics of the coupled socio-ecological systems in the three cities and to illuminate the system dynamics in a way that is not easily quantified. In the context of indicator development, Hinkel (2011:202) finds, furthermore, that frameworks such as PNAS "do not provide arguments for aggregation, because they say nothing about the processes through which the different variables interact and may lead to future harm." This gets to the question of the functional form of relationships among variables in any quantitative approach, which is largely unknown (de Sherbinin 2014). ${ }^{52}$ Yet any quantitative assessment (model) needs to specify these relationships.

Using the PNAS framework as an example, Levy (2012) argues that the social science research community has become overly enamored of its analytical sophistication and has not paid sufficient attention to the data needed to enhance understanding of complex systems. ${ }^{53}$ Furthermore, the proliferation of frameworks has only added to the cacophony around the concept of

\footnotetext{
52 To illustrate using two commonly used indicators in spatial index approaches, infant mortality and precipitation, we do not know if, in any objective or quantifiable sense, 10 additional infant deaths per 1,000 live births "offsets" a $20 \mathrm{~mm}$ decline in rainfall, or if that relationship changes at higher levels of infant mortality or lower levels of rainfall. Nor do we know if there are critical thresholds for one indicator beyond which the system reaches a critical vulnerability level regardless of the values associated with other indicators.

53 He states, "We have been blinded by our analytical sophistication. We are theoretically smart, but quantitatively stupid."
} 
vulnerability; for example, the SREX framework includes social vulnerability (contextual vulnerability) as a separate element from exposure, which results in two officially adopted IPCC frameworks that both purport to illuminate vulnerability with very different definitions (Levy 2013). ${ }^{54} \mathrm{He}$ advocates simpler frameworks, such as the earlier risk-hazards or pressure-and-release models, with fewer moving parts and easier operationalization in quantitative assessments.

A search on the Thomson Reuters Web of Knowledge for papers citing Turner et al. (2003a) and containing the term "spatial" yielded 16 articles in February 2014. These articles refer to the framework in a number of ways. Some cite it as influential to the development of the analysis (together with similar frameworks) without explicitly using it as a framework (Frazier et al. 2013), others review it in the context of developing definitions or other conceptual frameworks of vulnerability (Birkmann et al. 2013, Soares et al. 2012, Preston et al. 2011, Füssel 2007) or cite the article for other reasons (Jaeger et al. 2013, Kienberger et al. 2013, Hinkel 2011, Ford et al. 2010). Only Kok et al. (2011), and Srinivasan et al. (2013), and Saldaña-Zorilla and Sanderberg (2009) employ a reduced form of the PNAS framework for quantitative spatial assessments.

Although it is easy to criticize the PNAS framework for being overly complex and too difficult to operationalize, one might equally well critique spatial VAs for providing static and two-dimensional depictions of vulnerability. As Preston et al. (2011:186) note, "most spatial assessments fall short of representing the interactive and dynamic nature of vulnerability, which propagates over multiple spatial and temporal scales." They conclude that "vulnerability maps alone may be inadequate for representing such complexity and are perhaps better employed as one of a portfolio of mutually supporting assessment tools" (p.187).

Ultimately, we agree with Hinkel (2011) that the PNAS and similar frameworks are primarily useful insofar as they identify a suite of variables that are important for the assessment of vulnerability based on best available conceptual and theoretical understanding. There is the risk-per Levy's critique above-that the frameworks propose indicators that cannot possibly be operationalized in a quantitative assessment. ${ }^{55}$ But it may also suggest that quantitative approaches need to be coupled with more qualitative

\footnotetext{
54 As noted in Chapter 1, vulnerability according to Working Group 2 is outcome vulnerability, not contextual vulnerability.

55 Tables 3.1 (Chapter 3) and 4.1 (Chapter 4) are based on a conceptual and theoretical understanding grounded in the PNAS framework, though data limitations were more severe for the latter.
} 
assessments, and that quantitative assessments may suggest where to look, and to some degree, what to look for, in carrying out qualitative assessments on the ground. With roots in political economy and concepts borrowed form sustainable livelihoods and entitlements theory, but with greater emphasis on environmental factors, the PNAS framework stresses the reciprocal relationship between society and nature, with societies simultaneously transforming natural systems while being impacted by those transformations (Birkmann et al.2013). According to Birkmann et al. (2013:198), "It argues that the exposure and susceptibility of a system can only be adequately understood if these coupling processes and interactions are addressed." It allows an interrogation of the larger context - historical, cultural, and political - in an effort to explain patterns of vulnerability that may otherwise be hidden by purely quantitative assessments. ${ }^{56}$ It identifies contextual vulnerability factors that more quantitative researchers tend to avoid precisely because they cannot be easily quantified.

\subsubsection{Utility of the PNAS Framework in the Context of this Dissertation}

There is general agreement that a fundamental aspect of studies of complex socio-ecological systems is that they are place-based, meaning they focus on a specific place and period of time. According to Soares et al. (2012:13), "The central idea is that the [coupled human-environment system] is intrinsically related to a particular geographical area and therefore establishing that delimitation helps to identify the dimensions and scales of interaction and influence relevant to the coupled system under analysis." Thus, it is not surprising that the primary applications of the PNAS framework have been in such place-based analyses (e.g. Chapter 3, and Turner et al 2003b). Applying the framework to much larger spatial units, such as Africa (Chapter 4 ) or entire countries (Chapter 5), has the inherent drawback that complex socio-ecological systems cannot be adequately modeled or understood at this scale.

Given that we did not explicitly adopt the PNAS framework as an organizing approach for two of the three chapters that represent quantitative/mapping assessments (Chapters 4 and 5), one might ask if our approach would have changed substantially had we done so? In Chapter 4 key variables were identified through a review of the literature and a framework developed by the Food Insecurity and Vulnerability Information Mapping System (FIVIMS), which guided the identification of some of the distal drivers of nutritional status. Given that this research was firmly rooted in the literature on food

\footnotetext{
56 For an example of contrasting a reduced form model of environmental security with a model that includes a broader socio-political-historical understanding, see de Sherbinin (1996).
} 
security, it is an open question as to whether the adoption of the PNAS framework would have contributed more to the modeling of the determinants of child malnutrition. It may have pointed to the identification of additional stressors or resiliency factors, but data of sufficient spatial resolution (e.g., continuous gridded variables or for small administrative units) would probably not have been available for major elements of the framework. Busby et al. (2011) and Davies and Midgley (2010) resorted to the use of national-level indicators to represent many of the sensitivity and adaptive capacity measures.

In Chapter 5, we used the sustainable livelihoods framework together with an understanding of ecosystem services gleaned from the Millennium Ecosystem Assessment, but pointed out ways in which the mapping was consistent with a systems understanding that would be gleaned from the PNAS framework. The livelihoods approach focuses on the coping capacities of rural subsistence-based communities through the five capitals, and emphasizes dependency on those resources. It has less to say about the reciprocal links, i.e., the way in which those societies have always adjusted and even manipulated their environments (also known as adaptation) as part of the coupled socio-ecological system. ${ }^{57}$ The approach also does not address to the same degree the macro-institutional environment and the broader political economy. Finally, the sustainable livelihoods framework is less overt about exposure to hazards, although it does refer to a "vulnerability context" of shocks, trends and seasons. The livelihood assets (or capitals) are seen as part of system resilience, but the framework is not explicit about potential hazards. This is a weakness of the livelihood framework, but it did not prevent us from representing stressors in the maps. On the other hand, it is doubtful that the other factors, such as the CHES or macro-institutional context, could have been brought out in the maps.

\subsection{The Way Forward}

The field of spatial vulnerability (and spatial impact assessment) is expanding rapidly. In many cases "vulnerability assessment" is seen as virtually synonymous with spatial VA owing to an understanding that vulnerability and

57 Indeed, Batterbury (personal communication) wrote in review comments of the Sahel map in In Search of Shelter (Figure 2.20) and accompanying text, "The fact that large populations do not live in Sahelian villages year round is a western view of what is 'right' - it does not conform to centuries of movement in West Africa. The fact that people leave for short periods or long periods of time is perfectly normal and I doubt the evidence is showing there are now more such movements than before, since they ebb and flow." His understanding is one in which shifting livelihood strategies and migration have been a long-standing feature of the coupled socio-ecological system of the Sahel, and that current trends are merely a continuation thereof. 
its constituent components exhibit high degrees of spatial and temporal heterogeneity (Preston et al., 2011). Indeed, the PROVIA Research Priorities on Vulnerability, Impacts and Adaptation (PROVIA 2013a) highlights "measuring and mapping vulnerability" as a first priority for supporting adaptation decision-making. In the field of vulnerability assessment there are emerging guidelines and inventories for the conduct of VAs, such as the PROVIA Guidance on Assessing Vulnerability, Impacts and Adaptation (PROVIA 2013b) and the Nairobi Work Programme's Adaptation Assessment Planning and Practice (UNFCCC 2010). There are also sectoral vulnerability assessment guidelines, such as ones that have been developed for the health sector (e.g., Health Canada 2011, Ebi and Burton 2008) or coastal VAs (e.g., Klein et al. 1999).

Despite the development of general guidelines for VAs and the recognition of the importance of spatial methods for vulnerability and impact assessment, the field of spatial VA is still largely characterized by experimentation. It is true that some approaches for conducting spatial VAs, such as the additive approach using the IPCC vulnerability framework described in Chapter 1, represent if not "best practice" then at least one commonly accepted practice. Yet there is little consensus among researchers regarding which methods are most appropriate and in what circumstances. Recent reviews have attempted to categorize and draw lessons from recent work (de Sherbinin 2014, Preston et al. 2011), but there are as yet no guidelines that are widely accepted.

Taken one way, this could be viewed as problematic and a barrier to progress. According to Preston et al. (2011:188), "In the absence of greater guidance regarding how to undertake an assessment as well as which methods and tools are useful in which contexts, assessments will likely continue to be dominated by arbitrary methods, which may, in some instances, inhibit effective learning and outcomes." We would argue instead that the material and methods applied to spatial VA are relatively recent, and hence experimentation (e.g., Lang et al.'s (2008) development of "geons" and their application in a policy-oriented report (UNEP 2011)) should be viewed positively, so long as the general considerations for spatial VAs identified in Chapter 1 are understood and applied.

In this closing section, a number of future avenues for vulnerability mapping are explored. While we make some recommendations, the primary goal is to identify major issues that have been brought up in this dissertation and to suggest areas for further research. This section moves from the general to more specific by first describing trends in vulnerability assessment more broadly and linking these to the potential for deploying spatial methods. We then discuss stakeholder engagement, spatial data needs, issues with 
conveying uncertainty in final map outputs and associated reports, and recommendations for those developing spatial VAs.

\subsubsection{Trends in Vulnerability Assessment and Spatial Approaches}

Soares et al. (2012) describe the evolution from climate impact assessments in the 1990s, which was epitomized by a top-down approach to generating climate scenarios and estimating likely impacts on biophysical systems, ${ }^{58}$ to vulnerability assessment and more recently adaptation assessment. VA approaches were, grosso modo, characterized by bottom-up or communitybased studies more aligned to social and integrated approaches to vulnerability. The shift was associated with more stakeholder engagement, socioeconomic scenarios (such as the shared socioeconomic pathways), consideration of adaptation measures, and, importantly, the adoption of decision support tools such as GIS. They argue VA and adaptation assessments are more appropriate for local scales; top-down assessments are better for global to regional scales.

However, our sense is that this categorization and representation of "evolution" in terms of climate assessments is overly simplified, as spatial approaches can be appropriate at all scales for both impact and vulnerability assessment. For example a neighborhood-level assessment of flood or storm surge risk to infrastructure and housing is surely an impact assessment, and can entail extensive engagement with local populations and decision makers (e.g., UNHABITAT 2013, Preston et al. 2009). Similarly, broad scale vulnerability maps such as those presented in Chapter 2 by their very nature cannot accommodate community involvement.

Klein (2012) notes that the vulnerability assessment community as a whole has lacked rigor with regards to methods and approaches, with the result that the community is often replicating studies that have already been done or repeating avoidable mistakes. He points to the existence of 15 separate impact assessments for sea level rise in the Nile Delta that have been developed independently as evidence that the community is disjointed and out of touch with accepted scientific practice in other disciplines, where such duplication of effort (and the lack of citation of earlier research) would not be tolerated. This may be a function of the community's diverse disciplinary representation or of redundancy in the donors that fund such work, but as vulnerability assessment progresses and the risk of serious climate impacts becomes greater, the community cannot afford to ignore prior research in

58 Adding to the "Babylonian confusion" (Hinkel 2011) around the term vulnerability is the fact that many impact assessments were then and continue to be labeled "vulnerability assessments". See for example Ramieri et al. (2011). 
this way. Although the PROVIA guidelines (PROVIA 2013b) are an important step forward, it is notable that they do not provide specific guidance on methods or approaches for spatial vulnerability assessment. A community process could lead to development of recommendations if not actual guidelines. ${ }^{59}$

Although it is perhaps too early in the development of spatial VA to speak of trends, recently developed assessments have demonstrated a number of innovations, including the explicit use of climate data and climate projections in relatively sophisticated ways (USAID 2014, de Sherbinin et al. 2014a, Midgley et al. 2010), assessment of multi-model scenarios using climate impact models (Piontek et al. 2013), and the use of geons, an aggregation method for modeling spatial units where homogeneous conditions apply with respect to a set of previously defined sub-indicators as well as spatial heterogeneity (Hagenlocher et al. 2013, Kienberger et al. 2009). This suggests that spatial VA is an area ripe for innovation. Further work could usefully explore geographic teleconnections among regions, since climate impacts and vulnerability in one region rarely leave other regions untouched (e.g., the so-called "hot systems" approach described in Chapter 2). For example, drought or flooding in major cereal producing regions can result in commodity price jumps that result in added stressors in distant regions (e.g. Krugman 2011). There may also be winners as well as losers, as competing cereal producing regions benefit from higher prices.

\subsubsection{Stakeholder Engagement}

Stakeholder engagement is increasingly being seen as a critical ingredient in environmental and global change research, and vulnerability assessment is no different. Defined as a person or entitiy that would be affected by a particular impact, action, or policy, there are a wide range of stakeholder groups, including communities, policy makers, the public, the media, NGOs, and industry (Soares et al. 2012). Whether there is direct involvement of community groups using participatory approaches or broader consultations with donor representatives and domain experts, engagement of stakeholders from the targeted area and in relevant domains is important in terms of determining goals and objectives of the assessment. At later stages, direct engagement of communities, especially when it entails the co-production of knowledge (e.g. Kienberger 2012), can increase the likelihood that assessment results will be used (Soares et al. 2012).

This new emphasis on stakeholder engagement is a reaction to the traditional research approach, which has been characterized as top-down and supply-

\footnotetext{
59 A workshop, "INQUIMUS: Spatial indicators and assessment of vulnerability and resilience", in Salzburg, Austria, 15-17 September 2014, has begun this process.
} 
driven, with a sole focus on generating scientific understanding and an implicit or explicit expectation that policy communities are responsible for uptake and applying results. There is a growing recognition in the climate adaptation community that this traditional approach does not typically yield useful policy or practical solutions to societal problems because the research questions are driven by intellectual inquiry on the part of scientists rather than being the joint product of a discussion. A new transdisciplinary science seeks to provide answers relevant to policy making through a process of coproduction of knowledge (Pahl-Wostl et al. 2012). Moser and Boykoff (2013) provide several examples of "adaptation science" that involve extensive interactions with stakeholders with strong policy relevance.

Clearly the emphasis on stakeholder engagement applies to spatial VA as well, although its appropriateness depends on the scope of the assessment and time and resource constraints, since transdisciplinary research tends to be more time and resource intensive. Furthermore, in the climate change adaptation arena there is evidence in the U.S. that local government agencies are beginning to be overwhelmed by requests from researchers to serve on stakeholder advisory groups, often because researchers are required by federal funding agencies to seek such input (Wu personal communication). Overall there is considerable evidence that spatial VA is strengthened by engagement with stakeholders (Kienberger 2012, Preston et al. 2009), and thus there is a clear imperative to seek the views of stakeholders wherever possible. Care must be taken, however, that this doesn't become faddish or a pro forma step to meet the requirements of funders much in the way that community consultations have been undertaken by agencies in response to government mandates to conduct participatory rural appraisal (PRA), but without any real commitment to heed community views (Chambers 1994).

\subsubsection{Spatial Data Needs}

The results of a spatial VA are only as good as the data streams on which it depends. As discussed in Section 1.3.1, data limitations can significantly constrain results. Data gaps, poor quality and low resolution data, and data that exist but are not publically accessible limit the accuracy of spatial VAs and increase uncertainty. There are incipient efforts to identify data gaps and to improve the availability of high quality data in a number of domains relevant to climate vulnerability assessment. These include a workshop on climate VIA (Vulnerability, Impacts and Adaptation) data organized by the author in 2012 (findings of which are summarized in Box 6.1), and a 2011 workshop, "GEOSS support for IPCC assessments: A workshop on the data needs of the climate impacts, adaptation and vulnerability research community," that brought together more than 40 experts associated with the IPCC and the Group on Earth Observations (GEO). Here we summarize a 
number of domains in which data are either improving or in need of improvement.

Taking the socioeconomic data first, census data are vital for vulnerability assessment (Martine and Schensul 2013, Malone 2009). Yet census data are often not released by national census bureaus at the highest spatial resolutions possible, that is, at the census tract or enumeration area level that still preserves anonymity. Even where the more spatially detailed tabular data can be obtained, obtaining matching boundary data remains a challenge. The reasons for limiting access to the spatially detailed data are not always clear, but they could be tied to a predisposition to view these data as sensitive or valuable (and therefore worthy of cost recovery). A growing movement towards open data is making inroads in many countries, propelled in part by a recognition that governments can in fact generate more revenues by expanding their tax bases through fostering value added information-based industries than by selling the data (Piotrowski 2014, Vickery 2011).

In the past 15 years the number of surveys, such as the Demographic and Health Survey (DHS), that include spatial location information for survey respondents has increased, and this has opened up a whole domain of spatial research linking environmental factors to health outcomes (e.g., Chapter 4, Balk et al. 2004). Generally the administrative units or regions for which the data can be averaged and still be statistically robust are quite large. This has spawned an increasing amount of research using the cluster-level data, representing approximately 100 households. Once cluster point values are calculated, it is possible to interpolate between points using Bayesian methods (de Sherbinin et al. 2014a, Jankowska et al. 2012). Though relatively labor intensive, this approach yields higher resolution data with which to work. Data from the World Bank's Living Standards Measurement Surveys (LSMS) are also being georeferenced and successfully employed in spatial VA (USAID 2014).

There is a similar need for higher resolution epidemiological and mortality data. If the field of vulnerability assessment is to progress, it needs to move towards outcome measures and away from proxies by employing longitudinal data sets with sufficiently high spatial and temporal resolution to be able to associate specific climate events (e.g., heat or rainfall extremes) with morbidity and mortality. Unfortunately, data on mortality are also often unavailable at sufficiently high spatial resolution for confidentiality reasons. The author is part of a team assessing urban heat stress in Philadelphia, and the syndromic surveillance system for this city recording mortality at block level is unavailable for research use. 
There are a growing number of spatial conflict-related data sets such as Armed Conflict Location \& Event Data Project (ACLED), the Peace Research Institute of Oslo (PRIO) Grid, and the Global Database of Events, Language, and Tone (GDELT). These data sets are important in least developed regions with ongoing or intermittent conflicts, since they are important measures of state capacity. Yet in most conflict zones data on a range of human wellbeing metrics relevant to vulnerability assessment are not available.

Remote sensing data are an increasingly valuable source for climate vulnerability assessment. Where socioeconomic data of a sufficiently high resolution are not available, remote sensing can sometimes be used to develop proxies (e.g., de Sherbinin 2010, Ebert et al. 2009). In urban areas, information on the income levels of settlements (e.g., slum or low income areas) can often be gleaned from remote sensing (Sliuzas et al. 2008). For example, Baud et al. (2010) were able to identify sub-standard housing areas in Delhi using remote sensing based on the structure of layout, built-up density, building size and other site characteristics. However, there are issues with the use of high resolution data relating to confidentiality that need to be considered (VanWey et al. 2005). Climate impact data for events such as flood and drought are now available from a range of sources, from eventbased archives (e.g., the Dartmouth Flood Observatory) to long-term measures of NDVI (e.g., the Global Inventory Modeling and Mapping Studies NDVI time series dating back to 1983). Brakenridge et al. (2013) demonstrate the utility of MODIS flood extents in a study that surveyed remote sensing results obtained for three catastrophic storm surges Hurricane Katrina in the Mississippi River Delta, Cyclone Aila in the GangesBrahmaputra Delta, and Cyclone Nargis in Myanmar. de Sherbinin et al. (2014a) used the coefficient of variation of NDVI (greenness) as a proxy for rainfall variability in Mali, since the observation of NDVI is at much higher spatial resolution than rainfall. Remote sensing data sets have been increasingly integrated into global hazard data sets (e.g., UNISDR 2013), which because they measure past climate-related disaster losses and frequencies are key inputs for spatial VAs.

\section{Box 6.1: Summary Results of a Workshop on Data Gaps for Climate Research}

In June 2012, a Workshop on Data Gaps for Research and Action on Climate Change Vulnerability, Impacts and Adaptation (VIA) was held in Tuscon, Arizona, immediately after the Adaptation Futures conference hosted by the University of Arizona. Organized by the NASA Socioeconomic Data and Applications Center (SEDAC) with co-sponsorship by the UNEP PROVIA, the workshop drew more than 60 participants from universities, research centers, and governmental and nongovernmental organizations from around the world, including more than 20 from developing countries. Four breakout 
groups addressed data needs related to: 1) Vulnerable groups; 2) Urban area and critical infrastructure; 3) Natural resource management; and 4) Hazards. The breakout groups were each given a set of common questions to address, including: What are the top research priorities regarding climate VIA?, What are the top decision-making needs regarding climate VIA?, What are the primary obstacles to obtaining the relevant data to meet these needs?, What are the high-priority, low difficulty data sets to develop?, and What strategies would be most promising for getting high-priority, high-difficulty data?

The Vulnerable Groups breakout noted the difficulty of combining physical and social indicators, and of assessing causality in complex humanenvironment interactions. Development of consistent definitions of key factors across borders and over time, e.g., for educational levels, is needed. It is clear that the decision-making community could use process-based decision support tools that could work at multiple scales. High priority data that should be relatively easy to obtain are spatial poverty data, health data from existing surveys, and more detailed climate scenario data that indicates levels of certainty and agreement and trends in extremes. More difficult but important to obtain are data describing livelihoods by urban/rural class.

The Urban/Infrastructure breakout group identified research on the impact of climate change on households at the community and local level and on health and infrastructure as high priorities. Protocols and standards for data collection are needed. Obstacles include the high cost of high resolution remote sensing data and the lack of high resolution health data due to privacy restrictions and limited collection of location information. High priority data that should be relatively easy to obtain are high resolution remote sensing data useful for ecosystem-based adaptation and socioeconomic data at the neighborhood scale. More difficult to access is health data on neighborhood or finer scales, e.g., depersonalized data from surveys, health care providers and insurers.

The Natural Resource Management breakout group identified the need to link and reconcile data across a range of spatial scales and resolutions, so that local adaptation can be assessed in a broader context. This also leads to the need to better define the most appropriate spatial units for integrating social and ecological dynamics. Another need is for research protocols to harmonize local knowledge and to integrate local knowledge with quantitative scientific data. Key problems are spatial and temporal inconsistencies in time series (e.g., boundaries that do not match or that change), data gaps, access to fine scale data, missing metadata, the cost of meteorological and climate data, and the limited availability of data on land tenure and crop and livestock production. In many cases, historical meteorological and climate data in developing countries are hard to access, expensive to obtain, and/or 
are of uncertain quality, making it especially difficult for developing country scientists to establish baselines and assess impacts.

The Hazards breakout group identified research priorities related to the interrelated issues of coastal flooding, storm surge, and sea level rise; understanding the impact of spatial scale in identifying vulnerable areas; combining socioeconomic data and local knowledge and culture in IAV research; linking of ecological data on vegetation with water use and availability, and downscaling methods. Data needs that may be relatively easy to meet are improved remote sensing data on land cover and land use, historical hazard and impacts data, and better erosion and soils data. More difficult to address is integration of socioeconomic, cultural, and spatial data and knowledge, as well as obtaining more detailed topographic data from LIDAR in key areas, especially in the least developed countries.

Key messages from the general workshop discussions included:

- Data needs at local/national levels depend a lot on local priorities. However, there are some needs that are consistent globally, such as remote sensing-derived land use/land cover and ecosystem data, high resolution elevation data, and livelihood data.

- Some proprietary data such as from reinsurance companies would be valuable for research.

- Some planning will be needed to build consensus on the highest priority data sets needed by the VIA community (similar to earlier initiatives to develop global land cover data sets).

- An overall cyberinfrastructure is needed for sharing data and results of micro-level studies.

Infrastructure data area also important for spatial VA, but unfortunately are incomplete or inaccessible in many cases. Although progress has been made in mapping irrigated areas (Siebert et al. 2013), large dams (Lehner et al. 2011), and roads (CIESIN et al. 2013), there are still major gaps, such as energy or telecommunications infrastructure, which are generally available only for restricted or commercial use. Night-time lights data have been used as a proxy for infrastructure concentration and economic development in a number of spatial VAs (de Sherbinin et al. 2014c, Midgley et al. 2011), and the new VIIRS instrument provides substantially improved spatial resolution over the Defense Meteorological Satellite Program's Optical Line Scanner (DMSP-OLS).

Climate data needs are significant and have been discussed in Chapter 1. There is a need both for increased spatial resolution for both gridded historical climate data sets and for downscaled projections of future climate (Trzaska and Schnarr 2014). There would also be substantial demand for pre-calculated climate parameters of relevance to spatial VA practitioners, 
such as precipitation variability and trend, temperature trend, substantial gaps in rainfall during rainy season months, and trends in rainfall extremes. Such parameters are challenging to calculate without specialized climate expertise. Yet the relevance of each indicator depends in many cases on local climatology, and hence there is still some need for localized climate knowledge.

Given the likely accelerated pace of climate change, it will be important to invest in data development for more accurate mapping activities that will lead to decision support. The next section addresses the current state of play with regards to uncertainty in mapping.

\subsubsection{Conveying Uncertainty to Policy Audiences}

Wood et al. (2014) present a number of factors that are important for the uptake of vulnerability assessment results by policy-makers. These include credibility, which is governed by the technical quality and the degree to which levels of uncertainty are reduced and communicated; salience, which relates to the timeliness, relevance and demand for the assessment; and legitimacy, which is a function of the process for generating results that is participatory and includes multiple stakeholders from different sectors. All three are important, but salience may be beyond the control of the researcher (except insofar as the researcher chooses timely research topics), and legitimacy through stakeholder participation was the subject of Section 6.4.2. Hence, the focus here is is uncertainty and the role it plays in policy communication.

Uncertainty assessment and validation of results are vital parts of the scientific enterprise. Yet, between the scientific and the policy communities there remain significant differences in the tolerance levels for uncertainty and even the basic understanding of what uncertainty means (de Sherbinin et al. 2014b). For scientists, error terms around results are commonly understood means of characterizing the confidence we can have in them. For example, the IPCC conveys results in terms ranging from low to very high confidence (with associated likelihoods). But for some policy-makers, the use of the term "uncertain" in the context of spatial VA results could be interpreted to mean that results are suspect or lack credibility. ${ }^{60}$

As a result, some in the research community prefer speaking of ranges of results or the likelihood (risk) of something happening rather than uncertainty for fear that results will be entirely ignored or discounted by policy-makers. This is a very real possibility in the field of climate change

$60 \mathrm{I}$ am indebted to participants in a breakout group on uncertainty and policy communication at the Africa Resilience to Climate Change (ARCC) Experts Meeting on Climate Change Vulnerability Assessment Utility and Uptake from 15-16 April 2014 for a number of these insights. 
VIA, where skepticism abounds and many politicians prefer to apply high discount rates to the future.

In the field of vulnerability mapping, it is difficult to validate results since vulnerability is an emergent phenomena. One of the few ways of validating is to observe system responses to an actual stressor. The subject of validation and outcome measurement have been addressed in Chapters 1 (Section 1.3.3) and 4. Although this may be the only way to validate if one's model of vulnerability performs correctly, there are so many unobserved and potentially confounding variables that even this method is not fool proof. Thus it is hard to speak of uncertainty when it relates to the accuracy of our measurement of the concept of vulnerability and the mechanisms that produce it. One of the few recourses scientists have is to convey uncertainty in terms of confidence in the underlying data, expressed in terms of measurement errors.

As Kaye et al. (2012) point out, since "the quality of graphic design can directly impact decision-making by revealing or obscuring information, it is vital that suitable consideration is given to map design." There are a number of common methods for cartographic communication of uncertainty (MacEachren et al. 2005). One is to cross hatch areas or increase the color saturation in areas where results are more certain, such as where multiple climate model scenarios agree (Kaye et al. 2012). Another is to create fuzzy or fiat boundaries (Kienberger 2012) or to run a low-pass filter (spatial averaging) over results. The two climate hotspots maps for the Sahel in Chapter 2 provide contrasting approaches to communicating uncertainty. Figure 2.17 provides fuzzy boundaries based on the geon approach, whereas Figure 2.20 presents the grid cells from actual model outputs as if the data were categorical rather than continuous. With higher resolution gridded data such an approach may indeed convey a continuous surface, but with 0.5 degree grid cells the results are less satisfactory.

Additional methods for communicating uncertainty include providing inset maps that characterize the measurement error in key underlying data sets. de Sherbinin et al. (2014a) provide insets describing standard errors in the climate data and in the DHS data that provided the basis for seven out of 18 indicators (Figure 6.3). Although uncertainty levels could not be assessed for all data sets, this approach helped to show that regions to the West of Bamako and in the North that had higher levels of uncertainty owing to the spatial gaps in measurements for both data types. In addition, this mapping exercise included a sensitivity analysis and an alternative aggregation method (PCA) in order to determine the robustness of findings to methodological assumptions and indicator choices. These methods represent 
good practice for anyone seeking to characterize the robustness and uncertainty in mapping results. ${ }^{61}$

The reality is that decision-makers make decisions under uncertainty all the time (Mabey et al. 2011). Communication of uncertainty is tied to risk communication. The risks engendered by climate change are very high indeed according to the IPCC Fifth Assessment Report (AR5). Thus, there is a need for scientists to recognize that their science may be the best information available in a highly uncertain, complex, and interlinked world, and not simply hide behind the fig leaf of uncertainty in order to avoid responsibility for resulting decisions or criticism from colleagues. On the other hand, there is a need for policy makers to recognize and appreciate that uncertainty does not imply lack of value. Even knowing that for a given region $50 \%$ of scenarios suggest increasing rainfall and $50 \%$ predict decreasing rainfall is a piece of information that can translate to better decisions than would be taken in the absence of that information. Some may then do nothing but a stronger response may be to at least think through the ramifications of both, if not initiate appropriate preparedness measures.

A good deal more research could be usefully conducted on how decisionmakers read and interpret maps. Little is known, for example, on the degree to which formal geographic education and prior map interpretation experience leads to better understanding and ultimately better decisions. How much information can be gleaned from the maps directly versus from the accompanying text? And under what circumstances do decision-makers discount results, for example, if they do not conform to their own mental models or they perceive that results are too uncertain? Given the importance of maps in climate change communications, this is an important area for further research.

\footnotetext{
${ }^{61}$ For more on this subject, MacEachran et al. (2005) provide a good overview on methods to depict uncertainty in maps.
} 


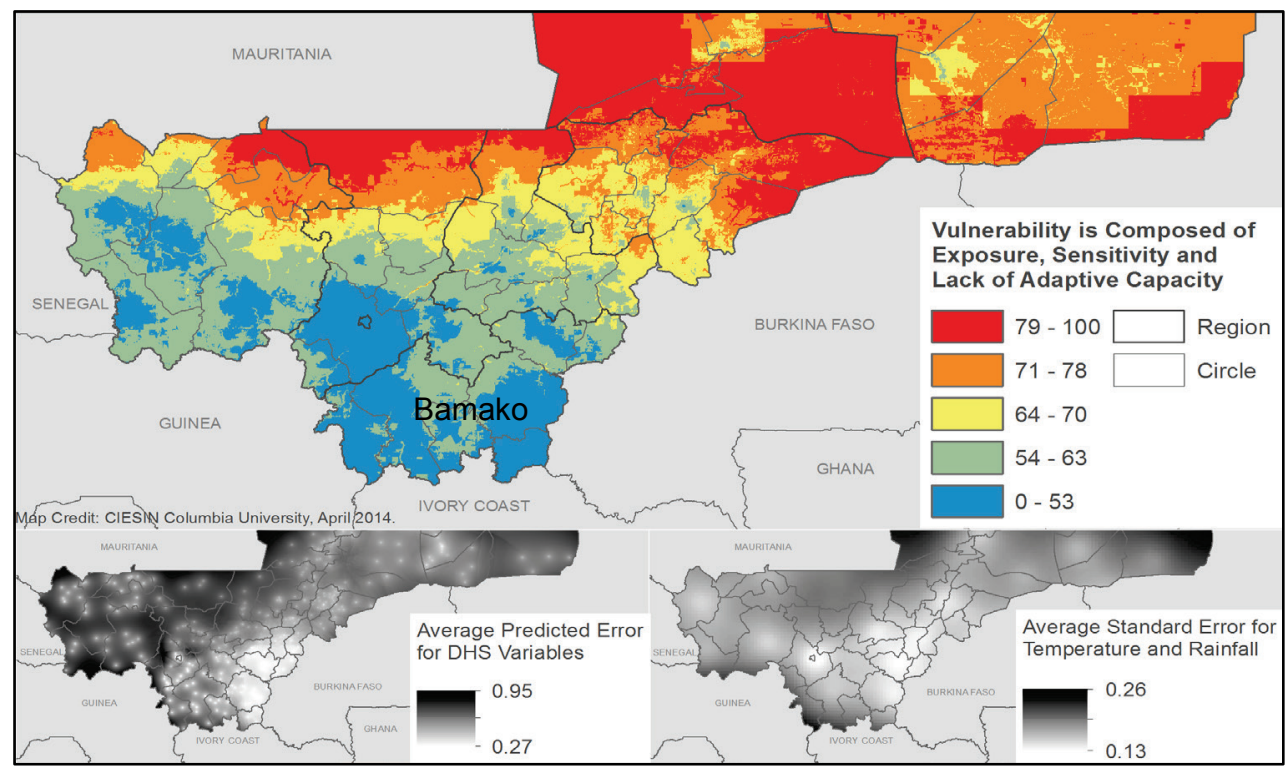

Source: de Sherbinin et al. 2014, Figure 5, p.12.

Figure 6.3: Communication of Uncertainty for the Mali Vulnerability Mapping

\subsubsection{Recommendations for Spatial VA Planning}

Some step-by-step recommendations for spatial VA planning are provided in Section 6 of de Sherbinin (2014), and are not repeated here. Instead the focus is on a set of questions developed by Preston et al. (2011) for anyone planning a spatial vulnerability assessment (Box 6.2). These key questions are taken up below.

In reference to the first set of questions, the goals and objectives of a spatial VA or impact assessment should be clearly stated up front, together with identification of the specific systems being assessed. As mentioned in Chapter 1, Füssel (2009) argues that quantitative vulnerability assessment requires definition of the system of analysis, the valued attributes of concern, the external hazard, and a temporal reference. While these may seem obvious, it is not uncommon for one or more of these to be missing, or for the "valued attributes" to be so broadly defined (e.g., human well-being) as to make any results meaningless. Where stakeholders are part of the process it is wise to hold a meeting to ensure agreement.

In reference to the second set of questions, alternative framings of vulnerability can be useful in vulnerability mapping, such as the SREX or livelihoods frameworks, and these are covered further in de Sherbinin (2014). O'Brien et al. (2007) argue that before developing adaptation plans, it is necessary to first build an understanding of the biophysical and socio- 
economic drivers that contribute to the vulnerability of the populations or systems under study. This is where the PNAS framework may help in assessing the multiple contributors to vulnerability.

\section{Box 6.2: Key Questions to Ask When Developing a Vulnerability} Assessment

1. What are the goals and objectives? Is there a particular utility associated with spatial analysis of vulnerability that justifies its use? If so, what are the anticipated goals and benefits to stakeholders? Are there potential risks associated with presenting information spatially that may undermine expressed goals?

2. How is the assessment of vulnerability framed? What aspects of systems are vulnerable and what are the determinants of that vulnerability? How are spatial, temporal, and multi-scale dynamics of vulnerability represented?

3. By what methods will vulnerability be assessed? What methods are used in the assessment and mapping of vulnerability and how does one cope with complexity and uncertainty?

4. Who participates and how are results translated into action? Who is responsible for designing and undertaking a spatial analysis, and which stakeholders will participate in the process? Who are the intended audiences and what efforts will be made to ensure information is presented in a relevant manner and, subsequently, interpreted appropriately? What are the processes by which an assessment of vulnerability can facilitate adaptive responses?

Source: Preston et al. 2011, p.179.

Issues related to spatial and temporal scale were covered in Chapter 1. System dynamics have been inadequately captured by most spatial VAs including in this paper for the same reason that they have not typically sought to apply extended vulnerability frameworks: modeling complex dynamics is difficult. Yet integrated assessment approaches have sought to address temporal and multi-scale dynamics, and may be suitable where data are available (Kok et al., 2010).

In reference to the third set of questions, the primary methods used in vulnerability mapping are addressed in detail in de Sherbinin (2014). These include spatial vulnerability indices, community-based and stakeholder-driven vulnerability mapping, climate impact mapping and modeling, and map illustrations. Process-based modeling is not included, even though it may generate maps, since these approaches generally do not take into account adaptive capacity. A range of methods is documented in Chapter 2, including process-based models. Some are more suitable than others to answer 
particular sets of questions or for communication purposes. Issues of uncertainty are addressed in Section 6.4.4 below.

Regarding the last set of questions, stakeholder engagement was addressed in Section 6.4.2. It is worth emphasizing that a new research paradigm (at least in climate adaptation science) is direct engagement with stakeholders, such that policy and management communities help define the research questions, and then are part of the process of interpreting results (see Box 6.3). It may be that the stakeholders bring more to the table in terms of understanding the "real world" aspects of the working of complex systems than the researcher who is bringing his/her tool set (spatial analysis) to a potentially new region or problem set.

\section{Box 6.3: Adaptation Science as Defined by the U.S. National Academy of Sciences}

U.S. National Academy of Sciences report, America's Climate Choices, sets out a new transdisciplineary science that is solutions focused. According the report, "The nation's climate change research enterprise should: 1) integrate disciplinary and interdisciplinary research across the physical, social, biological, health, and engineering sciences; 2) focus on use-inspired, fundamental research that contributes to both improved understanding and more effective decision making; 3 ) be linked to action-oriented programs focused on limiting and adapting to climate change; 4) be flexible in identifying and pursuing emerging research challenges."

Source: NRC, 2011.

\subsection{Mapping the Unmeasurable?}

We conclude this dissertation by returning to the question implied in the thesis title, Is vulnerability measurable? For if vulnerability cannot be quantified, then only qualitative approaches to mapping would be available. Spatial indices as described in Chapter 2, the Mali Vulnerability Mapping, and de Sherbinin (2014) would not be valid.

Measuring vulnerability was the topic of a workshop sponsored by UNU-EHS in 2005 (Birkmann and Wisner 2006). Participants agreed that a first step to measuring vulnerability is to arrive at a common definition of vulnerability. At its core, they state, vulnerability is the internal side of risk. There was broad acknowledgment that measurement is not only possible but desirable in certain contexts: "The creative tension is between the need in some cases for a single number that expresses vulnerability and in others for the need for...narratives that capture the dynamism and specificity of the processes in daily life that make a group vulnerable" (p.43). They cited the Hyogo 
Framework on Disaster Risk Reduction as an example of a policy document that specifically calls for measurement.

Hinkel (2011) acknowledges that the policy community often demands indicators of vulnerability, but he is less sanguine about the possibility of measuring it. He argues that instead of measuring vulnerability, we should talk of operationalizing the concept, which means a method must be developed for mapping it to observable concepts such as poverty rates or infant mortality. This is where he introduces the term "indicating variables" or indicators, which point from observable phenomena to a theoretical construct (see Chapter 1, Section 1.3.1). The core of his critique regards the aggregation of indicators to composite indices, where frameworks such as the IPCC vulnerability or PNAS frameworks are used. He argues, "Frameworks in general do not provide arguments for aggregation, because they say nothing about the processes through which the different variables interact and may lead to future harm and thus cannot capture the necessary forward looking aspect of vulnerability" (p.202).

After a thorough review of the literature and deconstruction of the concept of vulnerability, and a discussion of the basis for aggregation, he finds that of six types of problems that vulnerability indicators are meant to address, including allocation of adaptation funds and monitoring of adaptation policy, the only valid use of such indicators is for the identification of vulnerable people, communities and regions. And this only for local analyses where the system can be narrowly defined and inductive arguments, such as those described in Chapter 4, can be built.

While Hinkel's critique is one of the most thorough to date, he is not alone in questioning the utility of vulnerability indicators (see, for example, Barnett et al. 2008). We would argue that maps based on spatial indices of vulnerability play a useful role in policy communication and adaptation planning, but that they are unlikely to be sufficient in and of themselves for the design of actual interventions. While spatial indices (i.e., vulnerability or "hotspots" maps) may identify where to target adaptation assistance, more detailed field research and consultation with stakeholders are necessary in order to determine what is needed for adaptation programming and how to develop local resilience. In other words, spatial vulnerability assessment may be a useful entry point for adaptation priority setting, but it is not a replacement for rigorous field-based vulnerability assessments that deepen understanding of current and future impacts on key economic sectors, environmental systems, or people groups.

The power of spatial VA is that it presents a large amount of information in a simplified and visually attractive manner. Yet it shares the shortcomings inherent in any effort to model a complex world. To improve credibility, it is 
therefore important that the data and methods be clearly documented, and that information on uncertainties and assumptions be included in reports that accompany the maps. To ensure the transparency and replicability of spatial indices, technical annexes should provide detailed metadata on each map layer and the transformations used to convert the layers to indicators. Stakeholder engagement can also enrich the development and interpretation of vulnerability maps. Involving communities, the private sector, resource managers, government agencies, and policy makers in a process of indicator selection, identifying weights, evaluation of results, and discussion of policy solutions can only enrich this process and increase the legitimacy of results.

There are significant challenges in mapping theoretical constructs such as vulnerability. Yet, in a world where climate change impacts and vulnerabilities are going to continue to make headlines, it is clear that there will be continued demand for spatial VA from the policy community. It therefore behooves the scientific community to continue to refine approaches while being transparent in its methodologies and characterizing, to the best of its ability, uncertainties.

\subsection{References}

Balk, D., T. Pullum, A, Storeygard, F. Greenwell, and M. Neuman. 2004. A spatial analysis of childhood mortality in West Africa. Population, Space and Place, 10: 175-216

Barnett, J., S. Lambert, and I. Fry. 2008. The hazards of indicators: insights from the Environmental Vulnerability Index. Annals of the Association of American Geographers 98(1):102-119.

Batterbury, S. 2009. Department of Geography, University of Melbourne. Personal communication, May 2009.

Baud, I., M. Kuffer, K. Pfeffer, R. Sliuzas, S. Karuppannan. 2010. Understanding heterogeneity in metropolitan India: The added value of remote sensing data for analyzing sub-standard residential areas. International Journal of Applied Earth Observation and Geoinformation, 12(5): 359-374.

Baud, I., N. Sridharan, and K. Pfeffer. 2008. Mapping Urban Poverty for Local Governance in an Indian Mega-City: The Case of Delhi. Urban Studies, 45(7):1385-1412. doi: 10.1177/0042098008090679

Birkmann, J., O.D. Cardona, M.L. Carreno, A.H. Barbat, M. Pelling, S. Schneiderbauer, S. Kienberger, M. Keller, D. Alexander, P. Zeil, and T. Welle. 2013. Framing vulnerability, risk and societal responses: the MOVE framework. Natural Hazards, 67:193-211.

Birkmann, J. 2006. "Measuring vulnerability to promote disaster-resilient societies: Conceptual frameworks and definitions." In: J. Birkmann 
(ed.), Measuring vulnerability to natural hazards: Towards disaster resilient societies. Tokyo: United Nations University Press.

Birkmann, J., and B. Wisner. 2006. Measuring the Un-Measurable: The Challenge of Vulnerability. UNU-EHS SOURCE, No. 5. Bonn: United Nations University-Environment and Human Security.

Bohle, H.-G. 2001. Vulnerability and criticality: Perspectives from social geography. IHDP Update 2/2001. Newsletter of the International Human Dimensions Programme on Global Environmental Change: 1-7.

Brakenridge, G. R., J. Syvitski, I. Overeem, S. Higgins, A. Kettner, J. Stewart-Moore, and R. Westerhoff. 2013. Global mapping of storm surges and the assessment of coastal vulnerability. Natural Hazards, 66(3), 1295-1312. doi: 10.1007/s11069-012-0317-z

Busby, J.W., T.G. Smith, and K.L. White. 2011. Locating Climate Insecurity: Where are the most vulnerable places in Africa? Climate Change and African Political Stability Program Policy Brief No. 3.

Chambers, R. 1994. Participatory Rural Appraisal (PRA): Challenges, Potentials and Paradigm. World Development, 22(10): 1437-1454.

Davies, R.A.G., and S.J.E. Midgley. 2010. Climate Risk and Vulnerability Mapping for Southern Africa Status Quo (2008) and Future (2050). Cape Town, South Africa: OneWorld Sustainable Investments (Pty) Ltd.

de Sherbinin, A. 2014. Spatial Climate Change Vulnerability Assessments: A Review of Data, Methods and Issues. Technical Paper for the USAID African and Latin American Resilience to Climate Change (ARCC) project. Washington, DC: USAID.

de Sherbinin, A., T. Chai-On, A. Giannini, M. Jaiteh, M. Levy, V. Mara, and L. Pistolesi. 2014a. Mali Climate Vulnerability Mapping. Technical Paper for the USAID African and Latin American Resilience to Climate Change (ARCC) project. Washington, DC: USAID.

de Sherbinin, A., M. Levy, E. Zell, S. Weber, and M. Jaiteh. 2014b. Using Satellite Data to Develop Environmental Indicators. Environmental Research Letters, 9084013. http://dx.doi.org/10.1088/17489326/9/8/084013.

de Sherbinin, A., T. Chai-On, M. Jaiteh, M. Levy, V. Mara, L. Pistolesi, and E. Schnarr. 2014c. Mapping the Exposure of Socioeconomic and Natural Systems of West Africa to Coastal Climate Stressors. Technical Paper for the USAID African and Latin American Resilience to Climate Change (ARCC) project. Washington, DC: USAID.

de Sherbinin, A. 2010. "What are the Remote Sensing Data Needs of the Population-Environment Research Community?". Summary of a Population-Environment Research Network Cyberseminar, 10-21 May 2010. Accessed at http://www.populationenvironmentresearch.org/ seminars052010.jsp on 19 April 2014.

de Sherbinin, A. 1996. Human Security and Fertility: The Case of Haiti. Journal of Environment and Development, 5(1): 28-45. 
Dickson, E., J. Baker, and D. Hoornweg. 2012. Urban Risk Assessment. Washington DC: The World Bank.

Dransch, D., H. Rotzoll, and K. Poser. 2010. The contribution of maps to the challenges of risk communication to the public. International Journal of Digital Earth, 3: 292-311.

Eakin, H., and A.L. Luers. 2006. Assessing the Vulnerability of SocioEnvironmental Systems. Annual Review of the Environment and Resources, 31:365-394.

Ebert, A., N. Kerle, and A. Stein. 2009. Urban social vulnerability assessment with physical proxies and spatial metrics derived from air- and spaceborne imagery and GIS data. Natural Hazards, 48:275-294

Ebi, K.L., and I. Burton. 2008. Identifying practical adaptation options: an approach to address climate change-related health risks. Environmental Science \& Policy, 11(4), 359-369.

Ford, J.D., E. C. H. Keskitalo, T. Smith, T. Pearce,, L. Berrang-Ford, F. Duerden and B. Smit. 2010. Case study and analogue methodologies in climate change vulnerability research, WIREs Climate Change, May/June 2010.

Frazier, T.G., C. M. Thompsona, R. J. Dezzani, D. Butsick. 2013. Spatial and temporal quantification of resilience at the community scale. Applied Geography, 42:95-107.

Füssel, H.-M. 2009. "Review and quantitative analysis of indices of climate change exposure, adaptive capacity, sensitivity, and impacts." Background note to the World Development Report 2010. Washington, DC: World Bank. http://wdronline.worldbank.org/worldbank/a/nonwdrdetail/145

Füssel, H.-M. 2007. Vulnerability: A generally applicable conceptual framework for climate change research. Global Environmental Change, 17:155-167.

Hagenlocher, M., S.Lang, D. Holbling, D. Tiede, and S. Kienberger. 2013. Modeling Hotspots of Climate Change in the Sahel Using Object-Based Regionalization of Multidimensional Gridded Datasets. IEEE Journal of Selected Topics in Applied Earth Observations and Remote Sensing.

Harley, J.B. 1989. Deconstructing the map. Cartographica, 26(2):1-20.

Health Canada. 2011. Adapting to Extreme Heat Events: Guidelines for Assessing Health Vulnerability. Ottawa, Ontario: Health Canada. Accessed at http://www.hc-sc.gc.ca/ewhsemt/pubs/climat/adapt/index-eng.php on 1 February 2014.

Henry, S., B. Schoumaker, and C. Beauchemin. 2004. The Impact of Rainfall on the First Out-Migration: A Multi-level Event-History Analysis in Burkina Faso. Population and Environment, 25(5):423-460.

Hinkel, J., S. Brown, L. Exner, R.J. Nicholls, A.T. Vafeidis, and A.S. Kebede. 2012. Sea-level rise impacts on Africa and the effects of mitigation and 
adaptation: an application of DIVA. Regional Environmental Change, 12(1), 207-224. doi: 10.1007/s10113-011-0249-2

Hinkel, J. 2011. "Indicators of vulnerability and adaptive capacity": Towards a clarification of the science-policy interface. Global Environmental Change, 21: 198-208.

ICRST (Indore City Resilience Strategy Team). 2012. Final Report on city resilience strategy, Indore, G.K. Bhat, V.P. Kulshreshtha, U.A. Bhonde, U. Rajasekar, A.K. Karanth, and M.K. Burvey (eds). TARU Leading Edge Pvt. Ltd.

IPCC (Intergovernmental Panel on Climate Change). 2012. Managing the risks of extreme events and disasters to advance climate change adaptation. In A Special Report of Working Groups I and II, C.B. Field (ed.). Cambridge: Intergovernmental Panel on Climate Change.

Jaeger, W. K., A. J. Plantinga, H. Chang, K. Dello, G. Grant, D. Hulse, J. J. McDonnell, S. Lancaster, H. Moradkhani, A. T. Morzillo, P. Mote, A. Nolin, M. Santelmann, and J. Wu. 2013. Toward a formal definition of water scarcity in natural-human systems. Water Resources Research, 49: 4506-4517, doi:10.1002/wrcr.20249, 2013.

Jankowska, M., D. Lopez-Carr, C. Funk, G.J. Husak, Z.A. Chafe. 2012. Climate change and human health: Spatial modeling of water availability, malnutrition, and livelihoods in Mali, Africa. Applied Geography, 33:4-15

Kaye, N.R., A. Hartley, and D. Hemming. 2012. Mapping the climate: guidance on appropriate techniques to map climate variables and their uncertainty. Geoscience Model Development, 5:245-256. www.geoscimodel-dev.net/5/245/2012/

Kienberger, S., T. Blaschke, and R. Z. Zaidi. 2013. A framework for spatiotemporal scales and concepts from different disciplines: the 'vulnerability cube'. Natural Hazards, 68, 1343-1369.

Kienberger, S. 2012. Spatial modelling of social and economic vulnerability to floods at the district level in Búzi, Mozambique. Natural Hazards, 64:2001-2019.

Kienberger, S., S. Lang, and P. Zeil. 2009. Spatial vulnerability units expert-based spatial modelling of socio-economic vulnerability in the Salzach catchment, Austria. Natural Hazards Earth System Science, 9, 767-778.

Klein, R.J.T. 2012. "Enhancing the rigour of climate change vulnerability, impact and adaptation research," Paper presented at the Climate Adaptation Futures: Second International Climate Change Adaptation Conference, May 2013, Tuscon, Arizona.

Klein, R.J.T. 2009. Identifying countries that are particularly vulnerable to the adverse effects of climate change: an academic or a political challenge? Carbon and Climate Law Review, 3:284-291 
Klein, R.J.T., R.J. Nicholls, and N. Mimura. 1999. Coastal adaptation to climate change: can the IPCC technical guidelines be applied? Mitigation and Adaptation Strategies for Global Change, 4(3-4):239252. doi: 10.1023/a:1009681207419.

Kok, M.T.J., M.K.B. Lüdeke, T. Sterzel, P.L. Lucas, C. Walter, P. Janssen and I. de Soysa. 2010. Quantitative analysis of patterns of vulnerability to global environmental change. Den Haag/Bilthoven, Netherlands: Netherlands Environmental Assessment Agency (PBL).

Krugman, P. 2011. "Droughts, Floods and Food." New York Times, 11 February 2011.

Lang, S., P. Zeil, S. Kienberger, and D. Tiede. 2008. "Geons - policy-relevant geo-objects for monitoring high-level indicators." Paper presented at the Geospatial Crossroads @ GI_Forum. Proceedings of the Second Geoinformatics Forum, Salzburg, Germany.

Lehner, B., C. Reidy Liermann, C. Revenga, C. Vörösmart, B. Fekete, P. Crouzet, P. Döll, M. Endejan, K. Frenken, J. Magome, C. Nilsson, J.C. Robertson, R. Rodel, N. Sindorf, and D. Wisser. 2011. High-Resolution Mapping of the World's Reservoirs and Dams for Sustainable River-Flow Management. Frontiers in Ecology and the Environment, 9:494-502. DOI: $10.1890 / 100125$.

Levy, M. 2013. Center for International Earth Science Information Network, personal communication, 2 December 2013.

Levy, M. 2012. "Data Implications of Priority Research Needs", Paper presented at the UNEP PROVIA Session, Adaptation Futures Conference, 31 May 2012, Tucson, Arizona.

Mabey, N., J. Gulledge, B. Finel, and K. Silverthorne. 2011. Degrees of Risk. Washington, DC: E3G. Accessed at: http://www.e3g.org/showcase/degrees-of-risk/ on 29 April 2014.

Malone, E.L. 2009. Vulnerability and Resilience in the Face of Climate Change: Current Research and Needs for Population Information. Report PNWD-4087, Battelle Pacific Northwest Laboratories. Richmond, WA: Pacific Northwest Laboratories.

Martine, G. and D. Schensul (eds.). 2013. The Demography of Adaptation to Climate Change. New York, London and Mexico City: UNFPA, IIED and El Colegio de México.

MacEachren, A.M., A. Robinson, S. Hopper, S. Gardner, R. Murray, M. Gahegan, and E. Hetzler. 2005. Visualizing Geospatial Information Uncertainty: What We Know and What We Need to Know. Cartography and Geographic Information Science, 32(3): 139-160

McGray, H. World Resources Institute Adaptation Program Manager. Personal Communication, 14 April 2014.

McLeman, R., and B. Smit. 2006. Migration as adaptation to climate change. Climatic Change , 76: 31-53, DOI: 10.1007/s10584-005-9000-7 
Meinzen-Dick, R.S., and P. P. Appasamy. 2002. Urbanization and intersectoral competition for water. Pp. 27-51 in Finding the source: The linkages between population and water. Washington DC: Woodrow Wilson International Center for Scholars. Accessed at http://ecsp.si.edu/PDF/popwawa3.pdf on 23 August 2014.

Midgley, S.J.E., R.A.G. Davies, and S. Chesterman. 2011. Climate risk and vulnerability mapping in southern Africa: status quo (2008) and future (2050). Report produced for the Regional Climate Change Programme for Southern Africa (RCCP), UK Department for International Development (DFID). Cape Town, South Africa: OneWorld Sustainable Investments.

Moench, D., S. Tyler, and J. Lage. 2011. Catalyzing Urban Climate Resilience: Applying Resilience Concepts to Planning Practice in the ACCCRN Program, Boulder CO: Institute for Social and Environmental Transition.

Monmonier, M. 1991. How to Lie with Maps. Chicago: University of Chicago Press.

Moser, S.C., and M.T. Boykoff. 2013. Successful Adaptation to Climate Change: Linking Science and Policy in Rapidly Changing World. New York: Routledge.

NAS (U.S. National Academies of Science). 2012. Himalayan Glaciers: Climate Change, Water Resources, and Water Security. Washington, DC: National Academies Press.

NRC (U.S. National Research Council). 2011. America's Climate Choices. Washington, DC: The National Academies Press.

O'Brien, K.L., S. Eriksen, L. Nygaard, and A. Schjolden. 2007. Why different interpretations of vulnerability matter in climate change discourses. Climate Policy, 7: 73-88.

Pahl-Wostl, C., C. Giupponi, K. Richards, C. Binder, A. de Sherbinin, D. Sprinz, T. Toonen, and C. van Bers. 2012. Transition towards a new global change science: Requirements for methodologies, methods, data and knowledge. Environmental Science and Policy, 28:36-47.

Piontek, F., C. Müller, T.A.M. Pugh, et al. 2013. Multisectoral climate impacts in a warming world. Proceedings of the National Academy of Sciences. doi: $10.1073 /$ pnas. 1222471110

Piotrowski, J. 2014. "'Misguided' nations lock up valuable geospatial data." SciDevNet, 15 January 2014.

Preston, B., E. Yuen, and R. Westaway. 2011. Putting vulnerability to climate change on the map: a review of approaches, benefits, and risks. Sustainability Science, 6, 177-202. doi: 10.1007/s11625-011-0129-1

Preston, B., C. Brooke, T. Measham, T. Smith and R. Gorddard. 2009. Igniting change in local government: lessons learned from a bushfire vulnerability assessment. Mitigation and Adaptation Strategies for Global Change, 14:251-283. doi: 10.1007/s11027-008-9163-4 
Preston, B. L., D. Abbs, B. Beveridge, C. Brooke, R. Goddard, G. Hunt, M. Justus, P. Kinrade, I. Macadam, T. G. Measham, K. McInnes, C. Morrison, J. O'Grady, T. F. Smith \& G. Withycombe. 2007. Spatial Approaches for Assessing Vulnerability and Consequences in Climate Change Assessments In Proceedings of MODSIM 2007: International Congress on Modelling and Simulation. Christchurch, NZ: Modelling and Simulation Society of Australia and New Zealand.

PROVIA. 2013a. Research Priorities on Vulnerability, Impacts and Adaptation: Responding to the Climate Change Challenge. Nairobi, Kenya: United Nations Environment Programme.

PROVIA. 2013b. PROVIA Guidance on Assessing Vulnerability, Impacts and Adaptation to Climate Change Consultation document. Nairobi, Kenya: United Nations Environment Programme.

Ramieri, E., A. Hartley, A. Barbanti, F. Duarte Santos, A. Gomes, M. Hilden, et al. 2011. Methods for assessing coastal vulnerability to climate change ETC CCA Technical Paper: European Environment Agency: European Topic Centre on Climate Change Impacts, Vulnerability and Adaptation.

Ranganathan, M. 2012. "Bangalore Flood Risk." Paper presented at the ICARUS III conference, Columbia University, New York (USA), 18 May 2012.

Saldaña-Zorilla, S.O., and K. Sanderberg. 2009. Impact of climate-related disasters on human migration in Mexico: a spatial model. Climatic Change, 96:97-118.

Sha, H. 2011. "Strengthening City's Disaster Preparedness and Disaster Response Capacity, Promoting the Harmonious Socio-economic Development", Speech of the Deputy Secretary General, Shanghai Municipal People's Government, at the UN Humanitarian Partnership Workshop for the Asia-Pacific Region, 12 October 2011. Accessed at http://www.scofcom.gov.cn/enldrjh/227371.htm on 28 March 2014.

Siebert, S., V. Henrich, K. Frenken, and J. Burke. 2013. Update of the Digital Global Map of Irrigation Areas (GMIA) to Version 5. Bonn, Germany: Institute of Crop Science and Resource Conservation, Rheinische Friedrich-Wilhelms-Universität. Accessed at http://www.lap.unibonn.de/research/downloads/gmia/siebert_et_al_2013_gmia5 on 19 April 2014.

Sliuzas, R., G. Mboup, and A. de Sherbinin. 2008. Report on the Expert Group Meeting on Slum Identification Using Geo-Information Technology, 2123 May 2008, Enschede, Netherlands.

Soares, M.B., A.S. Gagnon, and R.M. Doherty. 2012. Conceptual elements of climate change vulnerability assessments. International Journal of Climate Change Strategies and Management, 4(1):6-35.

Srinivasan, V., K.C. Seto, R. Emerson, and S.M. Gorelick. 2013. The impact of urbanization on water vulnerability: A coupled human-environment 
system approach for Chennai, India. Global Environmental Change, 23:229-239

Thow, A., and M. de Blois. 2008. Climate change and human vulnerability: Mapping emerging trends and risk hotspots for humanitarian actors. Bath, UK and Geneva, Switzerland: Maplecroft, and CARE International.

Tiwari, V. M., J. Wahr, and S. Swenson. 2009. Dwindling groundwater resources in northern India, from satellite gravity observations. Geophysical Research Letters, 36, L18401, doi:10.1029/2009GL039401.

Trzaska, S., and E. Schnarr. 2014. A Review of Downscaling Methods for Climate Change Projections. Technical Paper for the USAID African and Latin American Resilience to Climate Change (ARCC) project. Washington, DC: USAID

Turner, B. L., R. E. Kasperson, P. A. Matson, J. J. McCarthy, R. W. Corell, L. Christensen, N. Eckley, J. X. Kasperson, A. Luers, M. L. Martello, C. Polsky, A. Pulsipher and A. Schiller. 2003a. A framework for vulnerability analysis in sustainability science. Proceedings of the National Academy of Sciences, 100:8074-8079.

Turner, B.L., P.A. Matson, J.J. McCarthy, R.W. Corell, L. Christensen, N. Eckley, G.K. Hovelsrud-Broda, J.X. Kasperson, R.E. Kasperson, A. Luers, M.L. Martello, S. Mathiesen, R. Naylor, C. Polsky, A. Pulsipher, A. Schiller, H. Selin, and N. Tyler. 2003b. Illustrating the coupled human-environment system for vulnerability analysis: Three case studies. Proceedings of the National Academy of Sciences. 100(14):8080-8085.

Tyler, Stephen, Erwin Nugraha, Ha Kim Nguyen, Nhung Van Nguyen, Aniessa Delima Sari, Pakamas Thinpanga, Thao Thanh Tran, Sheo Shanker Verma, Darren Swanson and Livia Bizikova. 2014. Developing Indicators of Urban Climate Resilience. ISET Climate Resilience Working Paper 3, January 2014.

UNEP (United Nations Environment Programme). 2011. Climate Change, Conflict and Migration in the Sahel. Nairobi: UNEP. Accessed at http://www.unep.org/climatechange/adaptation/InformationMaterials/P ublications/tabid/6711/Default.aspx on 3 February 2014.

UNEP (United Nations Environment Programme) and ECLAC (UN Economic Commission for Latin America and the Carribean). 2010. Vital Climate Change Graphics for Latin America and the Caribbean. Accessed at http://www.grida.no/publications/vg/lac2/ on 20 January 2014.

UNFCCC (UN Framework Convention on Climate Change). 2010. Adaptation Assessment Planning and Practice: An Overview from the Nairobi Work Programme on Impacts, Vulnerability and Adaptation to Climate Change. Bonn, Germany: UNFCCC. Accessed at http://unfccc.int/ 
resource/docs/publications/10_nwp_adap_assess_en.pdf on 1 February 2014.

UNHABITAT (United Nations Human Settlements Programme). 2013. Flood Risk Assessment, Strategies and Actions for Improving Flood Risk Management in Kampala. Nairobi, Kenya: UNHABITAT.

UNHABITAT (United Nations Human Settlements Programme). 2011. Global Report on Human Settlements 2011: Cities and Climate Change. London, UK: Earthscan.

UNISDR (UN International Strategy for Disaster Reduction). 2013. Global Assessment Report on Disaster Risk Reduction. Geneva: UNISDR.

UNISDR (UN International Strategy for Disaster Reduction). 2004. Living with Risk: A Global Review of Disaster Reduction Initiatives. Geneva: United Nations.

USAID (U.S. Agency for International Development). 2014. Niger Vulnerability Map. Dakar, Senegal: USAID Sahel Joint Planning Cell.

VanWey, L., R. Rindfuss, M. Gutmann, B. Entwisle, and D. Balk, 2005. Confidentiality and Spatially Explicit Data: Concerns and Challenges, Proceedings of the National Academy of Sciences, 102 (43): 1533715342.

Vickery, G. 2011. "Review of Recent Studies on Public Sector Information ReUse and Related market Developments." Paper prepared for the European Commission. Paris: Information Economics.

Vörösmarty, C.J., P. Green, J. Salisbury, R.B. Lammers.2000. Global water resources: vulnerability from climate change and population growth. Science, 289 (5477): 284-288. doi:10.1126/science.289.5477.284.

Warner, K., T. Afifi, K. Henry, T. Rawe, C. Smith, and A. de Sherbinin. 2012a. Where the Rain Falls: Climate Change, Food and Livelihood Security, and Migration. Bonn, Germany: United Nations University and CARE.

Warner, K., K. van der Geest, S. Kreft, S. Huq, S. Harmeling, K. Koesters, and A. de Sherbinin. 2012b. Evidence from the Frontlines of Climate Change: Loss and Damage to Communities Despite Coping and Adaptation. Bonn, Germany: United Nations University.

Warner, K., C. Erhart, A. de Sherbinin, S. Adamo, and T. Chai-Onn. 2009. In Search of Shelter: Mapping the Effects of Climate Change on Human Migration and Displacement. Bonn, Germany: United Nations University, CARE, and CIESIN-Columbia University.

Wood, L., P. Caffrey, L. Kindberg, H. McGray, L. Moriniere, and S. Trzaska. 2014. Compendium of Lessons Learned from ARCC Climate Change Vulnerability Assessments. Technical Paper for the USAID African and Latin American Resilience to Climate Change (ARCC) project. Washington, DC: USAID.

Wu, S. 2014. Mayor's Office of Sustainability, Philadelphia, Personal communication. 


\section{Summary}

\section{Mapping the Unmeasurable? Spatial Analysis of Vulnerability to Climate Change and Climate Variability}

Climate change, climate variability, and climate extremes will have far reaching implications for societies in the 21st century. There is considerable policy interest in (1) identifying the specific vulnerabilities of populations that will be exposed to climate change impacts; (2) understanding how various climate impacts will impact urban and regional systems; and (3) how, in turn, populations will respond through in situ adaptation or migration. Because vulnerability is place-based, spatial analyses based on combinations of climate data, spatial representations of current climate hazards, spatial representations of population distribution, and spatial representations of factors that influence vulnerability can greatly assist in developing this understanding and in helping to target interventions. Indeed, spatial analysis and spatial data integration have become standard tools in the toolkit of climate change vulnerability assessments. Yet there remains considerable methodological diversity and there is little consensus in the research community on the best ways to measure and map vulnerability. There are even those who argue that for most purposes vulnerability as a concept cannot be adequately quantified and hence is "unmeasurable".

In this thesis we provide examples of spatial analyses - including quantitative and qualitative analyses and map representations - that contribute to understanding patterns of vulnerability to climate change. Specifically, we explore this methodological diversity and discuss the relative merits of different approaches to understanding spatial patterns of vulnerability with a particular emphasis on the utility of vulnerability maps for policy making. We also examine the utility of an extended vulnerability framework developed by a team of researchers at Harvard and Clark Universities for guiding research and illuminating vulnerabilities of coupled human-environment systems.

We conclude that there is no one universally applicable approach to climate vulnerability mapping, and that each of the methods presented in this thesis has its strengths and weaknesses. We examine some of the trends in spatial vulnerability assessment (VA), such as stakeholder participation and new geo-processing methods, and also explore some areas in which more work is needed, such as improved data and the characterization and communication of uncertainty. Overall, the power of spatial VA is that it presents a large amount of information in a simplified and visually attractive manner. Yet it shares the shortcomings inherent in any effort to model a complex world. To improve credibility, it is therefore important that the data and methods be 
clearly documented, and that information on uncertainties and assumptions be included in reports that accompany the maps. Where spatial indices of vulnerability are developed, technical annexes should provide detailed metadata on each map layer and the transformations used to convert the layers to indicators.

There are significant challenges in mapping theoretical constructs such as vulnerability. Yet, in a world where climate change impacts and vulnerabilities are going to continue to make headlines, it is clear that there will be continued demand for spatial VA from the policy community. It therefore behooves the scientific community to continue to refine approaches while being transparent in its methodologies and characterizing, to the best of its ability, uncertainties. 


\title{
Samenvatting
}

\section{Het onmeetbare in kaart brengen? \\ Ruimtelijke analyse van kwetsbaarheid ten gevolge van klimaatverandering en klimaatschommelingen}

\begin{abstract}
Klimaatverandering, klimaatschommelingen en extremen zullen verstrekkende gevolgen hebben voor samenlevingen in de 21ste eeuw. Vanuit het beleid is er aanzienlijke belangstelling voor: (1) het identificeren van specifieke kwetsbaarheden van populaties die blootgesteld worden aan de gevolgen van klimaatverandering; (2) het begrijpen hoe verschillende klimaat gevolgen stedelijke en regionale systemen zullen beïnvloeden; en (3) hoe vervolgens populaties zullen reageren door adaptatie ter plekke of door migratie. Omdat kwetsbaarheid plaats-afhankelijk is, kunnen ruimtelijke analyses van klimaatgegevens in combinatie met ruimtelijke representaties van huidige klimaat risico's, van bevolkingsspreiding en van factoren die kwetsbaarheid beïnvloeden in hoge mate bijdragen aan het vergroten van kennis en inzichten en het vaststellen van gerichte interventies. Sterker nog, ruimtelijke analyse en ruimtelijke data integratie zijn standaard hulpmiddelen geworden bij evaluaties van kwetsbaarheden ten gevolge van klimaatverandering. Toch bestaat er nog steeds een aanzienlijke methodologische diversiteit, en is er tussen onderzoekers weinig consensus over het antwoord op de vraag op welke manier kwetsbaarheid het best kan worden gemeten en in kaart gebracht. Er zijn er zelfs die beweren dat kwetsbaarheid als concept voor de meeste doeleinden niet adequaat kan worden gekwantificeerd, en dientengevolge "onmeetbaar" is.
\end{abstract}

In dit proefschrift behandelen we voorbeelden van ruimtelijke analyses inclusief kwantitatieve en kwalitatieve analyses en kaart representaties - die beogen bij te dragen aan een beter begrip van patronen van kwetsbaarheden ten gevolge van klimaatverandering. Meer specifiek verkennen we de methodologische diversiteit en bespreken de relatieve voordelen van verschillende benaderingen om ruimtelijke patronen van kwetsbaarheden te leren begrijpen, met name vanuit het oogpunt van bruikbaarheid van risicokaarten voor beleidsmakers. Tevens onderzoeken we de bruikbaarheid van een uitgebreid raamwerk voor de analyse van kwetsbaarheden, dat is ontwikkeld door een groep onderzoekers van de universiteiten van Harvard en Clark, en dat kwetsbaarheden van gekoppelde mens-omgeving systemen beoogt te verhelderen.

We concluderen dat er géén universeel toepasbare aanpak is voor het in kaart brengen van klimaatrisico's, en dat elk in dit proefschrift gepresenteerde methode sterke en zwakke kanten heeft. We onderzoeken enkele trends in ruimtelijke risico-waarderingen (VA), zoals stakeholder 
participatie en nieuwe methoden voor het verwerken van geo-informatie, en verkennen enkele onderwerpen waarvoor meer onderzoek nodig is, zoals betere data en de karakterisering van en communicatie over onzekerheid. In het algemeen ligt de kracht van ruimtelijke risico-waarderingen (VA) in het presenteren van een grote hoeveelheid informatie op een eenvoudige en visueel aantrekkelijke manier. Desalniettemin ontkomt VA niet aan de tekortkomingen die inherent zijn aan elke poging om de complexe wereld te modelleren. Ten einde de geloofwaardigheid te vergroten is het daarom belangrijk dat de data en de methoden goed worden gedocumenteerd, en dat informatie over onzekerheden en aannames wordt opgenomen in de rapporten die de kaarten vergezellen. Als ruimtelijke indicatoren voor kwetsbaarheid zijn ontwikkeld, dan dienen in technische bijlagen gedetailleerde meta data opgenomen te zijn over elke kaart-laag, inclusief de transformaties die zijn gebruikt om uit de kaartlagen de indicatoren af te leiden.

Er bestaan substantiële uitdagingen met betrekking tot het in kaart brengen van theoretische constructen als kwetsbaarheid. In een wereld waarin de gevolgen en kwetsbaarheden van klimaatverandering met enige regelmaat de krantenkoppen zullen blijven vullen, is het evident dat er ook een voortdurende vraag zal zijn naar ruimtelijke risico-waarderingen (VA) vanuit beleidsgremia. Daarom past het de wetenschap om benaderingen continu te verfijnen met inachtneming van transparantie in de methoden en een zo goed mogelijke karakterisering van onzekerheden. 


\section{ITC Dissertation List}

http://www.itc.nl/research/phd/phd_graduates.aspx 